\title{
Urban Patterns of Growth
}

The Geography of Suppliers of High-Tech Companies in the Nordic Countries

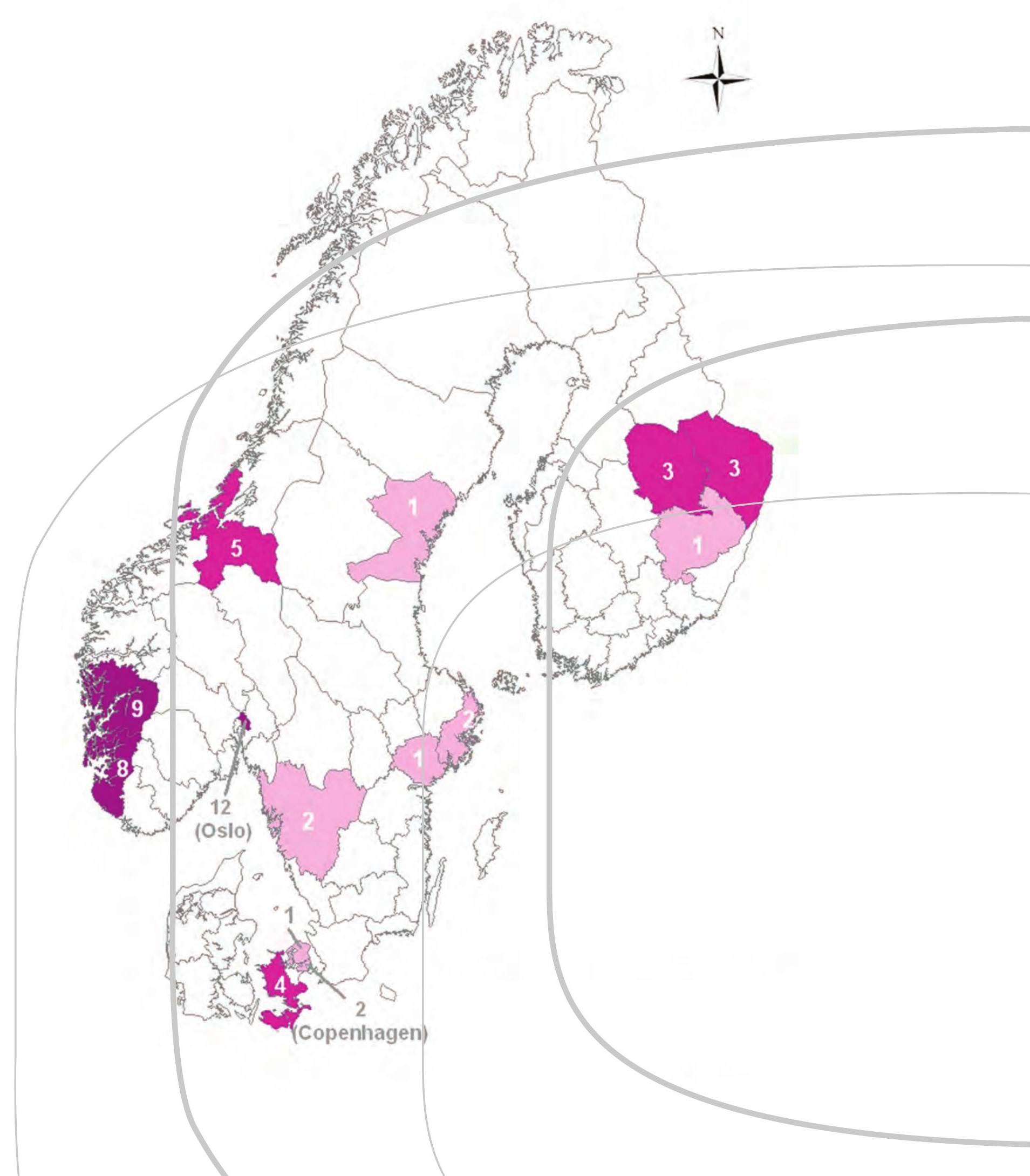



4 norden 



\section{Urban Patterns of Growth}

The Geography of Suppliers of High-Tech

Companies in the Nordic Countries

Niels Boje Groth and Lars Winther (Eds.)

Heikki Eskelinen, Timo Lautanen, Pasi Saukkonen, Olaf Foss, Frants Gundersen, Mats Johansson and Marcus Adolphson

TemaNord 2013:508 
Urban Patterns of Growth

The Geography of Suppliers of High-Tech Companies in the Nordic Countries

Niels Boje Groth and Lars Winther (Eds.)

Heikki Eskelinen, Timo Lautanen, Pasi Saukkonen, Olaf Foss, Frants Gundersen, Mats Johansson and Marcus Adolphson

ISBN 978-92-893-2471-7

http://dx.doi.org/10.6027/TN2013-508

TemaNord 2013:508

(C) Nordic Council of Ministers 2013

Layout: NMR

Cover photo: Patrik Karlsson Nyed

This publication has been published with financial support by the Nordic Council of Ministers. However, the contents of this publication do not necessarily reflect the views, policies or recommendations of the Nordic Council of Ministers.

www.norden.org/en/publications

\section{Nordic co-operation}

Nordic co-operation is one of the world's most extensive forms of regional collaboration, involving Denmark, Finland, Iceland, Norway, Sweden, and the Faroe Islands, Greenland, and Åland.

Nordic co-operation has firm traditions in politics, the economy, and culture. It plays an important role in European and international collaboration, and aims at creating a strong Nordic community in a strong Europe.

Nordic co-operation seeks to safeguard Nordic and regional interests and principles in the global community. Common Nordic values help the region solidify its position as one of the world's most innovative and competitive.

\section{Nordic Council of Ministers}

Ved Stranden 18

DK-1061 Copenhagen K

Phone (+45) 33960200

www.norden.org 


\section{Content}

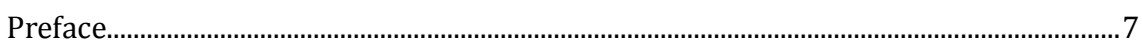

1. Main Findings............................................................................................................ 11

1.1 The companies.................................................................................................... 13

1.2 The suppliers........................................................................................................ 15

1.3 The geography of the world of production ................................................... 16

1.4 The geography of the world of markets and knowledge................................ 18

2. Theoretical Framework ................................................................................................ 21

$2.1 \quad$ The knowledge economy .............................................................................. 21

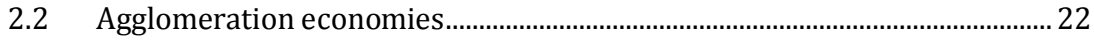

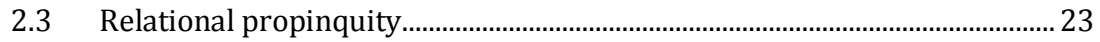

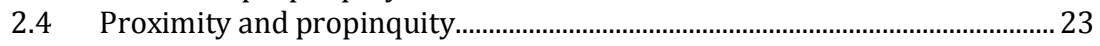

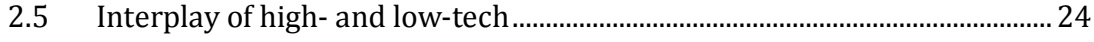

2.6 The knowledge base: analytic and synthetic................................................... 25

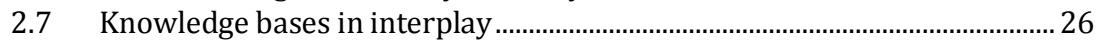

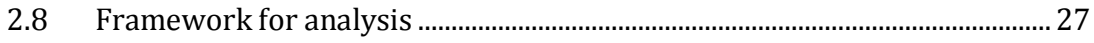

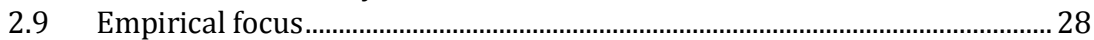

2.10 References......................................................................................................... 30

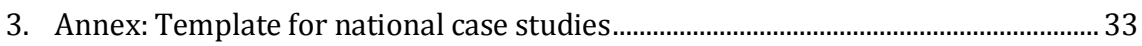

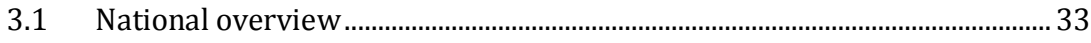

3.2 Interviews with companies............................................................................... 33

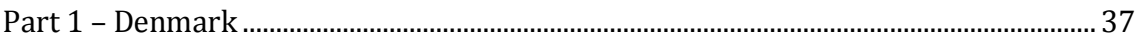

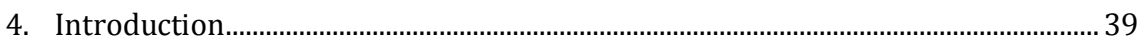

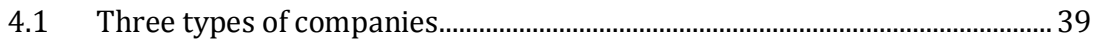

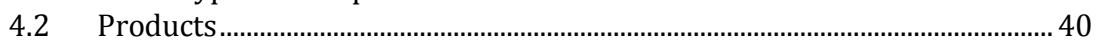

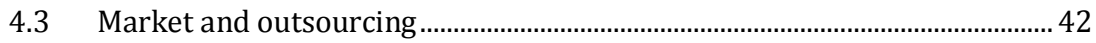

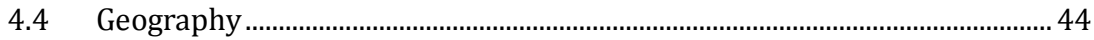

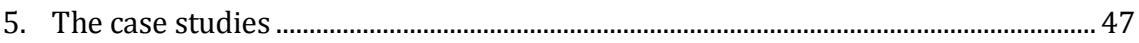

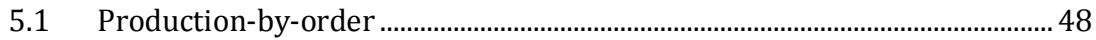

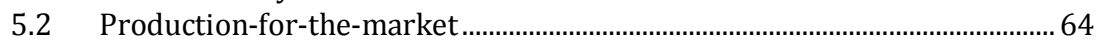

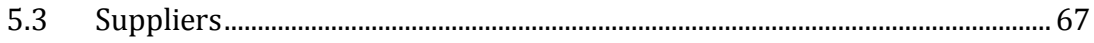

5.4 Business-to-business solutions .................................................................... 72

5.5 Common patterns........................................................................................... 79

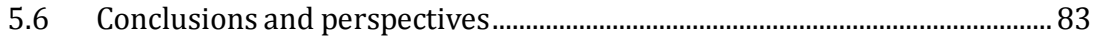

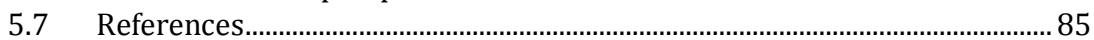

Part 2 - Finland

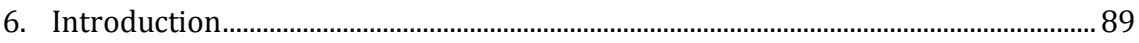

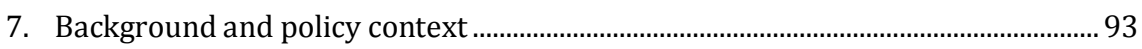

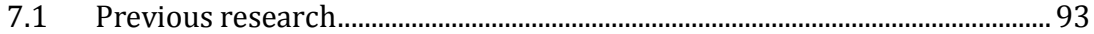

7.2 Domestic policy framework............................................................................ 97

7.3 Regional distribution of high and medium technology industries in

Finland......................................................................................................... 98

8. Regional characteristics of eastern Finland ……..................................................... 101

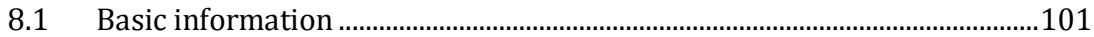

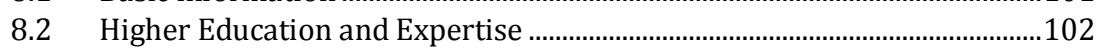

8.3 High and medium-high technology industries in Eastern Finland.............103 


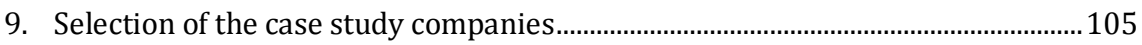

10. Observations from the case studies.........................................................................107

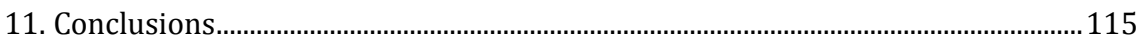

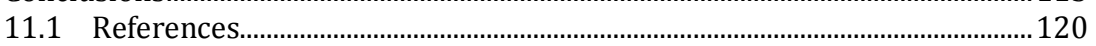

12. Appendix 1. Summary of the geographical dimensions of the case study

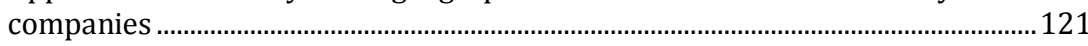

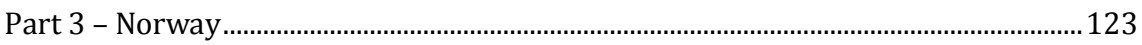

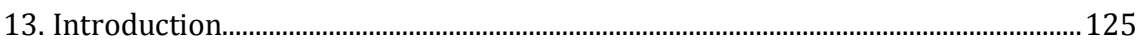

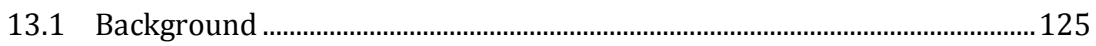

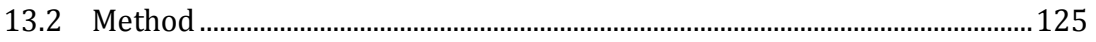

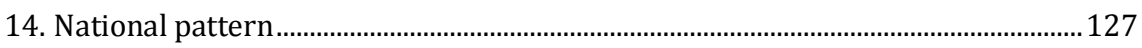

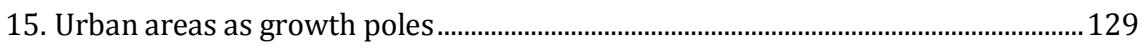

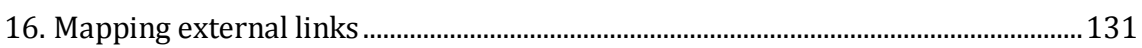

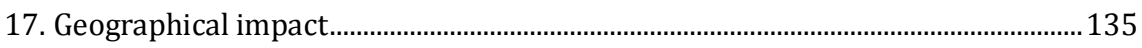

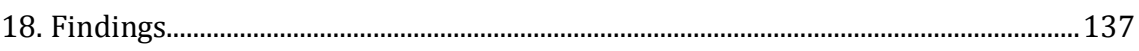

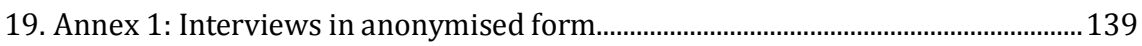

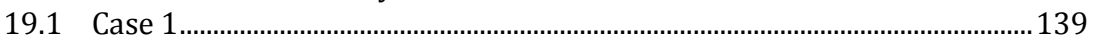

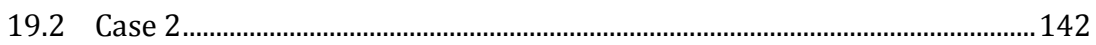

19.3 Case 3

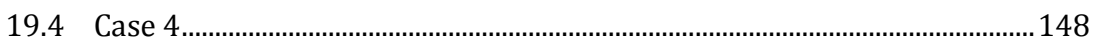

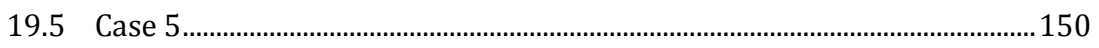

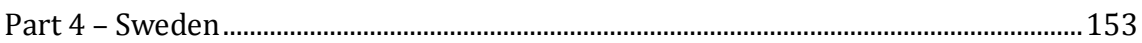

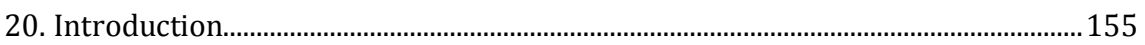

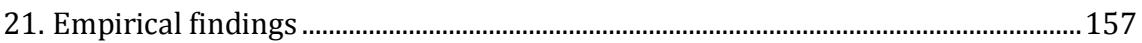

21.1 Companies in the Göteborg region...............................................................157

21.2 Companies in the Stockholm region...........................................................163

21.3 Companies in the industrial cluster of Timrå...................................................172

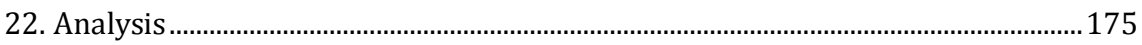

22.1 Differences in focus and degree of innovation .............................................175

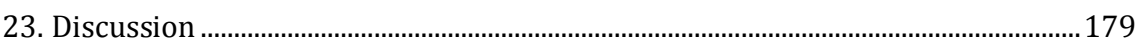

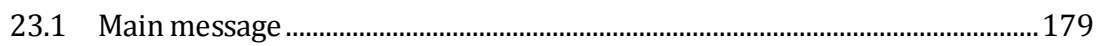

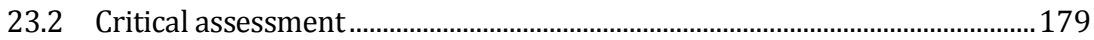

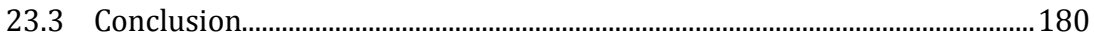

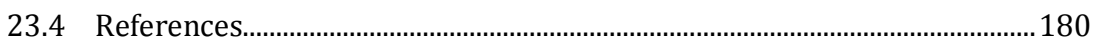

24. Appendix 1 (in Swedish) .......................................................................................... 181

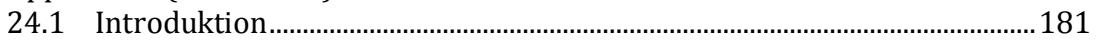

24.2 Grundläggande frågor om företaget..............................................................181

24.3 Relationer...................................................................................................... 181

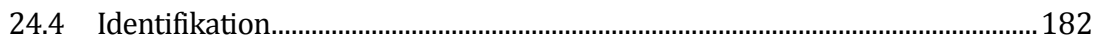

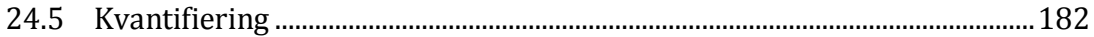

24.6 Effekter............................................................................................................ 183

24.7 Strategier för framtiden ..................................................................................183

24.8 Utvärdering av geografisk betydelse.............................................................183 


\section{Preface}

This is the final report of the project Urban Patterns of Growth, carried out by a Nordic team of researchers on behalf of the Nordic Council of Ministers. This report is part of the preparation of the next Nordic regional policy co-operation programme 2013-2016 and for the preparation of the national regional policies in the Nordic countries.

\section{The research issue}

A key issue for the Nordic Council of Ministers is the fact that economic growth and job creation in the Nordic countries has been taking place over the past decades in the largest cities. The background for this development is the transition from an industrial society to a knowledge society.

Several Scandinavian studies show that the large city regions, especially the capital city regions, have a strong economic position in the knowledge economies (Lundquist et al., 2008; Hansen \& Winther, 2010; Asheim \& Hansen, 2009). In figure 1 , for example, the dominance of high-tech production in the largest urban areas is compared to the more decentralised pattern of medium-tech in Finnish urban areas in 2010. This pattern was also recently confirmed in Denmark (Hansen et al., 2012).

Figure 1. Regional distribution of high-technology (left) and medium-technology (right) turnover in Finland, 2010 (Source: Statistics Finland, 2012)
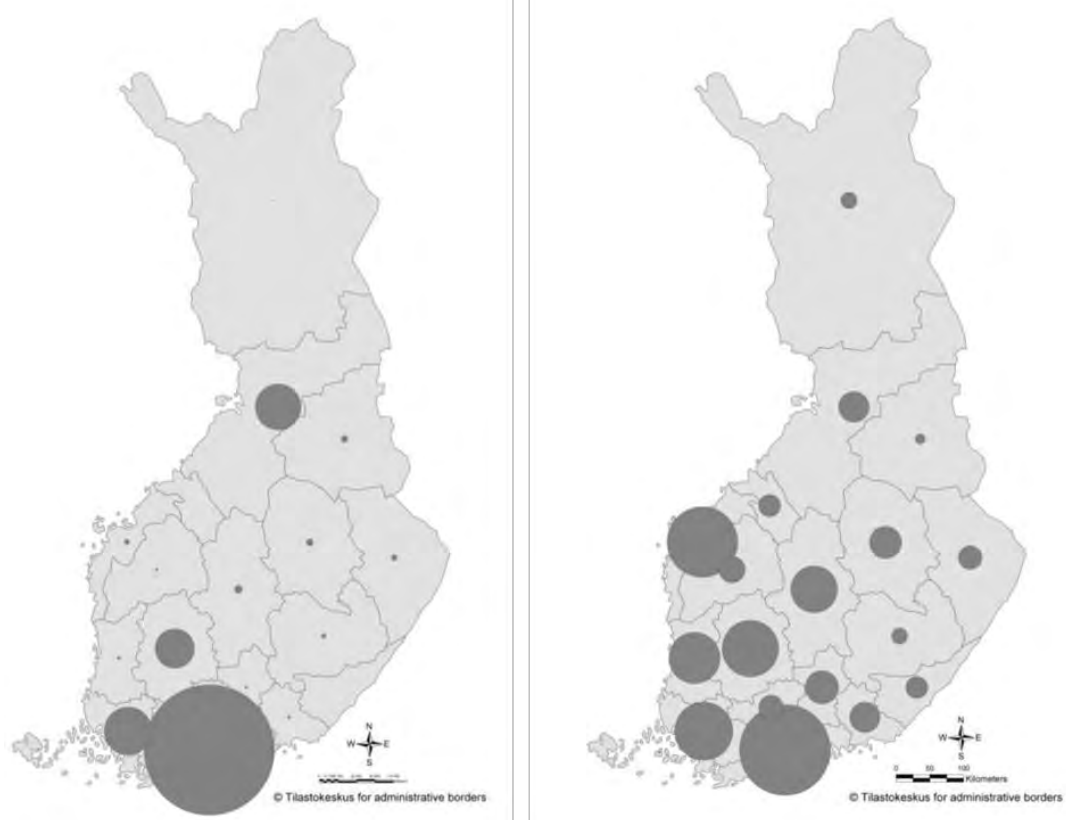
It is often argued that the growth and consolidation of the largest cities will benefit the entire country. This is because the largest cities are considered locomotives for growth in the remaining parts of the country. This argument dates back to the growth pole theory, as it developed in the 1950s and 1960s. At that time, the theory was developed in the context of industrial society. Empirical verification of the theory, however, was highly disputed. Today, it is even more uncertain whether the spread effects experienced during the 1960s are still valid, as economic growth in large cities today is connected to other drivers of the economy and other kinds of firms and enterprises. The rise of the knowledge economy and the use of human capital in the form of highly skilled or knowledge workers are key features in the urban economy. This development draws more on urbanisation economies, understood as positive economic effects that operate externally to industries but are within a bounded urban region. Furthermore, one of the effects of globalisation is the forming of specialised international networks of innovation and production established far beyond the commuting hinterlands, regional and national borders. These global networks connect specialised centres of production, knowledge and innovation. Much research has focused upon these new global networks, leaving behind the question of the spreading effects of the production that has not been outsourced. The purpose of this study, therefore, is to elucidate, via case studies, the extent to which the purchases of supplies and services from knowledge firms are located in proximity of the company, i.e. the commuting region, or whether these purchases have spread to the remaining part of the country. The case studies also try to elucidate the importance of foreign suppliers.

\section{The study}

Gaining detailed knowledge about the size and geography of supply networks is possible only by using questionnaires or interviews. Therefore, interviews were carried out in Denmark, Finland and Sweden, while a questionnaire survey was used in Norway. The data were collected during autumn 2011 and spring 2012.

Knowledge firms were asked to answer the following questions: Who are your most important suppliers and subcontractors of the firm? Where are they located? Where is future development of the firm planned to take place?

A template for the interviews is shown in the annex. In Norway, there was some difficulty setting up appointments for interviews. Therefore, a questionnaire-based survey was conducted. In Denmark, Sweden and Finland, the study was based upon interviews with 20 companies, seven in Denmark and Finland and six in Sweden. In Norway 32 firms took part in the questionnaire study. 
This report presents the project findings. In this first general section, the main findings of the four national studies are presented, along with the theoretical framework of the study. After the general section, the four national studies are presented by each of the national project teams.

\section{Project team}

\section{Denmark: University of Copenhagen}

Niels Boje Groth, senior researcher, project coordinator

Forest \& Landscape Denmark

Lars Winther, associate professor

Dept. of Geography and Geology

Finland: University of Eastern Finland, Karelian Institute

Heikki Eskelinen, dr. professor

Timo Lautanen, research manager ${ }^{1}$

Pasi Saukkonen, researcher

Norway: Norwegian Institute for Urban and Regional Research (NIBR)

Olaf Foss, research director

Frants Gundersen, researcher

Sweden: Royal Institute of Technology (KTH)

Mats Johansson, associate professor

Marcus Adolphson, researcher

Steering group

Hallgeir Aalbu, director general, Ministry of Local Government and

Regional Development, Norway

Bue Nielsen, geographer, Ministry of the Environment, Nature Agency, Denmark 



\title{
1. Main Findings
}

\author{
Niels Boje Groth and Lars Winther
}

The importance of proximity depends upon the geographic level of supplier relations. At the national level, supplier relations are clearly influenced by geographic proximity. Whenever alternative suppliers are available at the national level, companies tend to choose and build up relations in the home region of the production plant. Supplier relations at international level, however, are dominated by parameters other than geographical proximity. Usually, international supplies involve special components and materials of key importance for the quality and competiveness of the final products. They must be acquired from key suppliers wherever they are located, either in country or abroad. For this kind of supply, the decisive parameter is "quality" rather than "proximity."

The importance of national versus international suppliers varies considerably, as illustrated by data from six Danish Companies in table 1.1 below.

\begin{tabular}{|c|c|c|c|c|c|}
\hline \multirow[t]{2}{*}{ Origin of supply } & \multicolumn{4}{|c|}{ Company } & \multirow[t]{2}{*}{ average } \\
\hline & $\# 1$ & \#2 & $\# 5$ & \#6 & \\
\hline$\%$ of supply volume coming from domestic suppliers & 81 & 66 & 37 & 87 & 68 \\
\hline$\%$ of supply volume coming from foreign suppliers & 19 & 34 & 63 & 13 & 32 \\
\hline Total & 100 & 100 & 100 & 100 & 100 \\
\hline
\end{tabular}

* Supply of company \#1 is measured by number of suppliers, whereas supply of companies \#2, \#5 and \#6 is measured by purchase costs.

Not all supplier relations could be identified geographically. Large national or transnational suppliers, delivering from cities or regions that are only hubs for distribution, are not easy to locate. Only to a minor degree are the hubs actual beneficiaries of the turnover, since the final beneficiary, the TNC, is usually located elsewhere.

If we turn our attention from the location of suppliers to the kinds of companies being supplied, we found it relevant to include observations on the geographical development patterns of the companies. If companies are outsourcing or expanding abroad, this process will greatly affect their supplier relations. One company, reduced its proportion of domestic production from $100 \%$ in 2007 to only 10\% in 2011, and thus changed its pattern of suppliers accordingly. Some companies, however, stressed that supplier relations are not easy to change overnight. They build upon trust 
and selection criteria that, besides the company's own criteria, may include legal quality standards set up by national governments.

While, outsourcing is considered a general phenomenon, the study showed that order-producing companies manufacturing complex - often costly - products are less inclined to outsource than companies producing standardised products in large volumes. Companies producing complex and costly products are so intimately tied to the regional milieu that they try to remain more local. Rather than outsourcing, these companies are trying to be more cost-efficient by using lean production methods and automating production. The supplier relations for these kinds of companies are characterised by two types of networks: (1) local (i.e. proximity) networks of non-specialised supply and (2) national and international networks of specialised quality products, including e.g. OEM-components. These characteristics were emphasised by the Danish, Finnish and Swedish firms in our case studies.

Companies producing high-technological but standardised products in large volumes reveal other development and supplier patterns than do companies producing complex products. The high volume, standardised product manufacturing firms tend to move or expand close the markets and/or close to cheap labour markets, which in turn affects their supplier relations. New supplier relations are established in proximity to the new foreign production plants.

Some observations on national geography are worth mentioning. The Finnish case study concentrated all 7 interviews with companies situated in Eastern Finland; they were, thus, located in both Finland's national as well as the European periphery. The authors of the Finnish study observe that it is demanding, however possible to "run a high technology enterprise and grow fast also outside the largest urban centres and far away from the main markets." In these remote geographic areas, it became apparent that although the companies owed their existence to specific local ownerships, they owed their growth to the presence of a nurturing operational local environment of e.g. growth-oriented and internationalized "lower technology" suppliers and knowledge institutions.

The Swedish case studies were situated in three areas, the national capital Stockholm, the regional capital Göteborg and the industrial cluster of Timrå in northern Sweden. The study did not reveal any kind of network patterns specifically related to the three regions.

The companies of the Danish case-studies were situated in the Copenhagen commuting region (Greater Copenhagen and West and Eastern Zealand). The Danish supplier relations at national level showed clear tendencies to proximity. Beyond the metropolitan commuting region, we found that the second most important growth region in Denmark, East Jutland, including the regional capital Århus, seems to be more attractive than the neighbouring region, Funen. The importance of the large national centres was emphasised by the Finnish case study. The study observed that all the companies interviewed supplemented 
their tight intra-regional relations with supplier and R\&D relations with the capital region. Both case studies, therefore, emphasise the importance of the largest cities as national centres of growth, in their capacity to attract relations other than proximity relations.

The Norwegian study of knowledge intensive business services (KIBS) highlighted that the KIBS have created only few local supplier relations or local spin-offs. Rather, they have established distant links with companies in other Norwegian cities. These observations seems to be in line with Hanell and Neubauer (2005), who observe that global accountancy firms establish very decentralised regional offices in the Baltic Sea Region without promoting local supplier relations. They are attracted to even small local destinations in order to provide face-to-face services with customers. However, they do not seek out local suppliers. What they depend upon are relations with the expertise of the regional centres of the company in the large cities.

Keeping in mind all the deviations from the proximity pattern, what remains is that the overall spatial patterns of suppliers at the national level tend to follow the "rule" of proximity. It follows from the case studies that (1) the main beneficiary regions of the national supply of the high-tech companies are the home regions of high tech companies, and (2) that specialised, high quality supply is chosen by criteria other than proximity, e.g. quality and brand, and often acquired from distant locations. The general pattern of geographical concentration of economy is thus sustained by national suppliers, whereas specialised international suppliers deviate from the proximity pattern. Taking into consideration the dynamic growth patterns of high-tech companies, we found that companies producing high-tech but standardised products in large volumes are much more inclined to outsourcing and foreign expansion. They will tend to build up new foreign supplier relations and even replace former national ones, whereas order-producing companies, because they deliver complex and costly products, are inclined to remain in their home regions and to keep their supplier relations more stable.

\subsection{The companies}

The companies taking part in the study were located in capital and regional growth regions. An overview is given in figure 1.1. The companies were distributed as follows: Denmark (7 companies situated in the Copenhagen Region and Region Zealand), Norway (2 interviews and 32 e-mail and phone dialogues, located in Oslo, Bergen-Stavanger and Tronheim), Finland (7 companies in the three towns of eastern Finland, Kuopio, Joensuu and Mikkeli) and Sweden (7 companies in Stockholm, Göteborg and Timrå). 
Figure 1.1. Location at NUTS 3 level of the number of companies interviewed. In Norway the numbers shown relates to phone and e-mail dialogues and two interviews

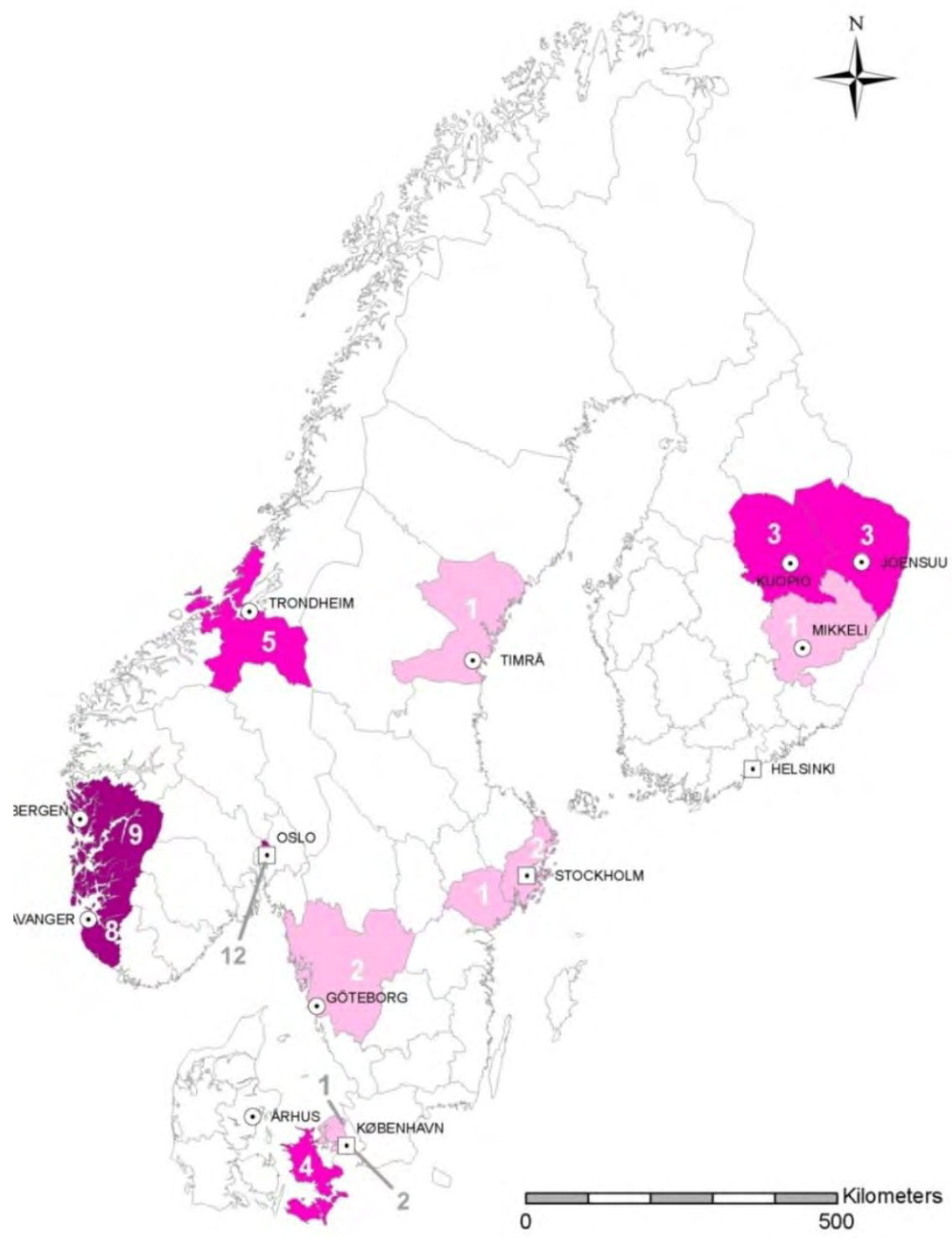

The case studies reveal that the different types of firms have very complex geographies of external linkages in terms of the company's three "worlds" of (1) production, (2) innovation and (3) market relations. This is further explained in the theoretical framework in the next section.

Each of the case studies tried to grasp patterns of supplier relations in relation to typologies of companies observed. The Finnish study distinguishes between firms that are (1) research-based, (2) process- or project-based and (3) production-based. Process-based firms deliver their 
products especially to public and semi-public institutions (e.g. public works), and are usually in need of continuing deliveries of supplies and services. Production-based companies deliver final products, e.g. investment goods for other companies.

The Danish data showed pronounced differences between (1) orderproducing, (2) market-producing and (3) research-based firms that deliver products or processes to facilitate other companies in further development of their products or production processes. The orderproducing firms deliver products tailored to individual customers, often as investment goods to other manufacturing firms, such as machinery to the printing industry, pharmaceutical industry or offshore drilling industry. The products are complex and often produced by product teams over a long period of time - in some of our cases, the production process was of 3 to 12 months' duration. The market-producing firms produce standardised high-tech products in large volumes to anonymous customers, distributed in the market, often to specialists, e.g. doctors or other professionals. The research-based companies are identified in the Danish and Finnish studies. They are characterised by intensive development of their own products in close cooperation between in-house R\&D and external research institutions - and by close cooperation e.g. business-to-business solutions with the customers.

The Swedish study distinguishes between (1) production-innovation companies (PICs) and (2) innovation companies (ICs). As with the above-mentioned order-producing companies, the PICs work closely with their customers, and the innovation and production processes are integrated and co-located, and hence, facilitated by the synthetic kind of knowledge base. In the ICs, innovation and production are usually separated, as with the above-mentioned market-producing companies. The study observes that the co-location of innovation and production is likely to take place outside urban centres, whereas the innovation, development and design function of the ICs benefit from urban advantages and hence, are likely to locate in the large urban centres.

The Norwegian study concentrated upon knowledge-intensive business services (KIBS). Even more than the high-tech firms, the KIBS are characterised by strong affinities to the largest urban centres and by much shorter chains of suppliers.

\subsection{The suppliers}

All the case studies conclude that supply varies from standardised generic and locally delivered supply to specialised, often customised supply from local as well as globally located subcontractors.

To understand the diversity of the knowledge firms' priorities and supplier relations, we further distinguished between different types of suppliers. One Danish firm had a clear typology that revealed the strate- 
gic importance of the suppliers: Key suppliers are those urgently needed for running the production process. High quality and competitive price are key issues, as well as geographical proximity. Strategic suppliers provide complementary competencies and components difficult to locate by putting out a tender. Relations with strategic suppliers are often characterised by partnership relations. Besides these two most important types of suppliers, the Danish firm relied upon routine (standard products) and capacity suppliers (used during peak productions).

Most firms distinguished between "direct supplies," e.g. raw materials and key components for the final product, and "indirect supplies" such as services and products, e.g., those needed for marketing the product. Another important distinction separated "catalogue suppliers" from "orderproducing suppliers" (i.e. supply specified by technical specifications, drawings and instructions). Catalogue suppliers (often including direct supply) tend in many cases to be transnational firms (TNCs). Deliveries normally originate from hubs located in national logistic centres or neighbouring countries. They are too large to be influenced by deliveries to the case study firms. Geographical proximity of suppliers of original equipment components, the OEM suppliers, is a factor not usually considered by the firms. The OEMs might be TNCs, but they do not have to be. Most important is that they deliver components that have high quality, specialised function and high reliability. Finally, the case-study firms distinguished process deliveries (e.g. furbishing metal frames and components) from supply of components and services. In the Finnish case study, about onethird of the total supply consisted of services and the remaining twothirds were raw-materials and components.

\subsection{The geography of the world of production}

The supplier networks include both global and local suppliers. The global suppliers of Original Equipment Manufacturer (OEM) and specialised, knowledge-intensive input and subcontractors produce standardised products or products by design. Local suppliers and subcontractors also range from highly specialised, knowledge intensive inputs to more standardised and generic inputs. Generally, however, the firms examined tended to use suppliers located within their own region, and we can observe that geographical proximity seems to have an importance. Other considerations, such as costs, OEM, new technologies, ownership, etc. create relations at a distance.

The most important factor for choosing distant (global or national) rather than local suppliers or subcontractors is when there is a need for highly specialised components or OEM products and specific raw materials. This observation is clear from the Swedish, Finish and Danish case studies. Considering that most firms interviewed for this report operate at the global level, they are deeply concerned with product quality to 
remain globally competitive within their specific field. Therefore, the firms are dependent on quality of the supply, and they choose the best components or services no matter where the suppliers are located. In some of the cases, however, the firms were concerned not only about the quality of the supply but also about specific brands. Thus, one firm placed high priority on components showing the high-quality brands of the "originally equipment manufacturers" (OEM).

In Denmark, the supplier relations depend upon the type of production. Firms producing by order (customisation or dedicated products) tend to prefer domestic suppliers to a larger extent than firms producing generic products for global markets. This tendency is also noted in the Swedish study. Three of four order-producing firms in the Danish study use between $65 \%$ and $90 \%$ domestic suppliers. The fourth firm deviates from this pattern, most likely because it is a subsidiary of a large European TNC that requires the firm to use "in-house" supply; hence, ownership seem to have an impact on the geographies of the production relations. Market-producing firms (generic products in high volumes for global markets) have outsourced substantial parts of their production and reorganised their suppliers, such that their domestic suppliers were replaced by suppliers closer to the outsourced plants located abroad. The factors behind outsourcing are normally either access to cheap labour or access to the markets. The different geographies of supplier relations of order-producing, market-producing and business-tobusiness solutions are shown in diagrammatic form in figure 1.1.

Figure 1.2 shows a relatively dense network of domestic supply for order-producing firms combined with global suppliers of specialised components. It is a case of transnational firms delivering high quality standard components and/or original and branded components. The orderproducing firms keep the primary production in their home region. The market-producing firms, on the contrary, outsource primary volume production, keeping only R\&D and pilot production in the home country. Being able to monitor distribution only of their domestic suppliers, they tend to locate in regional proximity of firms or in the large urban centres.

This geography of production relations can also be identified in Finland and Sweden. In Finland, one-third of the most important suppliers for the firms supply services and two-thirds raw materials and components. In general, services are obtained from firms that are relatively close by, whereas raw materials and specific components are often acquired from distant suppliers. This division is typical for high quality, specified components not produced locally, and in many cases not even domestically (the producer may have a dealer in Finland, most often in the capital region). Distance to suppliers of raw-materials and specific components is not perceived as a major problem. The meaning of distance appears to be a more challenging issue for relations with current customers (needed, for instance, for product development) and for reaching potential new customers. In Sweden, the case-studies show that knowledge firms generally 
have an aspiration to maintain some proximity to their suppliers. The importance of distance decreases in two kinds of supplier relations: (1) when the supplier is providing a specialised component and service and (2) when long term relations are of importance.

In the KIBS sector, as revealed by the Norwegian study, the geography is characterised by very limited relations between the home city of the firm and the regional hinterland. Instead, there are discontinuous links between the largest cities. However, regional impacts are identified by 4 out of 10 firms as spin-offs of new companies. When asked about their future strategies, however, these companies expected to establish new branches or firms at national level (probably in the largest cities) rather than locally.

Figure 1.2. Illustrations of the geography of "order-producing," "marketproducing" and "supply of business solutions"

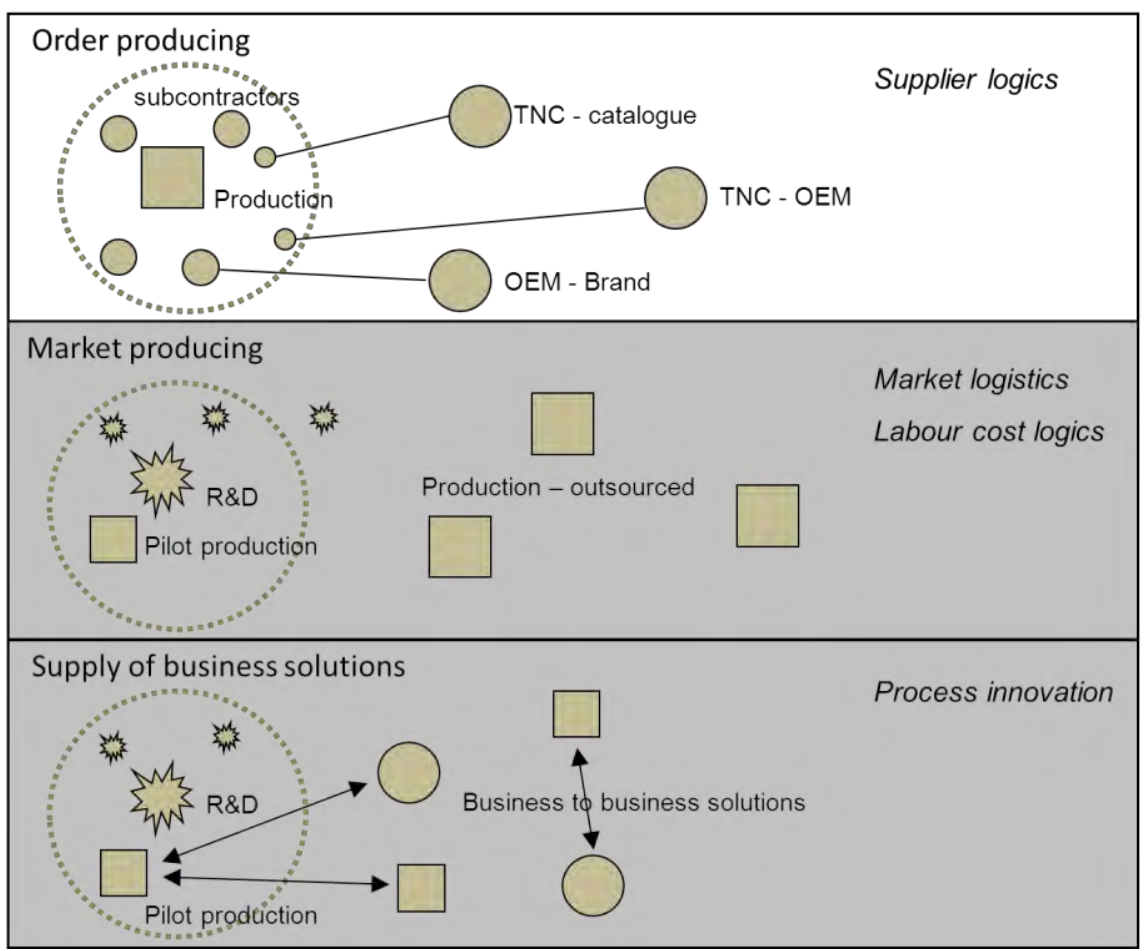

\subsection{The geography of the world of markets and knowledge}

Most of the firms interviewed in the Danish, Finnish and Swedish case studies are international competitive firms operating on global markets.

The Finnish case study observes that three of the five firms operate on global markets. Internationalisation is considered the most important source of growth for the firms in terms of markets, knowledge and production. Thus, in the realm of markets and customers, most of the firms in 
manufacturing operate on global markets, exporting to many countries. This is the case for those firms producing customised products and for firms producing generic product for mass consumption. Likewise, the realm of knowledge and innovation shows strong global, distant linkages among the firms, ranging from knowledge institutions to key strategic suppliers.

Data from the knowledge firms in the case studies reveals that innovation and knowledge networks, knowledge sources and strategies vary tremendously among firms. The firms range from those using radical innovation strategies based on analytical, scientific knowledge to those producing incremental innovations through customisation and learning by doing based on synthetic knowledge. Likewise, the knowledge networks and key sources of knowledge of the firms differ accordingly, in terms of both inhouse resources (R\&D department, teams of workers or key individuals), key partners (research institutions, suppliers, costumers) and geographic scale (global, national or regional). In the Danish case study, the world of knowledge varies from firms with strong R\&D efforts (14\% of turnover) and global research networks to locally-based knowledge networks and product customisation. It is especially, the customers and key strategic suppliers who seem important for innovation in the order-producing firms, whereas in-house R\&D and local and global knowledge relations to institutions and other firms are more relevant for the firms producing generic high-tech products. This is also evident in Finland. In terms of research and development cooperation, the geographical distribution and degree of internationalization among Finnish firms appear to vary across firms. However, the data clearly suggest that geographical proximity between the partners contributes to cooperation. In general, all of the seven Finnish case study firms have invested strongly in product development, mainly in the form of in-house operations and in the current geographical location of the company. In terms of the research and development partner network, the Finnish case study firms have local and domestic connections, and on average, the number of key partners varies from between two and seven per company. The importance of proximity is highlighted by the fact that more than two-thirds (64\%) of the domestic R\&D partners are local, i.e. within the same NUTS 3 region. Three of the firms have some of their key research and development partners abroad. On average, the number of foreign partners is five, but depending on the product development phase, the firms may have up to 20 public organisations as partners involved in testing of their product. Most often, the research and development partners are other firms (on average 2 per firm), universities or some other kind of higher education institutions (on average 1.7 cooperating institutions per firm). The average number of other public institutions who assist as development partners is less than one per company. 
Overall, two conclusions from the Finnish study can be highlighted: First, local concentration of innovation can be crucially important for most firms. Second, apart from basic research operations, the customers' role in initiating product development processes is essential. 


\title{
2. Theoretical Framework
}

\author{
Lars Winther and Niels Boje Groth
}

Recent decades have seen a major transformation and restructuring of the economic geography of the Nordic countries, due mainly to globalisation, the rise of the knowledge economy and the concentration of growth in the large urban areas. Globalisation processes have transformed the economies of the Nordic countries and the rest of Europe through, for instance, increased price competition from the low-wage countries, the expansion of new markets and stronger competition among global and local firms. As a result, many firms in Europe and the Nordic countries have increased their focus on innovation, as the competiveness of firms depends on their ability to innovate and improve their productivity through process improvement, new forms of organisation, increased product quality or producing new products (David \& Foray, 2002). Knowledge is fundamental to innovation, and hence, the rise of the knowledge economy, e.g. an economy that is based on the production, distribution and use of know-how, has become a major constituent of the modern European economy.

\subsection{The knowledge economy}

The knowledge economy has become visible in many places in the Nordic economic landscape, particularly in the large urban regions that offer a higher degree of accessibility to qualified labour and to diverse labour markets, as well as proximity to knowledge institutions, markets and global linkages (Andersen et al., 2010; Hansen \& Winther, 2012; Lautanen, 2012). Although this is evident for especially high-tech industries and knowledge-intensive business services located in urban regions (Skytt, 2011), the knowledge economy also produces an uneven economic geography of economic growth and, hence, affects local economic growth outside the main growth regions.

The growth of the large city regions has been labelled the urban turn (Hansen \& Winther, 2012). The urban turn emphasises the importance of large cities and city-regions as the key places of economic growth in modern capitalism (Scott, 2008). Concurrently, with the rise of the knowledge economy, the use of human capital in the form of highly skilled people, talents or knowledge workers is seen as a key resource in 
the economy - as it is the ability of people or groups of people to produce, use and distribute knowledge and thus generate new ideas or combine existing knowledge in new ways that contribute to innovation. This development draws on urbanisation economies, understood as positive economic effects that operate externally to industries but are within a bounded urban region. Urbanisation economies are related to all firms in all industries, and the basic argument is that density and diversity can reduce search cost and expose firms to unexpected events that can bring with it new knowledge.

This understanding of knowledge as a key resource and knowledge production as a central process in urban and regional studies draws heavily on institutional and evolutionary economic theories and the vast innovation literature. Three main strands can be identified (Asheim and Mariussen, 2003). The first strand of research emphasises institutions, formal and informal rules, norms and legislation as prerequisites for economic development, knowledge production and innovation. The second strand has a focus on geography, pointing to localised learning, geographical proximity, clusters and localisation economies, e.g. positive economic effects that are external to the firm but internal to an industry within a region (Feldman, 2003). This literature also stresses the necessity of face-to-face contact and regards socio-cultural proximity as fundamental to innovation and knowledge transfer between economic agents. Clusters, industrial districts and regional innovation systems have been the main focus of this research. This is an outcome of the third strand, which concerns the innovation system that underpins the innovation process (Lundvall, 1992; Edquist, 1997).

\subsection{Agglomeration economies}

In recent decades, focus has turned to the analysis of agglomeration economies and clusters, e.g. localisation economies (cf. Asheim et al. 2006; Martin and Sunley, 2003; Amin, 2003). The analysis of geographical clusters focuses on the identification of local or regional capabilities. The theoretical framework emphasises growth industries, the customer and supplier networks and the general institutional set-up created within clusters but external to firm advantages. The dynamics have been theorised thoroughly, but empirical confirmation is needed (Malmberg and Maskell, 2002; Malmberg, 2003). 


\subsection{Relational propinquity}

Contrary to the argument of localised learning, the relational position emphasises relational propinquity and is associated with Amin's (2003; 2004), Amin and Thrifts' (2002) and Amin and Cohendet's (2004) analyses of globalisation, urban and regional development, urban change and the production of knowledge. In Amin and Thrift (2002), location is understood as situated, distanciated networks. For instance, they argue that relational or organisational propinquity is more important than geographical proximity in the transfer of tacit knowledge. Amin and Cohendet's (2004) discussions of the production of knowledge in firms illustrate the relational position. They focus on the firm rather than the region being the locus of knowledge production. In doing so, they identify various factors underpinning the knowledge-producing processes. They do not exclude geography as an important factor shaping firm networks, but the space in which the firms operate cannot be reduced to a matter of geographical scales. The firm's network is constituted by the firm's relations, and, hence, the analytical focus should be on the space defined by the firm relations, i.e. the spatial extension of the relations.

\subsection{Proximity and propinquity}

Bridging the two positions, Bathelt et al. (2004) promoted a theoretical sketch which discusses a) the local production of knowledge as a product of local "buzz" or as a presence of actors embedded in a geographical community, and b) knowledge stemming from channels of communication, called "pipelines," which are linked to places outside the community. Thus, an increasing return to location of economic activity is not only restricted to local spill-over effects but also to the relational spaces of firms that stretch beyond the territorial entities. Relational propinquity provides new insight into the competitiveness and location of firms with its focus on relations. However, to understand the industrial location dynamics, it is vital to recognise how places underpin the relational and organisational spaces, as revealed by the case study firms in this project. These Nordic firms have production, knowledge and market networks that stretch across economic spaces and geographical scales. The economic landscape of firms, regions and cities can be analysed in its own right. However, it must always be understood in relation to other aspects, as it is related to the structures, relations and processes that originate from the social dynamics, political visions, governance structures, regulation and cultural identities in which social action is embedded (Granovetter, 1985; Grabher, 1993; Peck, 2005). The economic geographies of the region and the location and innovation strategies of the firms are not only related to the economic spaces but also to other social and 
political processes. Emphasising these relations, focus is on the dynamics of the economic landscape. The economic landscape is constituted by a range of heterogeneous and differentiated spheres, e.g. physical and material structures in space, organisational and institutional set-ups and the geography of technology, knowledge and learning. This creates path-dependency, where former processes, relations and structures influence the ongoing regional competitiveness of firms and industries. The process of path-dependency points to the history of the economic landscape. An important feature of capitalism is that it produces and reproduces different geographies in different industries and sectors at different scales at the same time.

\subsection{Interplay of high- and low-tech}

As a result of seeing knowledge as a key resource and knowledge production as the central process, many studies of urban and regional growth have recently focused on the knowledge production of firms, the firms' knowledge relations and networks and how the local and regional institutional setup supports knowledge creation in firms and industries. This is evident in Scandinavia as well.

Recent studies also stress, however, the relevance of a broad conception of the knowledge economy which goes beyond the academic and policy focus of high-tech industries. Low-tech industries continue to have an important impact on manufacturing in terms of employment, value added and export within the EU. These low-tech industries compete on the ability to create tailor-made solutions. Further, evidence from Denmark and the UK suggests that low- and high-tech industries are closely interconnected because low-tech firms play important roles both as partners in the innovation processes of high-tech firms and as buyers of high-tech products which ultimately link them in space (Hansen \& Winther, 2011; Hansen, 2010). Moreover, a general increase in human capital intensity in manufacturing has taken place in the past decades. This increase in human capital intensity is not limited to R\&D intensive, high-tech industries. In fact, empirical evidence from Denmark reveals that the increase in talent intensity is relatively higher in lowtech industries (Hansen et al., 2012). The growth in human capital, however, reveals considerable geographical differences between urban regions and other regions. This uneven geography of human capital is not confined solely to high-tech industries being located in and around large urban areas. Low- and medium low-tech industries in metropolitan areas also show a higher growth in the share of human capital than in the rest of the country (Hansen et al., 2012). 


\subsection{The knowledge base: analytic and synthetic}

Another means of distinguishing innovations is to consider their relation to current level of technology (Hansen \& Winther, 2011). A constant improvement of a product or a production process is considered an incremental innovation, as it is not fundamentally different from wellknown technologies in the field. A radical innovation, in contrast, is completely different from the current products or processes available on the market. A number of related radical innovations, taken together, can constitute a technological revolution, which has great impact on society as a whole, creating new technological paradigms. Whether the firms in an industry primarily create incremental or radical innovations depends fundamentally on the characteristics of the industry. In general, this can be termed the "industrial knowledge base" (Asheim and Gertler, 2005; Asheim and Coenen, 2006; Asheim, 2007) and is related to the frameworks of national and regional innovation systems. It includes the institutional framework of the innovation process as well. Asheim and Gertler (2005) distinguish between two main industrial knowledge bases. The "analytical knowledge base" is characterised by knowledge creation through the use of scientific methods and modelling. The links between research institutions, universities and firms is therefore of great importance for this kind of knowledge production. The use of codified knowledge is extensive, and the results are most often also codified and documented through patents and publications. However, even highly codified knowledge requires tacit knowledge to implement (Nonaka and Takeuchi, 1995; Amin and Cohendet, 2004). Overall, these characteristics imply that most innovations based on an analytical knowledge base are mainly radical. In contrast to the analytical knowledge base, the "synthetic knowledge base" utilises existing knowledge rather than creating completely new knowledge. The availability of workers with practical and engineering skills is regarded as essential and tacit knowledge, learning by doing and learning by using therefore have greater importance than the scientifically-based codified knowledge. The objective of the innovation process is often to solve specific problems for a customer, and the relations between agents/firms in the commodity chain are thus of significant importance for producing new innovations. A knowledge base with these attributes will therefore primarily produce incremental innovations. Asheim (2007) subsequently introduced a third knowledge base, called the "symbolic knowledge base," which is not considered in this project. 


\subsection{Knowledge bases in interplay}

Many firms combine the two ideal types of knowledge bases (Hansen \& Winther, 2011). Jensen et al. (2007) find that such firms tend to be more innovative than firms relying on only one of the two knowledge bases. Jensen et al. (2007) confirm how the Science, Technology and Innovation (STI) mode (associated with the analytical knowledge base) and the Doing, Using and Interacting (DUI) mode (associated with the synthetic knowledge base) complement each other: experiences and practical knowledge are frequently essential for scientists working in R\&D departments of high-tech firms in the process of designing research projects and interpreting results. Similarly, scientific knowledge is often part of the solution for firms which otherwise emphasise learning-bydoing and learning-by-using. Accordingly, the STI and DUI modes are not entirely dependent on the analytical and synthetic knowledge base, respectively, but include elements from both (Asheim, 2009).

The radical innovations that derive from an analytical knowledge base are often given prominence over the incremental innovations. However, several criticisms have been raised of this model, which has subsequently been termed the "linear model of innovation" (Nelson and Winter, 1982; Dosi et al., 1988; Lundvall, 1992; Nonaka et al., 1996; Edquist, 1997; Amin and Cohendet, 2004). Firstly, few innovations actually happen in this way. Innovations are often driven by demand, or they result from new ways of combining known knowledge. The importance of science-based knowledge production had been exaggerated, and the learning processes are highly complex and cross-cut various communities (Amin \& Cohendet, 2004). Secondly, the linear model ignores the interactions and feedbacks from customers and suppliers that are so important to innovation processes (Kline and Rosenberg, 1986). The case studies from the four Nordic countries reveal the importance of this insight, as they include firms that draw mainly on either the analytical and synthetic knowledge bases; this is also the conclusion drawn regarding innovation among low-tech and medium firms in Denmark and the UK (Hansen \& Winther, 2011; Hansen, 2011; 2012). 


\subsection{Framework for analysis}

The project has identified three central "worlds" of the firm regarding the external impact of the knowledge firms, (1) the world of knowledge and innovation; (2) the world of production, that includes suppliers and labour input; and (3) the world of markets, pointing to the importance of the customers, see figure 2.1.

\section{Figure 2.1. Framework for analysis: worlds of the firm}

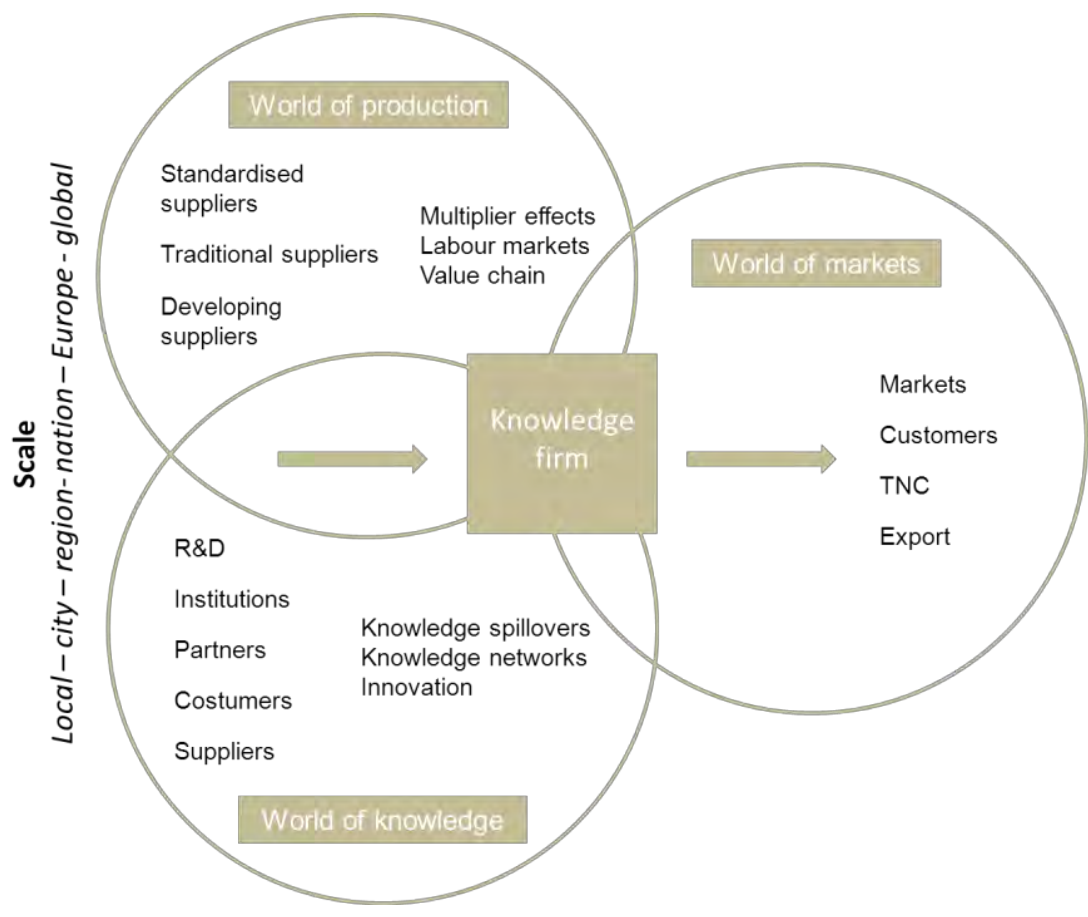

The three worlds overlap, of course; hence, in many instances, knowledge and innovation draw heavily on user-producer interaction, and customisation also plays an important role in firm innovation, especially in low- and medium-tech firms (Hansen 2010; Hansen \& Winther, 2011) - see figure 1.2. In recent years, much has been said about the knowledge relations and knowledge spill-overs of the firm and industries. In this report, we have focussed on the world of production and production networks in order learn more about the geography of direct impact on supplier networks. In many cases, the supplier networks overlap with the world of knowledge and innovation, as some of the suppliers are crucial partners in creating new knowledge and/or producing incremental innovation. 


\subsection{Empirical focus}

The main part of this report consists of four empirically-based national reports from the participating four Nordic countries. The case studies focus on the impacts of firms' external relations, especially relations with subcontractors. Although the three worlds of production, knowledge and markets are interrelated, it was not possible to provide an even and balanced analysis of the three worlds. The point of departure was the growth effects of high-tech firms. They owe their growth to the markets and knowledge, but the effects of growth are primarily the foot-prints of the world of production. Thus, we focused on the supplier relations. And so did the firms. Often, interviews were given by the procurement managers rather than e.g. the president or director. Thus, many of the interviews focused on supplier relations. Other topics covered were relations with strategic partners (e.g. R\&D), owner relations, and relations with R\&D departments and customers, where relevant. Figure 2.1 presents a case from Finland.

Figure 2.2. Location of the most important suppliers and R\&D relationships of Finnish research based firms

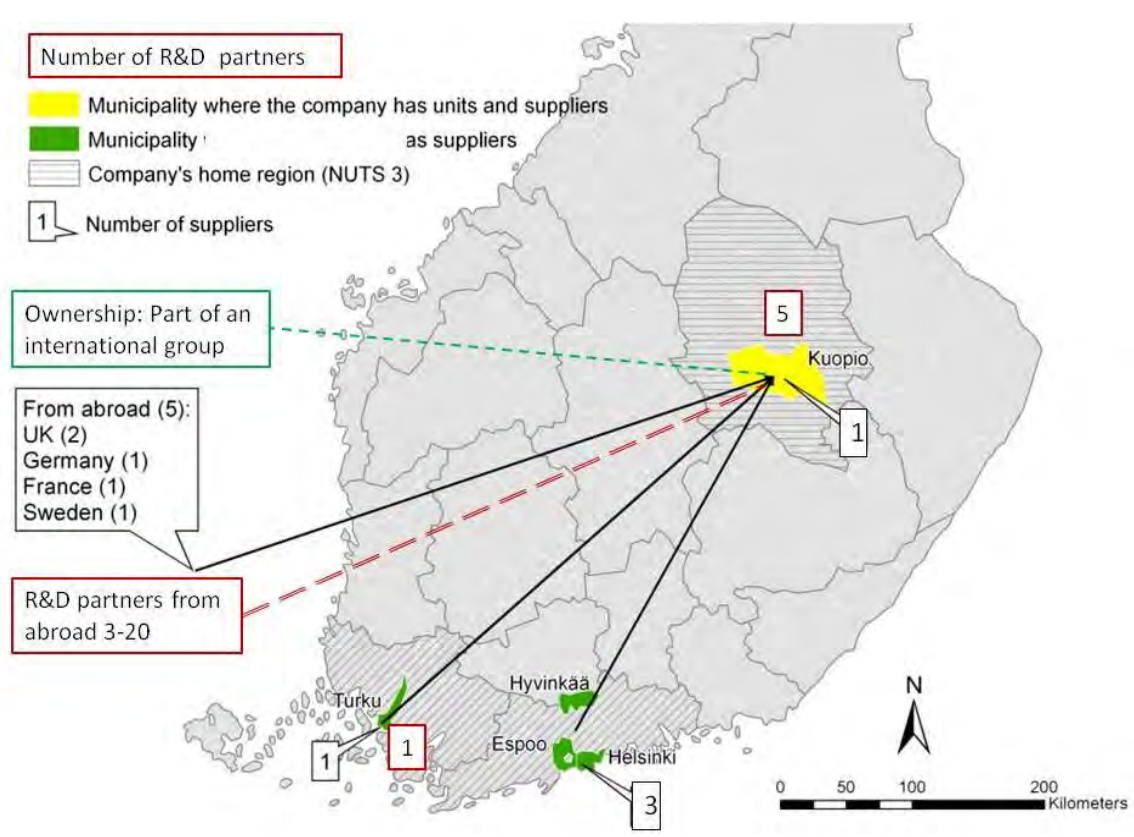

Thus, the large urban region has a strong position in the knowledge economy at the production sites of the knowledge firms in high-tech and medium-tech industries. This reflects mainly the better access to highly skilled labour, research institutions and global linkages. The Swedish study observes that the Innovation Companies (ICs) tend to locate in central urban locations. The strong concentration of the knowledge firms in urban regions becomes even more evident when examining knowledge-intensive business services. According to the Norwegian 
inquiry, knowledge- intensive business service firms (KIBS) prefer location in large cities due to access to highly skilled labour, customers, the industrial milieu (urbanisation economies) and access to R\&D and other knowledge activities (see table 2.1 below).

Table 2.1. Location preferences of Norwegian knowledge-intensive business service firms (KIBS)

\begin{tabular}{lc}
\hline Location preferences & \% of survey firms \\
\hline Skilled workers & 95 \\
Customers & 90 \\
Industrial milieu & 71 \\
R\&D and other competence (consultants) & 57 \\
Suppliers & 40 \\
Infrastructure & 40 \\
\hline
\end{tabular}

Source: the Norwegian survey.

It is worth noting that the high priority given to access to customers was not so prominent in the survey interviews of manufacturing knowledge firms in Sweden, Finland and Denmark. Most of these manufacturing firms were operating on global markets. Thus, in the world of market relations, the manufacturing firms were not dependent on the large urban centres. The importance of the large urban centres becomes more evident when one examines the two "worlds" of "production" and "knowledge." This is evident from the case studies: many of the firms located outside the main city regions have suppliers and knowledge relations in the capital regions, and the firms located in the capital regions have strong local production and knowledge relations, a pattern emphasised in the case studies from Denmark and Sweden. Moreover, firms that draw mainly on the analytical knowledge base tend to have strong linkages to the urban regions and research institutions, to knowledge-intensive suppliers and knowledge-intensive business services. The Norwegian case study focused on service firms, which tend to have fewer suppliers than manufacturing firms. The study observes that partners, distribution networks and $R \& D$ relations are dispersed over most of Norway, but only between the largest cities. 


\subsection{References}

Amin, A. (2003) Spaces of corporate learning. In Peck, J. \& Yeung, H.-W. (eds.): Remaking the Global Economy: Economic Geographical Perspectives (pp. 114-129). London, Sage.

Amin, A. (2004) Regions Unbound: Towards a New Politics of Place. Geografiska Annaler, 86B, 33-44.

Amin, A. \& Cohendet, P. (2004) Architectures of Knowledge: Firms, Capabilities and Communities. Oxford: Oxford University Press.

Amin, A. \& Thrift, N. (2002) Cities. Reimagining the Urban. Cambridge: Polity.

Andersen, K.V, Hansen, H. K, Isaksen, A., \& Raunio, M. (2010) Nordic City Regions in the Creative Class Debate: Putting the Creative Class Thesis to a Test. Industry and Innovation, 17: 215-240.

Asheim, (2007) Differentiated Knowledge Bases and Varieties of Regional Innovation Systems. The European Journal of Social Science Research, 20(3): 223-241.

Asheim, B. T. (2009) Regional Endowment. In: J. Potter \& G. Miranda (eds.) Entrepreneurship and the Innovation System of the Agder Region, Norway. Paris: OECD, pp. 151-173.

Asheim, B. T. \& Coenen, L. (2006) The role of regional innovation systems in a globalising economy. Comparing knowledge bases and institutional frameworks of Nordic clusters. In: G. Vertova (ed.) The Changing Economic Geography of Globalization. Abingdon: Routledge, pp. 148-165

Asheim, B., \& Gertler, M. (2005) The geography of innovation: Regional innovation systems. In Fagerberg, J., Mowery, D. C. \& Nelson, R. R. (eds.) The Oxford Handbook of Innovation. (pp. 291-317). Oxford: Oxford University Press.

Asheim, B. \& Hansen, H. K (2009) Knowledge Bases, Talents and Contexts: On the Usefulness of the Creative Class Approach in Sweden. Economic Geography, 85: 425.

Asheim, B. T. \& Mariussen, A. (2003) Innovations, Regions and Projects-Studies in New Forms of Knowledge Governance, Report 2003-3. Stockholm: Nordregio.

Bathelt, H., Malmberg, A. \& Maskell, P. (2004) Clusters and Knowledge: Local Buzz, Global Pipelines and the Process of Knowledge Creation. Progress in Human Geography, 28: 31-56.

David, P.A. \& D. Foray (2002) An Introduction to the Economy of the Knowledge Society. International Social Science Journal, 54: 9-23.

Dosi G, Freeman C, Nelson RR, Silverberg G \& Soete L (1988) Technical Change and Economic Theory. London: Pinter Publishers.

Edquist, C. (1997) Systems of Innovation: Technologies, Institutions and Organisations. London: Pinter.

Feldman, M. (2003) Location and Innovation: The New Economic Geography of Innovation, Spillovers and Agglomeration. In Clark, G., Gertler, M. \& Feldman, M.A. (eds) Handbook of Economic Geography. Pp. 373-394). Oxford: Oxford University Press.

Grabher, G. (1993) The Weakness of Strong Ties. In Grabher, G. (ed.) The Embedded Firm. London: Routledge.

Granovetter, M. (1985) Economic action and social structure: The problem of embeddedness. American Journal of Sociology, 91: 481-510.

Hannel, T. \& Neubauer, J. (2005) Cities if the Baltic Sea Region - Development Trends at the Turn of the Millennium. Nordregio Report 2005:1.

Hansen, H. K. \& Winther, L. (2012) The Urban Turn: Cities, Talent and Knowledge in Denmark. Aarhus: Aarhus University Press.

Hansen, R., Hansen, T. \& Winther, L. (2012) Human Capital in Low-Tech Manufacturing: the Geography of the Knowledge Economy in Denmark. University of Copenhagen: Submitted paper.

Hansen, T. (2010) The Danish fabricated metal industry: A competitive medium-lowtech industry in a highwage country. Danish Journal of Geography, 110, (1): 65-80.

Hansen, T. (2012) The Geography of the Knowledge Economy. Innovation, Interaction and Industrial Development. PhD Thesis, University of Copenhagen. 
Hansen, T. \& Winther, L. (2011) Innovation, regional development and relations between high- and low-tech industries. European Urban and Regional Studies, 18: 321-339.

Jensen, M.B., Johnson, B., Lorenz, E., \& Lundvall, B.A. (2007) Forms of knowledge and modes of innovation. Research Policy, 36, (5) 680-693.

Kline S.J. and Rosenberg N. (1986) An overview of innovation. In Landau R and Rosenberg N (eds.) The Positive Sum Strategy: Harnessing Technology for Economic Growth. Washington DC: National Academy Press. Pp. 275-304.

Lundquist, K-J, Olander, L-O. and Svensson Henning, M. (2008) Decomposing the Technology Shift. Evidence from the Swedish Manufacturing Sector. Tijdschrift voor Economische en Sociale Geografie, 99: 145-159.

Lundvall, B.-Å. (1992) National Systems of Innovation. London: Pinter.

Malmberg, A. and Maskell, P. (2002) The elusive concept of localization economies: towards a knowledge-based theory of spatial clustering. Environment and Planning A, 34: 429-449.

Malmberg, A. (2003) Beyond the cluster. Local milieus and global connections. In Peck, J. and Yeung, H. (eds) Remaking the Global Economy. London: Sage.

Martin, R. \& Sunley, P. (2003) Deconstructing clusters: chaotic concept or policy panacea? Journal of Economic Geography, 3: 5-35

Nelson, R.R. \& Winter, S.G. (1982) An Evolutionary Theory of Economic Change. USA: The Belknap Press of Harvard University Press

Nonaka, I. \& Takeuchi, H. (1995) The Knowledge-Creating Company: How Japanese Companies Create the Dynamics of Innovation. Oxford, Oxford University Press.

Nonaka, I., Takeuchi, H., \& Umemoto, K. (1996) A theory of organizational knowledge creation.

International Journal of Technology Management, 11, (7-8) 833-845.

Peck, J. (2005) Struggling with the creative class. International Journal of Urban and Regional Research, 29: 740-770.

Scott, A. J. (2008) Social Economy of the Metropolis. Oxford: Oxford University Press

Skytt, C. B. (2011) The Geography of the Knowledge Economy in Denmark: Unpacking the Socio-Spatial Relations of Knowledge Creation in Danish Regions. Copenhagen: University of Copenhagen, $\mathrm{PhD}$ thesis.

Winther, L \& Hansen, H. K. (2006) The economic geographies of the outer city: industrial dynamics and imaginary spaces of location in Copenhagen. European Planning Studies, 14 (10), 1387-1406. 



\section{Annex: Template for national case studies}

The national case studies should comprise interviews with a selection of 5-9 companies and an introductory overview of relevant national research in the area.

\subsection{National overview}

An overview of national research in the area should be organised by each partner. Desk studies should focus on research and literature relevant for the project rather than general reviewing. At the joint meeting in January 2012, overviews shall be presented and further decisions shall be taken on the reporting.

\subsection{Interviews with companies}

The interviews are the main contribution to the project.

\subsubsection{Type of companies}

The type of companies selected for interviews should be.

- Knowledge intensive.

- Preferably include production and R\&D/Innovation.

- Larger than 50 employees (companies, relying on several subcontractors (e.g. the PVA TePla in DK cf. the pilot interview) may be smaller!).

- Growing.

- At least ten years of existence.

- Foreign ownership is acceptable.

- Referring to NACE Codes, HT companies should be given first priority (cf. Annex). 


\subsubsection{Location of companies}

- The company must be located in national as well as regional centres.

- Preferably, the national centre should be included.

- 2-3 firms in two or three centres (5-9 firms in total).

- The centres should be delimited as commuting regions, radiating e.g. $60-80 \mathrm{~km}$ from the centre.

- As commuting regions, NUTS3 regions - (in some metropolitan regions the best proxy of two or more NUTS3 regions) - should be used as data bearing units.

\subsubsection{Company overview (to be produced prior to the interview)}

- Location of head quarters.

- Location of subsidiaries (manufacturing and R\&D).

- NACE type.

- Ownership (national or foreign?).

- Most important products and kind of markets.

- Turnover 2010.

- Turnover 2000.

- Mapping the company and subsidiaries within NUTS3 regions.

\subsubsection{Relations}

Relations between the company, on the one hand, and suppliers, knowledge institutions and markets, on the other hand, should be identified, localised and quantified.

\section{Identification}

Since relations vary from company to company, each study may need further refinement of the categories to each case study. The categories below are based on theoretical considerations and on the pilot study.

\section{Product relations}

- Traditional supplies of services and products related to the branch of the company, e.g. "catalogue products and services."

- Customized supplies of services and products based on detailed technical specifications. Quality control of deliveries.

- Suppliers of innovation (product innovation and/or innovation of manufacturing processes).

\section{Knowledge and R\&D}

- Internal R\&D units.

- Universities and other institutions.

- Strategic Partners.

- Costumers. 
- Suppliers.

- Market.

\section{Export markets}

- TNCs.

\section{Localisation}

Relations must be localised in geography as follows:

- Within the commuting region.

- In other regions of the country (the municipality + the region / NUTS 4 + NUTS 3).

- Other countries.

- TNC - transnational companies.

- NWC - nation-wide companies difficult to locate, e.g. due to broadly located distribution centres.

\section{Mapping}

Relations must be mapped per company. Example - se pilot interview with PVA TePla.

\section{Quantification}

Relations are going to be identified by "importance" only rather than by other factors such as turnover. More than one aspect is going to be considered jointly:

- Historical importance of large reliable suppliers, however ubiquitous and easy to replace, if needed.

- Strategic importance (e.g. related to core product, R\&D, long duration)

a) Difficult to replace by another subcontractor (you may ask for partners, suppliers and knowledge institutions involved during production of the most recently successfully developed products?).

b) Important but possible to replace.

- Economically important (e.g. cheap labour or suppliers, large market segments).

a) Heavy (the deliveries are costly and influencing the final price of the product).

b) Not heavy.

\subsubsection{Impacts}

Which kind of impacts on urban and regional development is the company aware of: 
- Spin offs from the company.

- Suppliers attracted by or set up servicing the company.

\subsubsection{Strategies for the future}

Where (which region, country, other country) is the company planning for expansion in the future?

- New relations.

- New subsidiaries.

\subsubsection{Evaluation of geographical importance}

- Urban environment (metropolitan milieu).

- Industrial environment (industrial milieu).

- Infrastructure accessibility to labour markets, product market, strategic partners.

Table 3.1.Nace Codes

\begin{tabular}{|c|c|c|c|c|c|}
\hline \multicolumn{2}{|c|}{ NACE CODES } & \multirow{2}{*}{$\frac{\mathbf{R}}{\mathrm{x}}$} & \multirow[t]{2}{*}{ HT } & \multirow[t]{2}{*}{ KIBS } & \multirow[t]{2}{*}{ MT } \\
\hline 73 & Research and development & & & & \\
\hline 24.4 & Manufacture of pharmaceuticals, medicinal chemicals and botanical products & & $x$ & & \\
\hline 30 & Manufacture of office machinery and computers (ICT) & & $x$ & & \\
\hline 32 & Manufacture of radio, television and communication equipment and apparatus & & $x$ & & \\
\hline 33 & Manufacture of medical, precision and optical instruments, watches and clocks & & $x$ & & \\
\hline 35.3 & Manufacture of aircraft and spacecraft & & $x$ & & \\
\hline 72 & Computer and related activities & & & $x$ & \\
\hline 74.2 & Architectural and engineering activities and related technical consultancy & & & $x$ & \\
\hline 74.3 & Technical testing and analysis & & & $x$ & \\
\hline 24 & Manufacture of chemicals and chemical products & & & & $\mathrm{x}$ \\
\hline 29 & Manufacture of machinery and equipment n.e.c. & & & & $x$ \\
\hline 31 & Manufacture of electrical machinery and apparatus n.e.c. & & & & $x$ \\
\hline $\mathrm{R}$ & Research firms with R\&D & & & & \\
\hline HT & High-tech industry & & & & \\
\hline KIBS & Knowledge and innovation based services & & & & \\
\hline MT & Medium Technology & & & & \\
\hline
\end{tabular}




\section{Part 1 - Denmark}

Niels Boje Groth and Lars Winther 



\section{Introduction}

The Danish sample consists of seven companies. They are of different size and from different sectors, but all of them are in the global elite in their field of production.

The companies contacted were provided in cooperation with the Confederation of Danish Industry, at a meeting held in September 2011 with research director Charlotte Rønhof and chief consultant Richard Boltinus Larsen. Only a few companies refrained from taking part in the interviews.

All of the companies have been open-minded and enthusiastic during the meetings. We usually met the procurement managers. All but one company gave detailed information about the geography of the suppliers, either during the interviews or by handing out Excel-files after the interviews showing the locality (municipality or postal code), purchase (percentages or amount) and eventually type of supply. All names of suppliers were anonymous. In this report, addresses of the suppliers are aggregated at Nuts 3 and Nuts 2 level in tables and figures and hence further anonymized.

\subsection{Three types of companies}

During the first case studies, we identified two different types of hightech companies, showing two different patterns of geographies and relations with subsidiaries and suppliers. On the one hand, there were companies producing complex and complicated products by order and, on the other hand, companies producing advanced standardised products for the market. Both types of companies produce final products for the end consumer or buyer. In the final interview, a third type of company was identified: companies that were themselves suppliers of highly specialised inputs for final products of other companies. Usually, this third type of company enters into business-to-business solutions with the end producer, improving the producer's process or product by providing specialised inputs into the production process.

In the sample, four companies are order-producing, two are market-producing and one company is an advanced supplier of businessto-business solutions. In what follows, we shall characterise the three kinds of companies according to four parameters: products, market, outsourcing and geography. 


\subsection{Products}

\subsubsection{Production-by-order}

Products-by-order are costly, complex and customised to the needs of each individual customer. These complex products will often include standard or customized components from other companies (the original equipment manufacturer, OEM). Besides the quality of these OEMs, the sheer brand of the OEM might add value to the final product. Thus, the order-producing companies were keen on purchasing components of highest quality at the cutting edge of innovation, but also - as emphasized by one of the companies (\#2) - components with high brand-value of their own, thus enabling them to add prestige to the final product.

Usually, the individually ordered products were produced by project teams - in a manner of shipbuilding - in "docking areas." A suitable building for this kind of production consists of a large room (e.g. $30 \mathrm{x}$ $75 \mathrm{~m}$ ) lit from the roof and with no bearing columns. Two of the companies (\#2 and \#5) organised their production in a number of parallel production docks in production buildings of this kind. Large planner boards at the end of each production dock indicated the state and progress of the production process.

During production, the knowledge input is complex, adjusted and negotiated in contact with the buyer and suppliers, and the product is tested prior to delivery. Innovation or improvements may be necessary in order to meet the buyer's requests and needs. The suppliers are often consulted or incentive contracts may compel the supplier to take part in product innovation. The knowledge needed for this kind of innovation - focused upon engineering processes and the functionality of the product - is called by Moodysson, Coenen and Aseheim synthetic knowledge as opposed to analytical knowledge (Moodysson et al., 2008). Synthetic knowledge is closely connected to the production process. Hence, it takes place continuously and is localised in the production site and production team. A sharp division of labour between prior research and subsequent production is difficult to establish. The people in the production teams help to improve the product, as do the procurement managers. One of the interviewed companies (\#2) emphasized the role of incentive contracts as a means of involving suppliers in product improvements.

The order-producing companies often rely upon product improvements rather than launching entirely new products.

The order-producing companies are heavily dependent upon the skills and commitment of their employees. Through the production process, they achieve and contribute with synthetic knowledge. This kind of knowledge is difficult to codify, copy and replicate in new settings or with new employees. Therefore, order-producing compa- 
nies find it difficult to outsource production. Rather than outsourcing, process improvements take place locally via automation and leaning of the production process. Thus, two companies (\#2 and \#6) had introduced highly advanced automation processes. Two other firms (\#1 and \#5) remained in the local settings after buy-up of large foreign companies, simply because difficulties in transferring the knowledge base and overt resistance of the key employees to move to another country. Finally, the logistical advantages of being close to the market are of lesser importance, since this kind of production is characterised by few deliveries, the total costs of which are not decisively influenced by delivery costs.

\subsubsection{Market production}

Market production is not for the individual buyer, but for the anonymous customer. When new products have been designed and tested, they are produced in large series, referred to as "volume production" by company (\#3).

These products differ from individually ordered products in many ways. They are not produced in dock areas but on assembly lines, not in small numbers but in large volumes. One of the companies in the sample produces about 600 million units per year. Once the production facilities have been set up, they are relatively easy to replicate but difficult and costly to innovate. Innovation takes place in research and development departments, often localised in sites other than the production site. Thus, the knowledge input is hierarchical: it takes place prior to production and is characterised by a more distinct division of labour between production and the R\&D than is the case in order-producing companies.

Innovation is more about new products than improving existing products. Normally, there is no room for OEM components.

\subsubsection{Business-to-business solutions}

The products of companies entering into business-to-business solutions are characterised as inputs (i.e. supplies) rather than end-products. They are inputs developed to facilitate the buyer's production with less energy-demanding or less risky processes, more environmentally sound and efficient processes. As with the OEMs, this kind of company delivers key inputs for the final product. But unlike the OEMs, the business-tobusiness solutions are not technical components. Rather, they help integrate the production process and, hence, are not visible to the end user. 


\subsection{Market and outsourcing}

The firm's relation to the market is another characteristic. Volume producers tend to move closer to the markets for logistical reasons, attracted by market-driven needs and national legal regulations or standards.

\subsubsection{Order production}

Order production tends to focus on the production of capital goods. Usually, the market consists of professional customers with whom the companies are in direct contact. This contact takes place not just during the period of contracting and production but also after the product is delivered because of the need for after-sale services. Of importance here are the technical merits of the product, which is a major concern of customers. This is why in some branches, customers and producers meet at specialised product fairs.

We became aware that one of the companies (\#6) deliver "AB factory." We are not certain whether this is common to order-production. However, we have observed that it is a type of delivery that is very different from that of the market-oriented production, which is fully dependent upon successful delivery to "AN customer."

Due to the aforementioned intimate relations between innovation and production, order production is difficult to outsource. A few years ago one company (\#2) faced special situation. Changes in production were needed, and outsourcing was considered. However, instead of outsourcing, a huge effort was made make production "leaner" and to introduce a sophisticated automation system in one part of the production process so that production could remain at home. In another case (\#6), after being acquired by an equity company, the company's production was automated and "leaned," rather than outsourced. For all companies, the established relationships with the local workforce are a major incentive for remaining at the production site. This relationship became visible after two of the companies (\#1 and \#5) were acquired by much larger foreign companies. In the case of \#1, the foreign company proposed that the new subsidiary relocate to Germany. In agreement with the key staff, the head of the company told the new owner that they would not leave Denmark. It was then decided to keep the company in Denmark. The decision was not questioned thereafter, and the subsidiary developed very profitably for the new owner. This development was based on a more risk-oriented product-development than before the take-over due to the relations of trust that had been established between the new owner and the subsidiary. 


\subsubsection{Market production}

Products for the market are aim at the anonymous customer. Rather than technical merits, these products also are dependent upon conceptual merits and branding. The products reach the customer via advertising and mediating bodies such as specialised shops, or via specialists such as physicians or various kinds of consultants. In our case, the two companies (\#3 and \#4) produce products for personal care and are dependent upon face-to-face specialists and clinics.

To reach the anonymous customer requires a huge market-related effort, including packaging, branding, diffusing product information, meeting the test-requirements and costly and time-consuming adaptation to consumer and market regulations. This is why a substantial amount of supply services offered by subcontractors revolves around testing, control, consultancy, packaging, branding, design and logistics.

Whereas the order production firm is focused on "after-sales" services, i.e. keeping the complex products running or updated, the market-related products require a focus on the aforementioned "pre-sales" services.

An important requirement for the market products is reliable standardisation in order to ensure that customers get what they buy each and every time they buy it. Therefore, reliability in high volumes is needed. The companies producing high volumes are tempted to outsource production for two or eventually three reasons. Both companies in our sample outsourced large parts of their production in order to profit from cheaper labour costs. One of the companies (\#3) was stimulated to outsource because of a shortage of highly skilled labour. At the time of outsourcing, Denmark was experiencing a shortage of qualified engineers, thus leading to a decision to outsource part of production. Worth mentioning is that the company took great advantage of advice and assistance from another Danish company already outsourcing in the same foreign country; it appears that positive experiences from other companies may contribute to a further trend of outsourcing, causing a snowball effect. After the outsourcing decision, the quality of production increased. The company therefore established yet another enterprise in another town of the country and made plans to further extend the production at these two sites. The company has established production not only in two European countries but also in China and the United States. Due to the need for market supply, the production is supplemented by logistics. The company \#3 is currently setting up a new, large logistics centre in Hamburg, one of Europe's large logistical hubs.

Both companies are enthusiastic about the advantages of proximity to the production plants. This is why both companies chose to set up production in East European countries and still count on them as the prime production sites. Furthermore, company \#3 argues that the benefit of lower labour costs, in e.g. China, is partly reduced by more difficult logistics. 
The outsourcing of the two companies entails a loss of jobs in Denmark in the primary production, and a reduction of Danish suppliers. Both companies, however, emphasize that it is only volume production that is outsourced. This will also continue in the future. Both companies want to keep R\&D departments, testing and pilot production in Denmark. For these activities a certain supply is needed.

\subsubsection{Business-to-business solutions}

The business-to-business solutions are related to the market only as inputs to final products within a diversity of consumers, e.g. households, technical supplies, agriculture and industrial production. As with production by order, business-to-business companies deliver specifically ordered products to a specialized buyer. However, the deliveries are often developed by research-intensive initiatives of the company and in close contact with the buyer, in order to optimise his needs and further develop and improve his products or processes. As with marketproducing companies, on the other hand, the production of business-tobusiness solutions relies heavily on analytical knowledge provided by R\&D departments in-house as well as in close contact with university departments. The shares of R\&D cost of total turnover are $4 \%$ and $9 \%$ for the two market-producing companies (\#3 and \#4) and 14\% for the company (\#7) developing business-to-business solutions.

As mentioned earlier, the companies want to keep R\&D and pilot production closely related and to retain these activities in Denmark, whereas volume production is being expanded abroad. Hence, company \#7 reports that it plans to keep economic activities in Denmark at the present level in the years to come, while expanding its production activities abroad.

\subsection{Geography}

Before presenting the case-studies, we shall summarise the abovementioned characteristics and attempt to provide a more general picture of the supplier geography of the market and of the order-producing companies. Since we only obtained information on the domestic suppliers of the company delivering business-to-business solutions, our comments are restricted to the above-mentioned order- and marketproducing companies

Figure 4.1 shows the geographic characteristics of the companies studied. Dense networks of domestic supply characterize the orderproducing companies combined with global suppliers of specialised components, i.e. transnational companies delivering high quality of standard components, originally equipped and high-branded components. The order-producing companies keep the primary production 
at home. The market-producing companies, on the other hand, are outsourcing their volume production, keeping only their R\&D and pilot production at home. Volume production is located in countries where labour is cheap, or close to important markets. Finally, like the market-producing companies and the companies producing businessto-business solutions prioritize close relations between $R \& D$ and pilot production. $R \& D$ is combining in-house activities and cooperation with research institutions.

Figure 4.1. Diagrams of the geography of "production-by-order," "production-for-the-market" and "supply of business solution." The dotted circles represent national borders. The geography of production-by-order is influenced by the geography of important suppliers. The geography of production-for-the-market influenced by the geography of the market segments and, finally, the geography of the production of business-to-business solutions is influenced by the location of most important business partners

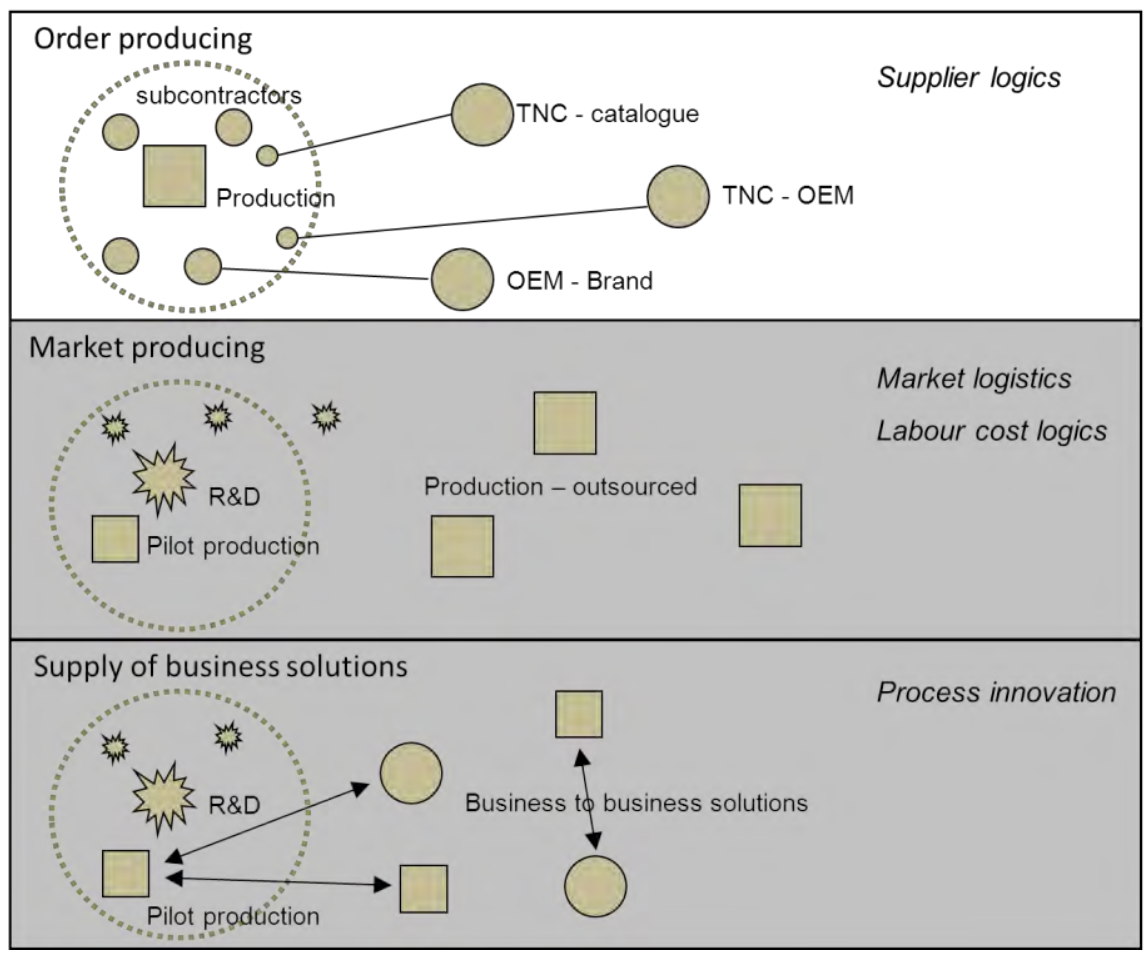





\section{The case studies}

The locations of the companies interviewed are shown in 4.2. All six companies are located on the island of Zealand, three in the Capital Region and three in the administrative Region Zealand.

Figure 4.2. The two home regions of seven companies in the Danish Case study (one company present in both regions)

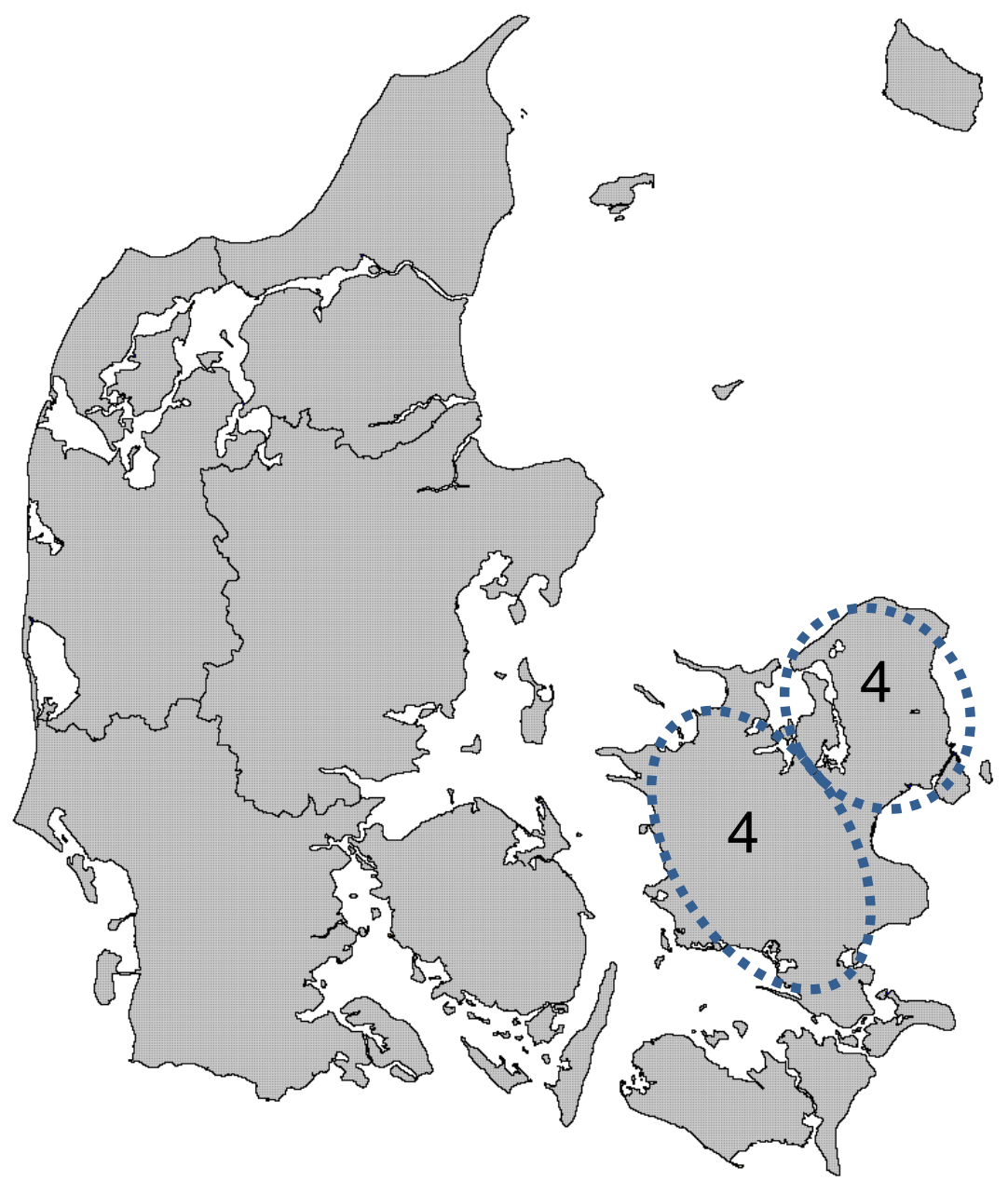

In what follows, a brief description is provided of each company, starting with the four production-by-order companies and followed by the two production-for-the-market companies. After the descriptions, some common patterns are discussed. 


\subsection{Production-by-order}

\subsubsection{Company \#1}

\begin{tabular}{lcc}
\multicolumn{2}{l}{ Table 4.1.Main characteristics of company \#1 } & \\
\hline Year & 2004 & 2010 \\
\hline Turnover & $\sim € 10$ million & $\sim € 120$ million \\
No. employees & 6 & 15 \\
\hline
\end{tabular}

The company is world leading in its field. It produces specialised capital goods for the electronics sector. It is a spin-off from a Danish company and was then sold to a foreign company. The change of ownership boosted the turnover. This was due partly to increasing flexibility accepted by the new owner. A plan for relocating the company from Denmark to the home country and home town of the new owner was effectively prevented by the staff.

Innovation is about improvements of the basic product rather than innovation of new products. Much of the product improvements are taking place in cooperation with the customers. The R\&D activities are handled by the company's technicians and external suppliers, especially as concerned IT. For example, the automation of the basic product was requested by one of the most important customers, a Chinese company. The process lasted for 2-3 years. The core actors were the staff and the IT consultant. A pilot was installed in the Chinese company. He replied that it was not working, but he believed in the process development as it was proceeding. Hence, the customer asked the company to continue, and they did so successfully. To prevent theft of the technique, a device is installed in the machinery that deletes the automation program if someone tries to open it.

\section{Strategy for the future}

There is no concrete strategy for expansion, other than to maintain its leading international position and keep up with demand, which could further increase due to the growing need for sustainable energy and transport. Keeping close, reliable and trustful relations with customers is important. Three principles are significant here:

- Prompt delivery of services.

- Reasonable price.

- Ability to show continuing product improvements.

\section{Subcontractors}

The company relies heavily on subcontractors. The company distinguishes between two kinds of subcontractors: (1) consultants and suppliers of machinery parts on the basis of technically specified orders to 
be delivered or of services and (2) "catalogue" suppliers, delivering standardized - but often high quality - mechanical parts. Assembly of the machines is carried out solely by the company on its own premises. The kind of subcontracting-by-order delivers machine parts (welding, ALU casting), surface treatment (painting and burnishing) parts, IT monitoring, and electronic components. Catalogue supply includes electronic motors, gear, metal tools, high precision ball bearing.

None of the suppliers are solely dependent on the company. Most dependent, probably, is the IT consultant. Suppliers are concerned about duly servicing the company. This includes a nation-wide and a transnational supplier, both of which have special staff who coordinate servicing and deliveries to the company.

\begin{tabular}{|c|c|c|}
\hline 12 & Danish Regions & \\
\hline 1 & Nation-wide & \\
\hline 1 & TNC & \\
\hline \multirow[t]{3}{*}{2} & Abroad & \\
\hline & - Germany & 1 \\
\hline & - Italy & 1 \\
\hline 16 & All & \\
\hline
\end{tabular}

\section{Market}

Company \#1's customers are located in China, Korea, Germany, Thailand, Japan, the United States, India and Italy.

Figure 4.3. Location of Danish suppliers of company \#1

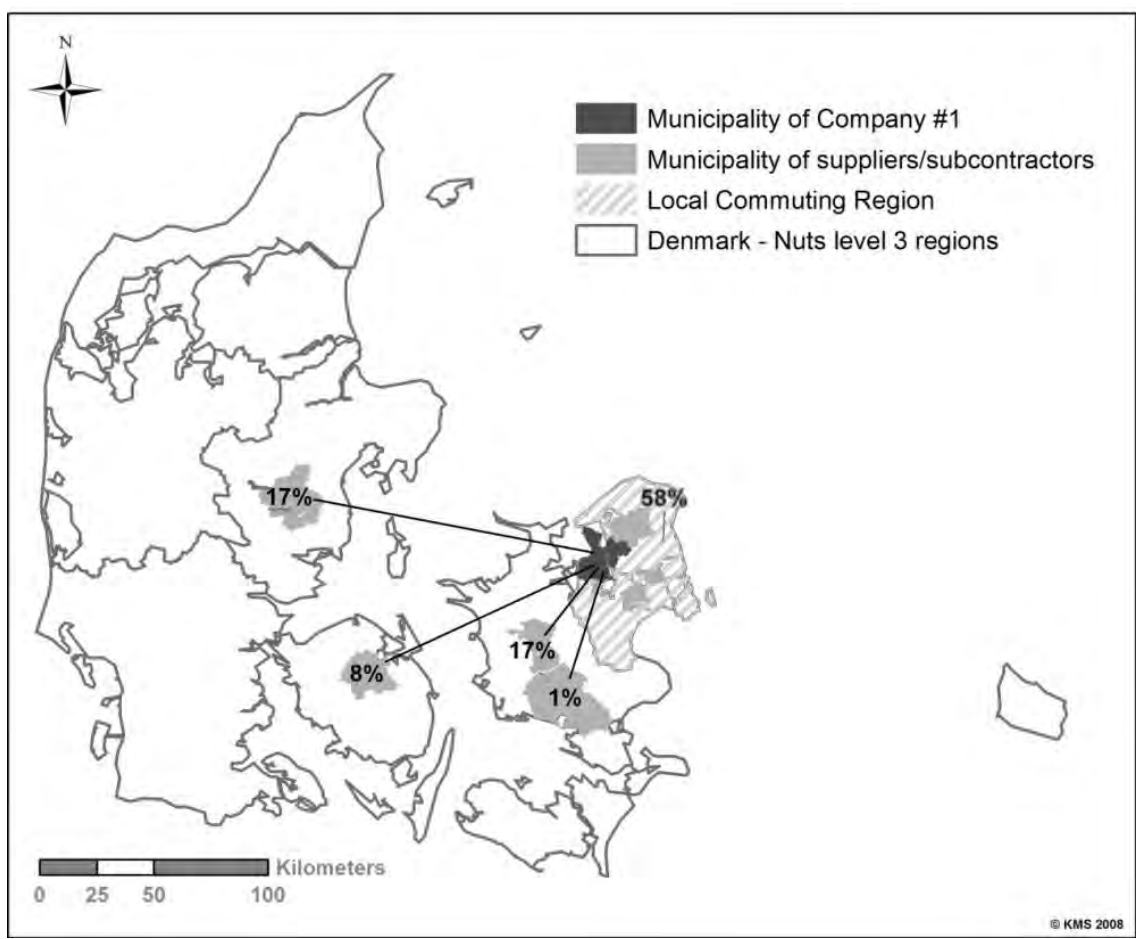


Table 4.3. Geography of suppliers (number of suppliers in \%), company \#1

\begin{tabular}{|c|c|c|c|}
\hline \multicolumn{4}{|c|}{ All suppliers } \\
\hline \multicolumn{3}{|c|}{ Domestic } & 81.3 \\
\hline \multicolumn{3}{|c|}{ Foreign } & 18.8 \\
\hline \multicolumn{3}{|c|}{ All } & 100.0 \\
\hline \multicolumn{4}{|c|}{ Domestic suppliers (NUTS 3) } \\
\hline & Copenhagen $\mathrm{CPH}$ & DK011 & \\
\hline & $\mathrm{CPH}$ Surroundings & DK012 & \\
\hline & N Zealand & DK013 & 58.3 \\
\hline & E Zealand & DK021 & \\
\hline \multirow[t]{6}{*}{$x$} & W\&S Zealand & DK022 & 16.7 \\
\hline & Funen & DK031 & 8.3 \\
\hline & S Jutland & DK032 & 0 \\
\hline & W Jutland & DK041 & 0 \\
\hline & E Jutland & DK042 & 16.7 \\
\hline & $\mathrm{N}$ Jutland & DK050 & 0 \\
\hline \multicolumn{3}{|c|}{ All domestic suppliers } & 100.0 \\
\hline
\end{tabular}

$\mathrm{X}$ : Location of company \#1.

\subsubsection{Company \#2}

Table 4.4. Main characteristics of company \#2

\begin{tabular}{lcc}
\hline & 2007 & 2011 \\
\hline Turnover & $€ 100$ mio & $€ 95$ mio \\
No. of employees & & $\sim 300$
\end{tabular}

\section{Products}

The company produces capital goods machinery for processing parts for packing. The product program includes different kinds of machines tailored for a variety of needs. Most of the machines are built up on a standard module frame, two by two, monitored by an electronic unit.

The production programme has undergone massive development in order to keep up with technical standards and a broadening variety of needs.

The company has been a leading technological driver on the world market and holds about $15-20 \%$ of the world market in its field. Actual production takes place at two addresses: the headquarters located in Denmark and a subsidiary in the United States. The most advanced are produced in Denmark. Virtually all of its production (98\%) is for export.

\section{History}

The company was founded about 1920 by a Danish Engine works situated in Copenhagen. In the 1960s the company relocated outside Copenhagen to what is now Region Zealand and established an international sales organisation. Contact to customers is carried out at international specialised fairs. Joint ventures have been established in several countries. The production facilities have been expanded, and the production process has been rationalised by a very advanced automation of basic machine elements and by introducing lean systems in the production process. 
Faced by global competition, the company in 2003/2004 set up two alternative strategies for future development:

a) Outsourcing parts of or the entire production to low-wage countries

b) Investing in more efficient production equipment in Denmark and improving the skills of the workforce and managing team.

The company chose the second alternative. The investments in production equipment included an automation of high-precision drilling and turning of metal components. Much of the automation machinery was developed in-house.

\section{R\&D}

Major product improvements are handled in-house by the company's engineers. However, the in-house improvements are supplemented by OEM manufactures and partnership agreements between the company and subcontractors.

At a day-to-day level, the company tries to establish partnerships with core subcontractors, requesting that they improve or reduce the price of their products. These partnerships are based on mutual interests, since the partner or subcontractor and the company share in the profits generated by the subtractor's improvements.

Product improvements are thus constituted by a combination of adoption of new techniques and improvements/cost reduction of existing techniques, both of which are decisive in order to remain competitive.

Our study indicated that customers are not drivers of the technological improvements in the company. Rather, the company tries to stay competitive in a market characterised by technological innovations. However, the basic design of the machines, e.g. the standard units are prepared so that the individual product can be tailored to the needs of the customer.

\section{Subcontractors}

Although a substantial part of the metal processing is done in-house, the company has several subcontractors. These include generic subcontractors carrying out simple but high quality metal work (e.g. bolts and metal frames) and original equipment manufacturers (OEM) delivering advanced, finished components and units.

The total amount of subcontracting is about DKK 266 million, of which DKK 72 million was carried out by OEM subcontractors, DKK 48 million by direct contractors and DKK 146 million by indirect subcontractors 
Table 4.5. Subcontractors: OEM, indirect and direct

\begin{tabular}{lcc}
\hline \multicolumn{2}{l}{ Subcontrators DKK 266 mio } & \\
\hline OEM & Indirect & Direct \\
DKK 72 mio & DKK 48 mio & DKK 146 mio \\
\hline
\end{tabular}

The OEMs deliver final technological products that need only minor adjustments. Usually, the OEM units are identifiable by their original brand so that the OEM brands become part of the company's brand.

The procurement manager subdivides the subcontractors into categories of economic and strategic importance as follows:

Figure 4.4. Economic impact and supply risk. The K-S-C-R suppliers

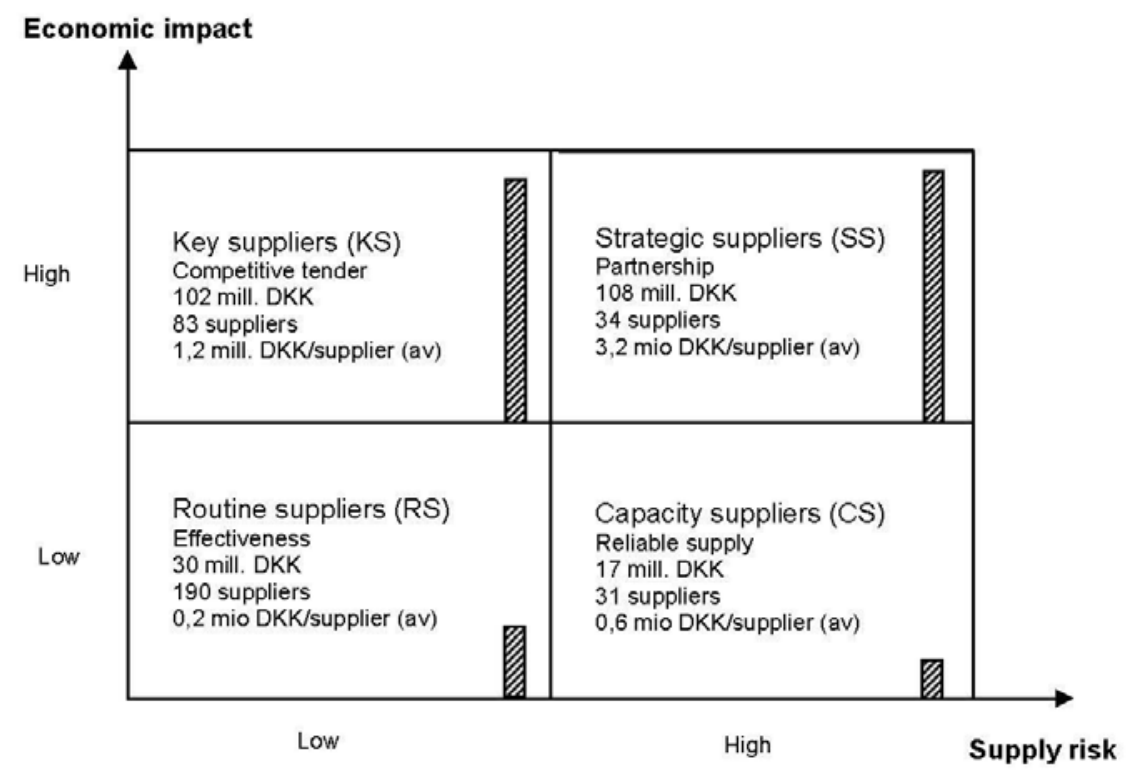

The strategic supply (SS) is characterised by high economic impact on the price as well as importance for product delivery. On average, their supply is DKK 3.2 million. The second most important are the key suppliers (KS), also characterised by high economic impact on the price of the product. The average KS supply (DKK 1.2 million) is much smaller than the average SS. Due to their importance, the strategic suppliers are made strategic partners via agreements on mutual sharing of profits developed from product improvements and/or cost reductions ("incentive agreements)". The KS suppliers are selected by invitation for competitive tenders. All in all, the turn-over of the KS and the SS supply is just above DKK 100 million each.

At a much lower total level of supply are the routine (RS) and capacity (CS) suppliers. The most numerous are the routine suppliers, which deliver an average of DKK 200,000 of small supplies. The capacity sup- 
pliers (CS) are called for whenever the capacity of the in-house production is exceeded by the orders.

All together, the vast majority of of supplies and suppliers come from Denmark: $66.4 \%$ of supplies and $84.7 \%$ of suppliers. The large proportion of suppliers corresponds to a smaller rate of supply, indicating that small deliveries are located in proximity to the firm.

An overview of the purchase and origin of all supplies is shown in table 4.6.

\begin{tabular}{|c|c|c|c|c|}
\hline Country & $\begin{array}{r}\text { No. Of } \\
\text { suppliers }\end{array}$ & $\begin{array}{r}\text { Average amount paid } \\
\text { to each supplier }\end{array}$ & $\begin{array}{l}\text { Proportion of supply by } \\
\text { country of origin (in \%) }\end{array}$ & $\begin{array}{l}\text { Proportion of } \\
\text { suppliers per } \\
\text { country (in \%) }\end{array}$ \\
\hline Denmark & 589 & 296,529 & 66.4 & 84.7 \\
\hline Total foreign, of which: & 106 & & 33.6 & 15.3 \\
\hline Austria & 3 & 374,268 & 0.4 & 0.4 \\
\hline Belgium & 2 & 362,856 & 0.3 & 0.3 \\
\hline China & 2 & 47,093 & 0.0 & 0.3 \\
\hline Czech Republic & 1 & 74,643 & 0.0 & 0.1 \\
\hline Finland & 2 & 540,596 & 0.4 & 0.3 \\
\hline France & 2 & 8,542 & 0.0 & 0.3 \\
\hline Germany & 33 & 606,347 & 7.6 & 4.7 \\
\hline Italy & 1 & 116,886 & 0.0 & 0.1 \\
\hline Japan & 2 & 207,518 & 0.2 & 0.3 \\
\hline Latvia & 1 & $8,975,696$ & 3.4 & 0.1 \\
\hline Lithuania & 1 & 623,728 & 0.2 & 0.1 \\
\hline Mexico & 1 & 5,198 & 0.0 & 0.1 \\
\hline Netherlands & 5 & $3,354,740$ & 6.4 & 0.7 \\
\hline Poland & 4 & 370,688 & 0.6 & 0.6 \\
\hline South Africa & 1 & 5,227 & 0.0 & 0.1 \\
\hline Spain & 2 & 684,943 & 0.5 & 0.3 \\
\hline Sweden & 11 & 229,895 & 1.0 & 1.6 \\
\hline Switzerland & 6 & $1,373,095$ & 3.1 & 0.9 \\
\hline UK & 17 & $1,313,207$ & 8.5 & 2.4 \\
\hline USA & 9 & 286,898 & 1.0 & 1.3 \\
\hline Total & 695 & & 100.0 & 100.0 \\
\hline
\end{tabular}

Approximately one-third of the supplies originate from abroad, originating not only from European countries but also from countries in Asia, America and Africa. The purchases vary from one country to another. For example, the purchase from a single Latvian supplier is about DKK 9 million, a little more than the purchase from all six suppliers from Switzerland.

Worth noting is that most of the foreign average suppliers are much larger than the domestic suppliers, indicating that the "rule" of proximity is broken when the company is in need for specialised - and often more costly components.

In table 4.7, the purchases from the K-S-C-R suppliers are shown in more detail. As mentioned earlier, the $S$ and $K$ supply is of equal size each about $40 \%$ of the total turnover. Being the least specialised supply, it is not surprising that the Routine supply is characterised by the highest rate of national origin (90\%). 
Table 4.7. Share of turnover, S-K-C-R suppliers

\begin{tabular}{lrr}
\hline Location & Type of supplier & Share \\
\hline $\begin{array}{l}\text { Domestic } \\
\text { Foreign }\end{array}$ & Strategic suppliers & $20 \%$ \\
All & & $21 \%$ \\
Domestic & Key suppliers & $41 \%$ \\
Foreign & & $31 \%$ \\
All & & $9 \%$ \\
Domestic & & $40 \%$ \\
Foreign & Capacity suppliers & $4 \%$ \\
All & & $3 \%$ \\
Domestic & & $7 \%$ \\
Foreign & & $11 \%$ \\
All & Routine suppliers & $1 \%$ \\
Total & & $12 \%$ \\
Domestic & & $100 \%$ \\
Foreign & & $\mathbf{1 0 0 \%}$ \\
Total & & $66 \%$ \\
\hline
\end{tabular}

Taking a closer look at the geographic origin of the national suppliers at NUTS 3 level, we find that the largest source of supply is located in the home region of the company, cf. table 4.8. The second most important region is the Capital Region, the importance of which is due to the general strength and proximity of the Capital Region as neighbour to the home region of the company. Worth noting is that the third most important region - just behind the Capital region - is the East Jutland Region although it is located at further distance from the home region of the company than the neighbouring Funen/South Jutland regions. 
Figure 4.5. Relative distribution (in \%) of purchase costs from Danish suppliers, company \#2
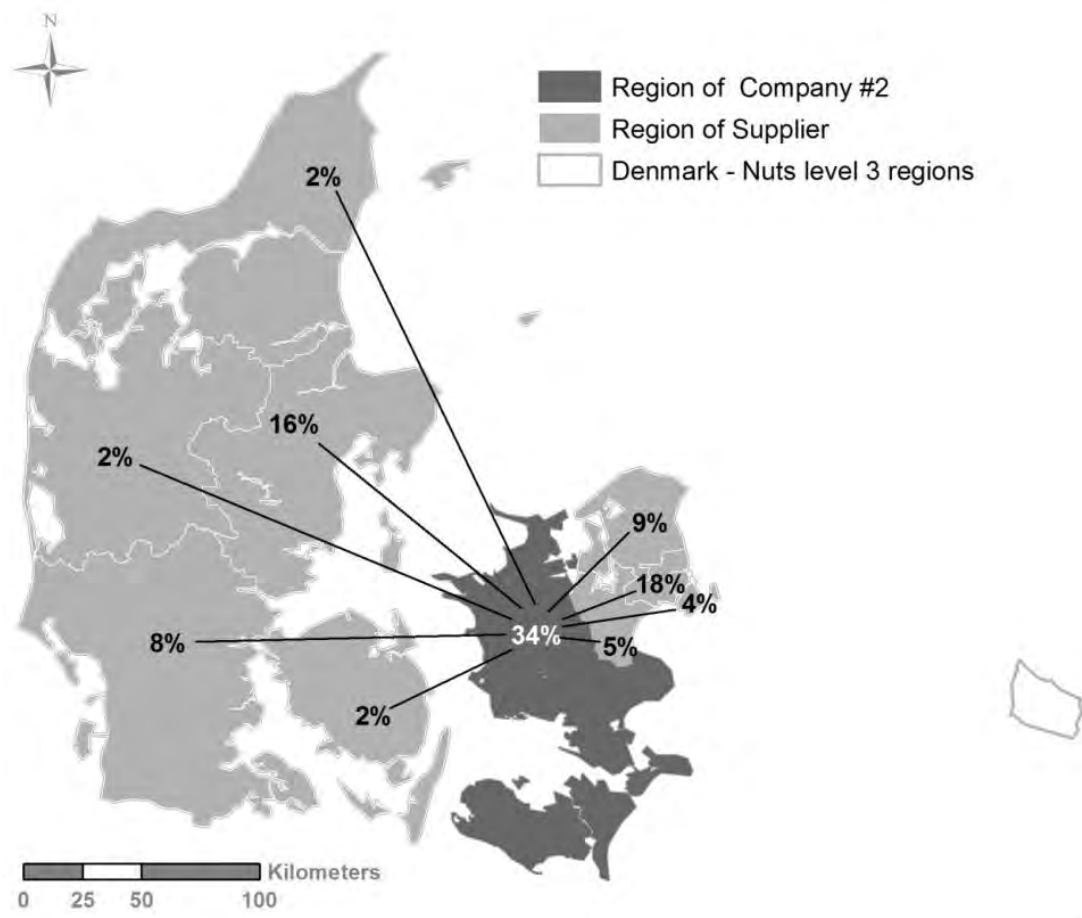

Table 4.8. Geography of supply turnover (\%), company \#2 All suppliers

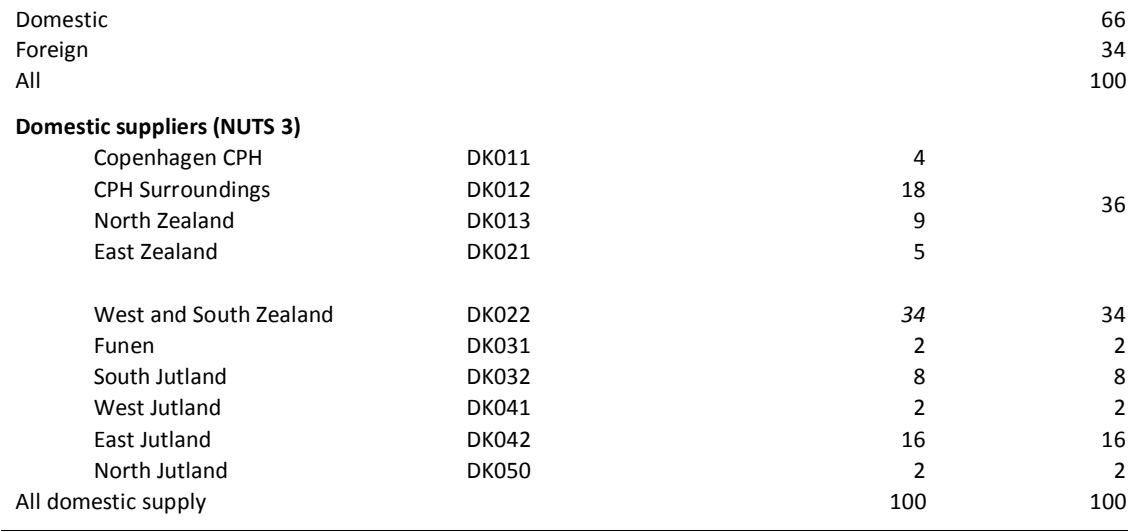


Figure 4.6. Distribution (in \%) of purchase costs from four types of Danish suppliers to company \#2
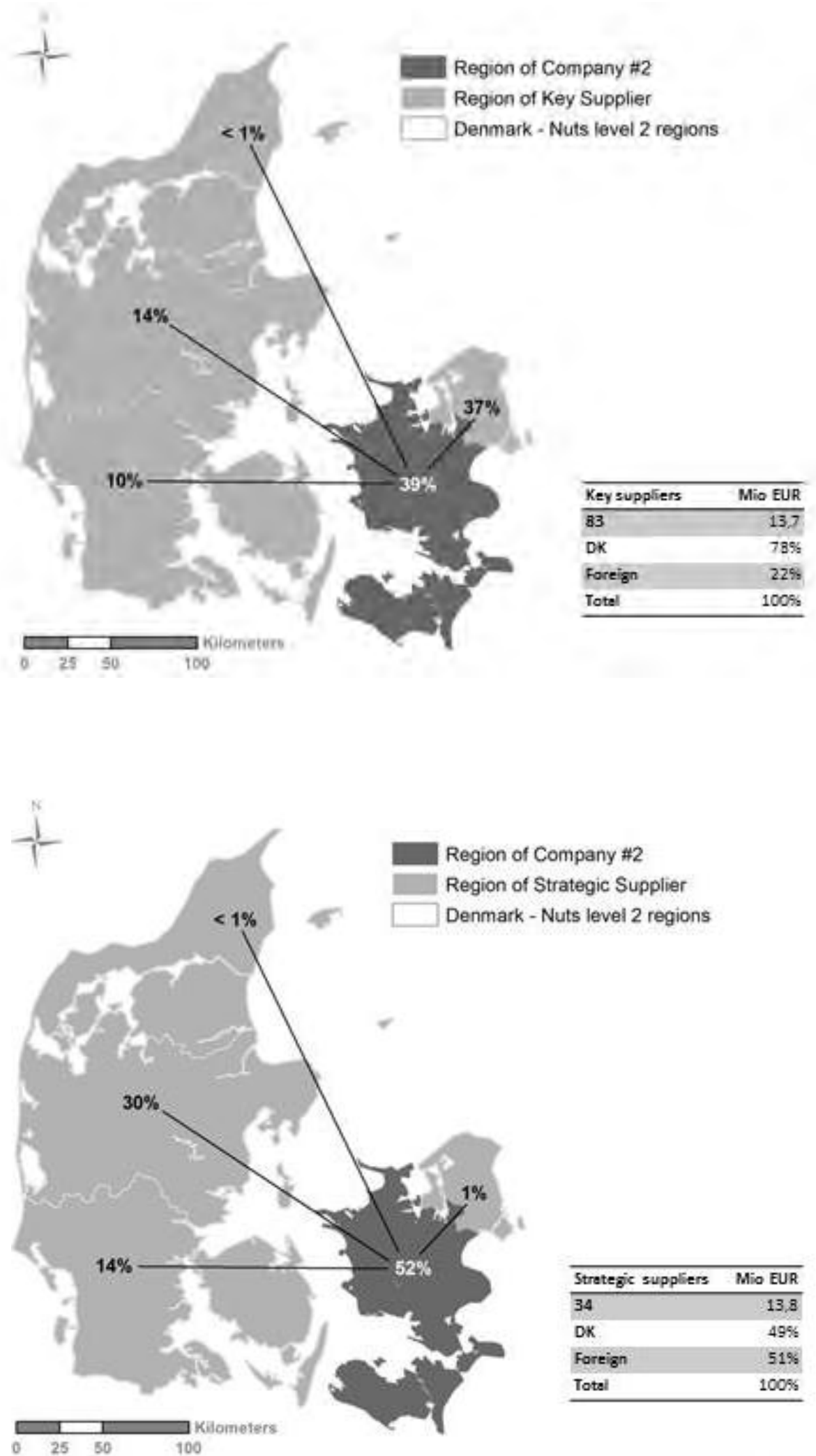

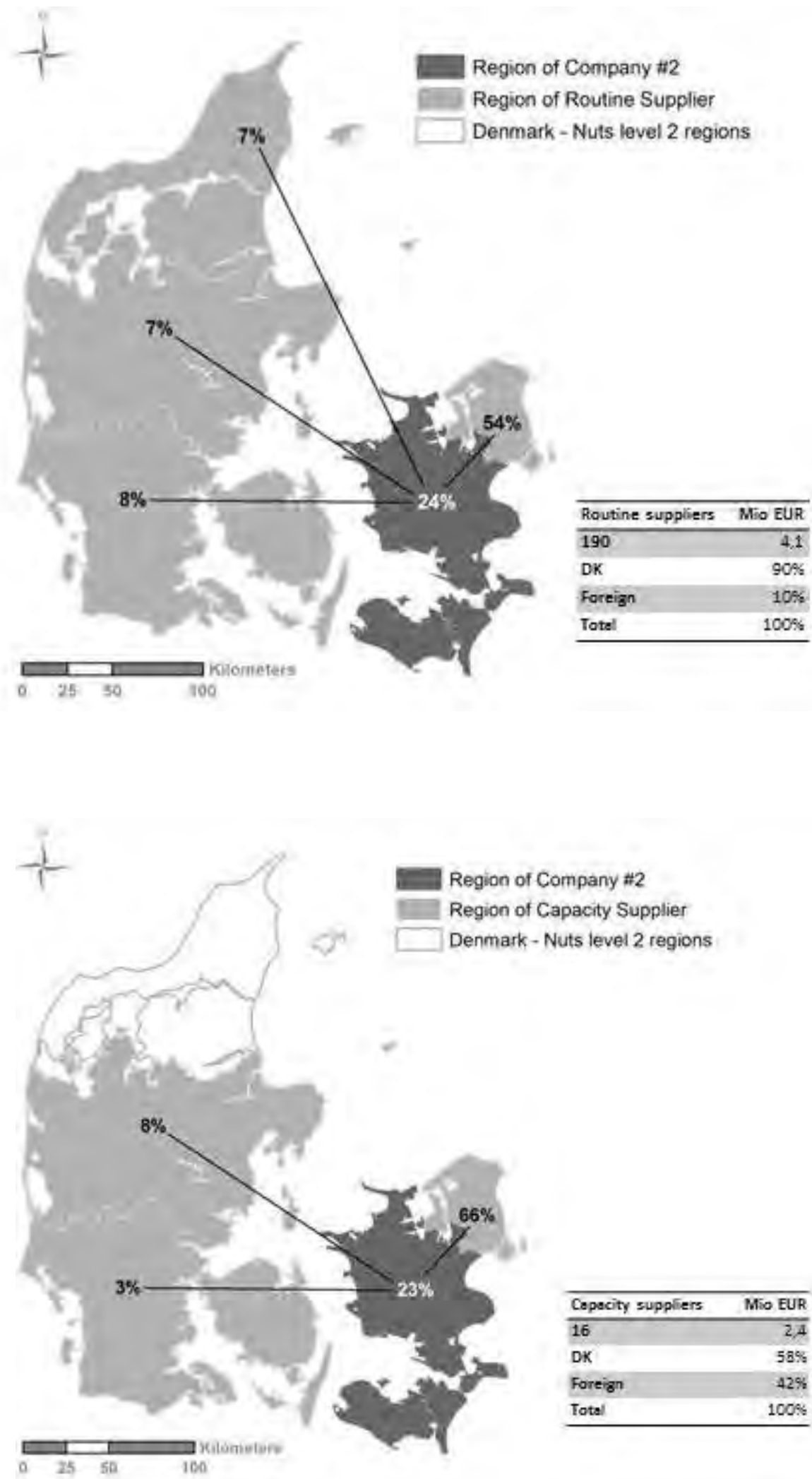
The geographical distribution of company \#2's the suppliers shows a complex interplay between attractiveness of proximity and attraction of the two largest centres in Denmark: the Capital Region (Copenhagen) and the East Jutland/Århus region. At the bottom, we find the Northern Jutland excluded due to distance in combination with low economic strength. The high ranking of the East Jutland region also characterises companies \#1, \#4 and \#7.

\subsubsection{Company \#5}

Table 4.9.Main characteristics of company \#5

\begin{tabular}{lcc} 
& 2005 & 2011 \\
\hline Turnover & $>€ 8.0$ million & $€ 13$ n20 million \\
No. of employees & 75 & 100 \\
\hline
\end{tabular}

Company \#5 specializes in designing and manufacturing machines for the pharmaceutical and the medtec industries all over the world. It consists of single machines and complete lines. This covers the entire process chain in assembly, handling, visual inspection and packaging solutions. The firm is a market leader and exports globally. The company is itself an OEM.

\section{Ownership and history}

In 2003 a large German corporation bought $51 \%$ of the shares of the company and the remaining $49 \%$ in 2007 . Hence, company \#5 is now part of a larger group of producers of machines for the medtec industries. It is part of a multinational corporation's product line and is currently changing its structure and culture according to its embeddedness in the mother corporation.

The firm started in 1962 with machine production for agriculture. In 1993, it merged with a similar company and began to design and produce machines for the pharmaceutical and medtech industries, becoming a market leader by the 1990s. In 2001 and 2003, production was expanded in the current location and further expansion of the production facilities took place in 2009. Today, the company has about 100 employees.

\section{R\&D}

The company relies on a synthetic knowledge base; and research and development is mainly in-house and in relation to suppliers and customers. Thus, product improvements take place through customisation processes or by developing new technologies using in-house in teams that combine a diversity of local competences or in cooperation with suppliers, either through OEM or new designs. 


\section{Subcontractors}

Company \#5 has a total purchasing budget of DKK 100 million, of which $37 \%$ is spent within Denmark. The global purchases are concentrated on OEM, machines and equipment, with suppliers located mostly in Europe in order to ensure the quality of, for instance, motors and to ensure purchases of standard supply from the mother company. Figure 4.7 and table 4.10 shows the impact of supply from company \#5, of which $41 \%$ is located in Jutland, $27 \%$ in Copenhagen and the rest in Funen. Thus, company \#5 has a relatively strong national impact in terms of suppliers. Compared to some of the other firms, however, company \#5 has no local impact. The local impact comes from hiring of local employees, as it is only the top management that live outside the region.

Figure 4.7. Geographic distribution (in\%t) of purchasing costs from Danish suppliers, company \#5

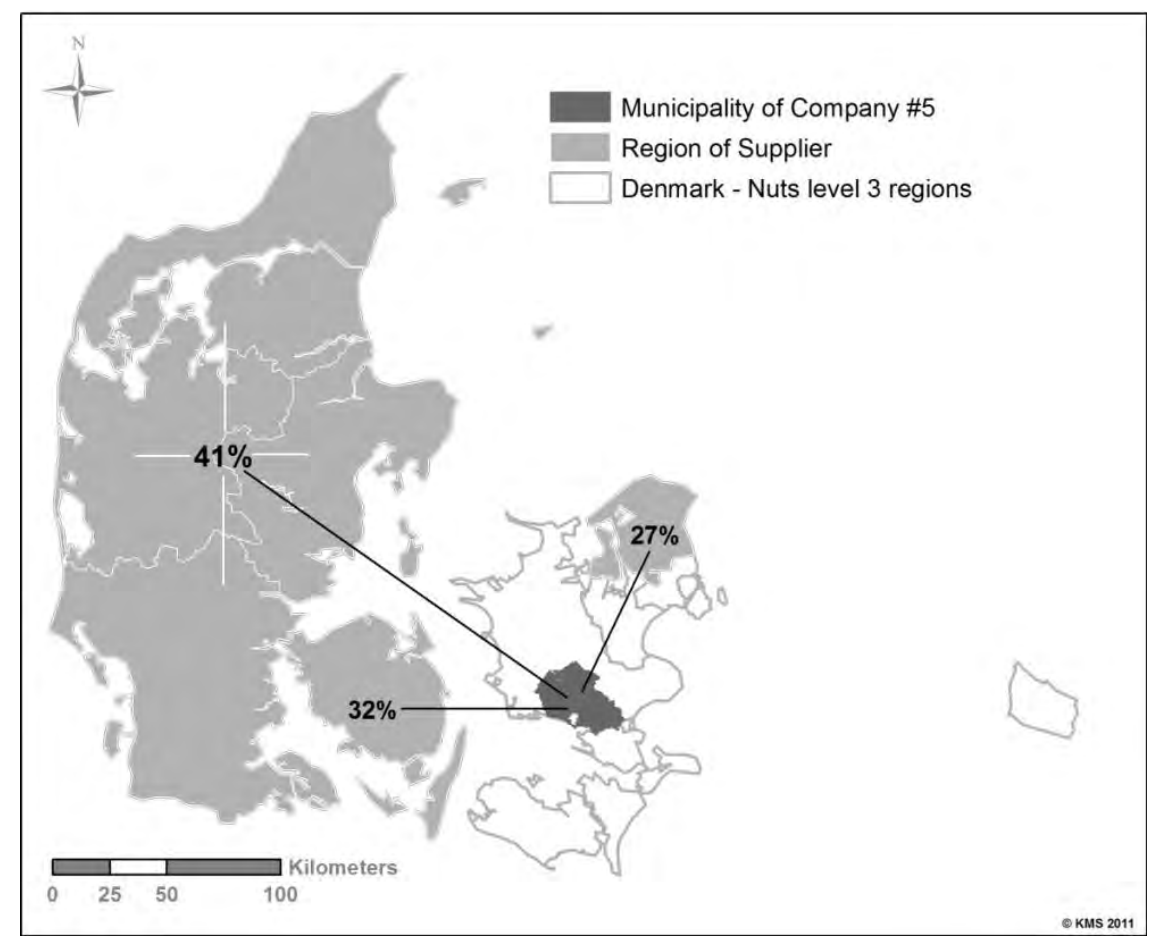


Table 4.10. Geography of supply turnover (\%), company \#5

\begin{tabular}{|c|c|c|c|c|}
\hline \multicolumn{5}{|c|}{ All suppliers } \\
\hline \multicolumn{3}{|c|}{ Domestic } & & 37 \\
\hline \multicolumn{3}{|c|}{ Foreign } & & 63 \\
\hline \multicolumn{3}{|c|}{ All } & & 100 \\
\hline \multicolumn{5}{|c|}{ Domestic suppliers (NUTS 3) } \\
\hline & Copenhagen $\mathrm{CPH}$ & DK011 & 0 & \\
\hline & $\mathrm{CPH}$ Surroundings & DK012 & 0 & \\
\hline & North Zealand & DK013 & 27 & 27 \\
\hline & East Zealand & DK021 & 0 & \\
\hline \multirow[t]{6}{*}{$x$} & West and South Zealand & DK022 & 0 & 0 \\
\hline & Funen & DK031 & 32 & 32 \\
\hline & South Jutland & DK032 & & \\
\hline & West Jutland & DK041 & 41 & 41 \\
\hline & East Jutland & DK042 & & \\
\hline & North Jutland & DK050 & & \\
\hline \multicolumn{3}{|c|}{ All domestic } & 100 & 100 \\
\hline
\end{tabular}

$\mathrm{X}$ : location of company \#5.

\subsubsection{Company \#6}

\begin{tabular}{lll}
\multicolumn{2}{l}{ Table 4.11. Main characteristics of company \#6 } & \\
\hline & 2006 & 2010 \\
\hline $\begin{array}{l}\text { Turnover } \\
\text { R\&D }\end{array}$ & $€ 100$ million & $>€ 80$ million \\
& $€ 1.3$ million \\
No. of employees & $\sim 550$ & $\sim 550$ \\
\hline
\end{tabular}

\section{Products}

Company \#6 is a world leading producer of products and systems for advanced infrastructure installation in a variety of buildings, ships and tunnels. The quality parameters are twofold: the technical functioning of the units and the optimal settings of entire systems to the environments they are servicing.

Due to the reputation of the company, the products are offered as OEM products, i.e. as components of customised systems set up by other enterprises.

The competitive advantages of the company are (1) product quality and (2) the competencies in being able to tailor each individual system to the needs of the customer. The engineers at the company are specialists in complex calculations. The products are silent, durable and very efficient. The high price of the products is partly compensated by low operating costs.

\section{Ownership and history}

Currently, the company is owned by a Danish equity firm. It was founded in the 1940s by an engineer of a local section of an iron casting company. 
The company developed following two tracks: technical development and development of an international sales organisation.

The company is situated in a harbour city in Region Zealand, in a set of large, single-storied, shed-roofed buildings from the late 1960s /early 1970s. The company moved to its present location from the centre of the city.

The harbour is mainly in use for companies located at the harbour and for bulk-transport. The product of the company, however, is shipped by containers in trucks, and in case of overseas locations via Hamburg. The company is situated at some distance from the national motorways. However, the transportation of final products and supply for the company is not a problem. Rather, the distance from Copenhagen causes some restrictions on access to skilled labour, especially academic specialists. Worth noting, however, is that much of the company's knowledge base is embedded in a skilled labour force of people employed for several years by the company. The two procurement managers are commuters, from Odense (Funen) and Copenhagen, respectively.

\section{R\&D}

The company has organised a R\&D department. The R\&D department collaborates with private companies in specialised fields and universities. The procurement manager, however, was not well-informed about the exact external relation.

The procurement managers are not involved in product improvements. The subcontracting orders with foreign suppliers are not large enough to give rise to special component development. The procurement managers use incentive contracts, based mostly on the priceparameter (i.e. not quality).

\section{Product relations}

The company produces all its systems in two plants, in Denmark and China. The Chinese plant is especially responsible for delivering products to the Asian market, as it benefits from lower logistical costs and can better meet special Asian product requirements.

Recently, the production plant in Denmark was made more efficient by the introduction of lean-principles and automation. This reorganisation was made possible by a major investment (DKK 40 million) when the new owner acquired the company. Since most products are produced after being ordered by customers, they are managed as individual projects by project teams, supervised by the project leader. Each project has been technically specified by the engineers. The project team is responsible for assembly. 


\section{Market}

Products are sold worldwide. Thus, sales offices are located in Norway, Netherlands, UK, Japan, China, Korea and Singapore.

\section{Strategies for the future}

Being an equity fund, the owner is interested in profits from selling the company, especially after the production was made more efficient, as earlier described.

The company has not considered outsourcing. The company in China was established due to the special needs of the market and to reduce the transport costs from Denmark. The low degree of labour intensity in the production makes it unprofitable for outsourcing.

\section{Subcontractors}

The most important subcontracting is related to specialised products and processes as follows:

Adjusted "catalogue products"

- Motors are delivered from Brazil, France and two large European TNCs (AAB and Siemens).

- Coils are delivered by European firms.

Products by order

- Core components are ordered by the R\&D department. These include components formed by pressure casting of aluminium.

\section{Processes}

- Surface coating, such as zinc and epoxy coating, is carried out by special enterprises close to the company or in the neighbouring region of Funen.

In addition, "capacity" suppliers are used during seasons of high demand, as is the facse with components such as mounting frames. 
Figure 4.8. Geographic distribution (in \%) of purchasing costs from Danish suppliers, company \#6

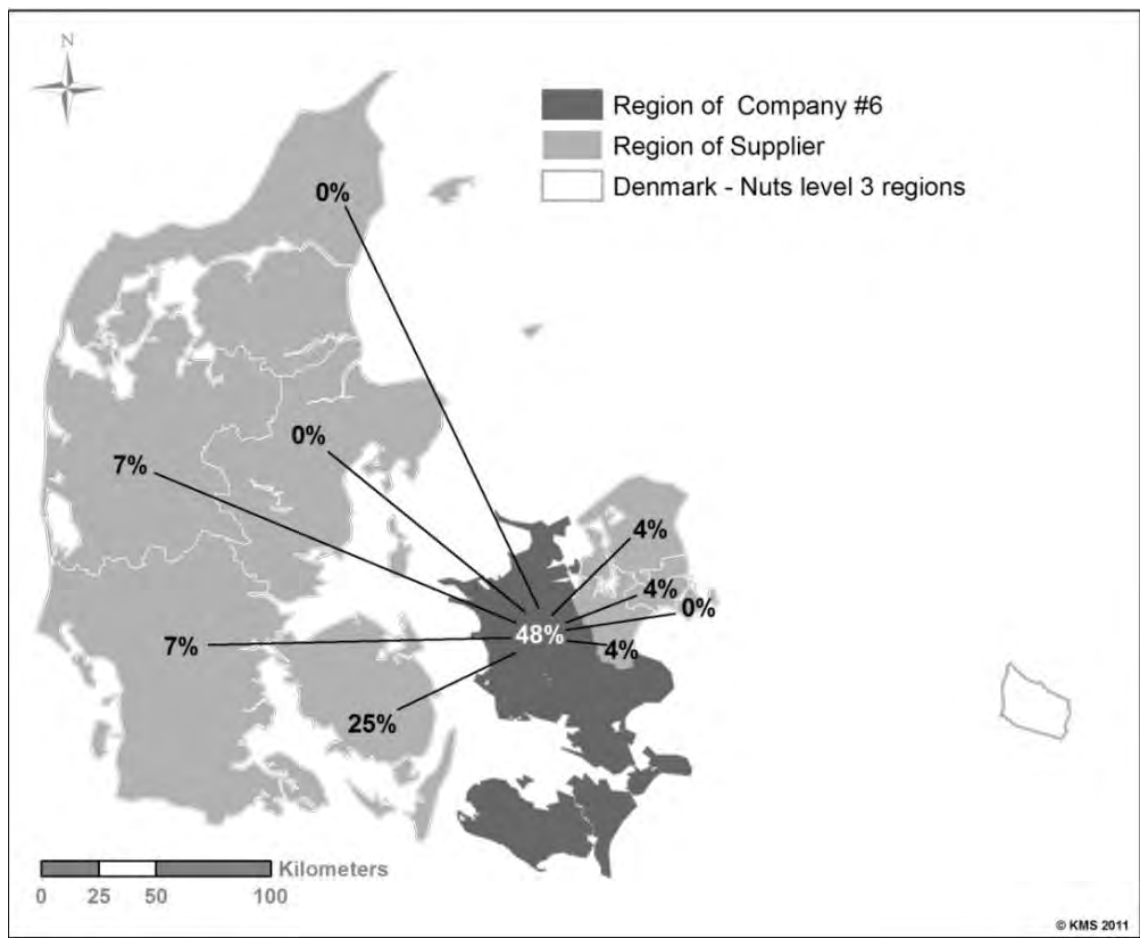

Table 4.12. Geography of supply turnover (\%), company \#6

All suppliers

Domestic

Foreign

All

Domestic suppliers (NUTS 3)

Copenhagen $\mathrm{CPH}$

$\mathrm{CPH}$ Surroundings

North Zealand

DK011

DK012

DK013

$\mathbf{x}$

DK021

48.1

DK022

South Jutland

DK031

West Jutland

DKO32

East Jutland

DK041

North Jutland

DK042

DK050

7.3

7.2

All domestic

0.0
100

X: location of company \#6.

Subcontractors with annual orders exceeding 100,000 DDK, not including component supply (i.e. catalogue and adjusted standard products).

The supply includes.

(1) "by-order" supply, i.e. deliveries specified for each individual product (45\%).

(2) two general suppliers of surface treatments (32\%).

(3) four suppliers of stock components (the two foreign and two domestic) (22\%). 


\subsection{Production-for-the-market}

\subsubsection{Company \#3}

\begin{tabular}{lrr} 
Table 4.13.Main characteristics of company \#3 & \\
\hline & $\mathbf{2 0 0 6 / 0 7}$ & $\mathbf{2 0 1 0 / 1 1}$ \\
\hline Turnover & $>€ 1,000$ million & $>€ 1,300$ million \\
R\&D & $>€ 40$ million & $>€ 50$ million \\
No. of employees & 7,000 & 7,300 \\
\hline
\end{tabular}

\section{The company}

The company is family-owned, started up in late 1950s. The headquarters is located in Northern Zealand. It operates globally, employing 7,300 people in 53 countries. About half the employees work in distribution. Manufacturing is carried out in only six countries.

\section{Products}

The company develops, manufactures and markets products for personal hygiene. 75\% of their turnover is within Europe. In the markets for the key products, the company is world-leading and the largest in the world. The product portfolio is very long and consists of older as well as newly developed products.

\section{History}

The company started in the mid-1950s. The first product was invented by a nurse who was deeply concerned about the personal impacts of following cancer surgery. Together with a small but successful plastics company, the founder invented a device for personal care and started a company a few years later.

\section{Organisation}

The products are manufactured in eight plants, employing 3,800 persons in the production sector and additional 3,500 in sales, service and management, totalling 7,300 employees. The company produces 600 million units per year. The eight production plants are situated in: Denmark (Jutland and Northern Zealand), China, Hungary (2 plants), France (a minor production) and the United States ( 2 plants). An additional

Over the past decade, outsourcing of the production has taken place. Whereas all production was located in Denmark in 2001, only $15 \%$ of production remains in Denmark. The remaining $85 \%$ is manufactured abroad by the above-mentioned six subsidiaries. It is a matter of principle that new products and pilot series of production are developed and produced in Denmark. Only when a new product is ripe for "volume production" is it moved to the subsidiaries abroad. Thus, no volume production is located in Denmark. 
Two most decisive framework conditions for the company are: qualified labour force and logistics for distribution of final products.

The outsourcing in 2001 began by setting up one of the subsidiaries in Hungary. The company took great advantage from the out-sourcinglessons learned by another large Danish company, established in Hungary in the same town a year earlier. Outsourcing was not only stimulated by low labour costs. There was also a "push" from Denmark, in that it was impossible at that time to hire qualified engineers. Outsourcing did not proceed further, since the company wanted to stay in Europe, close to its most main markets.

The founding family came from Northwest Jutland, which was one reason for keeping the plant in Jutland. The company has established a very large distribution hub in Hamburg and plans to establish one more in Hungary. Only if national or local authorities set time limits for distribution of products can the company organise small supplementary distribution centres locally. The company prefers to lease its distribution centers rather than own them because logistics is not a core activity for the company.

Adding to the requests for logistics is the need for sterilisation of several products. Sterilisation is a highly specialised and diversified service tailored to specific product materials, and some types of sterilisation treatments are very costly to set up. Hence, sterilisation is not done in-house. Instead products are transported from the manufacturing plant to the sterilisation plant and then to the distribution centres before distribution to the customers. Sterilisation is organised at sterilisation companies in Belgium or Denmark.

The cost arguments for outsourcing are related to costs of labour, distribution and raw materials.

In total, the cost differences are as follows (index, 2002/03):

Table 4.14. Costs of production in DK and subsidiaries (index)

\begin{tabular}{lrr}
\hline Country & Index total & Index labour \\
\hline DK & 100 & 100 \\
HU & 67 & 20 \\
CN & 65 & $>20$ \\
\hline
\end{tabular}

The difference between Denmark, on the one hand and Hungary and China, on the other, is primarily due to low wages in the two latter countries. Wage levels in China are also lower than in Hungary, although this is offset by higher logistical costs.

\section{The subsidiaries}

Volume production is located in Hungary and China. A production plant in eastern Hungary has 1,000 employees, and a second plant near Budapest employees 700 . Both plants produce key products. 
A rather large and successful plant is located in a free trade zone in China.

One of the two US plants produces costly and specialised products in low quantities, for example surgical implants. The other plant produces skin care products. The subsidiary in France produces niche products for the surgery sector.

The plans for the future are to expand production and distribution facilities in Hungary.

Product quality is decisive for the company. It must remain reliable and credible for the customer. The company succeeded in actually improving quality after outsourcing.

\section{Employment and value}

Figure 4.9 shows how employment in the production sector of the company has developed since 2006.

As a consequence of outsourcing, employment in Denmark was drastically reduced.

The value of the company has developed rapidly. Thus, in 2008 , the company's share value was estimated to be about DKK 15,000 million. In 2011 the estimated value had doubled, to DKK 32,000 million.

\section{Figure 4.9. Employment in production}

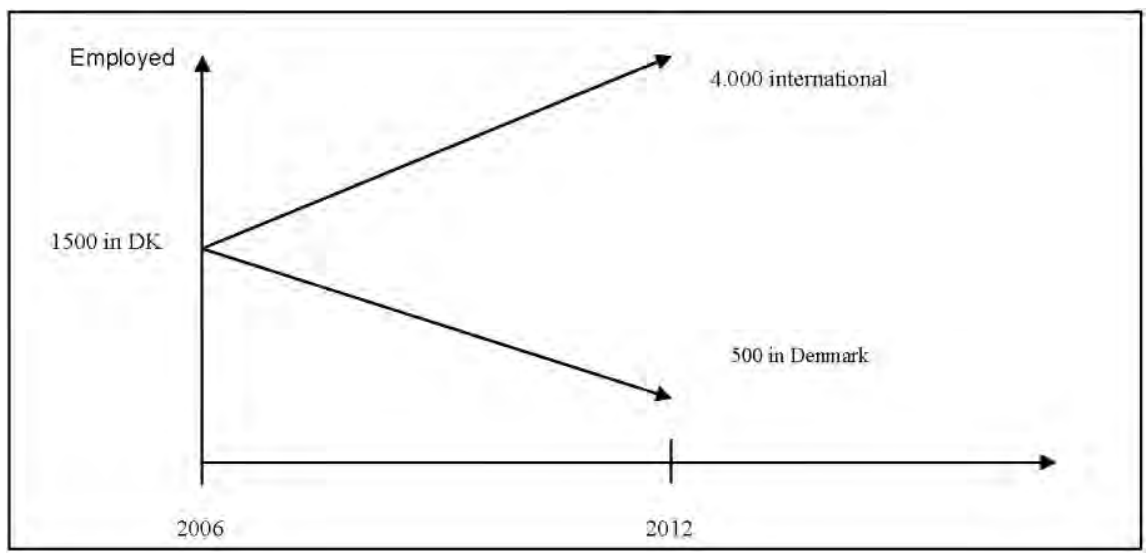

\section{R\&D}

Like company \#2, company \#3 makes use of incentive contracts in the procurement of products. However, most innovation is carried out in-house, by the company's R\&D section. Innovation is also driven by the various regulations issued and controls carried out by national authorities. 


\subsection{Suppliers}

The company has a total of 16,000 suppliers, most of which are indirect. Only about 600 suppliers deliver raw materials for production. The indirect supply is situated close to the plants. During outsourcing, pronounced shifts occurred in the indirect supply system. Most of the suppliers of raw materials are large European global companies such as company \#3 itself. One such supplier, from the Netherlands, produces in Germany and Turkey. The company buys from its Turkish subsidiary. The use of TNCs makes it illusory to regard the supplier as coming from one specific country. The procurement manager explained: "It is difficult to speak about geography in this context. The suppliers are simply so big and organised so scattered - with headquarter in one country and production and distribution in several other countries."

In geographical terms, about $70 \%$ of the suppliers are European and the remaining 30\% Danish. The most important raw materials are procured by large international companies, rather than e.g. Danish companies. However, "we buy for more than DKK 1,000 million in Denmark per year from 2,500 Danish suppliers, some of which are TNCs with Danish located distributors." Typically, the Danish supply materials are not part of the critical core supply.

Several parts of the production, e.g., quick casting, are outsourced to subcontractors and then assembled by the company. Generally, the company does not organise in-house production if the production is too limited to maintain core competencies and remain cost-efficient. One such example is sterilisation. It is a highly specialised process and not carried out in-house, although the process is crucial to the company. One of the sterilisation sub-contractors, a US-based company, established a subsidiary in North Zealand, as neighbour to the company. The plant was established in the year 2000 on a lot formerly owned by company \#3. The company saw the advantage of having the sterilisation company located close by. Now most of the production has been outsourced to Hungary. However, they do not expect that the sterilisation company will follow. The kind of sterilisation needed in Hungary is very special and too costly to establish. Although company \#3 is a world player, it is in many respects a very small consumer of on raw materials.

The company is also trying to maintain its relations with Danish and German suppliers "because we know it works."

A section for machine construction has been set up in China for inhouse production of own production machinery. It is much cheaper to construct the machinery in-house (even though it is not a core competence). Earlier, the machinery had been built by special companies under the supervision of the company's R\&D staff. 
In China, $85 \%$ of raw materials and other inputs for the production are purchased locally in China. "We cannot buy raw materials in Denmark and Germany, transport them to China for production and then transport the final products back to Europe. As many raw products as possible must be purchased in the outsourcing country." Generally, the company accords high priority to geographical proximity of suppliers for the volume production. In Hungary, the proportion of Hungarian suppliers is not as high as in China. For logistical reasons, it is best to retain existing suppliers from elsewhere in Europe rather than trying to change to Hungarian suppliers, considering the effort involved in shifting supply chains and the existing good European infrastructure. "Every time we replace a supplier of raw material with another supplier, we do it carefully. It is a huge job, including testing, registration etc. We only do it if there is a reason for it. Not just to save half a percentage of costs."

\section{Comments}

The triangle between production, $R \& D$ and logistics of purchasing and distribution is decisive for the geographical location of a company of this kind that is based on volume production of high-quality but simple products.

Logistics is important to the distribution of many products from a small number of manufacturing plants to all over the world. Therefore, e.g. distribution hubs (Hamburg and small local hubs) are part of the concept. The need for high-quality raw materials makes it attractive to purchase from major global players or from local distributors of TNCs. Economies of scale make it attractive to outsource the volume production. The success of very distant outsourcing (e.g. China) depends on the degree to which it is possible to buy raw materials locally. R\&D and pilot/"ramp-up" production is separated from outsourced volume production in order to keep these strategic and early innovative stages of product development close to decisionmaking and qualified staff.

Table 4.15. Geography of supply turnover (\%), company \#3

\begin{tabular}{lr}
\hline All suppliers & \\
\hline Domestic & 15 \\
Foreign & 85 \\
All & 100 \\
\hline
\end{tabular}

Production of the high quality, fast but simple volume products differs from the slow production of small number of complex high quality units, and so does the geography. Efforts toward continual innovation of the complex products make it advisable to retain production at home and to purchase - often quality - parts from suppliers, no matter whether distant or nearby. Thus, innovation of the complex high quality products of 
companies \#1, \#2, \#5 and \#6 takes place in processes involving not only the R\&D department but also the purchaser and subcontractor, via instruments such as incentive agreements or contracts.

It is worth noting that future spreading effects of company \#3 seem to be modest, since only ramp-up production is kept in Denmark. The company plans expansion abroad, especially in Hungary.

\subsubsection{Company \#4}

\begin{tabular}{lrr} 
Table 4.16.Main characteristics of company \#4 & \\
\hline & $\mathbf{2 0 0 6}$ & $\mathbf{2 0 1 0 / 1 1}$ \\
\hline Net turnover & $>€ 650$ million & $>€ 900$ million \\
R\&D & $>€ 60$ million & $>£ 80$ million \\
No. of employees & $>4,500$ & $>6,000$ \\
\hline
\end{tabular}

\section{History, products and main organisation}

Company \#4, founded in 1904, designs and manufactures instruments for personal aid. The company employs more than 3,000 people around the world, and their products are sold through sales offices in 23 countries through some 80 independent distributors worldwide.

Approximately 615 employees work at the headquarters in the Copenhagen, including nearly 350 product and technology development specialists. The company has two production sites: a production facility in Jutland employs 600 people, and 400 people (including 60 specialised software engineers) work at a subsidiary in Poland.

Further, approximately 1,200 people are employed in sales and service functions around the world. Finally, 25 scientists are situated at the company's International Research Centre, dedicated to R\&D and user tests

The company is among the three largest providers of personal care solutions within its field on the world market. In 2008, it had a turnover of DKK 5.4 billion and an operating profit of more than DKK 1 billion.

\section{Organisational changes}

The organisation of the company has changed. In 1972 a new production facility was constructed in Jutland, considered a part of the Danish periphery, and therefore able to benefit from national regional funding. The headquarters and a strong R\&D department remained in Copenhagen. The plant in Jutland produced products for the world market until 2007. In 2007, the company bought a plant in Poland that had been owned by a former supplier. Today, the Polish plant produces $90 \%$ of the production while the remaining $10 \%$ is produced at the plant in Jutland. The plant in Jutland is now used as a test facility for new product lines. Thus, the company has a clear spatial division of labour with R\&D and senior management activities located in the Copenhagen city region, the test production in Jutland and the large scale production for the world market taking place in Poland. The latter is a result of an outsourcing strategy to save labour 
costs. Poland was chosen over Southeast Asia because of geographical proximity, as interaction between headquarters and the production plant remains important and because labour costs comprise only $10 \%$ of the final product price. Hence, although labour costs are higher in Poland compared to Southeast Asia, Poland was chosen because of geographical proximity argument and because of the relatively small cost reduction that would result by moving production to, say, Vietnam.

Because of the new plant in Poland, there has been a job loss in Jutland. However, there are no current plans to close the plant in Jutland, although distribution facilities are planned to be transferred to Poland within the next couple of years, further reducing the activities in Jutland. The redirection of the distribution from Denmark to Poland will have an effect on suppliers. Today, around 30\% of purchases in terms of volume are provided by Danish suppliers, but key supplies such as boxes and paper for packaging and printed papers are planned to be produced in Poland.

\section{Suppliers}

The company has 320-340 suppliers, of which 30 account for more than $80 \%$ of the total volume. The supplier network is global including the US and Australia, and for the main products and technologies the suppliers are often located in the dominant clusters of the specific technologies. Many of the key suppliers of the main technologies also supply the much larger mobile industry with some dominant suppliers within the key technologies (OEM).

Out of the total purchase volume, Danish suppliers account for close to $30 \%$, thus continuing to be an important supplier country for the company. In Denmark, the company has about 220 suppliers, of which 10-15 account for more than $80 \%$ of the total volume. The suppliers are located throughout the country, although only three out of the 19 largest suppliers are located outside the Copenhagen city region, and these three firms account for less than $10 \%$ of total Danish purchases. Besides the leading technologies and material input to the production, a large supply item consists of packaging and printing manuals and certifications. Further, some of the lead suppliers are the result of gemmations from the company, i.e. newly started companies based on related technologies. 
Figure 4.10. Geographic distribution (in \%) of purchasing expenditures for Danish suppliers, company \#4

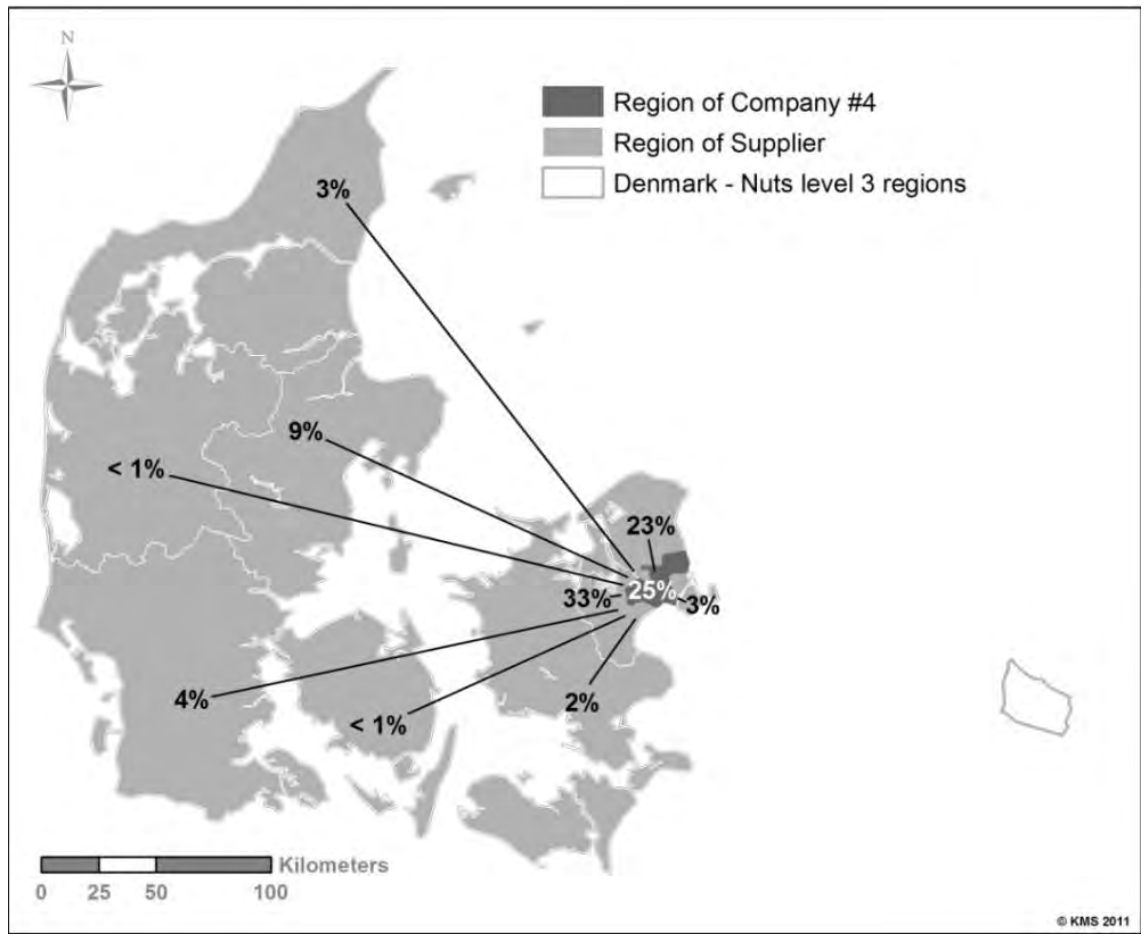

Table 4.17. Geography of supply turnover (per cent), company \#4

All suppliers

Domestic

Foreign

All

Domestic suppliers (NUTS 3)

$\mathrm{X} \quad \begin{aligned} & \text { Copenhagen } \mathrm{CPH} \\ & \text { CPH Surroundings } \\ & \text { North Zealand } \\ & \text { East Zealand }\end{aligned}$
West and South Zealand
Funen
South Jutland
West Jutland
East Jutland
North Jutland
All domestic

\begin{tabular}{rr}
24.6 & 83.3 \\
23.0 & \\
32.9 & \\
& \\
1.5 & 1.5 \\
0.4 & 0.4 \\
4.3 & 4.3 \\
0.2 & 0.2 \\
9.4 & 9.4 \\
2.8 & 2.8 \\
101.9 & 101.9 \\
\hline
\end{tabular}

$\mathrm{X}$ : home region of the company. 


\subsection{Business-to-business solutions}

\subsubsection{Company \# 7}

\begin{tabular}{|c|c|c|}
\hline & 2006 & 2011 \\
\hline Turnover & $€ 800$ million & $€ 1,400$ million \\
\hline No. of employees & & 5800 \\
\hline
\end{tabular}

The data on suppliers from this case-study was provided by the company, whereas other data was taken from the company website and a newspaper interview. Due to lack of time, it was not possible to arrange an interview. However, the data provided by the company are excellent, including two time series of data, from 2006 and 2011.

\section{Products}

The company is a world leading developer of biological processes suitable for replacing industrial chemical processes characterised by e.g. high pressure and temperature, energy consumption and harmful byproducts by alternative bio-chemical reactions, carried out under mild conditions, highly specific and at higher reaction rates.

Rather than selling final products, the company collaborates with its customers to create advanced industrial bio-solutions while improving the customers' business and industrial performance. The number of products is far more than 500 , and the products are used within several industrial sectors in more than 100 countries in Europe, Asia, and North and Latin America.

To enter new business areas, the company employs in-house projects as well as strategic alliances and acquisitions.

\section{The company}

The company was founded in the 1920s in Copenhagen. In the late 1960s, it was located at three addresses in the Greater Copenhagen and the Southwest Zealand. Today, the company has set up or acquired several subsidiaries in other parts of Europe, North and Latin America, China and Australia.

\section{R\&D}

The company owes its success to research and development of new methods and processes. It invests $14 \%$ of its revenue in research and development and has an extensive patent portfolio with more than 6,000 active patents, patent applications, and licensed patents. 


\section{Strategies}

Since the mid-1990s, the company decided to keep jobs in Denmark while expanding production abroad. The strategy is not to split "idea" and production. Rather, it is to maintain close relations between research and production. Therefore, the company tries to reduce the amount of manual work and to increase efficiency in the Danish production sites. "Over the last ten years, there have been fewer manufacturing jobs in the company. But if we did not optimize the production like we did, there would not have been anything left at all to day. We are not going to expand the plants in Denmark. Rather, we shall build new plants abroad." (Newspaper interview with one of the vicepresidents of the company).

\section{Suppliers}

From the total list of subcontractors, the company provided a separate list of Danish subcontractors, listing them anonymously, by only postal code and category. The postal codes were transformed into LAU, NUTS 3 and NUTS 2 territories. Questions arose every time a postal code "tentacled" into two or more LAU areas. In these instances, the LAU with the same name as the postal code was chosen.

As the only company of this project, the data provide synchronic views of the situation at two points in time: 2006 and 2011. The number of suppliers is impressive: about 3,000 in 2006 and about 2600 in 2011. The $11 \%$ decrease in the number of suppliers should be contrasted with the $20 \%$ increase in spending. The level is NUTS 3. Due to the intimate proximity of "Copenhagen" (DK011) "Surroundings of Copenhagen" (DK012), "North Zealand" (DK013) and "East Zealand" (DK021), the four territories are merged into one - here called "Greater Copenhagen."

All figures show a pronounced concentration of suppliers in the two "home" regions of Greater Copenhagen and West and South Zealand. Far beyond the two, Eastern Jutland is the third most important region.

The company has divided its suppliers into three categories:

1) Direct supply: input for production.

2) Indirect supply: input for administration, etc.

3) Technology and investments: investment maintenance, etc.

In the tables below, supplier spending (\%) and relative numbers of suppliers are shown within NUTS 3 territories. Below the tables, the figures are shown on geographical maps (this version: diagram maps - to be replaced by topographical maps).

The geographical distribution of supplier spending in 2006 and 2011 is shown in table 4.19 and figure 4.11, subdivided into the geographical origin and split into the afore-mentioned three categories of supply (direct, indirect and technology \& investments). 
Table 4.19. Proportion of Danish supplier expenditures by type and origin of supplies/company \#7

\begin{tabular}{|c|c|c|c|c|c|c|c|c|c|}
\hline \multirow[b]{2}{*}{ Volume - \% } & & \multicolumn{4}{|c|}{2006} & \multicolumn{4}{|c|}{2011} \\
\hline & & Direct & Indirect & $\begin{array}{r}\text { Tech \& } \\
\text { Invest }\end{array}$ & All & Direct & Indirect & $\begin{array}{l}\text { Tech \& } \\
\text { Invest }\end{array}$ & All \\
\hline \multirow[t]{4}{*}{ Greater Copenhagen* } & DK011 & & & & & & & & \\
\hline & DK012 & & & & & & & & \\
\hline & DK013 & 51.1 & 81.1 & 60.7 & 68.5 & 55.25 & 82.9 & 66.1 & 69.85 \\
\hline & DK021 & & & & & & & & \\
\hline W. \& S. Zealand & DK022 & 37.4 & 12.0 & 24.6 & 22.0 & 34.3 & 8.3 & 21.4 & 20.1 \\
\hline Funen & DK031 & 0.3 & 2.2 & 0.4 & 1.3 & 1.5 & 3.6 & 0.4 & 2.2 \\
\hline S. Jutland & DK032 & 1.2 & 1.0 & 6.9 & 1.9 & 0.6 & 0.4 & 3.8 & 1.1 \\
\hline W. Jutland & DK041 & 2.7 & 0.9 & 1.4 & 1.6 & 1.3 & 1.1 & 0.7 & 1.1 \\
\hline E. Jutland & DK042 & 6.5 & 2.5 & 5.4 & 4.2 & 6.8 & 3.4 & 7.4 & 5.4 \\
\hline N. Jutland & DK050 & 0.9 & 0.2 & 0.8 & 0.5 & 0.3 & 0.3 & 0.1 & 0.3 \\
\hline Total & & 100.0 & 100.0 & 100.0 & 100.0 & 100.0 & 100.0 & 100.0 & 100.0 \\
\hline
\end{tabular}

* Copenhagen (DK011), Surroundings of Copenhagen (DK012), North Zealand (DK013) and East Zealand (DK021)

Figure 4.11. Geography of supplier spending (\%), company \#7 in 2006 and 2011. Danish suppliers only

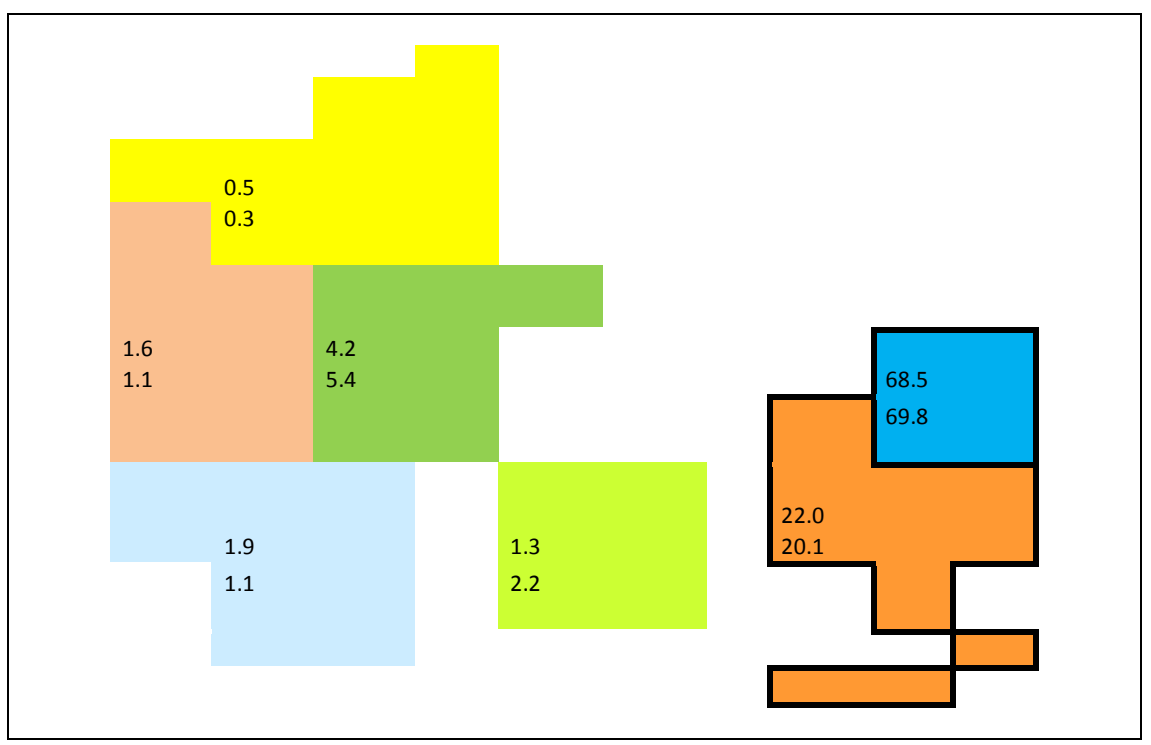

Upper digits: 2006. Lower digits: 2011.

The geographic distribution of the supply reveals a pronounced pattern of proximity. Thus, $90 \%$ of the supply originates from the two home regions of the company, i.e. the "Greater Copenhagen" (the pilot plant and company headquarters) and "West and South Zealand" (production plant), as indicated in figure 4.11 by bold border lines on the right.

Outside the two home regions of the company, supply patterns are not governed by sheer proximity. Although a relative neighbour to the company, Region Funen is only the fourth largest supplier region outside the home regions in 2006 and the second largest supplier region in 2011. East Jutland, including the Århus region, is by far the most important supplier region 
outside the two home regions in 2006 and is even more prominent in 2011. The expenditures for supplies from this region are $2 \frac{1}{2}-3$ times the expenditures for supplies coming from Region Funen.

Table 4.20 and figure 4.12 shows where the suppliers are located.

Table 4.20. Geography of supplier location, company \#7 - Danish suppliers

\begin{tabular}{|c|c|c|c|c|c|c|c|c|c|}
\hline & & \multicolumn{4}{|c|}{2006} & \multicolumn{4}{|c|}{2011} \\
\hline \multicolumn{2}{|c|}{$\begin{array}{l}\text { Relative numbers of suppliers } \\
\text { (per cent; total } N=1 / 2 \text { ) }\end{array}$} & Direct & Indirect & $\begin{array}{l}\text { Tech \& } \\
\text { Invest }\end{array}$ & All & Direct & Indirect & $\begin{array}{l}\text { Tech \& } \\
\text { Invest }\end{array}$ & All \\
\hline \multirow[t]{4}{*}{ Greater Copenhagen* } & DK011 & & & & & & & & \\
\hline & DK012 & & & & & & & & \\
\hline & DK013 & 66.2 & 73.9 & 63.8 & 71.1 & 63.6 & 73.0 & 61.0 & 69.3 \\
\hline & DK021 & & & & & & & & \\
\hline W. \& S. Zealand & DK022 & 11.3 & 12.1 & 12.8 & 12.3 & 9.1 & 11.0 & 12.3 & 11.3 \\
\hline Funen & DK031 & 3.0 & 2.5 & 2.9 & 2.6 & 5.0 & 2.5 & 3.2 & 2.8 \\
\hline S. Jutland & DK032 & 6.0 & 3.3 & 6.8 & 4.3 & 8.3 & 3.3 & 7.8 & 4.8 \\
\hline W. Jutland & DK041 & 1.5 & 1.4 & 2.6 & 1.7 & 2.5 & 1.8 & 3.4 & 2.2 \\
\hline E. Jutland & DK042 & 9.0 & 5.6 & 8.2 & 6.4 & 5.8 & 6.9 & 10.2 & 7.7 \\
\hline N. Jutland & DK050 & 3.0 & 1.2 & 2.8 & 1.7 & 5.8 & 1.5 & 2.1 & 1.9 \\
\hline Total & & 100 & 100 & 100 & 100 & 100 & 100 & 100 & 100 \\
\hline
\end{tabular}

* Copenhagen (DK011), Surroundings of Copenhagen (DK012), North Zealand (DK013) and East Zealand (DK021).

Figure 4.12. Regional distribution of Danish suppliers (\%), company \#7

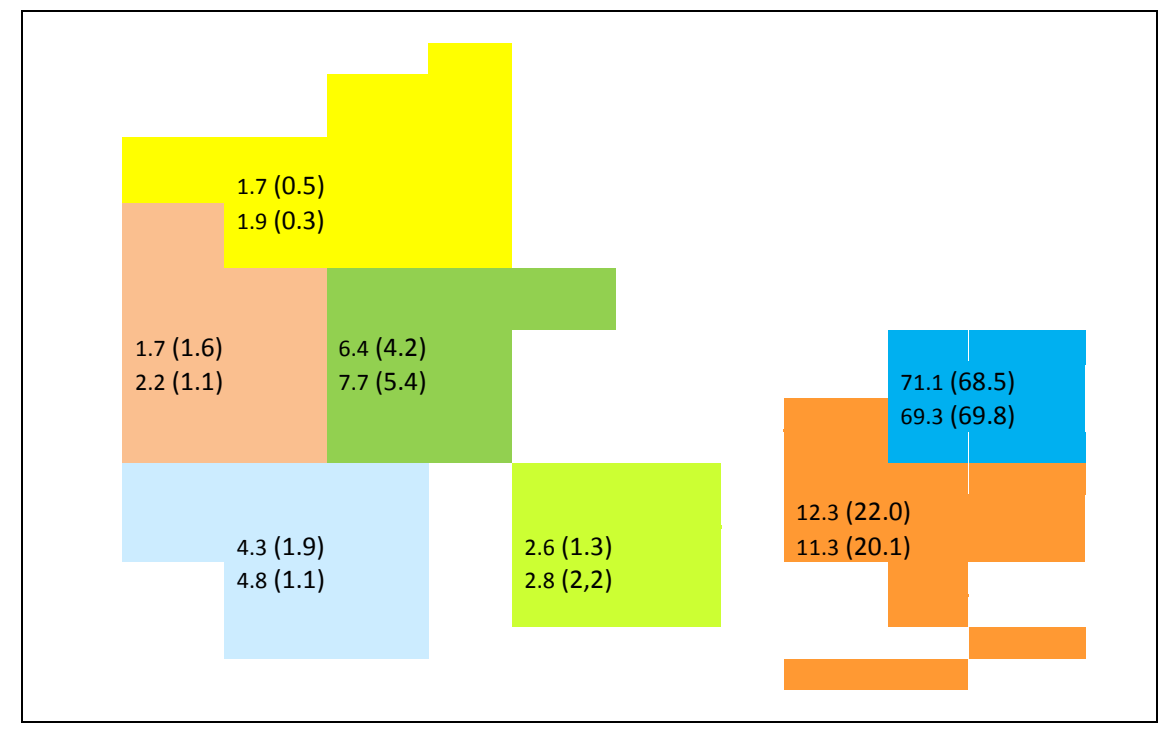

Upper digits: 2006. Lower digits: 2011. Figures in parenthesis show the relative distribution of supplier spending (cf. figure 4.11).

The location of the suppliers reiterates the geographical proximity pattern of the supply. The share of suppliers in W. \& E. Zealand is much lower than the corresponding share of supply volume. This is due to the fact that the direct suppliers from W. \& E. Zealand and - to some extent - the direct suppliers from the Greater Copenhagen are much larger on average than the suppliers located in regions outside the two 
home regions. Thus, especially the direct supply is governed by proximi$t y$, indicating that the major direct suppliers are situated in proximity to the production plant. Indirect supply and technology and investments supply, however, is more evenly distributed, cf. table 4.21 .

Table 4.21. Average size of supply per supplier (average supply in each category = 100) - Danish suppliers only, company \#7

\begin{tabular}{|c|c|c|c|c|c|c|c|}
\hline & & \\
\hline & & \multicolumn{3}{|c|}{2006} & \multicolumn{3}{|c|}{2011} \\
\hline & & Direct & Indirect & $\begin{array}{r}\text { Tech \& } \\
\text { Invest }\end{array}$ & Direct & Indirect & $\begin{array}{r}\text { Tech \& } \\
\text { Invest }\end{array}$ \\
\hline \multirow[t]{4}{*}{ Greater Copenhagen* } & DK011 & & & & & & \\
\hline & DK012 & & & & & & \\
\hline & DK013 & 77 & 110 & 95 & 87 & 114 & 108 \\
\hline & DK021 & & & & & & \\
\hline W. \& S Zealand & DK022 & 331 & 99 & 192 & 377 & 75 & 174 \\
\hline Funen & DK031 & 10 & 90 & 13 & 30 & 142 & 13 \\
\hline S. Jutland & DK032 & 20 & 31 & 101 & 7 & 13 & 49 \\
\hline W Jutland & DK041 & 182 & 69 & 52 & 54 & 62 & 20 \\
\hline E Jutland & DK042 & 72 & 45 & 65 & 118 & 49 & 73 \\
\hline $\mathrm{N}$ Jutland & DK050 & 30 & 13 & 28 & 6 & 20 & 7 \\
\hline Total & & 100 & 100 & 100 & 100 & 100 & 100 \\
\hline
\end{tabular}

Looking into the three categories of supply, we find the same geographical patterns of proximity, as with the total volume of supply (cf. figure 4.11 above) - see figures 4.13 and 4.14 .

Figure 4.13. Regional distribution of Danish supplies by category (\%), 2006, company \# 7

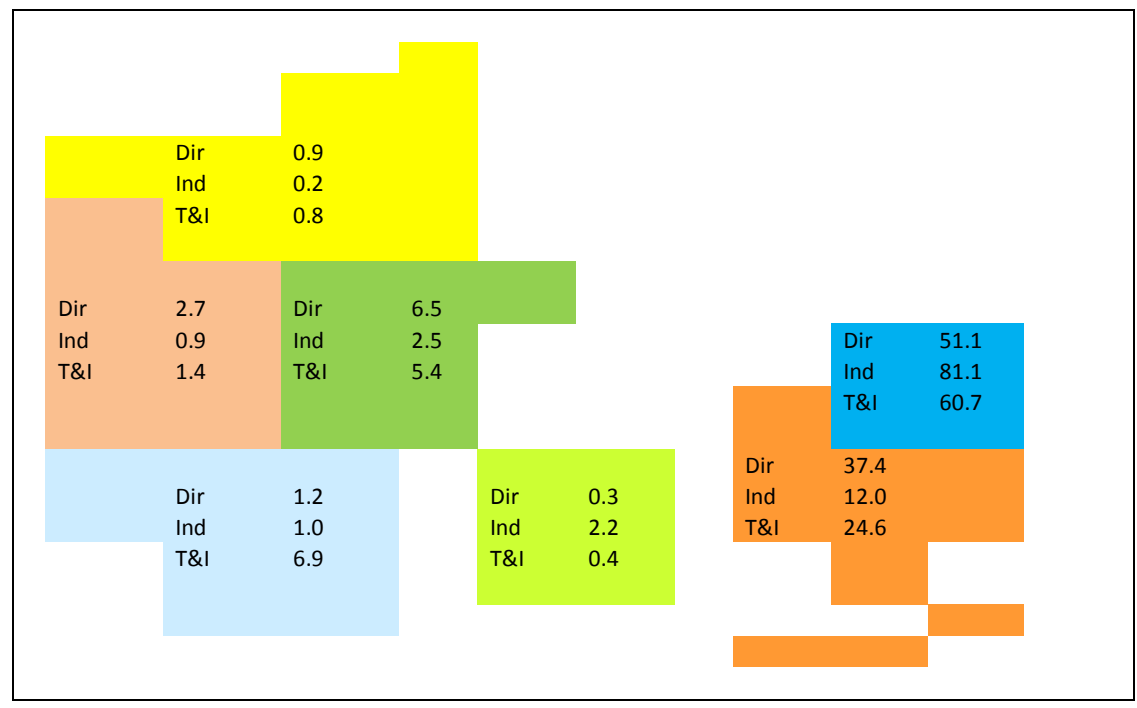


Figure 4.14. Regional distribution of Danish suppliers by category (\%), 2011 company \# 7

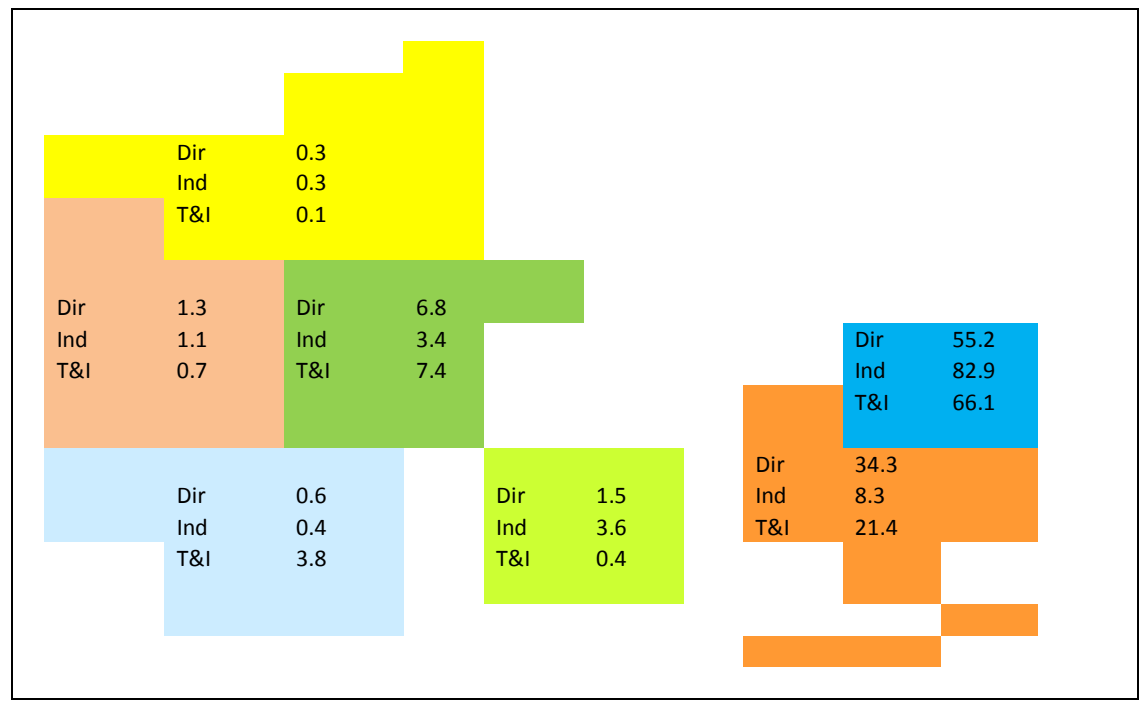

Outside the two home regions of the company, East Jutland is the most important supplier region. Region Funen is weak in direct supply and in technology and investments, but shows some strength in indirect supply 2006. Five years later, region Funen is positioned a little better. During the same period, East Jutland increases its position in all three categories of supply.

As we know from some of the other companies in the interview sample, suppliers of key importance deviate from the proximity rule. Regardless of distance, they have become suppliers due to special competencies, product quality or brand.

As an indicator of important supplier, we chose the economic size of the supplier and combined this with the geographical location of large suppliers. Table 4.22 indicates regions with an over-representation of large companies. We selected the $20 \%$ largest direct suppliers and the $10 \%$ largest indirect and T\&I suppliers. The overrepresentation of direct suppliers is due to the relatively small number of direct suppliers.

In the table, regions with an over-representation of large suppliers are highlighted. The table reveals that especially one of the home regions (W. \& E. Zealand) is endowed with large suppliers in 2006 and in 2011 as well. In 2011, Region Funen, West Jutland and East Jutland have a disproportionately large number of direct suppliers. The figures in table 4.22 are mapped in figure 4.15 and figure 4.16 as well. 
Table 4.22. Relative numbers of largest Danish suppliers minus relative number of all suppliers (\%), company \#7

\begin{tabular}{|c|c|c|c|c|c|c|c|c|c|}
\hline & & \multicolumn{4}{|c|}{2006} & \multicolumn{4}{|c|}{2011} \\
\hline & & $\begin{array}{r}\text { Direct } \\
20 \%\end{array}$ & $\begin{array}{r}\text { Indirect } \\
10 \%\end{array}$ & $\begin{array}{r}\text { Tech \& } \\
\text { Invest 10\% }\end{array}$ & All & $\begin{array}{r}\text { Direct } \\
20 \%\end{array}$ & $\begin{array}{r}\text { Indirect } \\
10 \%\end{array}$ & $\begin{array}{r}\text { Tech \& } \\
\text { Invest 10\% }\end{array}$ & Al \\
\hline $\mathrm{CPH}$ & DK011 & & & & & & & & \\
\hline $\mathrm{CPH}$ sur & DK012 & & & & & & & & \\
\hline $\mathrm{N}$ Zealand & DK013 & -8.5 & 4.1 & -4.1 & 0.7 & -9.5 & 0.8 & -4.1 & -1.6 \\
\hline E. Zealand & DK021 & & & & & & & & \\
\hline W. \& S. Zealand & DK022 & 11.8 & 0.4 & 9.4 & 3.5 & 15.9 & 4.3 & 14.1 & 7.8 \\
\hline Funen & DK031 & -3.0 & -1.0 & -2.9 & -1.6 & 3.4 & -0.8 & -3.2 & -1.0 \\
\hline S. Jutland & DK032 & -2.2 & -0.8 & 4.3 & 0.4 & -8.3 & -2.2 & -2.3 & -2.6 \\
\hline W. Jutland & DK041 & 6.2 & -0.4 & -1.3 & 0.0 & 1.7 & -0.6 & -3.4 & -1.1 \\
\hline E. Jutland & DK042 & -1.3 & -1.1 & -2.7 & -1.4 & 2.5 & -1.2 & 0.9 & -0.4 \\
\hline N. Jutland & DK050 & -3.0 & -1.2 & -2.8 & -1.7 & -5.8 & -0.4 & -2.1 & -1.2 \\
\hline Total & & 0 & 0 & 0 & 0 & 0 & 0 & 0 & 0 \\
\hline
\end{tabular}

Figure 4.15. Regional over- representations of large suppliers 2006 company \# 7 - Danish suppliers

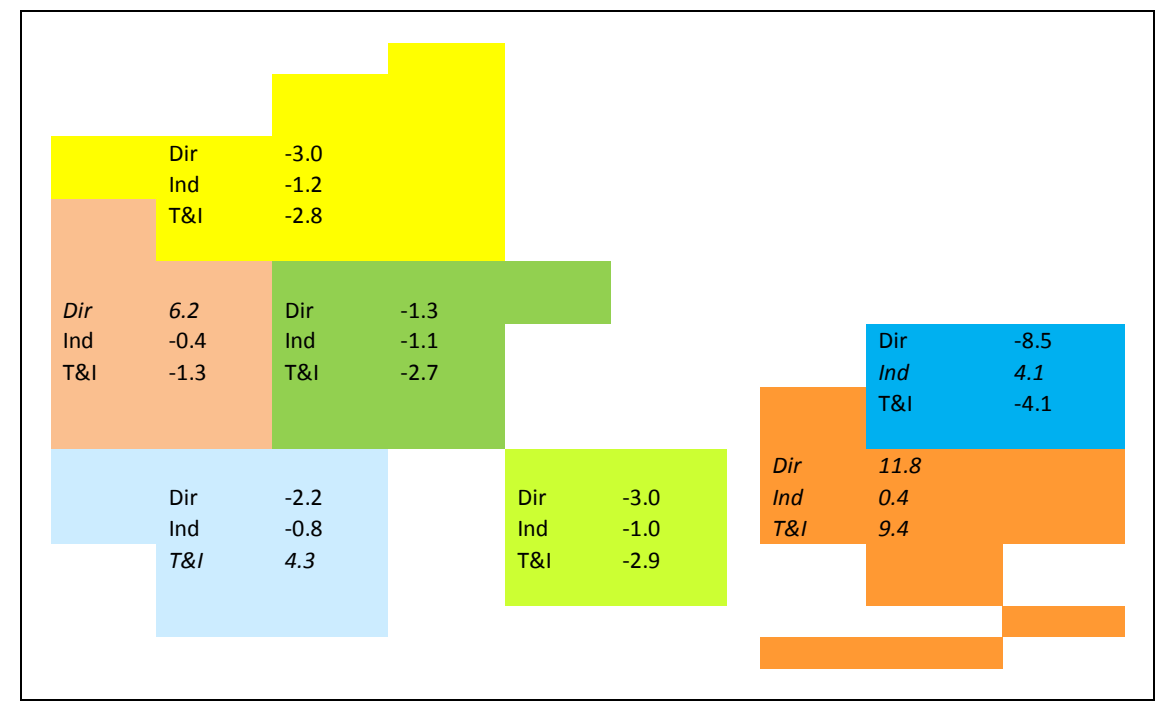

Percentages of large suppliers (20\% largest direct suppliers. 10\% largest indirect suppliers and $10 \%$ largest T\&I suppliers) exceeding percentages of all suppliers. Overrepresentation indicated by italic letters and figures. 
Figure 4.16. Regional over- representations of large Danish suppliers 2011, company \# 7

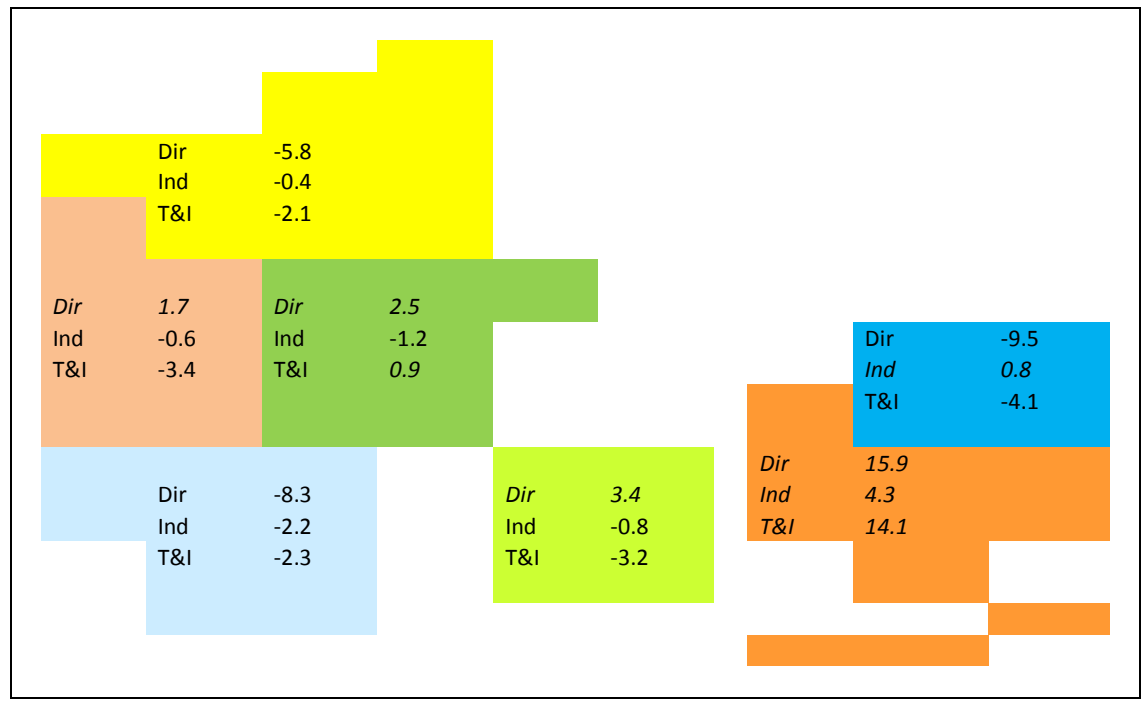

Percentages of large suppliers (20\% largest direct suppliers, 10\% largest indirect suppliers and $10 \%$ largest T\&I suppliers) exceeding percentages of all suppliers. Overrepresentation indicated by italic letters and figures.

\subsection{Common patterns}

\subsubsection{Domestic - foreign supply and production}

The case studies reveal a pronounced difference between the outsourcing activities between those companies producing by order and those producing for the market and the company producing business-tobusiness solutions. The latter type of companies is inclined to outsource volume production but keep pilot production and R\&D "at home," whereas the former is inclined not to outsource in order to keep the close interrelationship between production and the synthetic kind of ongoing innovation. The pattern is revealed by the proportion of domestic to foreign supply and production as extracted from tables 4.3, 4.8, 4.10, $4.12,4.15$ and 4.17 in table 4.23 and table 4.24 :

Table 4.23. Production-by-order: distribution of suppliers*

\begin{tabular}{llccc}
\hline Origin of supply & \multicolumn{3}{c}{ Company } \\
& $\# \mathbf{1}$ & $\mathbf{\# 2}$ & $\mathbf{\# 5}$ & \#6 \\
\cline { 2 - 5 } & 81 & 66 & 37 & 87 \\
\% of supply volume from domestic suppliers & 19 & 34 & 63 & 13 \\
\% of supply volume from foreign suppliers & & & & \\
\hline
\end{tabular}

* Supply of company \#1 is measured by number of suppliers, whereas supply of companies \#2, \#5 and \#6 is measured by purchase costs. 
Table 4.25 shows that a majority (66-87\%) of the supply of three of the companies producing by order is domestic. Company \#5 does not follow this pattern. This is most likely due to the fact that this company was acquired by a huge foreign TNC able to deliver several components, thereby ensuring that details of the subsidiary production is familiarised with design elements of the TNC. Thus, we were informed that the subsidiary was compelled to buy even small components from the mothercompany. As argued by the companies, proximity to suppliers is preferable, especially for supply-by-order and services. Concerning OEM components - and some catalogue components - priority is given to the quality and eventually brand rather than proximity. Hence, these components are often supplied by foreign subcontractors.

Due to the large shares of outsourcing by companies producing for the market, it makes little sense to maintain focus on all suppliers of the company, i.e. including the foreign-based production by the subsidiaries. Instead, we present in table 4.24 the proportion of domestic to foreign production. The figures indicate that a large proportion of production has been outsourced in both companies, causing a corresponding change in the supplier base. Outsourcing is still part of the strategy for both companies. For company \#7, we expect figures showing the same high proportions of foreign production, due to the large number of foreign subsidiaries and the strategy of expanding production outside Denmark.

Table 4.24. Companies producing for the market: Location of production facilities.

\begin{tabular}{lll}
\hline Type of production & \multicolumn{2}{c}{ Company } \\
& $\# \mathbf{3}$ & \#4 \\
\cline { 2 - 3 } Domestic production (per cent) & 15 & 30 \\
Foreign production (per cent) & 85 & 70 \\
\hline
\end{tabular}

\subsubsection{Proximity}

The maps showing of the location of the Danish suppliers reveal a common pattern of proximity between supplier and purchasing company; \#5 being the only exception. As mentioned earlier, company \#5 has been acquired by a huge European TNC able to deliver much of the supplies. Therefore, relatively few Danish suppliers are left, and they are not located in close proximity to company \#5.

Table 4.25 shows the geographic distribution of suppliers as weighted by purchase costs (\#1 by number of suppliers). All companies are located in Zealand, two of them in Greater Copenhagen, four in West \& Southern Zealand and one company (\#7) in both Greater Copenhagen and West \& Southern Zealand. In this project, the "Greater Copenhagen" area is defined as four cohesive and functionally integrated NUTS 3 areas: Copenhagen City, Surroundings of Copenhagen, Northern Zealand and East Zealand. Together with West- and Southern Zealand, these four 
regions comprise the island of Zealand. Current trends of regional enlargement make it reasonable to define Zealand as a single commuting area. Since all companies in our sample are located on the island of Zealand, table 4.26 shows a geographic distribution of suppliers on and outside Zealand as basis for examining whether proximity is a parameter for choosing suppliers. The table shows only the Danish suppliers.

The table shows a pronounced pattern of proximity, thus the largest shares of the suppliers of all companies - but \#5 - are located on Zealand, i.e. within 1.5 hours' commuting distance.

\begin{tabular}{lrrrrrrr} 
Table 4.25. Geographic distribution of the Danish suppliers (percentages) & & & \\
\hline & $\# 1$ & $\# 2$ & $\# 3$ & $\# 4$ & $\# 5$ & $\# 6$ & $\# \mathbf{7}$ \\
\hline Home region: Greater Copenhagen & & & $X$ & $X$ & & & $X$ \\
Home region: W. and S. Zealand & $X$ & $X$ & & & $X$ & $X$ & $X$ \\
Zealand Island & $75 \%$ & $70 \%$ & nda & $85 \%$ & $27 \%$ & $61 \%$ & $90 \%$ \\
Denmark outside Zealand Region & $25 \%$ & $30 \%$ & nda & $17 \%$ & $73 \%$ & $39 \%$ & $10 \%$ \\
Total & $100 \%$ & $100 \%$ & & $102 \%$ & $100 \%$ & $100 \%$ & $100 \%$
\end{tabular}

The distribution is related to only two geographic areas: the Zealand Island (All companies are located here) and the remaining parts of the Denmark. For company \#1 the proportions are measure by the percentage of suppliers located in the two geographic areas. For companies \#2 -7 , the proportions are measured by the percentages of purchase costs of the suppliers. No data is available for company \#3.

\subsubsection{Continuous and discrete patterns}

It must be emphasised that the observation of proximity relations should not be generalised as the only kind of relations influencing the geography of suppliers. Along with proximity, we found relations of relevance. Ubiquitous services and supply are chosen by the proximity rule, thereby indicating geographical patterns of continuous regularity. Other services, such as unique components, the cheapest or best components, are chosen by relevance or quality regardless of where the supplier is located, i.e. not by proximity. The OEM components belong to this category. Trust and reliability are also parameters able to overrule proximity. For example, company \#1 uses an Italian subcontractor for welding, painting and burnishing steel frames due to trustful relations with the company. Usually, this kind of delivery is more ubiquitous and available in Denmark. Company \#2 has established a durable relationship with a Latvian supplier of electronics. The Latvian supplier is one of almost 700 suppliers delivering more than $3 \%$ of the total supply. The relationship was greatly influenced by the lower salaries in Eastern Europe, but developed further due to the quality of the supply and established trustful relations.

The case-studies indicate yet another pattern, the importance of agglomeration. Thus, the second most important supplies to companies \#1, \#2, \#4 and \#7 outside Zealand are located at some distance, in East Jutland, the second largest conurbation in Denmark centred around Århus. 
Table 4.26. Geographic distribution of the Danish suppliers (per cent).

\begin{tabular}{lrrrrrrr}
\hline & $\mathbf{\# 1}$ & $\mathbf{\# 2}$ & $\mathbf{\# 3}$ & $\mathbf{\# 4}$ & $\mathbf{\# 5}$ & $\mathbf{\# 6}$ & $\mathbf{\# 7}$ \\
\hline Denmark outside Zealand & 25 & 30 & nda & 17 & 73 & 39 & 10 \\
$\quad$ Funen & 8 & 2 & nda & $<1$ & 32 & 25 & 2 \\
East Jutland & 17 & 16 & nda & 9 & 41 & 0 & 5 \\
Southern Denmark & 0 & 8 & nda & 4 & & 7 & 1 \\
West Jutland & 0 & 2 & nda & $<1$ & & 7 & 1 \\
$\quad$ Northern Jutland & 0 & 2 & nda & 3 & & 0 & 0 \\
\hline
\end{tabular}

Since 2006, national planning in Denmark changed from an urban system approach to a regional approach, acknowledging the fact that regional enlargement to an increasing extent are linking together towns and cities into joint regional labour, service and housing markets. Two national growth regions, dominating the economic and spatial development at national level, were identified: East Jutland and Greater Copenhagen, including parts of Zealand Region (see figure 4.17). With some cautiousness, we find these two regions also seem to dominate the geography of the Danish suppliers of four companies in this study.

Our observations on the supplier geography correlate only indicatively with the general economic geography of Denmark. Another possibility is that some kinds of suppliers concentrate in specialised clusters. In order to follow-up on this issue, we contacted the Danish Centre for Subcontractors in Herning. Several high-tech products include machine components and metal frameworks, characterised by high quality deliveries, rather than specialised deliveries such as welding, surface treatment (painting and burnishing) and ALU casting of product components. Due to a strong traditional machine sector in Denmark, we suggested that there is a market for these kinds of subcontractors, and eventually the formation of clusters of subcontractors. If located in clusters rather than dispersed, this kind of subcontracting would add further elements to the discrete layers of supplier geography. Unfortunately, our investigation on this lead did not come to any conclusions. The relevance of the question, however, relates to local and regional development policies. The focus is often on the final producers and not the subcontractors. If clusters of subcontractors exist, efforts to sustain and further develop such clusters can be an alternative to policies focusing on high-tech companies. The question of identifying clusters of subcontractors, however, lies beyond the framework of this study. Thus, we will not examine it further. 
Figure 4.17. The "new geography of Denmark" Two growth regions dominate the spatial development of Denmark: Greater Copenhagen and Eastern Jutland

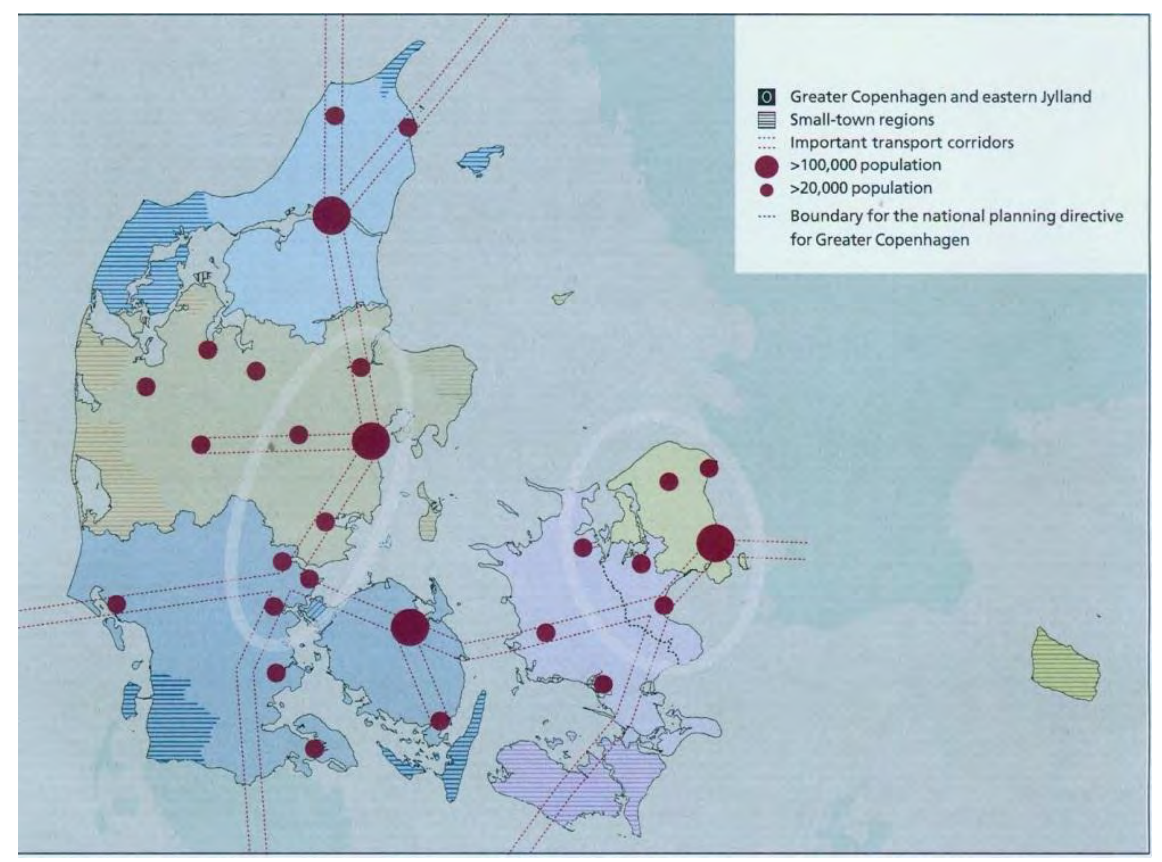

(Source: Danish Ministry of the Environment, 2006).

\subsection{Conclusions and perspectives}

On commencing this study, we knew little about supplier geography, since most literature on company-relations focuses on strategic cooperation, research and innovation. This literature emphasises that these kinds of relations are not ruled by proximity. Cooperation takes place, of course, between companies and local universities. But generally, strategic cooperation and innovation is ruled by relevance, across geographic distances, rather than by geographic proximity.

At the beginning of the study, we were curious about the suppliers. Would they show similar loose connections to geographical proximity, as with strategic relations and innovation?

\subsubsection{Proximity}

Generally, the supplier relations are ruled by proximity. Although we speak from experiences of only seven case studies, we believe that the proximity patterns revealed by the companies are more generally valid, simply because of the rational arguments we identified. An important exception from the proximity rule is the supply of specialised components (OEM) and high-quality components, especially to orderproducing companies. When a company is part of the global elite, components crucial to the final product are acquired from the most rele- 
vant suppliers, regardless of the geographical location of the supplier. A special kind of supplier, difficult to locate, are the TNCs. Supplies from TNCs are delivered from the nearest distribution hub of the TNC, in Denmark or abroad.

\subsubsection{Bias?}

Most of the companies in the Danish study are large companies. In large companies, it is difficult to obtain detailed information about relations that belong to different departments of the company, such as production and R\&D departments. The priority of the project is production rather than innovation, since the aim of the study is to examine the geographic "foot-prints" or multiplier effects of the company. We thus interviewed the procurement managers rather than R\&D managers, and we obtained excellent and detailed information about the supplier relations. We kept our focus on the suppliers and did not ask for supplementary interviews with R\&D departments. Considering the validity of the data acquired, we chose to keep our focus on the suppliers. One could argue that this strategy led to a certain bias of the study. We do not think so. It should be recalled that the study is about the product relations of the companies.

\subsubsection{Typologies}

Due to a sheer luck, we happened to include companies that revealed two types of high-tech companies: those producing on order and those producing for a mass market. These two kinds of production reveal distinct characteristics of supplier relations, knowledge base and affinities between the company and the local milieu, and with it, different strategies for outsourcing.

The order-producing companies deal with complex products, slow production and dependence on synthetic knowledge. They try to remain in the local milieu and to compensate for high production costs by leaning and atomising the production. Their knowledge inputs are from in-house engineering departments, OEM-suppliers and key suppliers as well as from the daily production teams. Outsourcing is not part of their strategies.

The market-producing companies develop and innovate their products in order to standardize production, so that they can produce fast and cost-efficient in larger volume. They rely on analytical knowledge provided by the R\&D department. They try to keep R\&D and pilot production together in their domestic locations but tend to set up subsidiaries via outsourcing and acquisition of foreign companies abroad in order to reduce costs and or to come closer to the markets.

In between the order- and the market-producing companies we find the companies developing industry-to-industry solutions. R\&D is a key activity of these companies. As with the market producing companies, 
they try to keep R\&D and pilot production closely related in domestic milieus. They attempt to outsource their volume production close to markets or in cheap labour areas. They do not produce for the end-user. Rather, they facilitate other companies in developing and improving their products. These kinds of companies are in fact suppliers; however they are not generic suppliers but strategic and innovative suppliers.

\subsubsection{Policy recommendations}

Two kinds of recommendations for regional policies are worth further consideration. First, the typology emphasises the relevance of two kinds of knowledge: analytical and synthetic. In the current debates on regional policy and education, greater emphasis is upon analytic knowledge, as represented by our universities. What seems relevant to order-producing companies are tailored education programmes, eventually on a consultative basis, that are more appropriate for improving the needs contextualised problem-solving in connection with concrete production tasks.

The second recommendation is to further investigate the existence of clusters of specialised subcontractors. Often mentioned are the stainless steel subcontractors in the Triangle region. Since much of the knowledge and innovation is developed by suppliers, it is likely that competiveness is not just related to the producing company but also to the competencies of the suppliers.

\subsection{References}

Danish Ministry of the Environment (2006). The New Map of Denmark - Spatial Planning under New Conditions. The 2006 National Planning Report - in Brief. Copenhagen: Danish Ministry of the Environment.

Moodysson, J., Coenen, L., \& Asheim, B. (2008). Explaining spatial patterns of innovation: analytical and synthetic modes of knowledge creation in the Medicon Valley life-science cluster. Environment and Planning A 40, 1040-1056. 



\section{Part 2 - Finland}

Timo Lautanen ${ }^{2}$, Pasi Saukkonen and Heikki Eskelinen

2 † Timo Lautanen, our friend, committed colleague and skilled researcher passed away September 22nd 2012 just after finalising the Finnish country report, for which he was the main responsible person. 



\section{Introduction}

High and medium-high technology industries represent about $16 \%$ of the total number of industrial establishments and $37 \%$ of the industrial turnover in Finland. The value of high technology exports was on average about EUR 10 billion per year in 2000-2008, but has dropped to less than half of this during the last three years (see Figure 5.1). At the same time, the proportion of high technology industries of the total exports of Finland has decreased from over 20\% to 8\% in 2011.

The growth of high technology production and exports in Finland in the 1990s was strongly dominated by one company; mobile phone producer Nokia. The growth of high technology production and exports was especially intense during the latter part of the 1990s as a result of the expansion of domestic operations by Nokia. However, during the last years the dominance of Nokia in these figures and the economy in general has diminished due to the partial relocation and decline of Nokia's activities. At the same time, pressure to activate smaller high technology companies to grow fast has increased. This resulted in the renewal of national growth and innovation policy to better and more efficiently support the growth of these companies.

Figure 5.1. Value of high technology exports (blue column) and imports (red column) in Finland, 1995-2011, billion EUR (source: Finnish Customs, 2012)

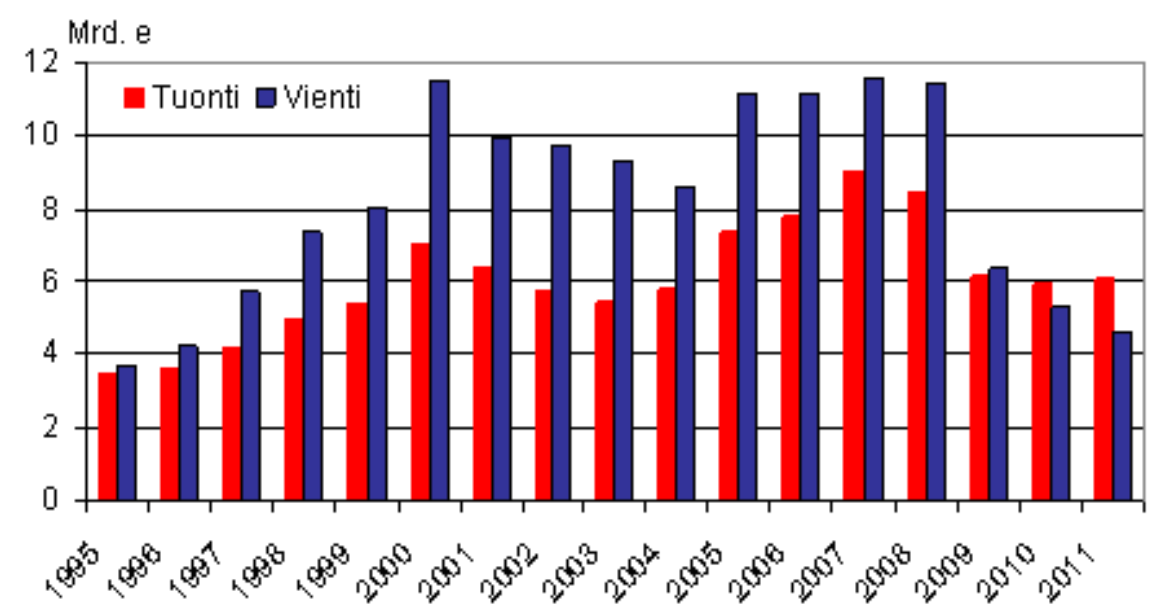

In the present URAGO study of fast growing technology companies our interest lies in the geographical dimensions the supplier, development and ownership networks of the companies located in national and regional centres. In the present, Finnish part of the study, the regional 
focus is however to some extent different from the other national studies of the project. In particular, the focus has been on companies located in smaller regional centres of Eastern Finland - not in the largest national or regional centres. This choice is grounded in the fact that some of the policy measures currently debated in innovation policy in Finland may have important implications especially for the smaller regional centres (this will be clarified in Section 2 below).

In practice, this study focuses on growing technology companies in three regional centres in Eastern Finland, which is on average characterized by sparse population and long distances between urban centres. The total number of inhabitants in the region is about 700,000, with less than $40 \%$ of these in the three regional centres. In recent decades, distinctive features of this region include a diminishing and aging population as well as a slower economic growth and higher unemployment rate as compared to the country's average. Another distinctive feature of the region is that it is located at Finland's (and EU's) border with Russia, rendering it geographically close to the Russian markets.

The technological capabilities in the region are most importantly based on the utilization of natural resources (such as forests) as well as health care technologies.

The Finnish research team consisted of three persons from the Spatia Centre for Regional Research of the University of Eastern Finland. The project was led by research manager Timo Lautanen, who also made all the interviews and took part in analysis of the data and reporting. Researcher Pasi Saukkonen was responsible for collecting the secondary materials regarding the case study companies, collected earlier literature and also was engaged in all the interviews with the case study companies. Professor Heikki Eskelinen worked as an expert on the project and provided valuable comments throughout the research process. In the very beginning of the project, research trainee Alisa Piipponen gathered some publicly available materials on the potential target companies for the study. Matti Fritsch carried out language editing and prepared the maps.

The report consists of the following sections. Section 2 below begins with a review of earlier research approaches to high tech enterprises and their networks in Finland, and an account of the policy framework. In addition, the regional distribution of high and medium tech industries is described here. Next, the report depicts the regional characteristics of eastern Finland, whose regional centres are the targets of this study (Section 3). The selection process of the case study companies are explained in Section 4. The last two sections discuss the findings from the interviews conducted and present conclusions. 
The data materials utilized in this study are largely based on interviews carried out in the case study companies. We do not, however, present the detailed interview reports from the case study companies due to the confidential nature of this material. During the interviews it was emphasized to the interviewees that the materials will be presented anonymously. However, the original reports were presented to the research group and they also have been verified by the interviewees during the research process. 



\section{Background and policy context}

\subsection{Previous research}

Inter-firm collaboration and networks have been investigated quite widely in Finland, but these studies do not typically consider the networks from a geographical point of view. The most common approaches focus on clusters and the competitiveness of companies, as well as innovation activity and regional innovation systems. In addition, the network structures of companies located in different types of localities have acquired attention in the Finnish research literature in this field of study. Table 6.1 presents observations from six empirical studies that report empirical evidence from Finland. Two of these studies focus on high technology industries or KIBS services (Jauhiainen and Suorsa 2008, Smedlund and Toivonen 2007). Although the other ones (Varis and Littunen 2012; Ala-Rämi and Suorsa 2012, Kautonen 2006, Virkkala 2007) deal with a broader group of enterprises, their findings are relevant for the URAGO's approach due to the fact that they investigate innovation activities. To our knowledge, research with a specific focus on fast growing high and medium-technology companies and their geographical dimensions has so far been non-existent in Finland.

Due to the small number of observations and the specific research settings of the studies, there is no scope for generalizations related to the study at hand. Some observations, however, are interesting from the point of view of the present study. First, the study of innovative high tech companies located in the peripheral regions of Northern Finland suggests that these companies tend to co-operate more often than other enterprises in the region (Jauhiainen et al. 2008). Innovation environments are multi-level and there do not seem to exist particular innovation-related systemic inter-firm entities that are formed at the regional level. However, companies may have important linkages to regional labour markets, higher education institutes and other science and technology infrastructure in the region (Kautonen 2006). In addition, Varis et al. (2012) observe a positive linkage between innovation and interregional/international networking. Virkkala (2007), who studied small and medium-sized companies in the "Oulu South" region, proposes that companies gained appropriate knowledge mostly through their clients located in the region. The response of the studied companies to globalization has been to upgrade skills and to take outsourcing as an oppor- 
tunity. Specifically, the enterprises studied had utilized co-location of firms belonging to highly specialized industrial niches and the proactivity of local knowledge institutes to upgrade their competitiveness.

Networks for production, development and innovation can be distinguished according to their character and the type of knowledge utilized in these networks. Networks for production emphasize explicit knowledge, networks for development emphasize tacit knowledge and networks for innovation emphasize emergent, potential knowledge (Smedlund et al. 2007). Regarding ICT technologies and inter-firm collaboration, Äla-Rämi (2007) suggests that ICT does not render geographical location and distance insignificant factors, at least not in high technology development. Instead, geographical location and clustering remain a positive factor for knowledge transfer, and face-to-face meetings remain as a widely used method of communication. 


\section{Study}

Author(s)

objective

The Regional Mika Kauto-

Innovation nen

The main concepts of the regional innovation system approach are scrutinized empirically by testing their relevance and applicability. Secondly, suggestions, critical notions and ideas System Bot-
tom-up: A

Finnish Per-

spective (2006)

Triple Helix in the periphery: the case of Multipolis in Northern Finland (2008)

SMEs and Their Peripheral Peripheral
Innovation Environment: Environment:
Reflections from a Finnish Case (2012)
Jussi Jauhiai- This study analyses how high-technology enterprises in Northnen, Katri Suorsa ern Finland collaborate with higher education and research the public sector initiative "Multipolis" is managed as an innovation network. Multipolis fosters high technology deve innovation network. Multipolis fosters high technology deve-
opment based on Triple Helix co-operation in the peripheral

Northern Finland.

The research answers three questions in relation to the Multipolis case. Firstly, it investigates the existence of the resources needed in high-technology development in peripheries. Secondly, it examines whether networked high technology enterprises are more successful and innovative than those that do not collaborate. Thirdly, it analyses the organization of the Multipolis network as a Triple Helix, a purposefully created and managed network intended to bring together public and private actors under innovation policy programmes.

Miika Varis, The study investigates whether the entrepreneurs of innovaHannu Littunen

tive and less-innovative SMEs perceive the quality of their regional innovation environment differently. The factors investigated include the quality of regional kno factors investigated nclude the qually of reglonal knowledge and production infrastructures, regional institutional and physica environments, the quality and availability of labour force, the quality of the living environment and the quality and avaliabi-
ity of public and private support services. In addition, it is ity of public and private support services. In addition, it is investigated whether there are differences in the entrepreneurs' perceptions about the need to increase public support for innovation and whether public financial support has had a positive impact on firms' performance and competences. The purpose is also to find out whether the geographical reach of firms' important innovation-related connections differentiates innovators from non-innovators and whether the innovativeness of firms is associated with their location within the region or in their industry.

\section{Data and Methodology}

Quantitative and qualitative method. The study is based on two connected firm-level datasets. The first one consists of a survey with 360 respondent firms and business units and the second one of 35 firms based on 38 executive interviews.

Statistics (e.g. high tech enterprises, R\&D), semistructured telephone interviews in 2004 (217 enterprises). The policy orientation of Multipolis in traced through thematic interviews conducted in 1996-2007 (10 key person in this network

Postal questionnaire sent to 1282 owner-managers of small firms located in the Norther

Savo region in 2006, 264

eligible questionnaires were

received (response rate 21\%).

\section{Case study}

Manufacturing and business services industries in Tampere and Jyväskylä regions in

Finland.

\section{High technology enterprises in} 14 localities outside the Oulu FUR as well as enterprises within the Oulu FUR, Norther Finland.

Small firms in the Northern Savo region

(a)

\section{Results}

There are no particular innovation-related systemic inter-firm entities formed at the regional level. On this basis, it is concluded that innovation systems or environments are spatially multilevel. The study reveals many regional-level ties and linkages that are important for innovation activities, such as regional labour markets, universities and other science and technology infrastructure in the two regions.

High technology-related material and social resources are scarce and geographically very unevenly distributed in Northern Finland. There is one major concentration of resources in the Oulu FUR and smaller ones scattered in this wide territory. Skills are very limited, thus active networking to find synergies and complementaries related to high technology is necessary. Innovative high-technology enterprises in peripheral Northern Finland co-operate more often than other enterprises. They rely in their co-operations mostly on the nearest higher education institutes. The Triple Helix in the Oulu FUR has much to do with geographical proximity. The Triple Helix culture does not seem to work easily through the Internet for various social and technical reasons.

By identifying differences between the perceptions of innovative and less-innovative firms, the study contributes to the literature on innovation as a regional-level phenomenon and also tentatively puts forward some managerial and policy implications, as well as suggestions for further research. A positive association between innovation and interregional/international networking is observed. Entrepreneurs aiming their firms should roduct and market innovation potential of their firms should realize the need to look beyond the boundaries of the local environment and to form collaborative contacts elsewhere in the country and also at the international level. Th use of different intermediaries would be a useful strategy, as they may potentially act as bridge builders between local firms and actors and markets located far away. A positive association between firms' performance and public innovation subsidies in the innovator group is observed. 


\begin{tabular}{|c|c|c|c|c|c|}
\hline Study & Author(s) & Objective & Data and Methodology & Case study & Results \\
\hline $\begin{array}{l}\text { Networking, } \\
\text { communication } \\
\text { and proximity } \\
\text { in high- } \\
\text { technology } \\
\text { enterprise } \\
\text { collaboration: } \\
\text { Case of North- } \\
\text { ern Finland } \\
\text { (2007) }\end{array}$ & $\begin{array}{l}\text { Katariina Ala- } \\
\text { Rämi }\end{array}$ & $\begin{array}{l}\text { Research questions: } \\
\text { How do high-technology enterprises choose and network with } \\
\text { their collaboration partners? } \\
\text { How does proximity influence inter-firm collaboration? } \\
\text { What kind of role do different modes of communication have } \\
\text { in inter-firm collaboration? } \\
\text { Can ICT substitute face-to-face contacts in developing high- } \\
\text { technology? }\end{array}$ & $\begin{array}{l}\text { The first two articles focus on } \\
\text { the meaning of networking, } \\
\text { communication and proximity } \\
\text { in high-technology companies. } \\
\text { The data covers } 77 \% \text { of all high } \\
\text { technology companies in } \\
\text { Northern Finland. The third } \\
\text { article is based on a survey of } \\
\text { software companies. For the } \\
\text { fourth article thematic inter- } \\
\text { views were conducted in three } \\
\text { software companies. }\end{array}$ & $\begin{array}{l}\text { Small and medium sized } \\
\text { company in Northern Finland }\end{array}$ & $\begin{array}{l}\text { ICT does not make geographical location and distance insignifi- } \\
\text { cant factors, at least not in high-technology development. } \\
\text { Geographical location and clustering are still an advantage to } \\
\text { knowledge transfer, and face-to-face meetings remain as a } \\
\text { widely used method of communication. Temporary clustering } \\
\text { with global actors is also vital for enterprises to receive up-to- } \\
\text { date information and credibility. ICT helps collaboration and is } \\
\text { more important when the collaboration partners are physically } \\
\text { distant. }\end{array}$ \\
\hline $\begin{array}{l}\text { The role of } \\
\text { KIBS in the IC } \\
\text { development } \\
\text { of regional } \\
\text { clusters (2007) }\end{array}$ & $\begin{array}{l}\text { Anssi Smed- } \\
\text { lund, Marja } \\
\text { Toivonen }\end{array}$ & $\begin{array}{l}\text { To introduce the concept of knowledge-intensive business } \\
\text { services (KIBS) in the context of regional networks and to } \\
\text { analyze the roles of KIBS in regional development, especially } \\
\text { from the viewpoint of regional intellectual capital.The roles of } \\
\text { KIBS are analysed in three types of regional networks that each } \\
\text { require a specific kind of information: } \\
\text { production networks; explicit knowledge } \\
\text { development networks; tacit knowledge; and } \\
\text { innovation networks; potential knowledge. }\end{array}$ & $\begin{array}{l}\text { Drawing from recent litera- } \\
\text { ture, the roles of KIBS in } \\
\text { regional networks are dis- } \\
\text { cussed. }\end{array}$ & $\begin{array}{l}\text { This is a review, based on } \\
\text { earlier empirical studies made } \\
\text { by the authors in Finnish } \\
\text { regions and companies. }\end{array}$ & $\begin{array}{l}\text { Networks for production emphasize explicit knowledge, net- } \\
\text { works for development emphasize tacit knowledge, and net- } \\
\text { works for innovation emphasize emergent, potential } \\
\text { knowledge. KIBS provide the timely information needed in } \\
\text { production networks, transfer best practices that support } \\
\text { learning in development networks, and function as sources of } \\
\text { innovation and facilitators of innovation processes in innovation } \\
\text { networks. }\end{array}$ \\
\hline $\begin{array}{l}\text { Innovation and } \\
\text { Networking in } \\
\text { Peripheral } \\
\text { Areas - a Case } \\
\text { study of } \\
\text { Emergence and } \\
\text { Change in } \\
\text { Rural Manufac- } \\
\text { turing (2007) }\end{array}$ & Seija Virkkala & $\begin{array}{l}\text { The study examines the features of successful forms of innova- } \\
\text { tion in rural areas characterized by geographical distance and } \\
\text { sparse population. The core questions are: } \\
\text { How firms compensate for the lack of a dense local network? } \\
\text { How rural clusters are emerging and changing? } \\
\text { How firms acquire knowledge for innovation processes? } \\
\text { How firms face the challenges of globalization, notably at the } \\
\text { level of value chains. }\end{array}$ & $\begin{array}{l}\text { The case study data cover } \\
\text { electronics cluster related to } \\
\text { wireless communication. The } \\
\text { primary data is based on } 22 \\
\text { interviews, } 10 \text { with represent- } \\
\text { atives of supporting agents } \\
\text { and } 12 \text { with representatives of } \\
\text { firms (gathered in two phases, } \\
\text { in December } 2002 \text { and May- } \\
\text { September 2004). Nine of the } \\
\text { firms were operating in } \\
\text { manufacturing and three } \\
\text { mainly in planning or R\&D. } \\
\text { Typical size of the firm was 5- } \\
50 \text { people. }\end{array}$ & $\begin{array}{l}\text { The case study area can be } \\
\text { referred to as "Oulu South," } \\
\text { located } 100-200 \mathrm{~km} \text { south of } \\
\text { Oulu (Northern Ostrobothnia). } \\
\text { Oulu South lacks a clear } \\
\text { regional centre, but is instead } \\
\text { a networking unit formed by } \\
\text { three equally large sub- } \\
\text { regions. }\end{array}$ & $\begin{array}{l}\text { The study shows how an agricultural region has been able to } \\
\text { develop a new industrial position in the interplay of national } \\
\text { and regional factors. This was made possible by two factors: co- } \\
\text { location of firms belonging to highly specialized industrial } \\
\text { niches and the pro-activity of local knowledge institutes. } \\
\text { Relevant SMEs in Oulu South gained appropriate knowledge } \\
\text { mostly through their clients located in the region. The second } \\
\text { important source was innovation cooperation between SMEs } \\
\text { and Centria Ylivieska (regional polytechnic). } \\
\text { The response to globalization by local firms was to upgrade } \\
\text { skills and to take outsourcing as an opportunity. In Oulu South } \\
\text { this means a change to more R\&D based activities and improv- } \\
\text { ing local firms' absorptive capabilities, within an overall ambi- } \\
\text { tion to shift forward in the value chain. }\end{array}$ \\
\hline
\end{tabular}




\subsection{Domestic policy framework}

In Finland, the growth of high tech companies is in the focus of recent renewals of the innovation policy. In addition, these renewals are related to the discussion concerning the connections between regional and innovation policies.

In recent years, the Finnish innovation system has been subject to major changes aiming at making it more efficient. These changes include, for instance, the University inventions act (1997), Universities act (2010) and the National innovation strategy (TEM 2008, see also IEFNIS 2009a and 2009b, TEM 2010). The aims and measures of Finnish innovation policy are also reflected in the alignments of the Research and Innovation Council for the years 2011-2015 (TIN 2010) and the strategy of the Finnish Funding Agency for Technology and Innovation 2012 (TEKES 2011).

The priorities of the research and innovation policy currently include, among others, the following:

- Growth intensity and internationalization of enterprises.

- High level science and research environments.

- Demand driven innovation.

- Regional centres of innovation.

- Decreasing the number of universities and polytechnics and increases in their efficiency.

- Commercialization of research-based inventions.

Regional centres of innovation have received much attention in the recent revisions of innovation and regional policy. The concept is mentioned in several key documents, such as the International Evaluation of Finnish National Innovation System (IEFNIS 2009a and 2009b), Government Decision-in-Principle on Urban Policy (TEM 2009) and Finland's Regional Development Strategy 2020 (TEM 2010b). The concept of innovation centre also plays an important role in the national innovation strategy. Its frame of reference is derived from the assumed characteristics of a good innovation environment in which the spatial concentration of innovations is argued to strengthen and these processes. Earlier it was thought that the process of invention and innovation is science- and technology-led and is located within organizations and companies, whereas today innovation processes are argued to be interactive and collaborative, that is, involving also end users.

From the policy point of view, the above outlined conceptualization of innovative processes is interesting for the obvious reason that if preconditions for innovations are conditioned by regional or local circumstances, they can also be created at least to some extent. However, the 
evaluation report of the Finnish innovation system presents observations on uneven development of productivity at the NUTS 2 level. Productivity has increased most rapidly in those regions where the firm structure has changed the most. This type of "creative destruction" has been most pronounced in southern Finland, whereas it has been slower in eastern Finland and in remote areas. Thus it is argued in the evaluation report (op. cit., p.17) that the policies may have protected jobs in the less productive industries, made companies dependent on public support and solidified company structures outside the centres. Deriving from this finding, the report suggests that competition and productivity should be improved by increasing competition. In addition, it is emphasized that growth will be centered in and around cities and that there should be made a difference between policies supporting innovation and policies aiming at decreasing inter-regional differences in development.

The policy outlines of the Research and Innovation Council for the years 2011-2015 (TIN 2010) also underline the view that the best resources for the creation of attractive centres of innovation are generally to be found in the largest cities. Yet, this is neither understood to mean earmarking of national resources for innovation policy for certain regions nor choosing the central regions of the country as target regions for this policy. Further, it is noted that in many regions the cities and higher education institutions have already started to create highstandard competence centres on their own initiative.

\subsection{Regional distribution of high and medium technology industries in Finland}

As can be seen in Figure 6.1, high technology industries are heavily concentrated in a few regions in Finland. The leading regions in this respect are the capital region and the regions around the urban centres of Tur$\mathrm{ku}$, Tampere and Oulu. As to the medium technology industries, the regional distribution is more even, and many regions of the western part of the country play an important role. 
Figure 6.1. Regional distribution of high (left) and medium (right) technology turnover in Finland, 2010 (data source: Statistics Finland, 2012)
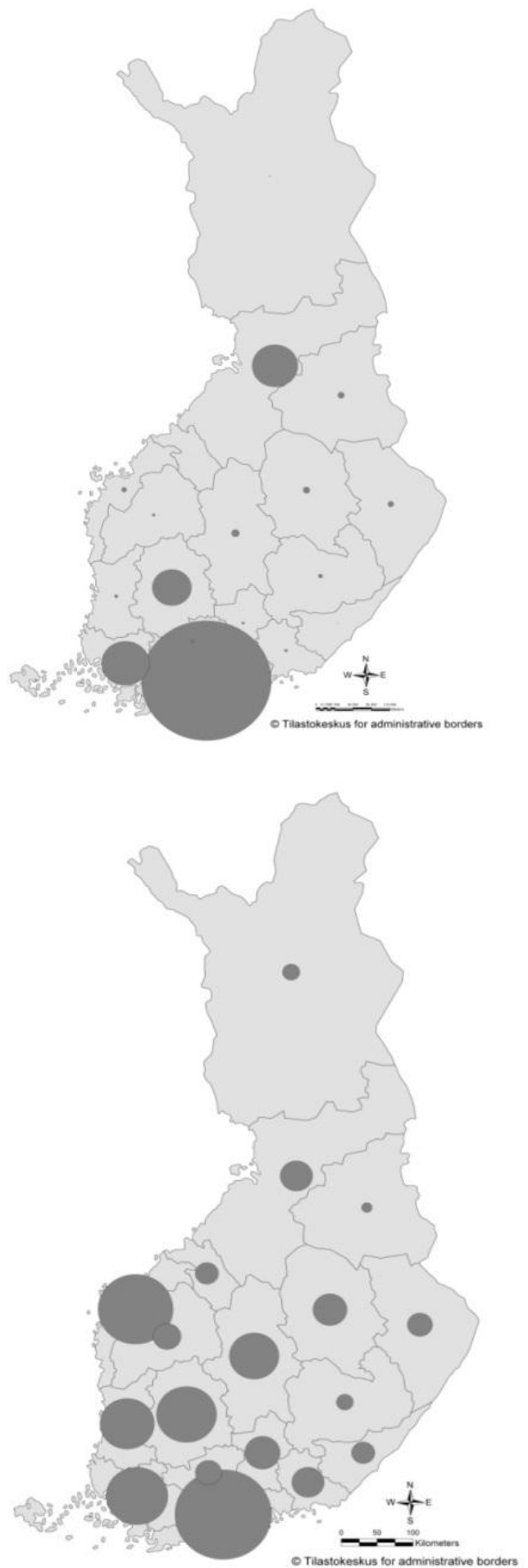

Figure 6.2 describes the role of high and medium technology industry in different regions. The most distinctive difference is that medium technology industry is not as spatially concentrated as high technology industries, but 
seems to play an important role in several parts of the country covering both the western and eastern part of the country (Vaasa, Kokkola, Jyväskylä, Kuopio, Joensuu).

Figure 6.2. Regional specialization in high (left) and medium (right) technology in Finland, 2010 (location quotients; data source: Statistics Finland, 2012)

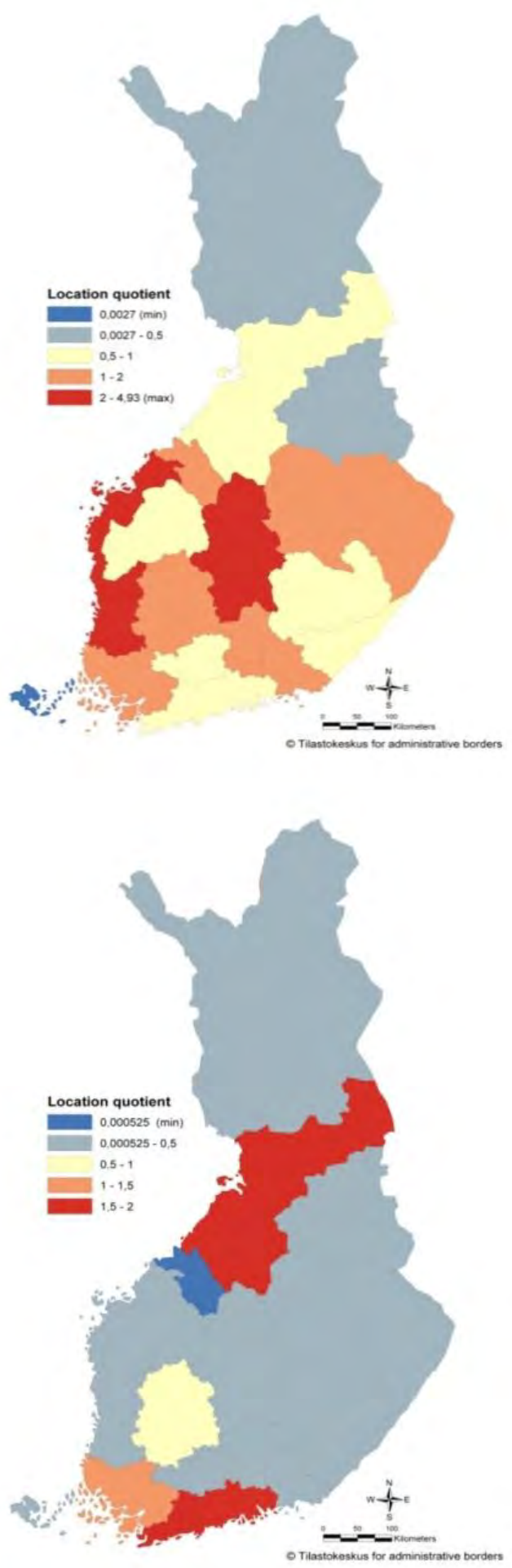




\section{Regional characteristics of eastern Finland}

\subsection{Basic information}

Eastern Finland is not a well-established institutional or functional region. Here, it is defined to consist of the (NUTS 3) regions of North Savo, North Karelia and South Savo. The regional centres of these three regions are Kuopio, Joensuu and Mikkeli, each having population numbers between 50,000 and 100,000. Among the 336 Finnish municipalities, Kuopio is the $9^{\text {th }}$ largest whereas Joensuu and Mikkeli are $12^{\text {th }}$ and $20^{\text {th }}$ largest.

Table 7.1. Number of population and population density of the examined regions

\begin{tabular}{lrrrr}
\hline NUTS 3 region & $\begin{array}{c}\text { Number of } \\
\text { inhabitants }\end{array}$ & $\begin{array}{r}\text { Population } \\
\text { density }\end{array}$ & Regional centre & $\begin{array}{r}\text { Number of inhabitants } \\
\text { of the regional centre }\end{array}$ \\
\hline North Savo & 274,943 & 15 & Kuopio & 96,793 \\
North Karelia & 165,866 & 9 & Joensuu & 73,305 \\
South Savo & 114,668 & 12 & Mikkeli & 48,751 \\
Eastern Finland & 568,774 & Total & 218,849 \\
\hline
\end{tabular}

Source: Statistics Finland, population 31.12.2010.

Eastern Finland is sparsely populated and characterized by long distances between the regional capitals. Its distinctive features include a decreasing and aging population and a slower economic growth as well as higher unemployment rate than the country on average. Also intra-regional differences in levels of development have grown as a result of the increasing spatial concentration of population in the main cities combined with a concomitant population decline in more remote areas. A specific characteristic of the region is its location at the external border of the European Union. Eastern Finland borders on the Republic of Karelia, which is a comparatively lagging region in the Russian Federation.

The occupational structure of eastern Finland is characterized by a relatively large public sector. The share of the service sector in the total number of companies is about one third. The most important industrial sectors are the production of wood products, metal products, machinery and equipment as well as foodstuffs. Export-oriented and fast growing industries are scarcer than in Finland on average. Structural change has been most pronounced in the forest-based industries, which have witnessed thousands of job losses during the last few years. 


\subsection{Higher Education and Expertise}

The most significant actors in higher education and research activities called expertise structure in the Finnish jargon of innovation policy - in the region are the University of Eastern Finland (campuses in Kuopio, Joensuu and Savonlinna) and three polytechnics (main campuses in Mikkeli, Kuopio, and Joensuu).

The research priorities of the University of Eastern Finland are forests and the environment, health and well-being, and new technologies and materials. New developing areas of expertise include broad-based expertise pertaining to Russia and certain fields of teacher education. In addition to the University of Eastern Finland, there are smaller units of the Lappeenranta University of Technology, University of Helsinki and Aalto University in the region.

The research institutes located in eastern Finland are closely related to the above-mentioned expertise areas at the higher education institutes: health, forests and other natural resources (see Table 7.2). The headquarter of the European Forest Institute (EFI), the leading international organization in its field, is located in the region. The subsidiaries of national research institutes located in the region, such as the Finnish Forest Research Institute (Metla), the Geological Survey of Finland (GTK), the National Institute for Health and Welfare (THL), the Finnish Food Safety Authority Evira and the MTT Agrifood Research Finland have specialized roles in the internal division of labour of their organizations (see Hirvonen \& Lautanen 2011).

\begin{tabular}{|c|c|c|c|}
\hline $\begin{array}{l}\text { European Forest } \\
\text { Institute }\end{array}$ & Joensuu & 130 & $\begin{array}{l}\text { Multiple use of forests, climate change, } \\
\text { forest energy, forest sector manage- } \\
\text { ment and future }\end{array}$ \\
\hline $\begin{array}{l}\text { Finnish Forest Re- } \\
\text { search Insitute }\end{array}$ & Joensuu & 130 & $\begin{array}{l}\text { Wood materials and wood-based value } \\
\text { chains, forest-based bioenergy, forest } \\
\text { resources and planning }\end{array}$ \\
\hline $\begin{array}{l}\text { MTT Agrifood Research } \\
\text { Finland }\end{array}$ & Maaninka, Mikkeli & 60 & $\begin{array}{l}\text { Milk production farms, organic produc- } \\
\text { tion and sustainable production systems }\end{array}$ \\
\hline $\begin{array}{l}\text { Geological Survey of } \\
\text { Finland }\end{array}$ & Kuopio, Outokumpu & 50 & $\begin{array}{l}\text { Operations serving mining industries and } \\
\text { environmental management }\end{array}$ \\
\hline $\begin{array}{l}\text { Finnish Game and } \\
\text { Fisheries Research } \\
\text { Institute }\end{array}$ & $\begin{array}{l}\text { Tervo, Enonkoski- } \\
\text { Joensuu }\end{array}$ & 40 & $\begin{array}{l}\text { Water and fish culture, research on fish, } \\
\text { game and reindeer }\end{array}$ \\
\hline $\begin{array}{l}\text { Finnish Meteorological } \\
\text { Institute }\end{array}$ & Kuopio & 20 & $\begin{array}{l}\text { Atmospheric fine particles and their } \\
\text { effects on climate and health }\end{array}$ \\
\hline $\begin{array}{l}\text { Finnish Food Safety } \\
\text { Authority Evira }\end{array}$ & Kuopio & 20 & Animal disease bacteriology \\
\hline $\begin{array}{l}\text { VTT Technical Research } \\
\text { Center of Finland }\end{array}$ & Kuopio, Joensuu & 10 & Measuring and sensor technology \\
\hline
\end{tabular}

*Rounded to the nearest 10 employees. 
In addition to the priorities of the higher education institutes, the innovation profile of the region is conditioned by their participation in the national competence clusters (Centres of Expertise programme). The aim of this programme is to enhance technology transfer, generate new expertise-based companies and promote the internationalization of businesses. The centres of expertise in Eastern Finland participate in the national clusters of HealthBIO, Health and well-being, Cleantech, Food development, Energy technology, Tourism and experience, Nanotechnology, Forest industry future and Living business (see Table 7.3). Overall, the most significant areas of innovation-oriented research in the region are related to forest technology, environmental technology, material technology and health and well-being technology.

Table 7.3. National competence clusters in which the Eastern Finnish Centres of expertise participate

\begin{tabular}{ll}
\hline Competence cluster & Centre of expertise \\
\hline HealthBIO & Kuopio \\
Health and well-being & Kuopio \\
Cleantech & Joensuu \\
Food development & Kuopio \\
Energy technology & Joensuu \\
Tourism and experience & Savonlinna \\
Nanotecnology & Joensuu, Mikkeli \\
Forest industry future & Joensuu, Mikkeli \\
Living business & Joensuu
\end{tabular}

\subsection{High and medium-high technology industries in Eastern Finland}

Table 7.4 summarizes information on the number of establishments and employees as well as the turnover of high and medium-high technology firms in Eastern Finland in 2010. ${ }^{3}$ The proportion of the three eastern Finnish NUTS 3 regions examined here is about $10 \%$ of the total number of establishments in these industries in Finland. Measured by the number of employees and turnover, their proportion is smaller (six and three\%, respectively). However, from the regional point of view, high and medium-high technology industries are important, since $24 \%$ of the total number of industrial employees and $24 \%$ of the turnover are found in these industries.

\footnotetext{
${ }^{3}$ According to the NACE Rev2-classification of industries: High technology: 21 Manufacture of basic pharmaceutical products and pharmaceutical preparations, 26 Manufacture of computer, electronic and optical products. Medium-high-technology: 20 Manufacture of chemicals and chemical products, 27 to 30 Manufacture of electrical equipment, Manufacture of machinery and equipment n.e.c., Manufacture of motor vehicles, trailers and semi-trailers, Manufacture of other transport equipment.
} 
Table 7.4. The number of establishments, number of employees, and the turnover of the high and medium-high technology industry in eastern Finland in 2010 (data source: Statistics Finland, 2012)

\begin{tabular}{lrrrrrrrrr}
\hline Region & $\begin{array}{r}\text { Number of } \\
\text { establishments }\end{array}$ & $\begin{array}{r}\text { \% } \\
\mathbf{( 1 )}\end{array}$ & $\begin{array}{r}\text { \% } \\
\mathbf{( 2 )}\end{array}$ & $\begin{array}{r}\text { Em- } \\
\text { ployees }\end{array}$ & $\begin{array}{r}\text { \% } \\
\mathbf{( 1 )}\end{array}$ & $\begin{array}{r}\text { \% } \\
\text { (2) }\end{array}$ & $\begin{array}{r}\text { Turnover, } \\
\mathbf{1 , 0 0 0} \text { eur }\end{array}$ & $\begin{array}{r}\text { \% } \\
\text { (1) }\end{array}$ & $\begin{array}{r}\text { \% } \\
\text { (2) }\end{array}$ \\
\hline North Savo & 154 & 4 & 15 & 3,203 & 3 & 27 & $845-983$ & 1 & 29 \\
North Karelia & 83 & 2 & 12 & 2,207 & 2 & 25 & $472-182$ & 1 & 23 \\
South Savo & 95 & 2 & 13 & 1,270 & 1 & 17 & $219-846$ & 0,4 & 17 \\
Eastern Finland & 332 & 9 & 13 & 6,680 & 6 & 24 & $1,538-011$ & 3 & 24 \\
Finland & 3,874 & 100 & 16 & 117828 & 100 & 37 & $56,880-858$ & 100 & 48 \\
\hline
\end{tabular}

(1) Proportion of high and medium-high technology industry in Finland.

(2) Proportion of manufacturing industries (NACE 10 to 33 ) in the region. 


\section{Selection of the case study companies}

For the identification of suitable case study companies meeting the criteria set of the wider URAGO research framework, several different company registers were utilized. It turned out that the number of companies satisfying all of the criteria was very limited in eastern Finland. The most demanding criteria to fulfill were company size (over $50 \mathrm{em}$ ployees) and its growth history (more than 10 years of growth). In eastern Finland, a typical high and medium technology company is a small firm employing less than 10 persons. The global economic crisis has also led to a decrease in the number of employees in 2009 to 2010.

Table 8.1. The number of high and medium technology enterprises employing at least 50 people in eastern Finland (data source: Statistics Finland, Business Register)

\begin{tabular}{lcc}
\hline & High-technology & Medium-high technology \\
\hline South-Savo & 4 & 14 \\
North-Savo & 4 & 25 \\
North-Karelia & 1 & 26 \\
Eastern Finland & 9 & 65 \\
\hline
\end{tabular}

The preliminary selection process resulted in 15 companies to be target as potential case studies. The managers of seven of these companies were interviewed. Two companies rejected to be part of the study for operational reason; being, for example, involved in the defense industry. The managing directors of the companies were contacted by email or by phone to make appointments for personal interviews. Thereafter they were sent a preliminary description of the company's history and operation based on desk research (utilizing internet, local newspapers, business registers, stock exchange information, etc.) as well the interview agenda. Six of the interviewed managers were CEOs and one was the Head of a business branch. Three of the companies are located in North Savo, three in North Karelia and one in South Savo (see Figure 8.1). 
Figure 8.1. Location of the seven case study companies in the three regional capital cities of eastern Finland

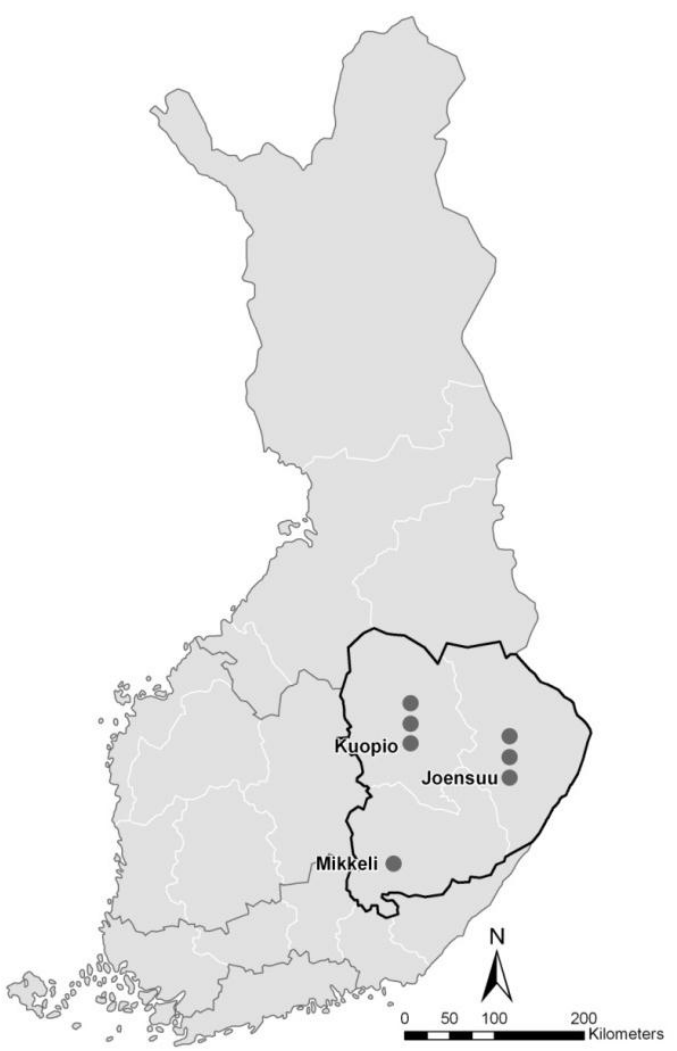

Of the seven firms interviewed, two were involved in high tech or medium tech manufacturing operations, two firms focused primarily on research activities, and three on knowledge-intensive services (see Table 8.2). The firms typically employ 50 to 100 people, and they are organized institutionally as limited companies. Two of the companies are parts of larger listed corporations and one is a member of a private business group. The studied companies have grown rapidly since 2000 and their expansion has not been based on mergers.

Table 8.2. Basic information on the case study companies

\begin{tabular}{llrlrr}
\hline Company & Organization type & Sector* & Type of technology & Personnel** & Growth*** \\
\hline X1 & Plc, group & 28 & Medium techmanufacturing & $250-500$ & $2001-2008>150 \%$ \\
X2 & Ltd, part of a Plc & 72 & Research and testing & $50-100$ & $2006-2010>300 \%$ \\
X3 & Ltd, part of Plc & $72 ; 21$ & Research andmanufacturing & $50-100$ & $2002-2010:>300 \%$ \\
X4 & Ltd, part of a group & $72 ; 71$ & Software, KIBS & $50-100$ & $2005-2011>150 \%$ \\
X5 & Ltd & 62 & KIBS, Software & $20-50$ & $2004-2011>1,000 \%$ \\
X6 & Ltd & 62 & KIBS, Software & $20-50$ & $2004-2011>650 \%$ \\
X7 & Ltd & 26 & High tech manufacturing & $20-50$ & $2001-2011>100 \%$
\end{tabular}

*NACE rev. 2: (21) Manufacture of basic pharmaceutical products and pharmaceutical preparations , (26) Manufacture of computer, electronic and optical products, (28) Manufacture of machinery and equipment n.e.c., (32) Manufacture of radio, television and communication equipment and apparatus, (62) Computer programming, consultancy and related activities , (71) Architectural and engineering activities; technical testing and analysis, (72) Scientific research and development, **According to the latest information available (rounded). ${ }^{* *}$ Growth in terms of the number of personnel. 


\section{Observations from the case studies}

All case study companies have originated in eastern Finland. At least from this point of view, they appear to be rooted in the region. In addition, their connection with the region has generally been strengthened by the development of their operational environment, that is, their location in the eastern part of Finland and the specific benefit that the companies could gain from their location in this specific region. According to the interviews, the most salient benefit or advantages are the availability and low turnover of a competent work force as well as favourable conditions for research, development and innovation activity. The climatic and natural conditions also play a role; they are seen as demanding but stable. In addition, the socio-economic conditions in Finland in general are seen as a clear benefit.

Information from case $\mathrm{X} 4$ suggests that geographical proximity to research and development organizations is not a precondition for a high tech company's growth, even if the company's location is not seen as optimal. Neither does a location in a science park appear to be a precondition for high tech growth or internationalization (X4, X5).

Distance to markets clearly represents a challenge in the case of manufacturing (X1), but also in knowledge-intensive services it causes additional costs. The cases X4 and X6 suggest that life cycle services and after-sales markets can be an important precondition for and source of business in project deliveries, which emphasizes the importance of physical closeness with the customers. This can be seen as a barrier to entering international markets as such a move generally requires the company to establish a unit abroad (cases X4, X5, X6). Companies may also utilize life-cycle services as a source of information needed for the further development of operations (X4, X6).

The supplier types and networks of the case study companies can be generally classified as service producers and suppliers of rawmaterials as well as components. In terms of services, geographical proximity appears to be a decisive criterion in the selection of a supplier. Contrary to this, specialized raw materials suitable for particular purposes of the company as well as specialized high quality components are most often purchased from locations further away in Finland, or from abroad (X1, X2, X3, X4, X7). 
All of the companies invest markedly in product development (or the development of processes and operations in general). Contrary to our expectations, this development is to a large extent an in-house activity, although the companies use customer information and research as a source of information. From a locational point of view, companies consider the stability of their operational environment as an especially important characteristic of their location, in fact this holds true in all cases here. Problems with the current location are mostly related to the remoteness from current and potential new customers (often being located abroad, as in cases X1, X2 and $\mathrm{X} 3$ ). In terms of the acquisition of raw materials and components, long distances, despite causing extra costs, do not form an insurmountable problem (X1, X2, X3, X4, X7).

On the basis of their type of operations, the studied companies can be classified into the following three groups: research companies, process- or project-based companies and product-based companies. The regional dimensions of the supplier and R\&D networks of the five case study companies are depicted in Figures 9.1a - 9.1b and Appendix 1. Table 9.1 presents a tentative typology of the companies, including their characteristics.

Figure 9.1a. Research-based company X3: Location of the most important suppliers and $R \& D$ relationships

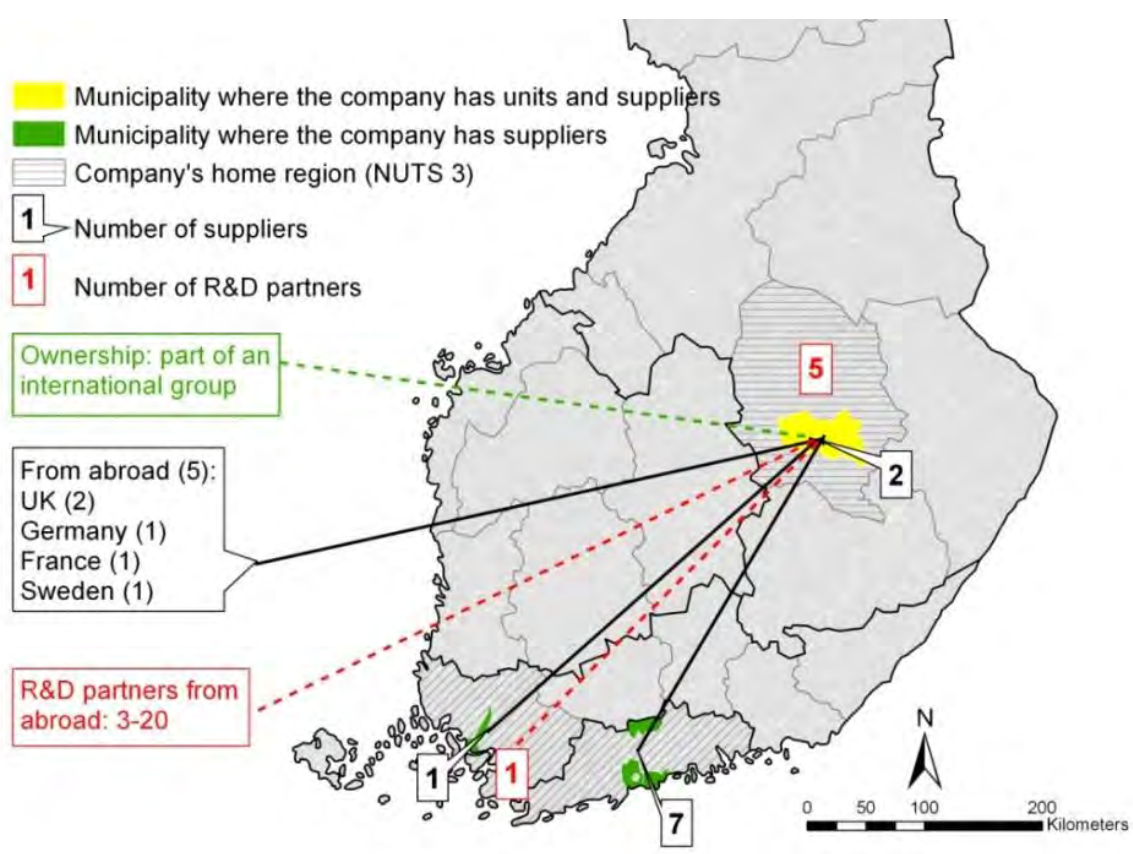


Two of the companies can be classified as research-based companies (X2 and X3). They operate in a truly international operational environment and markets, and are heavily specialized in certain product segments. Their production typically forms part of the product development process of a customer company. They may, however, at the same time engage in intensive development of their own products, with the aim to enter markets with these themselves (X3). Research and development activities in these companies are intensive (X2 and X3) and may also include basic research (X3). The key players in the cooperative networks of these companies include local partners, but to large extent also partners from abroad. The latter pattern, however, appears to be influenced heavily by the foreign ownership of the companies. Cooperation with higher education institutes is also essential for them. In addition to the availability of workforce, the key resources terms of their current operational environment include local competence structures (specialized companies, research institutes, universities and polytechnics) and beneficial conditions for their operation in general (such as specialized production environments, the stability of socio-economic conditions).

Figure 9.1b. Research-based company X2: Location of the most important suppliers and $R \& D$ relationships

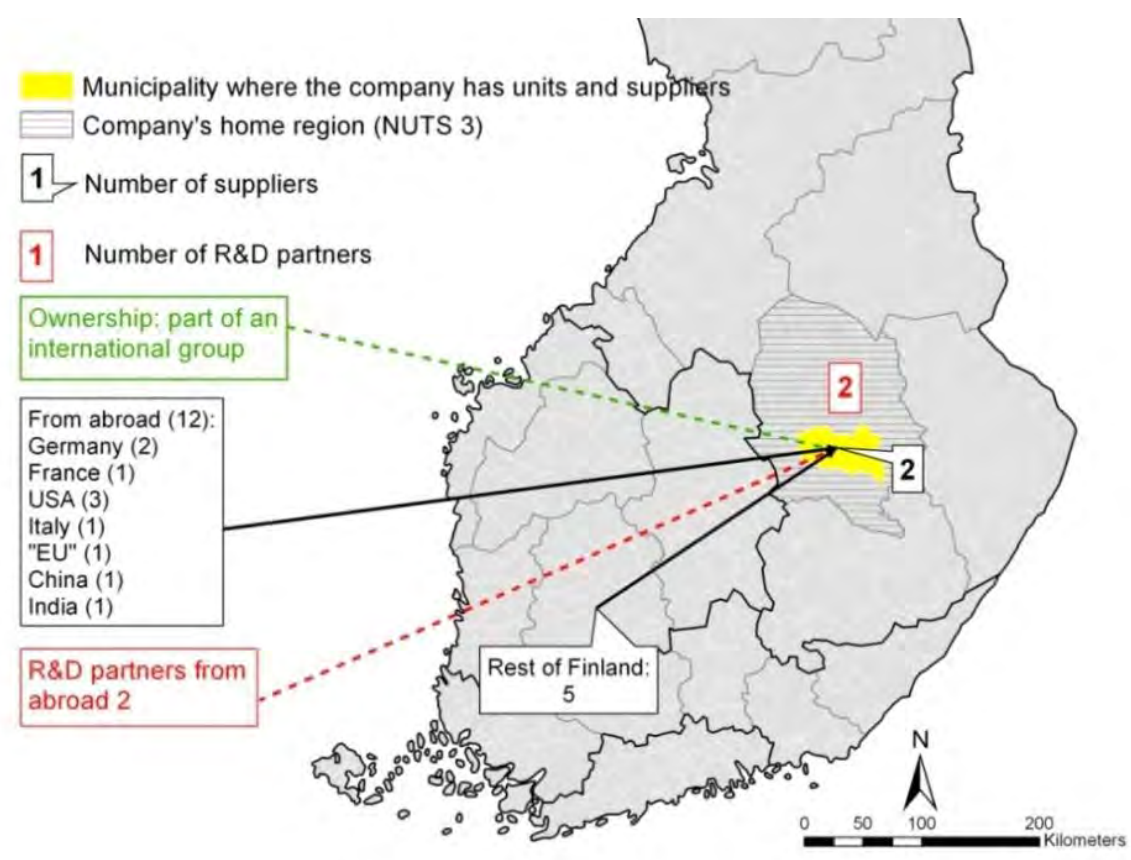


Figure 9.2a. Process-based company X5: Location of the most important suppliers and $R \& D$ relationships

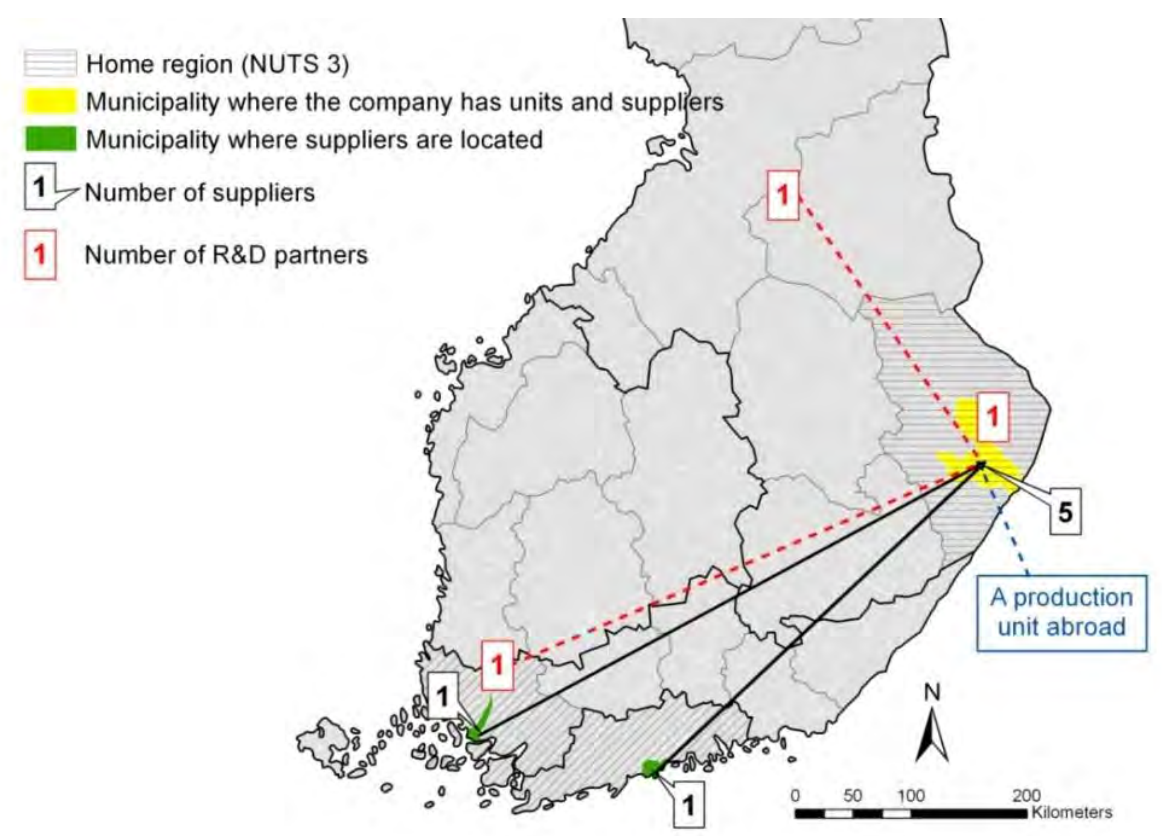

Process- or project-based companies are represented in the research material by three companies (X4, X5 and X6). The customers of these companies particularly include public and semi-public organisations. The typical product is a process or a project, which becomes part of a customer's production of service process. The markets are local or national, whereas the obstacles to enter the international markets are notable. In contrast to the other two types of companies, networks of their most important suppliers include suppliers close to the location of the company or close to the location of the project delivery. Also raw-materials and components are often acquired domestically, even if they would originate from abroad (MNEs). In the local operational environment, the companies particularly appreciate closeness of suitable education facilities and programmes. Product development is important and mostly takes place within the customer projects. 
Figure 9.2b. Process-based company X4: Location of the most important suppliers and $R \& D$ relationships

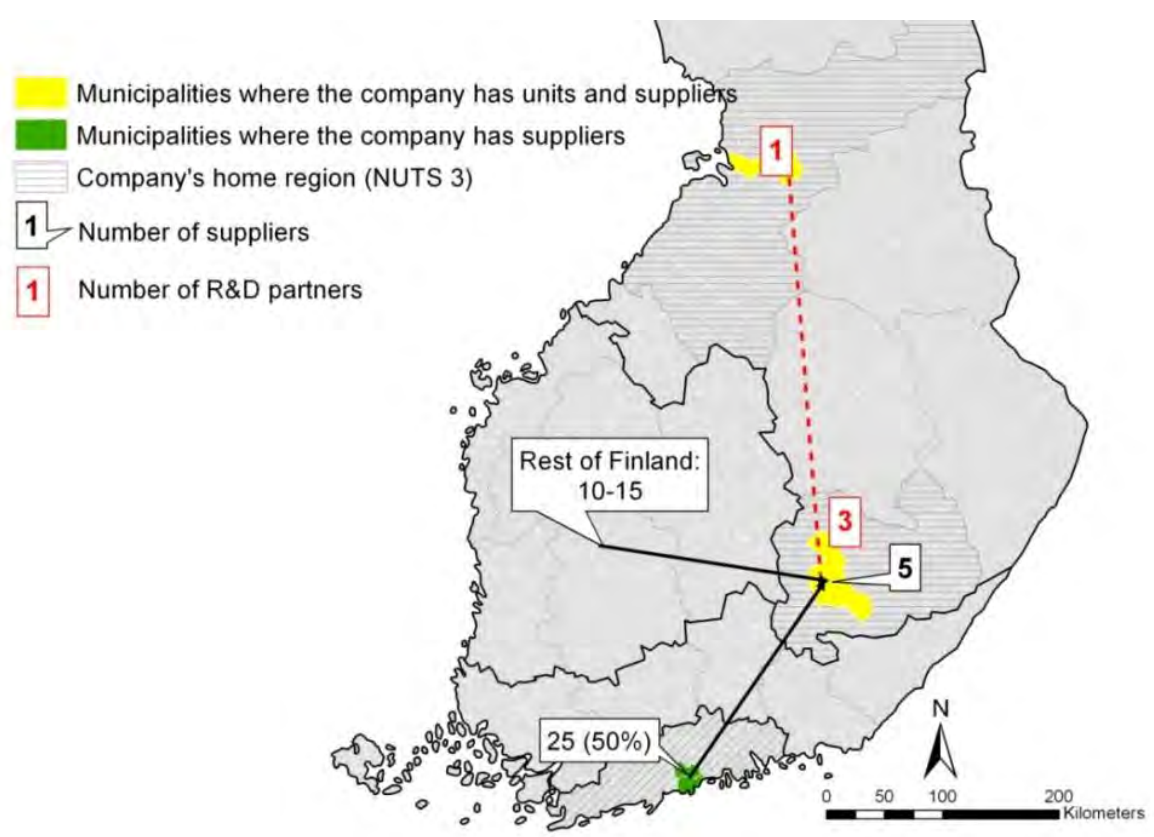

Figure 9.2c. Process-based company X6: Location of the most important suppliers and $R \& D$ relationships

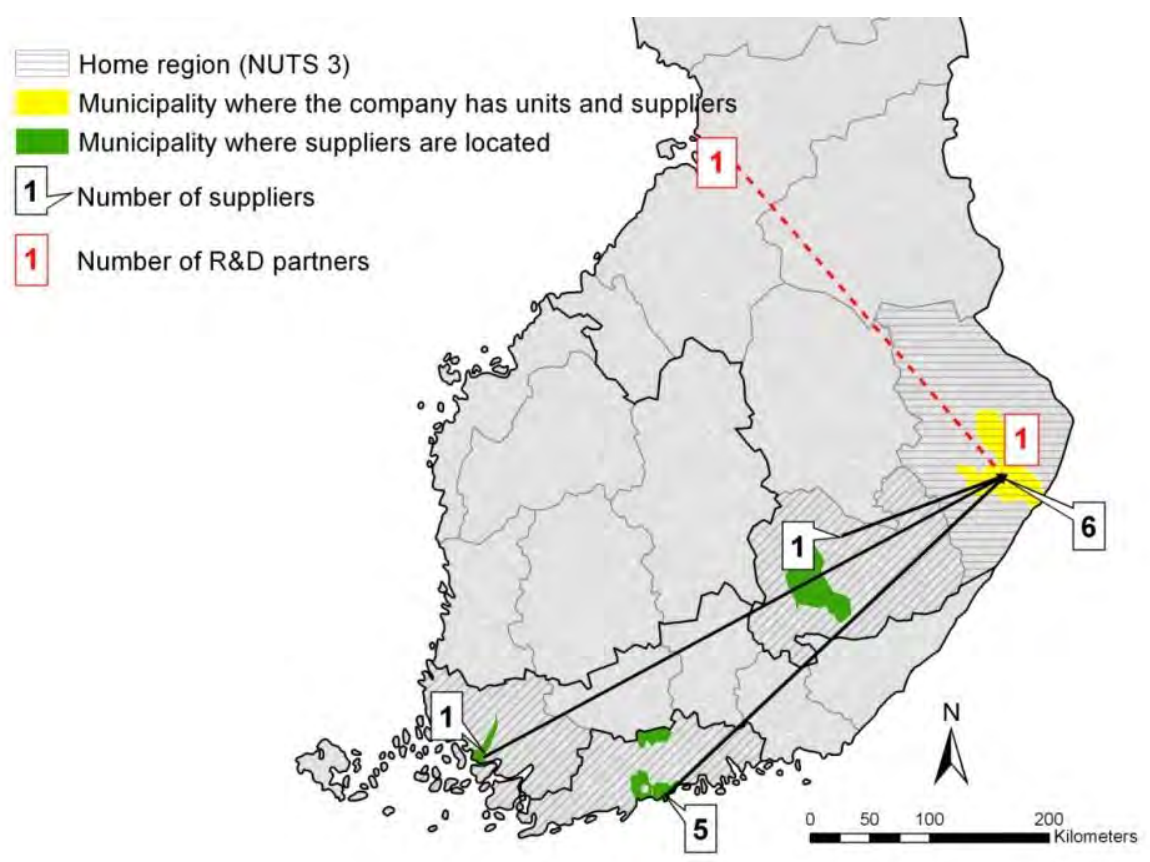


The research material included two production-based companies (X1, X7) that produce final products for private customers (typically small enterprises). The markets for their products are global. The most important suppliers of services (typically via subcontracting) to the company are local, whereas the most important suppliers of raw materials and components are foreign-based due to the limited supply of these in Finland. The companies have their own product development unit. The local region serves as a test site for the companies' products. This means that the companies has a few trustworthy customers that test product prototypes in authentic conditions, which helps them to make needed improvements before taking the products to the wider markets. Typically, other collaborative partners of the firms are other firms that are located elsewhere in Finland. The companies utilize the local competence environment especially for obtaining a suitable work force. This is again related to the lower turnover of workers compared to, for example, the capital region. The companies also cooperate with the region's research institutes. The location of the company is remote from its main markets, which results in the fact that acquiring the raw-materials and components from across long distances causes extra costs.

Figure 9.3a. Product-based company X1: Location of the most important suppliers and $R \& D$ relationships

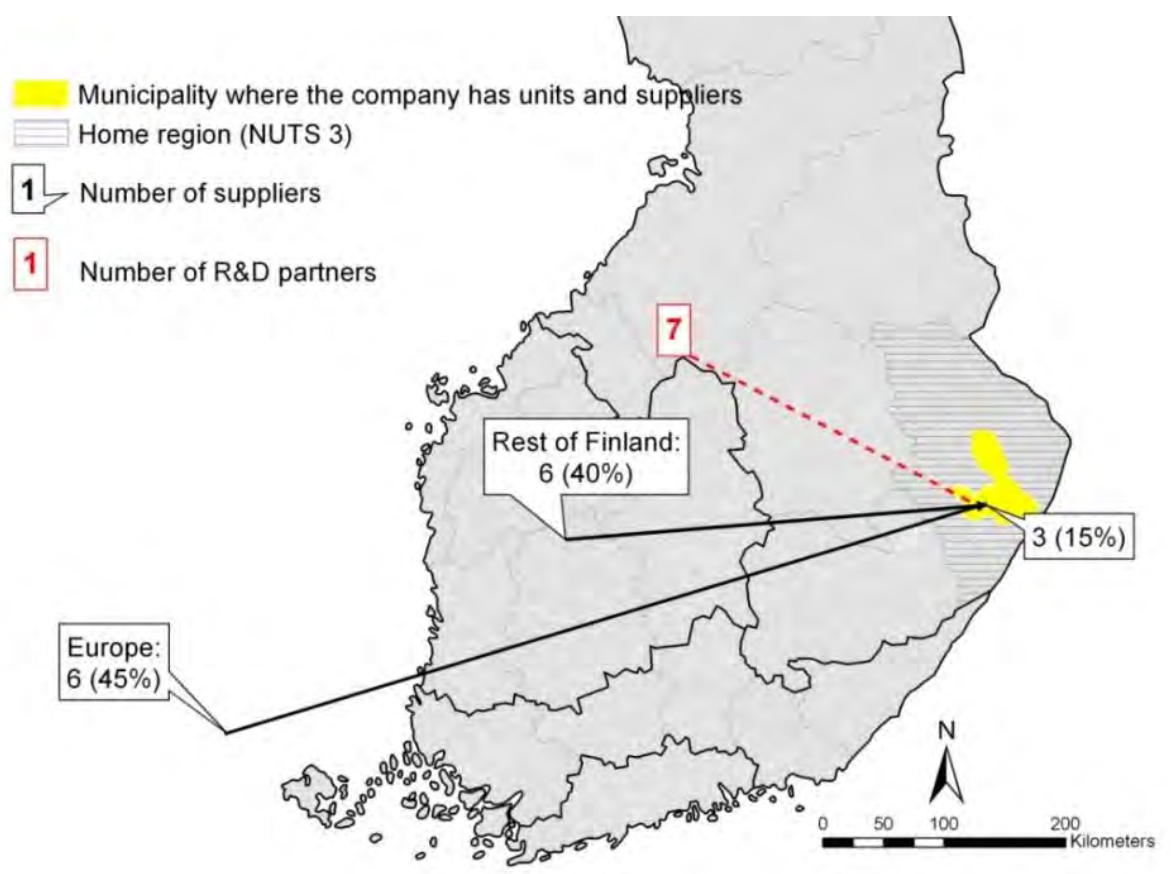


Figure 9.3b. Product-based company X7: Location of the most important suppliers and $R \& D$ relationships

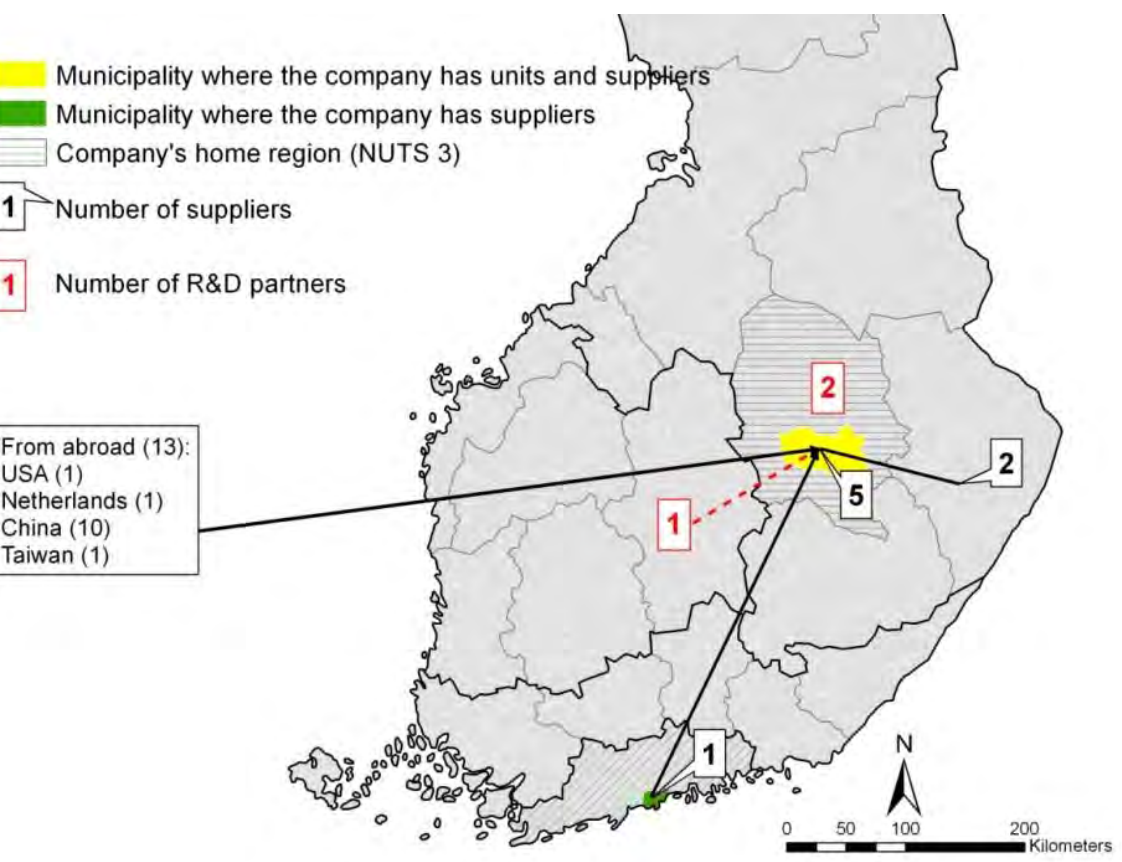

Table 9.1. Typology of companies with their characteristics

\begin{tabular}{|c|c|c|c|}
\hline & Research & Process/project & Product \\
\hline Operations & Research service & Project delivery & Production (partly by order) \\
\hline $\begin{array}{l}\text { Key steps in } \\
\text { production and } \\
\text { marketing }\end{array}$ & Research, commissions & $\begin{array}{l}\text { Planning, conducting the } \\
\text { project, life-cycle services }\end{array}$ & $\begin{array}{l}\text { Marketing, production, } \\
\text { delivery, warranties, } \\
\text { service when needed }\end{array}$ \\
\hline Markets & International, niche-markets & Domestic and regional & International, segmented \\
\hline Customer type & Private companies & $\begin{array}{l}\text { Public and semi-public } \\
\text { organizations, companies }\end{array}$ & $\begin{array}{l}\text { Private companies, public } \\
\text { organisations }\end{array}$ \\
\hline $\begin{array}{l}\text { Supplier net- } \\
\text { work }\end{array}$ & $\begin{array}{l}\text { Components domestic and foreign, } \\
\text { services from nearby and from } \\
\text { elsewhere in Finland }\end{array}$ & $\begin{array}{l}\text { Components domestic. } \\
\text { Services from nearby }\end{array}$ & $\begin{array}{l}\text { Components domestic and } \\
\text { foreign, services from } \\
\text { nearby }\end{array}$ \\
\hline $\begin{array}{l}\text { Product devel- } \\
\text { opment }\end{array}$ & $\begin{array}{l}\text { Research and product development, } \\
\text { also basic research. Partners geo- } \\
\text { graphically close or internation- } \\
\text { al/abroad }\end{array}$ & $\begin{array}{l}\text { Product development } \\
\text { takes place in projects for } \\
\text { customers }\end{array}$ & $\begin{array}{l}\text { Domestic companies and } \\
\text { local trustworthy custom- } \\
\text { ers are important partners }\end{array}$ \\
\hline $\begin{array}{l}\text { Meaning of the } \\
\text { region for the } \\
\text { company }\end{array}$ & $\begin{array}{l}\text { Availability and low turnover of } \\
\text { competent workers, competence } \\
\text { structures, other socio-economic } \\
\text { environment }\end{array}$ & $\begin{array}{l}\text { Professional training, low } \\
\text { turnover of competent } \\
\text { workers }\end{array}$ & $\begin{array}{l}\text { Availability and low } \\
\text { turnover of competent } \\
\text { workers }\end{array}$ \\
\hline $\begin{array}{l}\text { Regional growth } \\
\text { effects }\end{array}$ & $\begin{array}{l}\text { Mostly through services; companies } \\
\text { are part of the regional competence } \\
\text { cluster and participate in the } \\
\text { development of it }\end{array}$ & $\begin{array}{l}\text { Through acquirement of } \\
\text { services and components }\end{array}$ & $\begin{array}{l}\text { Through services; partly } \\
\text { limited by the need for } \\
\text { outsourcing }\end{array}$ \\
\hline
\end{tabular}





\section{Conclusions}

This study is based on observations from interviews with the directors of seven high and medium technology companies located in eastern Finland. In contrast to earlier studies in this field of research in Finland, the present study focused specifically on fast growing technology companies. In addition, compared to other national studies of the URAGO project, the focus in the Finnish case has been on companies that are located in regional centres rather than the largest national centres.

Overall, the findings indicate that it is possible to run a high technology enterprise, operate competitively and grow fast also outside the largest urban centers and far away from the main markets. However a peripheral location is a demanding starting point for fast growth. Firstly, there is a need to get supplier and customer relations operating efficiently across potentially long distances. Secondly, the customers are often far away, which influences, for example, product development and can make it difficult to receive valuable feedback on the quality of the products. Overall, this study suggests that the number of companies satisfying the criteria of the URAGO project - fast growing high technology companies with more than 50 employees - is very limited in eastern Finland. Especially the size and the demand of a continuous growth history of 10 years limit the number of suitable firms that could be included into the study. In other words, high technology as such does not imply high growth.

Fast growing high-tech companies need competitive, growthoriented and internationalized "lower" technology enterprises around them (as suppliers, R\&D partners, customers as well as suppliers of knowledge intensive and basic services). High and medium technology companies located far away from the main markets are obviously dependent on efficient specialization and functionality of their networks for minimizing possible disadvantages resulting from their location. Innovativeness and the continuous improvement of products and processes are essential for the companies to stay competitive. In general, it seems that the competitiveness of the companies is not primarily based on low costs, but on differentiation and specialization. However, this does not mean that cost efficiency is irrelevant but rather that a lowering of costs is not the central strategy for the companies. Having said that, there is one company among the seven that aims to streamline and outsource its operations and supplier networks on the basis of cost.

From a geographical point of view, the study clearly implies that specific location factors are of decisive importance to high growth technolo- 
gy companies. The companies selected for the case study originate from the region, and are all (based on) family-owned businesses, or businesses owned by two/three key persons. They appear to be rooted in the location mostly through these ownership histories. The importance of location is reflected also in the significance of the local operational environment for the companies, their supplier networks, and research and development cooperation relations. An important characteristic of the local operational environment for the companies is that it offers access to a competent work force with a lower turnover as compared to the major (urban) centres in the country. In addition, the companies do utilize - or can even be highly dependent upon - the regional innovation environment and competence structures such as research and higher education institutions and other companies in the field of operation. The distance to suppliers of raw-materials and components, on the other hand, is generally not perceived as a major problem. The importance of distance/proximity appears to be a more challenging aspect for relations with current customers (needed, for instance, in initiating product improvements) and reaching potential new customers. Overcoming this barrier is of great importance for the future competitiveness of the companies due to the fact that they consider (further) internationalization as the most important source of growth.

Observations from the companies' supplier networks suggest that services are generally acquired sources that are geographically close, whereas raw-materials and specified components are often acquired from across long distances. Services acquired locally include rather basic ones as well as highly specialized and high quality services related to the competence structures of the region. As to the components, the companies typically require high quality, specified components that are not produced locally, and in many cases not even domestically (the producer may however have connection to a dealer in Finland, most often located in the capital region). The networks are reasonably stable as only one of the interviewees anticipated that the supplier network will be cut back due to difficulties in the management of networks and increased need for cost efficiency.

In terms of research and development cooperation, the geographical distribution and degree of internationalization appears to vary across the companies, but the data clearly suggests that geographical proximity between the partners benefits the cooperation. In general, all of the seven case-study companies are strongly investing in product development, mainly in form of in-house operations and in the current geographical location of the company. In terms of the research and development partner network, the case study companies have local and domestic connections, and on average the number of key partners is varying between 2 and 7 per company. The importance of proximity is highlighted by the fact that almost two thirds (64\%) of the domestic R\&D partners are local, that is, within the same NUTS 3 region and the proportion of 
these local partners of all research and development partners is on average $44 \%$. Three of the companies have some of their key research and development partners abroad. On average, the number of foreign partners is five, but, depending on the product development phase, the companies may have up to 20 public organizations as partners involved in testing of a product. Most often the research and development partners are other companies (on average 2 per company) and universities or other kind of higher education institutions (on average 1.7 cooperative institutions per company). The average number of other public institutions as development partners is less than one per company. Overall, the following two conclusions from the research and development relations of the companies can be highlighted here: local concentration of innovation can be crucially important, and - apart from basic research operations - the customers' role in initiating product development processes appears to be essential.

This study has identified three types of companies according to their type of production: project-based (3), product-based (2) and research-based companies (2). Four of the companies (three projectbased and one product-based company) fall into the "order producing" category in the Nordic summary report, one (a product-based company) into the "volume or market producing" category and two (research-based companies) primarily to the "business-to-business" category. The following conclusions are mainly based on this typology. It should be noted, however, that this classification is not strictly defined, but based on the main business operation of the companies. In addition, there may be aspirations to re-orientate the operation of the company in a way that, for example, a business-to-business type company may develop its own volume products.

- A striking feature of one of the product-based companies is that it is the only one among the seven cases that has substantially replaced domestic production of components with production in low-cost countries as part of the company's continuous search for opportunities for lowering costs. Compared to its size, this company has a comparatively large international supplier network of components (mostly in China). In the future also more complex components and duties may be shifted to low cost countries as soon as the quality of production can be guaranteed. Also the logistical position of the company is planned to be improved by establishing logistical units for the European and Asian markets. The product development is currently taking place locally or domestically, but in the future also some parts of the development work may be outsourced. The headquarters is likely to stay in the current location. The company is the market leader in Finland and very export oriented (export markets covering some $70 \%$ of the turnover). 
- In the case of the project/process-based companies, mainly producing to order, proximity is important in many respects. The companies are producing customized final products and have a large international network of suppliers of components. In these respects, distance is not perceived as a major factor. The three project-type companies are more dependent on domestic suppliers, and they also utilize services close to the locations of each project site. Most importantly, proximity is significant for these companies as they acquire services locally and have cooperation with local suppliers and customers, which improves their product development processes. These companies do not have extensive international R\&D cooperation networks, but current and potential foreign customers are important in initiating product improvements. Research and development operations are difficult to differentiate from other businesses, i.e. these two dimensions are integrated. The process based companies studied are only in the initial stages of their internationalization process, but are aiming at the international markets through the establishment of either strategic partnerships or their own units abroad.

- The research-based companies (business-to-business companies, partly order producing) are thoroughly internationalized both through their markets, suppliers and their research and development relations. Proximity matters to these companies mostly in their intensive cooperation with local research institutes and laboratories. In other words, they are dependent on the local and extremely specialized research in their area. These companies are also under international ownership, which has extended the geographical dimension of their R\&D cooperation network. Foreign ownership may have offered the company new resources in R\&D or offered a basis for international research cooperation already from the beginning. Thus, a typical feature of these companies is that they are dependent of the local innovation centre and have very international supplier and R\&D network. The main strategy to improve their competitiveness is to strengthen the local innovation base and strengthen - both at the university and the company - their readiness to cooperate. Even though the companies are internationally owned, they appear to be rooted in their location through these connections.

In Finland, the spatial concentration of economic activities in the main cities, i.e. then Helsinki region, Turku, Tampere and Oulu, has continued. Within the regions (NUTS 3), the main trend has been an increasing concentration into regional capitals. From this point of view, there are two main case study findings. On the one hand, it seems that the supplier and $R \& D$ relations of the case study companies are directed towards the largest cities or their labour market areas, and thus reflect the overall pattern of spacio-economic change; all of the companies have connections to the capital city region. In addition, only one of the companies has 
a larger number of suppliers within the region than outside of the home region. In the other companies, the suppliers outside the region outnumber the local ones by a factor of 1.2 to 8.5. In other words, supplier relations generally appear to be domestic inter-city relations or foreign connections, rather than intra-city relations. On the other hand, however, the companies do have intra-city connections, for example, with local knowledge institutions as well as suppliers and subcontractors that are of crucial importance to their competitiveness. In addition, the growth of the number of employees has taken place around the location of their headquarters in eastern Finland. As to differences between the regional capitals studied, the case study information does not provide a firm basis for conclusions except that the companies appear to reflect the regional specialization in production and knowledge resources of the respective regional capitals.

The Finnish innovation policy is currently undergoing a shake-up, according to the recent international evaluation of the country's innovation system. Changes include a redefinition of the role and strategy of the National Funding Agency for Technology and Innovation (TEKES), which plays a key role in companies' innovation activity and product development in Finland. The new strategy focuses on providing business support for innovative, growing and internationalizing companies. A policy concept that is currently receiving much attention in regional development and innovation policy documents are socalled "regional centres of innovation," the basic idea of which is to concentrate funding into fewer innovation centres, or major cities, in the country. In terms of their operations, the companies that have been examined as part of this study are positioned within the focus of this innovation policy, but they are located outside the largest centres. A shift to an exclusive focus on the main urban centres in regional development policy is thus disquieting from the individual case companies' point of view. The support of development of operative connections of technology companies in peripheral regions should not be overlooked in a climate of spacio-economic concentration. From the regional point of view, a persevering and credible commitment to the development of certain technologies is also essential. 


\subsection{References}

Ala-Rämi, K. (2007) Networking, communication and proximity in high-technology enterprise collaboration: Case of Northern Finland. Nordia geographical publications, vol. 36:2. Geographical Society of Northern Finland, Oulu.

Hirvonen, T. and T. Lautanen (2011) Keskustelua itäsuomalaisesta innovaatiokeskittymästä. Spatian Raportteja 3/2011.

http://www.uef.fi/c/document_library/get_file?uuid=3edb510d-e39c-4c3a-9a424ff99a86deec\&groupId=325583\&p_l_id=330131

IEFNIS (2009) International evaluation of Finnish National Innovation System. http://www.evaluation.fi

IEFNIS (2009b) Suomen innovaatiojärjestelmän kansainvälisen arvioinnin tulokset ja suositukset. Tiivistelmä.

http://www.tem.fi/files/25901/Innovaatiojarjestelman_arviointi_11012010\%29.pdf

Jauhiainen, J. and K. Suorsa (2008) Triple Helix in the periphery: the case of Multipolis in Northern Finland.

http://papers.ssrn.com/sol3/papers.cfm?abstract_id=1361422

Kautonen, M. (2006) The Regional Innovation System Bottom-up: A Finnish Perspective. http://acta.uta.fi/pdf/951-44-6702-7.pdf

Littunen, H. and M. Varis (2012) SMEs and Their Peripheral Innovation Environment: Reflections from a Finnish Case.

http://www.tandfonline.com/doi/full/10.1080/09654313.2012.665034

Smedlund, A. and M. Toivonen (2007) The role of KIBS in the IC development of regional clusters. http://www.emeraldinsight.com/journals.htm?issn=1469$1930 \&$ volume $=8 \&$ issue $=1 \&$ articleid $=1585620 \&$ show $=\mathrm{html}$

TEKES (2011) Tekes strategia.

http://www.tekes.fi/fi/community/Strategia/332/Strategia/627

TEM (2008). Kansallinen innovaatiostrategia. Työ- ja elinkeinoministeriö. http://www.tem.fi/files/19704/Kansallinen_innovaatiostrategia_12062008.pdf

TEM (2009). Kaupunkipolitiikan periaatepäätös 2009-2011. Työ- ja elinkeinoministeriö, Alueiden kehittämisyksikkö. 13.5.2009. http://www.tem.fi/files/23983/Kaupunkipolitiikan_periaatepaatos_2009-2011.pdf

TEM (2010a). Kysyntä- ja käyttäjälähtöinen innovaatiopolitiikan jäsentely ja toimenpideohjelma (osa II). Luonnos 16.2.2010. Työ- ja elinkeinoministeriö. http://www.tem.fi/files/26093/OSA_2_final.pdf

TEM (2010b) Suomen aluekehittämisstrategia 2020. http://www.tem.fi/files/27071/23_2010_web.pdf

TIN (2010) Tutkimus- ja innovaatiopoliittinen linjaus 2011-2015. Tutkimus- ja innovaationeuvosto.

http://www.minedu.fi/export/sites/default/OPM/Tiede/tutkimus_ja_innovaationeuvosto/julkaisut/linjaus2011-2015.pdf

Virkkala, S. (2007) Innovation and Networking in Peripheral Areas - a Case Study of Emergence and Change in Rural Manufacturing, European Planning Studies, 15:4, 511-529. http://www.tandfonline.com/doi/pdf/10.1080/09654310601133948 


\section{Appendix 1. Summary of the geographical dimensions of the case study companies}
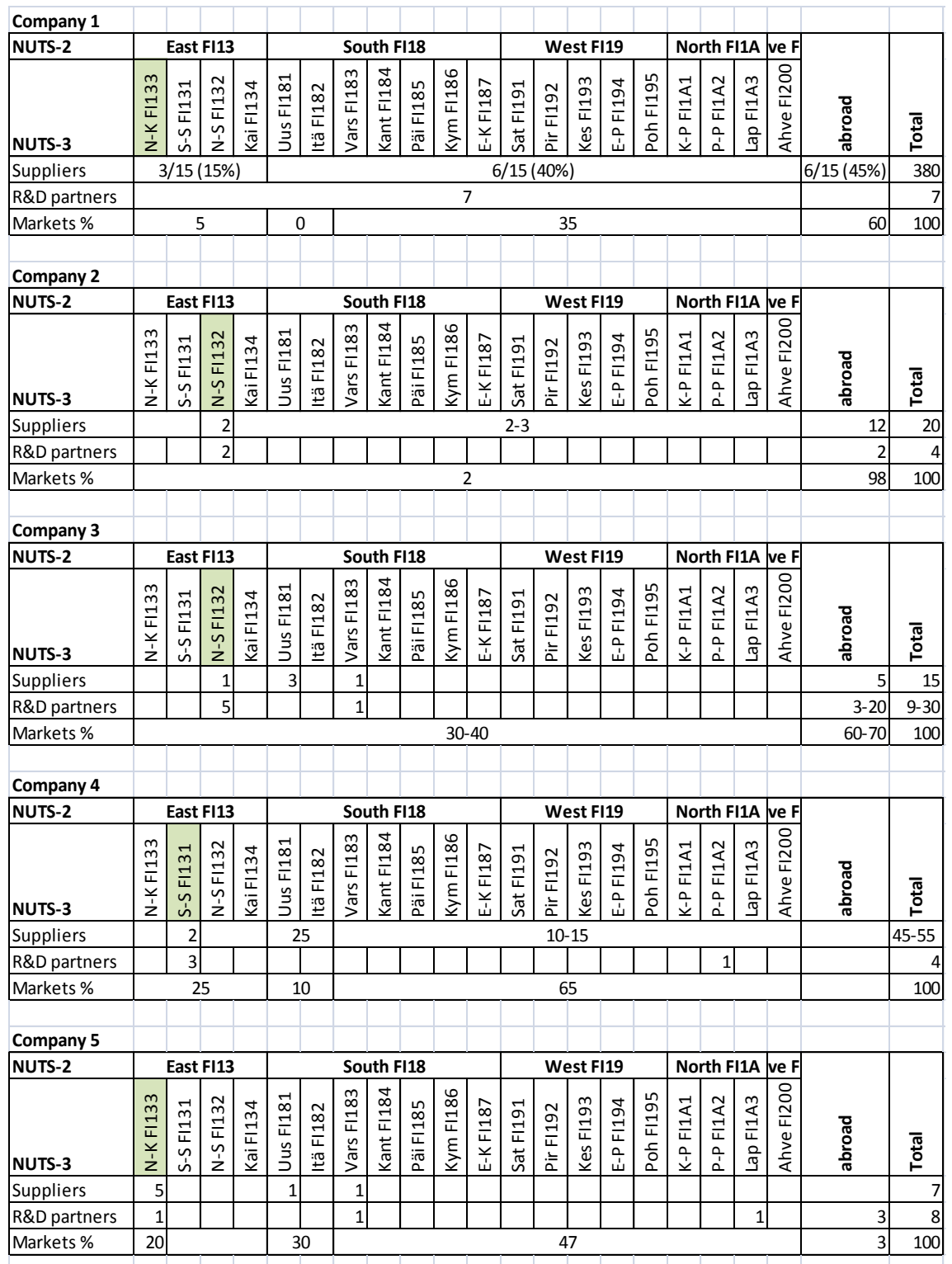


\begin{tabular}{|c|c|c|c|c|c|c|c|c|c|c|c|c|c|c|c|c|c|c|c|}
\hline \multirow{2}{*}{\begin{tabular}{|l|} 
Company 6 \\
NUTS-2 \\
\end{tabular}} & \multirow{2}{*}{\multicolumn{3}{|c|}{ East FI13 }} & \multirow{2}{*}{\multicolumn{6}{|c|}{ South FI18 }} & \multirow{2}{*}{\multicolumn{4}{|c|}{ West F19 }} & \multirow{2}{*}{\multicolumn{4}{|c|}{ North FI1A ve F }} & \multirow[b]{3}{*}{ 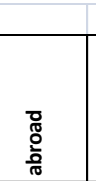 } & \multirow[b]{3}{*}{$\begin{array}{l}\overline{\widetilde{g}} \\
\stackrel{\circ}{\circ}\end{array}$} \\
\hline & & & & & & & & & & & & & & & & & & & \\
\hline NUTS-3 & 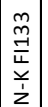 & $\begin{array}{l}\vec{m} \\
\overrightarrow{\vec{t}} \\
\vec{u} \\
\dot{n}\end{array}$ & 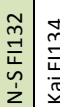 & 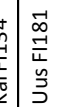 & 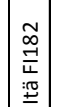 & 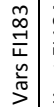 & 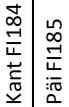 & 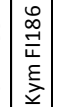 & 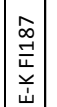 & $\begin{array}{l}\vec{\sigma} \\
\vec{H} \\
\begin{array}{c}0 \\
+ \\
\tilde{n}\end{array}\end{array}$ & 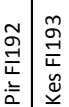 & \begin{tabular}{|c|c} 
\\
$\stackrel{一}{u}$ \\
0 \\
$\dot{u}$
\end{tabular} & $\mid \begin{array}{l}2 \\
\frac{1}{4} \\
\frac{1}{4} \\
\frac{0}{0} \\
0\end{array}$ & 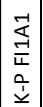 & $\mid \begin{array}{c}\mathfrak{d} \\
\frac{1}{4} \\
0 \\
\vdots \\
\vdots\end{array}$ & $\mid$\begin{tabular}{l|}
$\frac{m}{2}$ \\
$\frac{\partial}{4}$ \\
$\frac{0}{g}$ \\
$\frac{a}{9}$
\end{tabular} & 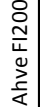 & & \\
\hline Suppliers & 2 & & 5 & \begin{tabular}{l|l} 
& 1 \\
\end{tabular} & & & & & & & & & & & & & & 13 & 21 \\
\hline R\&D partners & & & 2 & & & & & & & & 1 & 1 & & & & & & & 3 \\
\hline Markets \% & & & & & & & & & & & & & & & & & & & 100 \\
\hline
\end{tabular}

\begin{tabular}{|c|c|c|c|c|c|c|c|c|c|c|c|c|c|c|c|c|c|c|c|c|c|}
\hline \multirow{2}{*}{\begin{tabular}{|l|} 
Company 7 \\
NUTS-2 \\
\end{tabular}} & \multirow{2}{*}{\multicolumn{3}{|c|}{ East FI13 }} & \multirow{2}{*}{\multicolumn{7}{|c|}{ South F118 }} & \multirow{2}{*}{\multicolumn{5}{|c|}{ West F19 }} & \multirow{2}{*}{\multicolumn{4}{|c|}{\begin{tabular}{|l|} 
North FIIA ve F \\
\end{tabular}}} & \multirow[b]{3}{*}{ 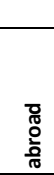 } & \multirow[b]{3}{*}{ 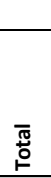 } \\
\hline & & & & & & & & & & & & & & & & & & & & & \\
\hline NUTS-3 & & 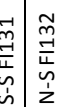 & 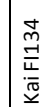 & 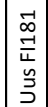 & 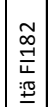 & 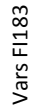 & 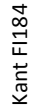 & 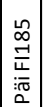 & 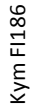 & 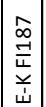 & 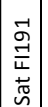 & $\mid \begin{array}{l}\tilde{\sigma} \\
\frac{7}{4} \\
: \frac{1}{\Delta}\end{array}$ & 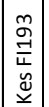 & $\begin{array}{l}\vec{J} \\
\stackrel{\vec{U}}{u} \\
0 \\
\dot{u}\end{array}$ & $\begin{array}{l}\frac{2}{2} \\
\frac{7}{4} \\
\text { 응 }\end{array}$ & 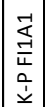 & 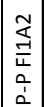 & $\mid \begin{array}{l}\frac{m}{2} \\
\frac{1}{4} \\
\frac{0}{0} \\
\frac{0}{G}\end{array}$ & 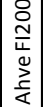 & & \\
\hline Suppliers & 6 & \begin{tabular}{l|l}
1 & \\
1
\end{tabular} & & 5 & 5 & 1 & & & & & & & & & & & 2 & & & & 15 \\
\hline R\&D partners & 1 & & & & & & & & & & & & & & & & 1 & & & & 2 \\
\hline
\end{tabular}




\section{Part 3 - Norway}

Olaf Foss, Frants Gundersen 



\section{Introduction}

\subsection{Background}

In Norway, the knowledge sector stands behind $10 \%$ of the employees in the private sector. This is not as much as in our neighbour countries, but it is often explained by the fact that the oil sector is not included in the knowledge intensive sector. Especially, the services in the oil-sector are knowledge intensive. However, in this study, the oil sector is excluded.

We also know that the knowledge sector is biased towards concentration in the urban areas, and that the sector is growing. Therefore, the main question for this study is: what is the trickle-down effect from growth in the knowledge sector in the largest cities to the areas outside these cities, through suppliers and demands from the knowledge companies? This study will try to shed some light on this topic.

The project was initiated by the Nordic Council of Ministers and is carried out in collaboration between Denmark, Sweden, Finland and Norway, with Denmark as project leader.

\subsection{Method}

We used the criteria from the project-specifications when selecting companies for interviews:

The NACE-code should be in 73, 24.4, 30-33, 35.3, 72, 74.2, 74.3, 24 or 29. This is the knowledge intensive industries, both manufacturing and services. The companies should also exhibit growth in the last decade preferable continuous growth. For this we used the number of employees.

Since the projects main question is the trickle-down effect from growth in the knowledge sector in the largest cities, or spread effect through demands from the knowledge sector in the cities to other industries outside the largest cities, the location of the companies needs to be in or near the largest cities in Norway. We focused on the functionally regions of Oslo, Bergen, Stavanger/Sandnes and Trondheim.

Two more limitations were faced. First, we sorted out all branches of bigger companies. In the register, it was possible to find local activity units with continuous growth, also within the knowledge sector. But as a part of a bigger company, it is almost impossible to map out the external links and spread effects. We therefore concentrated the sample on single companies. Second, the general marked varied through the decade, and it was hard to find companies with $100 \%$ continuous growth. So, companies with a clear 
overall growth, but with one or two years with decline in the number of employees, were also included.

When starting to contact companies for interviewing, it turned out that it was very hard to get appointments. For the company, to attend a conference, was of no help. After many telephone calls and e-mails, we only managed to get two appointments. With a limited budget for the project, it was necessary to change strategy. Thus, a questionnaire survey based on the interview guide provided earlier in the project was set up. We used the same sample of companies as already established, and 353 companies were invited by e-mail to answer the questionnaire.

After one reminder, 52 companies answered the questionnaire partly, and 21 companies answered the questionnaire totally. In addition, we conducted the two interviews we already had made appointments for. Of the 52 companies, 11 were in the manufacturing sector and 41 in the service sector. Both companies interviewed were in the manufacturing sector.

For some of the companies we made a mapping of external links, based upon a further e-mail dialogue with the companies. If so, it is mentioned in the document.

As statistical data, this sample is too small to generalize on spatial patterns. But together with interviews, e-mail correspondence and information from the companies' web-pages, it is possible to indicate some intermediate findings.

NIBR also has access to a copy of the Central Register of Establishments and Enterprises (CRE) provided by the Statistics Norway. We used this register to produce some extra statistics about the knowledge intense industries. This register is also the source for the sample for the survey. 


\section{National pattern}

The knowledge sector, as defined in this project (see below) stands for $10 \%$ of the employees in private sector in Norway. Since the value chain and the supply pattern will differ between manufacturing companies and service companies, we will distinguish between those two sectors. This is shown in the figure below.

Figure 13.1. The share of employees by industries in private sector in Norway, 2012

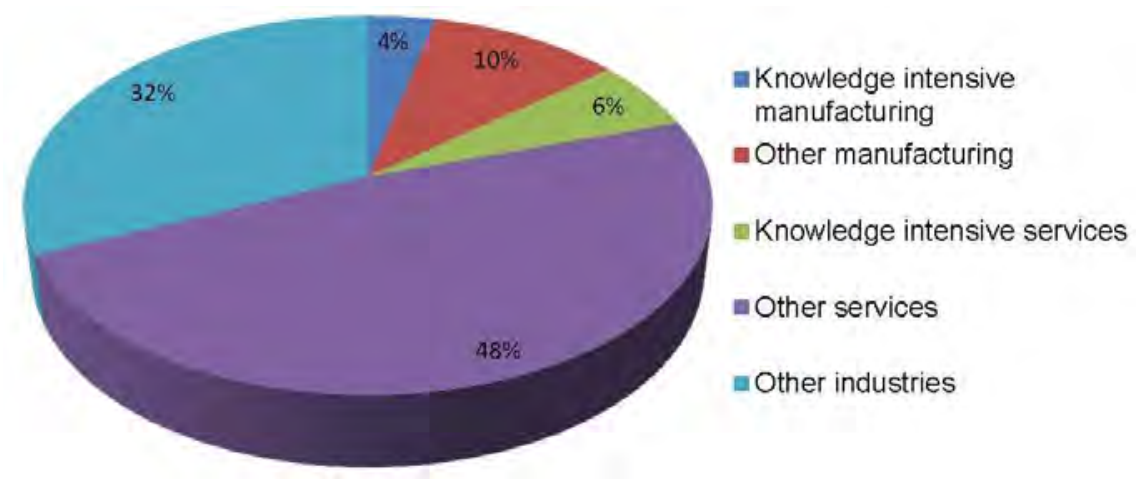

Only $4 \%$ of the employees are working in knowledge intensive manufacturing, and only $6 \%$ are working in knowledge intensive services. This is not much, and it may seem an odd starting point for this project. But the two sectors (knowledge intensive manufacturing and knowledge intensive services) stand out as sectors with a better growth rates of employment than other sectors. Although small, they are important for economic development and further growth.

As figure 13.2 shows, the knowledge sector has not a high growth rate of employment. But relative to other sectors, the performance is better in the period 2000 to 2012. In absolute numbers, "other industries" has the largest numbers of new employees, but as earlier mentioned, this sector includes the oil industry. If we take a look at the percentage changes during the same period, the knowledge sector is doing well, see figure 13.3. The number of employees in knowledge intensive manufacturing decreased from 2000 to 2012, but to a much lesser extent than the rest of manufacturing sector, and no sector increases more than knowledge intense services. 
Figure 13.2. The share of employees by industries in private sector in Norway, 2000-2012

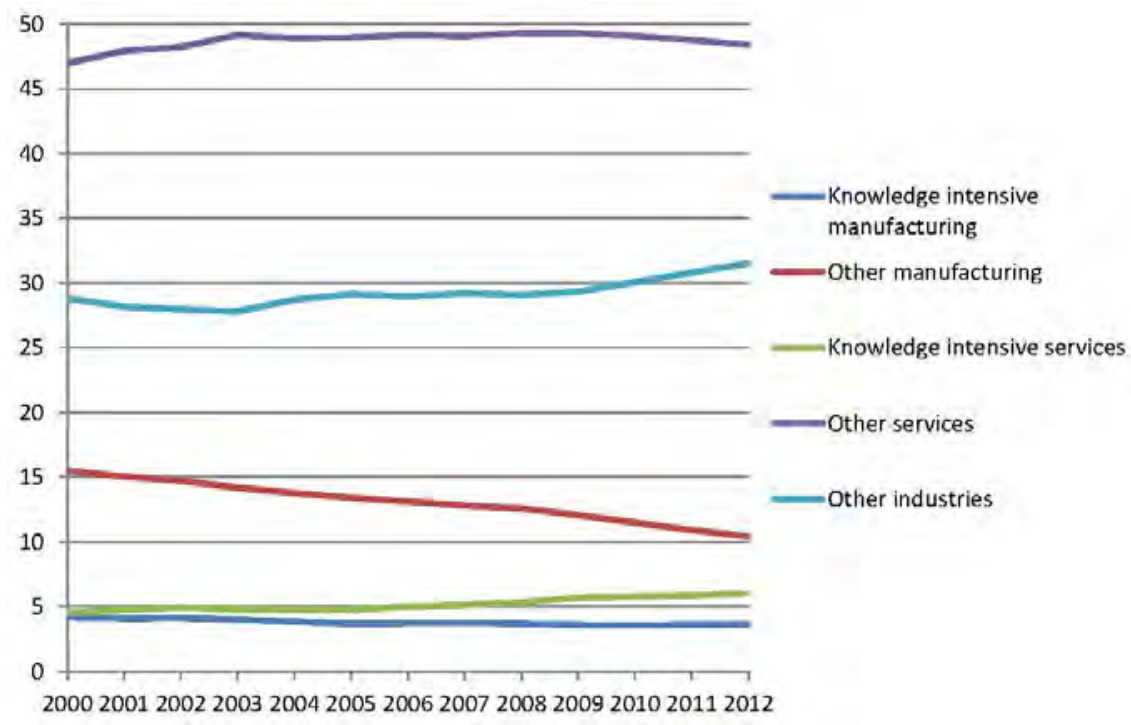

As earlier mentioned, the oil sector is part of "Other industries." During the last decade, the oil sector expanded substantially in Norway, and makes up most of the growth in the sector.

Figure 13.3. Change in employees by industries in the private sector in Norway.\% change 2000 to 2012

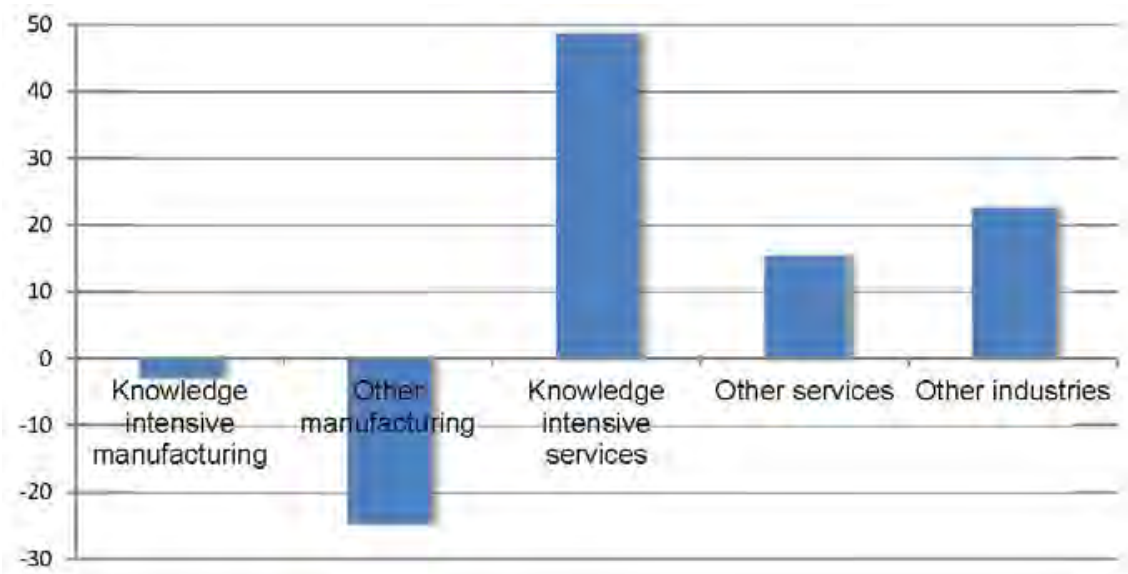




\section{Urban areas as growth poles}

One of the assumptions of this study is that the knowledge sector is concentrating in the largest urban areas, and that further growth will trickle down to other parts of the country from the knowledge sector in these areas. This assumption is supported by statistics. In figure 14.1, we show the share of knowledge industries by the size of the biggest city in the functional region. Knowledge intense services are very nicely distributed along this center-periphery axis, starting with a concentration of knowledge intensive industries in the Oslo region over five times the share of employees in the most sparsely populated regions. For the manufacturing sector, the picture is less clear. In this sector, we find the highest concentration in the medium-size city regions. The share of employess in this sector in the Oslo region is as low as in the most sparsely populated regions. It is the same picture, we found ten or twelve years ago, only with the manufacturing bars a bit higher and the service bars a bit lower.

Figure 14.1. Share of employees in the knowledge sector by type of region in Norway. 2012 \%

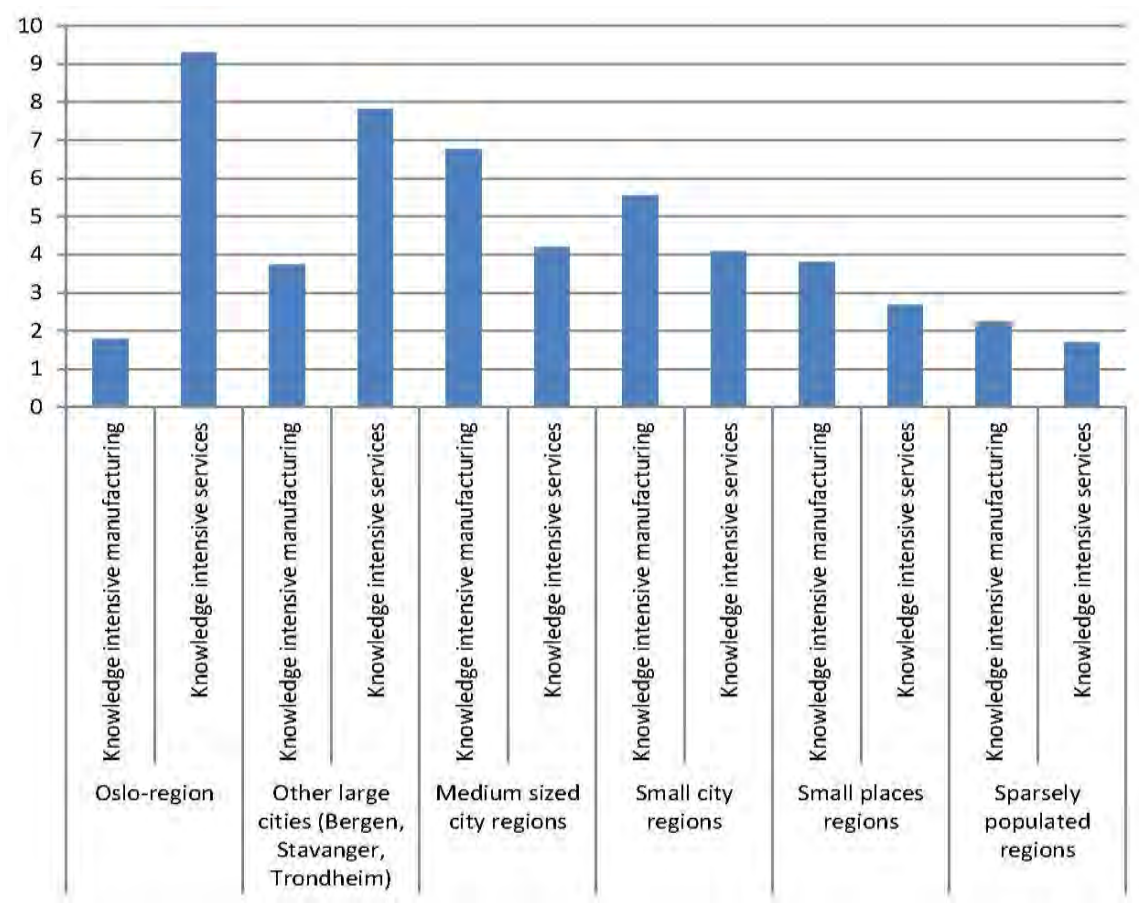


The dominance of the service sector in the largest city regions can also explain some of the results from our survey. We only asked firms in the largest city regions, i.e. the two left-most categories in the figure above. When asked about factors important for being located in a large city, the companies answered:

- Access to skilled workers: 95\%.

- Nearness to customers: 90.

- Nearness to suppliers: 40.

- Infrastructure: 40.

- $\mathrm{R} \& \mathrm{D}$ and other competence (consultants): 57.

- Industrial milieu: $71 \%$

Low score on suppliers and infrastructure would be quite surprising, if most of the firms had being manufacturing firms. But since most of the firms in the sample are in the service sector, the high rating of "access to skilled workers" and "nearness to customers" is quite understandable.

This raises a dilemma of this study: it is the service sector that is responsible for most of the growth in the knowledge intensive sector in the largest cities, but it is from the manufacturing sector, located in the medium-sized cities, we would expect most trickle-down effects, due to stronger value chains and need for a supplier networks. 


\section{Mapping external links}

Our main theme is the extent to which growth in the knowledge intensive sector in the large cities eventually causes growth in other part of the country. The starting point was the value chain, and the suppliers.

However, as we saw in the former section, most of the growth in the knowledge sector is not in the manufacturing sector - especially not in the larger cities. So, if we will stick to the projects main theme, we have to include the service sector. And for service companies, the value chain is "shorter." They are selling their knowledge, and only use a limited number of suppliers. ${ }^{4}$

$65 \%$ of the companies in the sample of this survey were fully Norwegian owned. The rest of companies were usually subsidiaries of foreign companies. The market orientation of the companies is as follows: $22 \%$ are oriented locally, $40 \%$ nationally, $8 \%$ internationally and $30 \%$ at "all levels." The relatively low share of international oriented companies is resulting from the selection criteria: we excluded big companies with at complex structure for easier mapping.

Among the manufacturing companies, there were both companies producing for stock/marked and order producing firms (see the Danish cases for typology). For service-companies, it is not possible to use the same kind of typology. But we find something like it: Sales are often dominated by a few large customers. Which seems reasonably - companies in the knowledge intensive sector are specialized and dependent on customers equivalently specialized.

There are, of course, exceptions, but the near relationships to the customers are illustrated by what the companies reported as important for development of their product/service:

- Internal (formal) development: $72 \%$.

- External cooperation with R\&D-institutions: $17 \%$.

- Systematic incremental improvement in day-to-day work: $90 \%$.

- Incidental improvement in day-to-day work: $80 \%$.

- In near cooperation with customers: $96 \%$.

- In near cooperation with suppliers: $80 \%$.

${ }^{4}$ I have not included suppliers of common goods that have no relation to the company's service/product (everything from toilet paper to printer paper). 


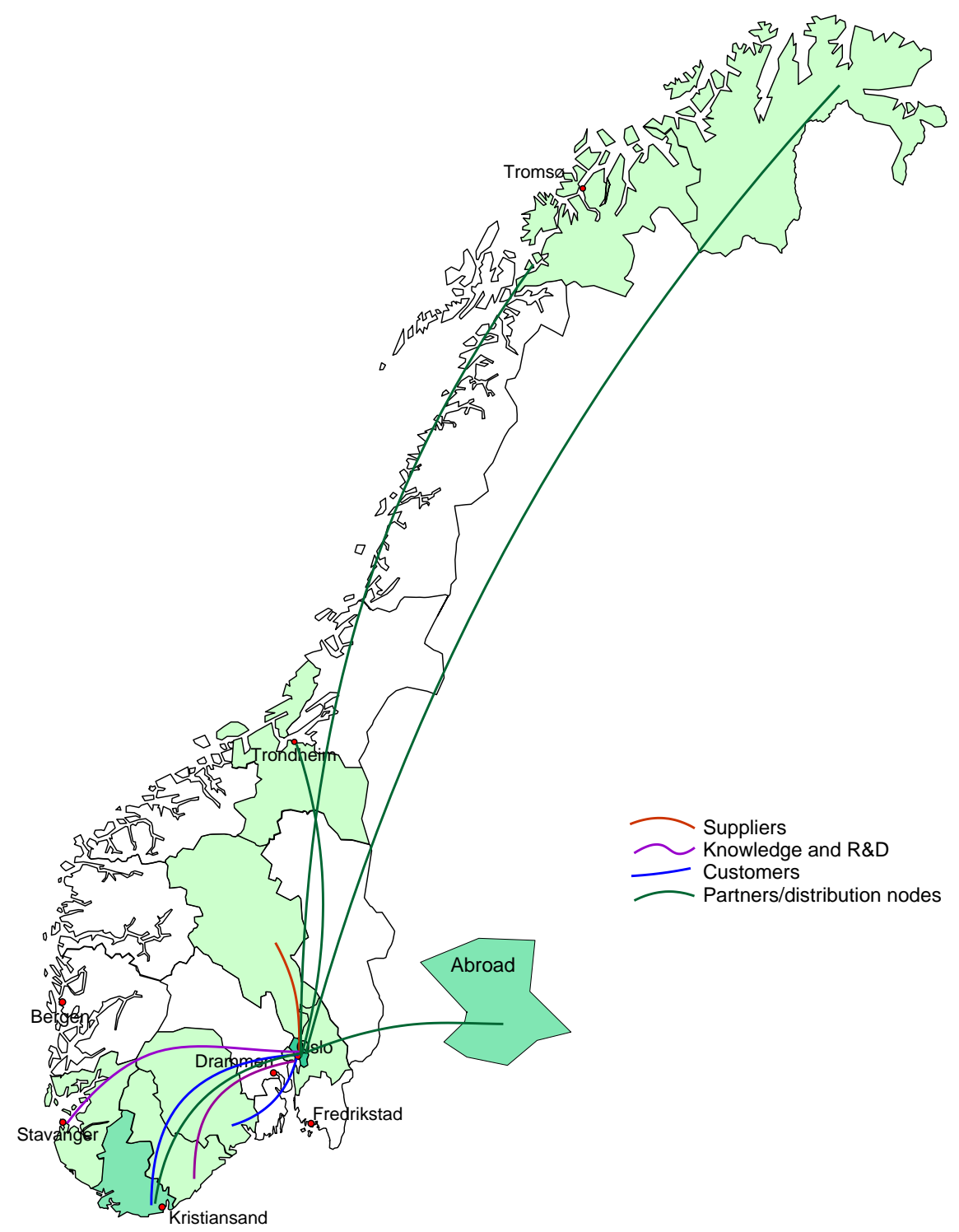

It is a bit surprising that "external cooperation with R\&D-institutions" was least important. After all, the companies are knowledge intensive. Some explanasion may be found in the large share of service companies. In figure 15.1, we have shown the reported links from one of the companies, a manufacturing company. Only one link is to a traditional supplier. More important to the company (when it comes to geographical pattern) are links to "partners" and "distribution nodes."

The map also illustrates a challenge for the analysis regarding the geographical level. When mapping the external links, we use NUTS 3 (county) as the unit. And it seems that the company has links to a large part of Norway, including rural areas. The companies specify which county and company the link goes, but they did not specify if the link is 
to a small/rural municipal or to a bigger city. However, manually we tracked down the exact location using the names of the companies. As a result we found is that the relations almost always are to companies in the largest city of the county. The spread effect to rural areas is therefore limited, and the map is somewhat misleading. This observation is true for most of the companies in the survey - external links are often to companies in other large or medium sized cities

When analyzing the external links for all companies, some main preliminary findings can be mentioned:

- Big customers are important, both for developing products/services and as stable economic links for the companies.

- Links are mostly to other (large) cities, not to rural areas.

- Partners and distributing networks are important, both for service companies and for manufacturing companies (but the material is too small to tell if manufacturing companies of the "order-producing" type is different). But those kind of links are related to access to the marked. This means that it is only links to partners in larger cities that are developed. The spreading effects of economic activities to rural areas of those kinds of links are therefore limited.

- R\&D-relations are few and concentrated to the largest cities.

The sample is chosen among SMEs with simple company structure, for easy mapping of relations. The relations to foreign institutions/companies are therefore of limited volume. 



\section{Geographical impact}

When asked about their regional impact the last decade, more than $50 \%$ of the companies responded that they have caused no regional impact. But 4 out of 10 mention establishing new companies off-site as an impact. These numbers also include all kind of activities, i.e. sales-offices and distribution network, see figure 16.1.

Figure 16.1. Share of known former geographical impact.\% of the companies

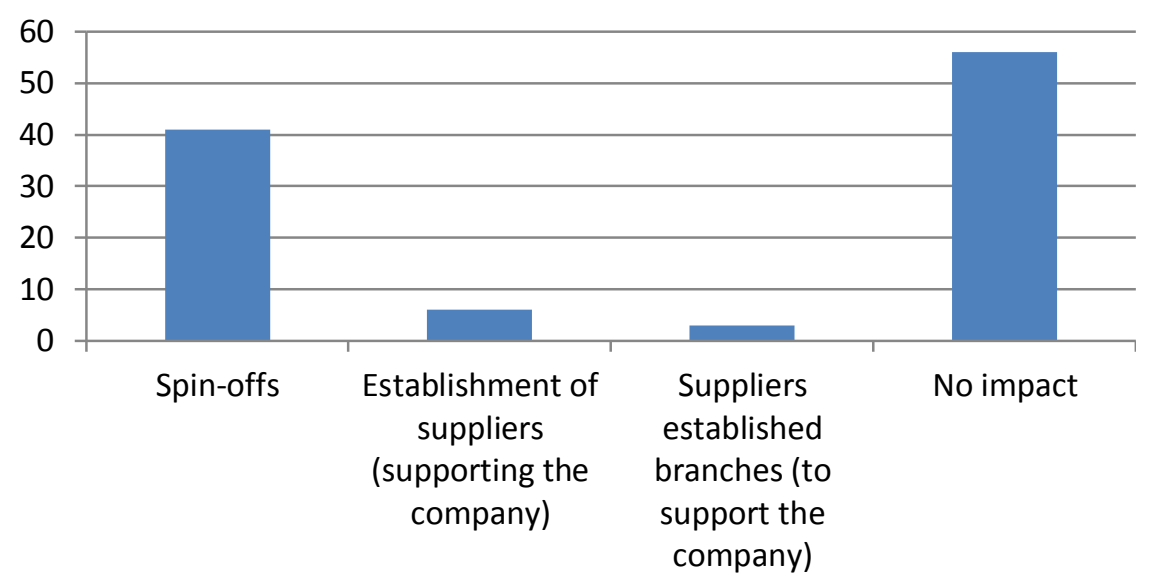

When asked of known plans, more than $60 \%$ of the companies had plans about cooperation with other companies, see figure 16.2. More than $50 \%$ of the planned cooperation was local. Buy-outs or merging with other companies was no option for most of the companies. Only $22 \%$ had some kind of plans in that direction. International expansion was usually not included in future plans, but this could be explained, as earlier mentioned, by selection criteria of the sample. 
Figur 16.2. Share of known plans with geographical impact.\% of the companies

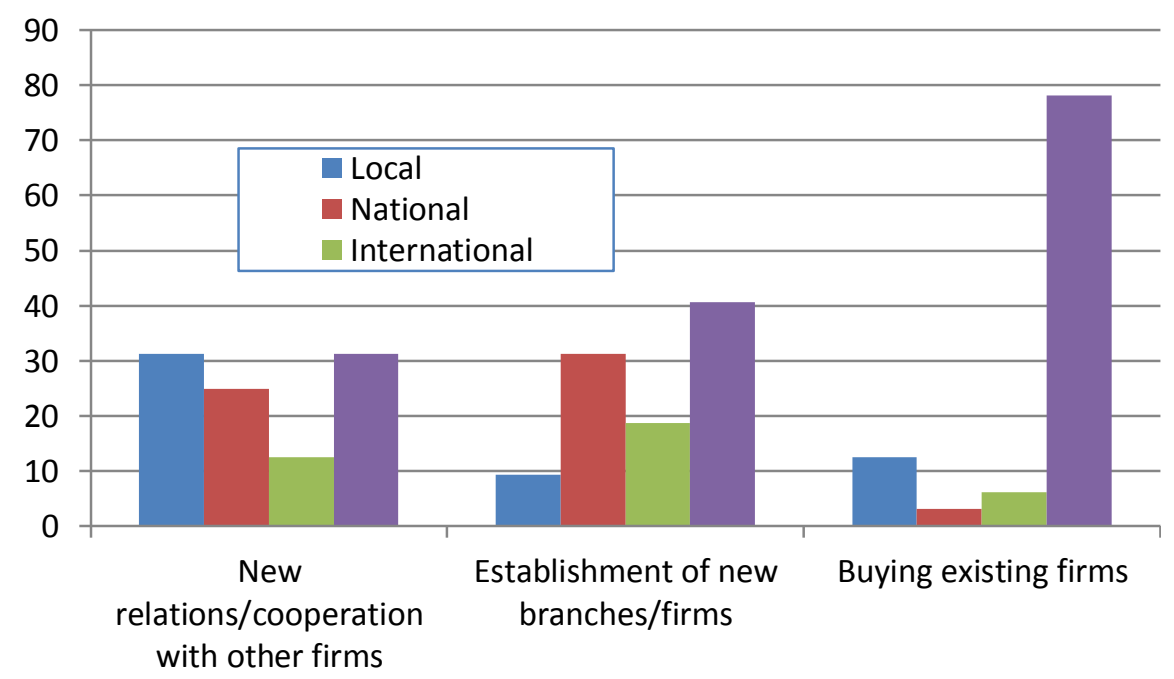




\section{Findings}

It is the service sector that stands behind most of the growth in the knowledge intensive sector concentrating in the largest cities. But it is from the manufacturing sector we would suspect more trickle down effects, due to stronger value chain and supplier networks.

This means that suppliers as the main source of "trickling down effect" is only part of the truth. Many of the firms in this study underlined the importance of distribution network and links to large customers as the most important links.

Most of the links from companies in large cities is to companies in other large or medium sized cities. Since links connected to the marked (distribution network and customers) are important, this is no suprise. But a direct growth effect in rural areas caused by growth in the knowledge sector in the largest cities is hard to find.

External links to R\&D-institutions are not as important as large customers for developing products or processes. 



\section{Annex 1: Interviews in anonymised form}

Four cases are included in this annex. Two ordinary interviews and two based on a combination of survey, telephone, e-mail correspondence and information from the companies' web-pages.

\subsection{Case 1}

\section{Table 18.1}

$\begin{array}{ll}\text { Date of interview } & \text { 2012-02-02 } \\ \text { Type of interview } & \text { Ordinary face-to-face interview } \\ \text { Interviewer } & \text { Frants Gundersen } \\ \text { Respondent } & \text { NN } \\ \text { Title } & \text { CEO } \\ \text { City } & \text { Oslo } \\ \text { Country } & \text { Norway } \\ \text { Status } & \text { Independent company } \\ \text { NACE } & 32.20\end{array}$

\subsubsection{The company}

Established in 1996 in Stavanger and gradually moved to Oslo. First product on marked in 2002. The company is fully Norwegian owned by three main investors.

Table 18.2. Employees

\begin{tabular}{cccc}
\hline $\mathbf{2 0 0 1}$ & $\mathbf{2 0 0 4}$ & $\mathbf{2 0 0 8}$ & $\mathbf{2 0 1 1}$ \\
\hline 5 & 12 & 23 & 42 \\
\hline
\end{tabular}

\subsubsection{Products/services}

$\mathrm{XX}$ is a leading developer of secure alarm transmission services. The solutions have been approved both for security (Intruder alarm transmission) and safety (fire alarm transmission), and are currently in largescale use in Norway, Sweden and Denmark. XX uses mobile networks as the primary route for secure alarm transmission.

$\mathrm{XX}$ provides its unique alarm transmission service after two models:

$\mathrm{XX}$ itself providing the service, selling XX alarm transmitters through wholesalers or large installers (currently the business model in Norway and Sweden). 
A partner purchases the right to establish a copy of the XX service for its defined market and distributing the XX alarm transmitters as an OEM (currently the business model in Denmark)

In both cases, XX supports the service with its knowledge base, and improvements, solutions to new challenges caused by telecom operators etc. are added to the solution regardless of model.

\subsubsection{R\&D}

All R\&D is made by the company, but some of the activity is subcontracted to smaller (and highly specialized) firms, e.g. in Grimstad and in Stavanger and Haugesund.

\begin{tabular}{llll} 
Table 18.3 Relations & & & \\
\hline Name of relation & County & Type & Importance \\
\hline R1 & Oppland (Gjøvik) & A2 & A2 \\
R2 & Aust-Agder (Grimstad) & A3 & A2 \\
R3 & Oslo & C1 & B1 \\
R4 & Oslo & A1 & A1 \\
R5 & Oslo & P1 & $?$ \\
R6 & Telemark (Skien) & P1 & A1 \\
R7 & Sør-Trøndelag (Trondheim) & P1 & A1 \\
R8 & Nordland (Harstad) & P1 & A3 \\
R9 & Denmark & P1 & A3 \\
R10 & Oslo & C1 & B1 \\
R11 & Finmark (Hammerfest) & P1 & A3 \\
R12 & Vest-Agder (Kristiansand) & C2 & A3 \\
R13 & Oslo & A2 & A2 \\
R14 & Sweden & P1 & A3 \\
R15 & Oslo & A3 & A2 \\
R16 & Telemark (Skien) & C1 & A3 \\
R17 & Akershus (Asker) & C2 & A3 \\
R18 & Vest-Agder (Kristiansand) & C1 & A3 \\
\hline
\end{tabular}

Type

A1 Traditional supplies of services and products related to the branch of the company.

A2 Customized supplies of services and products based on detailed technical specifications.

A3 Suppliers of innovation (product innovation and/or innovation of manufacturing processes).

B1 Internal R\&D units.

B2 Universities and other institutions.

C1 Strategic Partners - Costumers.

C2 Strategic Partners - Suppliers.

D1 Export markets.

D2 TNCs.

P1 Partners/distribution network.

Importance

A1 Easy to replace, if needed.

A2 Important and difficult to replace by another subcontractor.

A3 Important but possible to replace.

B1 Economic important - influencing the final price of the product.

B2 Economic important - do not influence on price of product. 


\section{Impacts}

$\mathrm{XX}$ is by far the most important customer in Oppland County

XX has a 24-7 service for their customers (monitoring the installed alarms). This service can bee located "anywhere," and is now located in Kristiansand. But it is considered to be moved to a smaler town because,

"the labor force is cheaper and more reliable, because of fewer options and job opportunities."

\section{Strategies for the future}

No buy-outs, mergings or spin-offs are planed, but further expansions through organic growth (no by-outs etc).

\section{Evaluation of geographical importance}

It was of vital importance to be located in a large urban milieus for the sake of skilled workforce, important customers and relations to knowledge institutions.

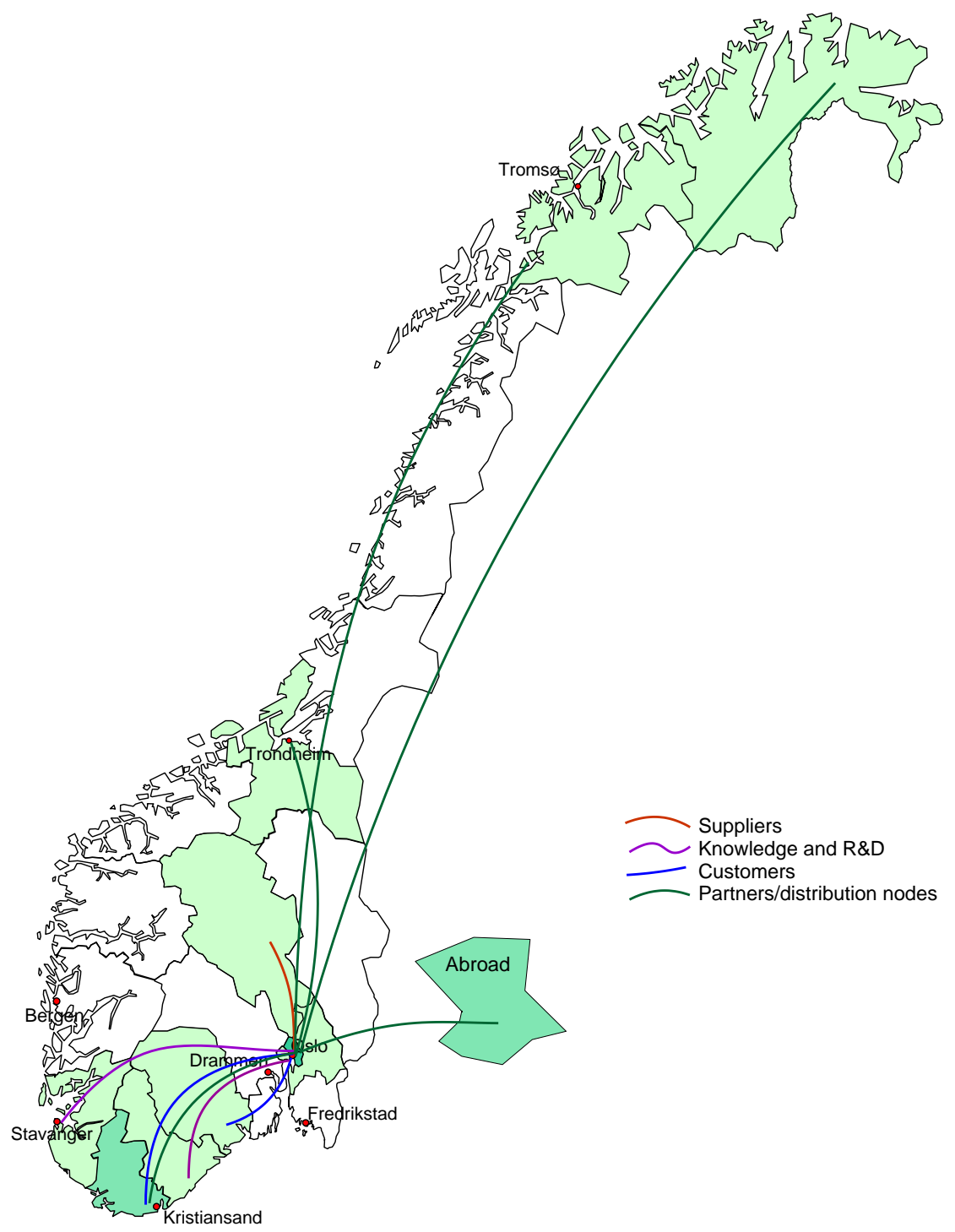




\subsection{Case 2}

\begin{tabular}{ll} 
Table $\mathbf{1 8 . 4}$ & \\
\hline Date of interview & 2012-01-22 \\
Type of interview & Answering web questionaire - mail correspondance - web-pages \\
Respondent & NN \\
Title & Department Manager \\
Company & XX \\
City & Bergen \\
Country & Norway \\
Status & Subsidary of foreign company \\
NACE & 74.30 \\
Mother company & NN \\
City & \\
Country & UK \\
\hline
\end{tabular}

\subsubsection{The company}

The company was established in 1971in Norway as an engineering company to target the growing nuclear power and petroleum industries. By the end of $2009 \mathrm{XX}$ became a member of a UK-based large company. XX have also subsidaries in USA (1), Sweden (2), UK (3) and China (1).

\subsubsection{R\&D}

No specific R\&D department. Development of products/services is closely link to cooperation with customers but they also have some cooperation with R\&D institution.

Table 18.5. Employees

\begin{tabular}{lrrrrrrrrrrr}
\hline & 2001 & 2002 & 2003 & 2004 & 2005 & 2006 & 2007 & 2008 & 2009 & 2010 & 2011 \\
\hline Avd Stavanger & & 1 & 7 & 8 & 7 & 12 & 15 & 18 & 17 & 18 & 17 \\
Avd Bergen & 7 & 7 & 12 & 13 & 12 & 14 & 13 & 21 & 24 & 22 & 22 \\
Avd Kjeller & & 53 & 58 & 63 & 68 & 63 & 60 & 61 & 62 & 65 & 68 \\
Avd Trondheim & & & & & & 2 & 4 & 14 & 19 & 18 & 22 \\
Avd sandvika & & & & & & & & 4 & 10 & 12 & 20 \\
\hline
\end{tabular}

\subsubsection{Products/services (from web site)}

$\mathrm{XX}$ is a leading independent risk management company with 40 years of experience in providing consulting services and software to the international market. $\mathrm{XX}$ offers services in the following areas:

- Health \& Safety.

- Risk Analysis.

- Quality.

- Environment.

- Reliability \& Maintenance.

- Flow Assurance. 
The company serves mainly the oil and manufacturing sector in Norway, but also the energy and building sector. XX develop three softwarepackages in their services. The company has both large customers with strong relations and more occasional customers with no formal relations.

Table 18.6 Relations

\begin{tabular}{llll}
\hline Name of relation & County & Type & Importance \\
\hline R1 & Rogaland/Oslo & C1 & A2 \\
R2 & Oslo/Hordaland/Rogaland & C1 & A2 \\
R3 & Sør-Trøndelag & B2 & A2 \\
R4 & Nation wide & C1 & A2 \\
+ Regional offices (see above) & & & \\
+ Seven offices abroad & & & \\
\hline
\end{tabular}

\section{Type}

A1 Traditional supplies of services and products related to the branch of the company

A2 Customized supplies of services and products based on detailed technical specifications.

A3 Suppliers of innovation (product innovation and/or innovation of manufacturing processes)

B1 Internal R\&D units.

B2 Universities and other institutions.

C1 Strategic Partners - Costumers.

C2 Strategic Partners - Suppliers.

D1 Export markets.

D2 TNCS.

P1 Partners/distribution network.

Importance

A1 Easy to replace, if needed.

A2 Important and difficult to replace by another subcontractor.

A3 Important but possible to replace.

B1 Economic important - influencing the final price of the product.

B2 Economic important - do not influence on price of product.

The customers in the table above are not just customers. They all have taken part in the development of the software XX use in their services.

\section{Impacts}

The establishment and growth of regional subsidaries and subsidaries abroad is the most important impact.

\section{Strategies for the future}

The company has lots of plans for expansion. There are plans for new offices abroad, new subsidaries in Norway and there are also plans for buying existing companies in Norway. 


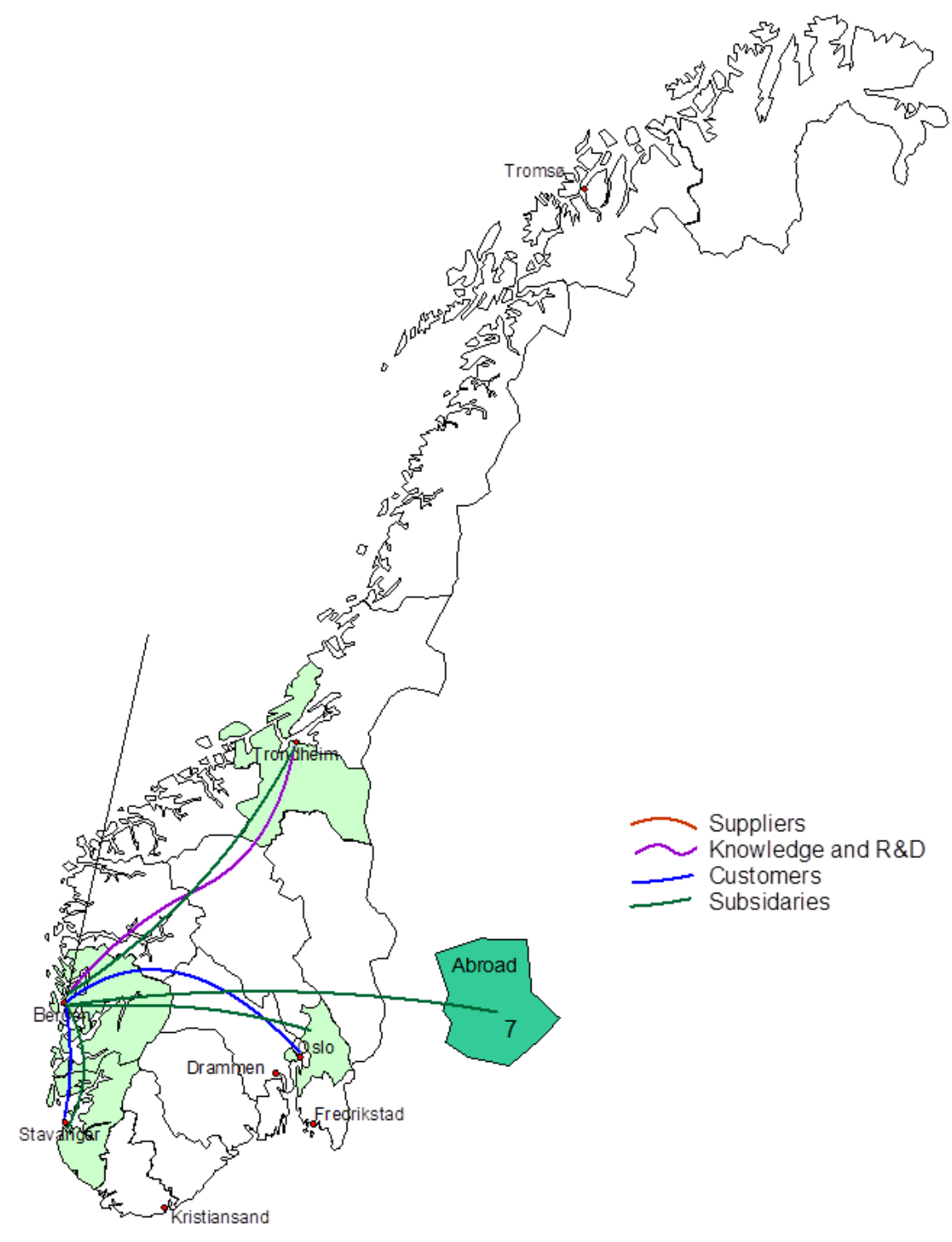

\subsection{Case 3}

Table 18.7

Date of interview

Interviewer

Respondent

Title

Company

City

Country

Status

NACE
2012-01-22

Answering web questionnaire - mail correspondence - web-pages

NN

Director of Communication

$\mathrm{XX}$

Oslo

Norway

Independent company

72.22 


\subsubsection{The company}

$\mathrm{XX}$ is a Scandinavian (fully Norwegian owned) consultancy delivering development and advisory services relating to information technology, interactive communication and enterprise management for the Norwegian market. XX has both large customers with strong relations and more occasional customers with no formal relations.

\subsubsection{R\&D}

No specific R\&D department. Development of services is closely link to cooperation with customers.

Table 18.8. Employees

\begin{tabular}{lrrrrrrrrrrrrr}
\hline & 2000 & 2001 & 2002 & 2003 & 2004 & 2005 & 2006 & 2007 & 2008 & 2009 & 2010 & 2011 \\
\hline Avd Haugesund & & & & & & & & 0 & 0 & 17 & 18 & 21 \\
Avd Oslo & 108 & 128 & 103 & 93 & 93 & 113 & 140 & 189 & 232 & 249 & 253 & 279 \\
Avd Stavanger & & 1 & 1 & 17 & 17 & 22 & 32 & 54 & 88 & 111 & 153 & 205 \\
Avd Bergen & & 1 & 1 & 1 & 1 & 1 & 6 & 8 & 10 & 27 & 30 & 38 \\
Avd Arendal & 1 & 1 & 1 & 1 & 1 & 2 & 3 & 4 & 3 & 3 & 3 \\
Avd Grenland & 1 & 1 & 7 & 7 & 7 & 6 & 6 & 8 & 11 & 14 & 15 \\
Avd Kristiandsand & 1 & 1 & 1 & 1 & 1 & 0 & 0 & 6 & 9 & 11 & 13 \\
Avd Trondheim & 1 & 1 & 7 & 7 & 7 & 10 & 9 & 22 & 25 & 28 & 35 \\
\hline
\end{tabular}

\subsubsection{Products/services (from web site)}

XX provides services described briefly in the following section. However, most deliveries are combinations of the service areas. The customers' needs are the deciding factors.

\subsubsection{Portals}

Today's portals serve the function of being an employee's most important working tool and a company's channel of communication with the public, partners, suppliers and customers. The portal gathers information from multiple underlying systems and facilitates easy access for the user.

\subsubsection{Custom application development}

Standard systems are often considered too general, and needs tailoring to fit the organization perfectly. Custom application development comprises different phases, from planning, mapping of requirements, analysis and design, implementation, testing and deployment. The development process benefits from being agile in order to meet changing demands throughout the process. 


\subsubsection{SAP}

SAP is one of the world's major software suppliers. XX is one of the leading companies within SAP competence in Norway. XX conduct total deliveries of SAP, adjustments, upgrades and enhanced utilization of already installed SAP-modules in addition to integration between SAP and other systems.

\subsubsection{Business Intelligence}

The availability of updated information about business operations and factors that can be of influence is critical in a market characterized by rapid change. The purpose of Business Intelligence (BI) is to collect, analyze and give access to information to obtain an optimal decision basis in order to facilitate qualified decisions and rapid adjustments.

\subsubsection{System integration}

Companies in general own, operate and maintain several different ITsystems. The different systems are often tailored and customized for a limited area. The collection of data from different systems can often provide useful tools for companies and the integration of systems eliminates the process of physically gathering the information. A Service Oriented Architecture (SOA) ensures that the systems support the business' needs and processes optimally. Bouvet has participated in several of the largest Nordic SOA-projects.

\subsubsection{Application management}

$\mathrm{XX}$ has developed a concept for application management. All elements related to an application assignment, such as phone support, corrective maintenance, configuration management, new releases and change management are included in the concept. It also involves activities for development and improvement of the application.

\subsubsection{Education \& training}

XX offers education and training within IT, project management and presentation technique. The courses are held by experts within the subject area. 


\begin{tabular}{llll} 
Table 18.9 Relations & & \\
\hline Name of relation & County & Type & Importance \\
\hline R1 & Oslo/Rogaland & $\mathrm{C} 1$ & $\mathrm{~B} 2$ \\
R2 & Hordaland & $\mathrm{C} 1$ & $\mathrm{~B} 2$ \\
R3 & Oslo & $\mathrm{C} 1$ & $\mathrm{~B} 2$ \\
R4 & Oslo & $\mathrm{C} 1$ & $\mathrm{~B} 2$ \\
R5 & Nordland & $\mathrm{C} 1$ & $\mathrm{~B} 2$ \\
R6 & Akershus (Kolbotn) & $\mathrm{A} 2$ & $\mathrm{~A} 2$ \\
R7 & USA & $\mathrm{A} 2$ & $\mathrm{~A} 2$ \\
R8 & Akershus (Bærum) & $\mathrm{A} 2$ & \\
+ Regional offices (see above) & & & \\
+ Three offices in Sweden & & & \\
\hline
\end{tabular}

Type

A1 Traditional supplies of services and products related to the branch of the company.

A2 Customized supplies of services and products based on detailed technical specifications.

A3 Suppliers of innovation (product innovation and/or innovation of manufacturing processes).

B1 Internal R\&D units.

B2 Universities and other institutions.

C1 Strategic Partners - Costumers.

C2 Strategic Partners - Suppliers.

D1 Export markets.

D2 TNCs.

P1 Partners/distribution network.

Importance

A1 Easy to replace, if needed.

A2 Important and difficult to replace by another subcontractor.

A3 Important but possible to replace.

B1 Economic important - influencing the final price of the product.

B2 Economic important - do not influence on price of product.

XX also mentions 26 different software companies as their "partners." But of those, only three have formal ties to XX and are included as "relations."

\section{Impacts}

NN stresses that the most important impact for regional development is the establishment and growth of XX regional offices.

Strategies for the future

The company has plans for new regional offices in various parts of Norway. 


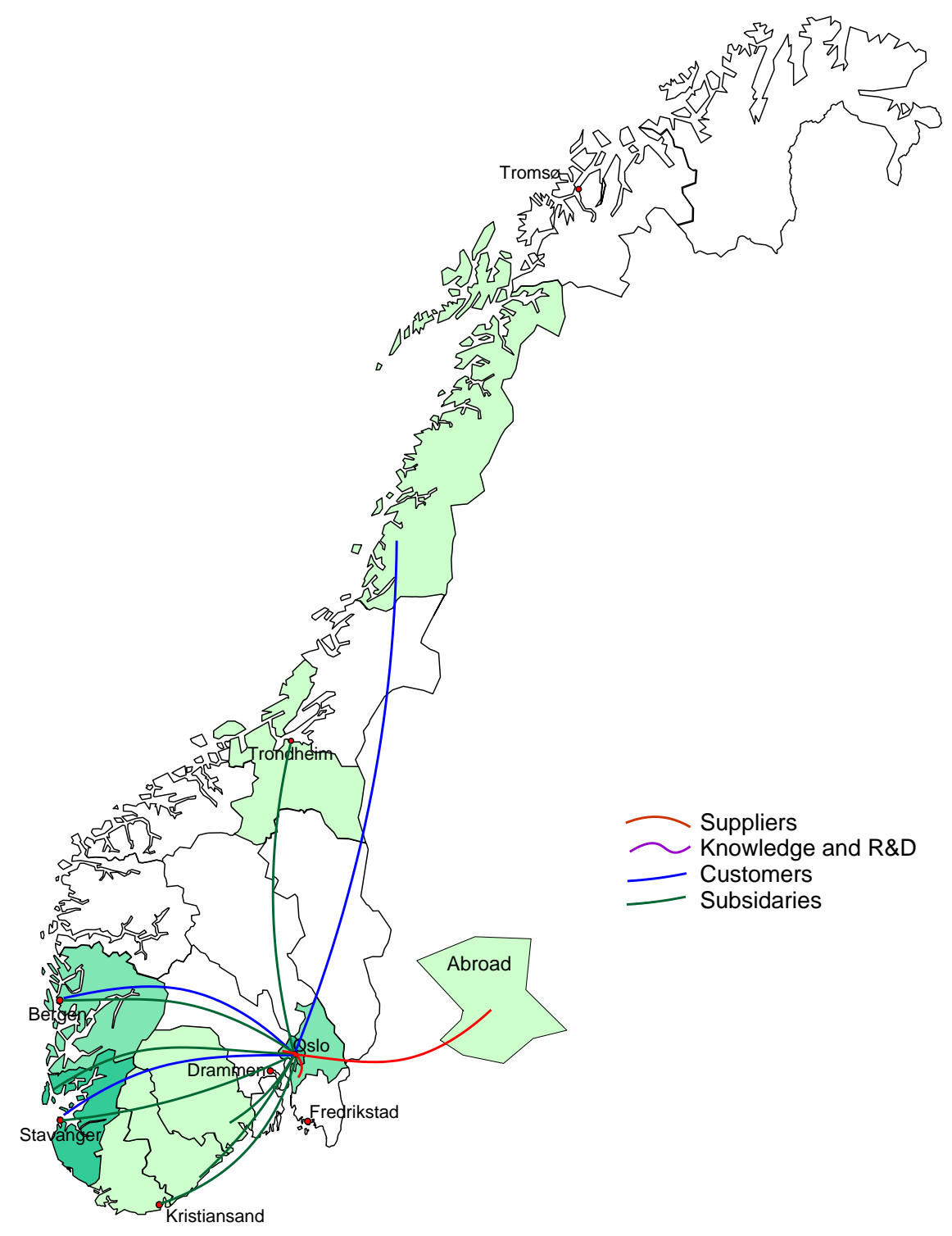

\subsection{Case 4}

\section{Table 18.10}

Date of interview

Type of interview

Respondent

Title

Company

Address

City

Country

Status

NACE
2012-01-22

Answering web questionnaire - mail correspondence - web-pages

NN

Head of Administration

$\mathrm{XX}$

Oslo

Norway

Independent company

72.30 


\subsubsection{The company}

$\mathrm{XX}$ is a Norwegian owned independent company. Its market is national, but concentrated on some few large customers. The company does not have any strategy for R\&D or other kind of further development of service, but says that interaction with the customer is very important.

Table 18.11. Employees

\begin{tabular}{ccccccccccc}
\hline 2001 & 2002 & 2003 & 2004 & 2005 & 2006 & 2007 & 2008 & 2009 & 2010 & 2011 \\
\hline 7 & 27 & 22 & 22 & 27 & 42 & 42 & 72 & 80 & 79 & 86 \\
\hline
\end{tabular}

\subsubsection{Products/services}

$\mathrm{XX}$ is the leading provider of IT as a service at a fixed price. XX take total responsibility for their customers' IT environment, and offers a flexible and scalable IT platform. Through targeted and focused work, they have developed specialized processes and support tools to optimize the IT infrastructure for small and medium-sized businesses.

\begin{tabular}{llll} 
Table 18.12 Relations & & & \\
\hline Name of relation & County & Type & Importance \\
\hline R1 & Oslo & A1 & A2 \\
R2 & Akershus & A1 & A3 \\
R3 & Akershus & A1 & A3 \\
R4 & Akershus & A0 & A3 \\
R5 & Oslo & C1 & B2 \\
R6 & Oslo & C1 & B2 \\
R7 & Oslo & A0 & A1 \\
R8 & Oslo & A0 & B1
\end{tabular}

Type

A1 Traditional supplies of services and products related to the branch of the company.

A2 Customized supplies of services and products based on detailed technical specifications.

A3 Suppliers of innovation (product innovation and/or innovation of manufacturing processes).

B1 Internal R\&D units.

B2 Universities and other institutions.

C1 Strategic Partners - Costumers.

C2 Strategic Partners - Suppliers.

D1 Export markets.

D2 TNCs.

P1 Partners/distribution network.

Importance

A1 Easy to replace, if needed.

A2 Important and difficult to replace by another subcontractor.

A3 Important but possible to replace.

B1 Economic important - influencing the final price of the product.

B2 Economic important - do not influence on price of product.

\section{Impacts}

No further impact.

\section{Strategies for the future}

$\mathrm{XX}$ is planning new relations with other companies within same county. 


\section{Mapping}

There are few links outside Oslo/Akershus, so no need for mapping.

\subsection{Case 5}

\begin{tabular}{ll} 
Table $\mathbf{1 8 . 1 3}$ & \\
\hline Date of interview & 2012-01-22 \\
Type of interview & Ordinary face-to-face interview \\
Interviewer & Frants Gundersen \\
Respondent & NN \\
Title & Head of production \\
Company & \\
Address & Oslo \\
City & Norway \\
Country & Subsidiary \\
Status & 29.56 \\
NACE & XX \\
Mother company & Oslo \\
City & Norway \\
Country &
\end{tabular}

\subsubsection{The company}

Subsidary of XX.

This structure was established in 2010. We have therefore not numbers of employees or turnover for just the subsidary.

In $2010 \mathrm{XX}$ was divided into three entities. The number of employees for the main company:

Table 18.14

\begin{tabular}{ccc}
\hline 2000 & 2008 & 2011 \\
\hline 13 & 23 & 43 \\
\hline
\end{tabular}

\subsubsection{Products/services}

$\mathrm{XX}$ offers an interdisciplinary environment with expertise in the fields of mechanical and electrical solutions. $\mathrm{XX}$ is a technology company specialised in engineering, automation, solar, aviation, HMI / Industrial IT and mechanical special production. All mechanical, hydraulic, pneumatic and electric assembly takes place in their own production hall, as well as they provide assembly and SATs at their customer's location. The machine park consists of CNC-controlled milling machines and lathes as well as manual machines. They perform both serial and special production. XX also holds expertise in tool making and 3D machining. All completed projects will be test run in their production hall before installation at the customers'. 


\subsubsection{R\&D}

No internal R\&D department, but one of the other subsidaries (in Sweden) serves the company as R\&D-provider, fousing on development rather than research. In addition, this other subsidary has some special competence in mechanical engineering that the Norwegian companies don't have, and they collaborate when needed. Further development of products is done closely in cooperation with customers, often "on-site" where they install the product.

\begin{tabular}{llll} 
Table 18.15 Relations & & \\
\hline Name of relation & County & Type & Importance \\
\hline R1 & Oslo & B1 & \\
R2 & Buskerud & A1 & A1 \\
R3 & Akershus (Asker) & A1 & A1 \\
R4 & Hedmark (Elverum) & A1 & A1 \\
R5 & Østfold (Fredrikstad) & A1 & A1 \\
R6 & Sweden & B1 & A2 \\
R7 & Oslo & C1 & B2 \\
R8 & Telemark & C1 & B2 \\
R9 & Oslo & C1 & B2 \\
R10 & Oslo & C1 & B2 \\
R11 & Oslo & B2 \\
\hline
\end{tabular}

\section{Type}

A1 Traditional supplies of services and products related to the branch of the company.

A2 Customized supplies of services and products based on detailed technical specifications.

A3 Suppliers of innovation (product innovation and/or innovation of manufacturing processes)

B1 Internal R\&D units.

B2 Universities and other institutions.

C1 Strategic Partners - Costumers.

C2 Strategic Partners - Suppliers.

D1 Export markets.

D2 TNCs.

P1 Partners/distribution network.

Importance

A1 Easy to replace, if needed.

A2 Important and difficult to replace by another subcontractor.

A3 Important but possible to replace.

B1 Economic important - influencing the final price of the product.

B2 Economic important - do not influence on price of product.

\section{Impacts}

No spin offs, but in 2006 they purchased a company in Sweden.

\section{Strategies for the future}

After restructuring in 2010, there are no plans for further expansions.

\section{Evaluation of geographical importance}

It was not important to be located in a large urban milieu for the sake of skilled workforce or relations to knowledge institutions. But to be close to the customers was very important. 


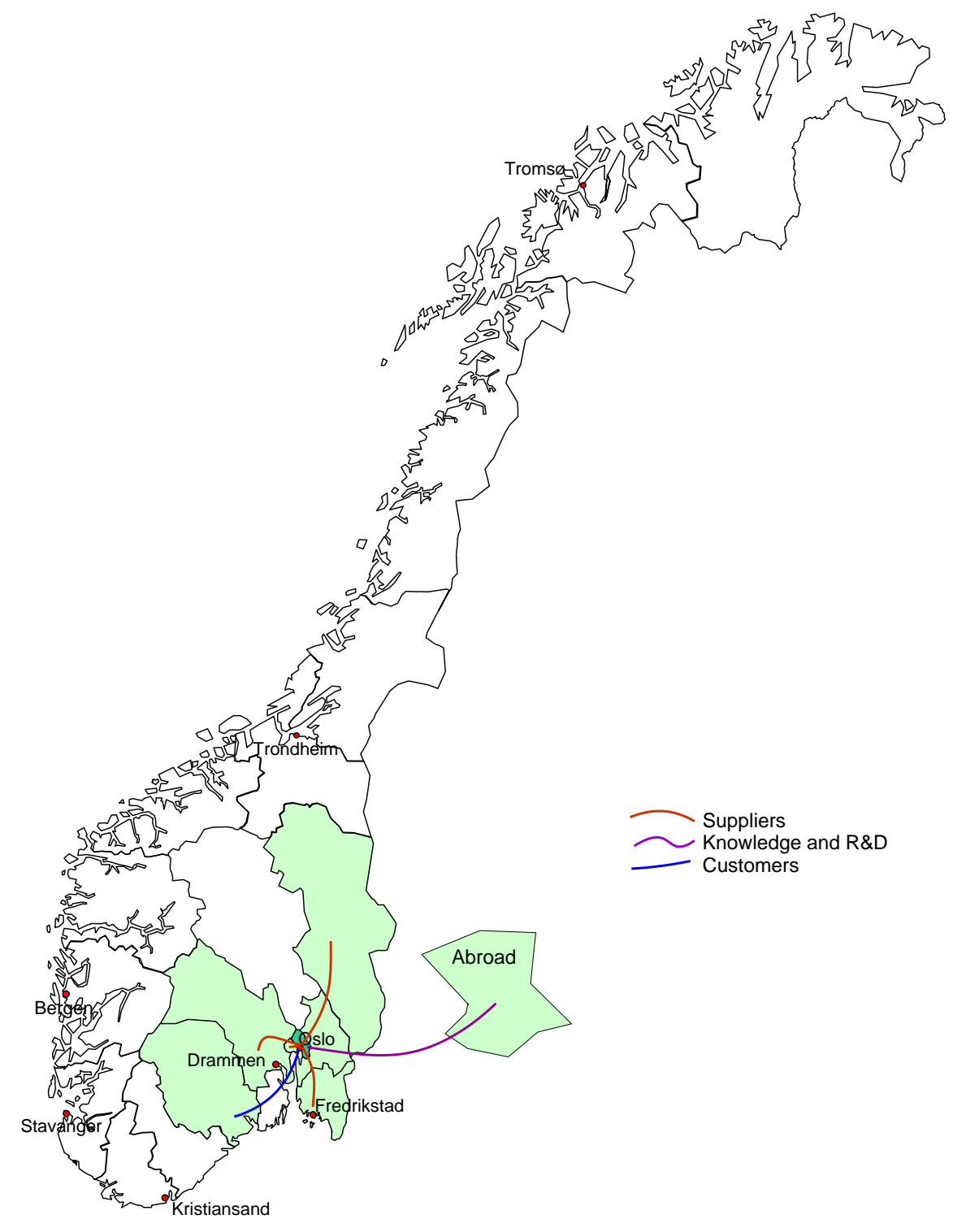




\section{Part 4 - Sweden}

Marcus Adolphson, Mats Johansson 



\section{Introduction}

According to guidelines in the Nordic joint research project Urban Patterns of Growth (URAG0) a number of companies in Sweden have been interviewed. The overall argument for the study is the European political goal to develop the European Union towards a competitive and prosperous actor on the global scene. Due to this issue economic resources shall be invested in - from an economic point of view - lagging areas. Still, the economic trade of in terms of economic growth and social welfare is disputed. For instance, according to the growth pole theory prosperous firms in growth regions "generating localized growth in the hinterland" (McCann 2001: 61). The main channel for this economic distribution effect is the "customer-supplier relationship" (McCann 2001: 60). The Nordic countries differ from the situation on the continental Europe in terms of volume and spatial distributions of people and firms. Due to this situation there is in a Nordic context a need of a further understanding concerning business networks and regional economic distribution effects of economic activities.

The aim is here to describe and understand possible regional effects of business activities in Sweden. According to the project application it is the relations between companies and their geography that shall be in focus of the project. The central research questions are: "Where are the growth effects of the most important knowledge driven enterprises of the large cities localised? Are these effects transmitted in local and regional networks, or is it so that mutual growth effects are dominated by linkages between the large cities? Framed otherwise, what are the urban systems (/patterns) of the growth effects?."

The project shall according to the application investigate the above mentioned problems by mapping the geography of the empirically verified relations of the knowledge driven enterprises. The sampling of enterprises shall be based upon interviews and theories of geographical enterprise relations.

In order to be able to present both a typical and broad picture of regional effects of economic growth a wide range of business types in three interesting urban regions have been selected. The selection process is based on four criteria: location, economic growth, size and representativeness of the business. The firms should be located in one of the two major metropolitan regions Stockholm and Göteborg characterised by a considerable growth during the last forty years or within the industrial cluster of Timrå in the northern part of Sweden. The industrial cluster of Timrå is regarded as an interesting study area from a European 
point of view as a consequence of its unique location - even if it is from a Swedish point of view a rather representative location. In order to be able to map the business network firms of a small-medium size employing in most cases 50-100 people are selected. The firms are usually in the manufacturing industry although in one case within the fashion industry and in another case in both innovation and services (programming/know how) sectors.

The firms in branches of "Manufacture of other special machinery," "Manufacture of bodies for motor vehicles," "Manufacture of semimanufactured plastics," "Manufacture of instruments and appliances for measuring, testing and navigation," "Industrial and product design activities" were selected using a combination of the service provided on "121.nu" and "Proff-the business finder web" web sites. Usually the purchase manager or the Chief Executive Officer was contacted.

In the interviews the same set of questions was used, see appendix 1. The interviews were recorded and the recordings were then documented and the information on the geographical relations was mapped. 


\section{Empirical findings}

Below there is a short description of the companies interviewed, their products, main markets, subcontractors. Results from the interviews regarding economies of urbanisation and localisation, and history are not comprised.

\subsection{Companies in the Göteborg region}

\subsubsection{Company \#1}

SNI Code: 28990 Manufacture of other special machinery Interview of Person \#1, purchasing HSE and Quality, 01.03.2012.

Introduction and presentation of the company and the main product Company \#1 has had a broad range of product types in their production. Nowadays their main products are gas turbines and various steel constructions. The main market is the off shore Norwegian oil industry. Subcontractors are to $90 \%$ local-regional and to $10 \%$ national, see Map 19.1. Company \#1 strive for long-term relationship with their suppliers. Most of the procedures connected to development and innovation is accomplished within the company. However, customized suppliers of certain importance are concentrated to the region in proximity to Company \#1. Standardized suppliers have a more geographically wide distribution - however regionally biased.

The history (the tale) of the Company \#1 is quite amazing. In the early 1960s the head of the company the Company \#X Person \#X had an great interest in football and specially in the local soccer team Team \#X. In about 1960 Team \#X was in great need of success. Person \#Y from Lödöse (near Göteborg) soccer team was then contracted for the center position - and was also employed at the Company \#Z3 drawing office. Person \#Y made drawings for Company \#Z3 in the weeks and scored for Team \#X in the weekends. Person \#Y realised that optic drawings was the future in this business and started Person \#Y Company \#Y located just outside Uddevalla. Person \#Y Company \#Y then developed into Company \#Z (still existing with offices in Uddevalla, Göteborg and Shanghai) and other business connected to maritime activities. The company Company \#Z1 was purchased in the early 1980s. All companies served each other with staff, material, equipment, etc. In the $1960 \mathrm{~s}$ Company \#Z2 made complete installation for the production of paper in 
the pulp industry. The company Company \#1 was established in 1980 as a result of focusing some of the business in Company \#Z2 in one specific company. Today the production is concentrated into two kinds of business: material for the off shore industry and gas turbines. The head office is located in Uddevalla. No subsidiary companies of Company \#1 exist (but a number of sister companies). The main products are heavy constructions for the off shore industry, gas turbines and steel constructions for the energy business. Most water power plants. The turnover in the year 2000 was about SEK 75 million and in 2010 SEK 130 million

\section{Innovation, design, research and development}

According to Person \#1 there are no specific activities in reserach and development.

\section{The markets}

The products for the off shore industry is solely located in the Norwegian west coast and for gas turbines, steel constructions and power plants the mid Sweden is the dominating market area. Company \#1 has basically monopoly in this segment of capacity in constructing large steel constructions and complete assembly in Scandinavia.

\section{Organisation}

Private owned by Person \#X (Person \#Ys son).

\section{Map19.1: Company \#1, organisation and market areas}

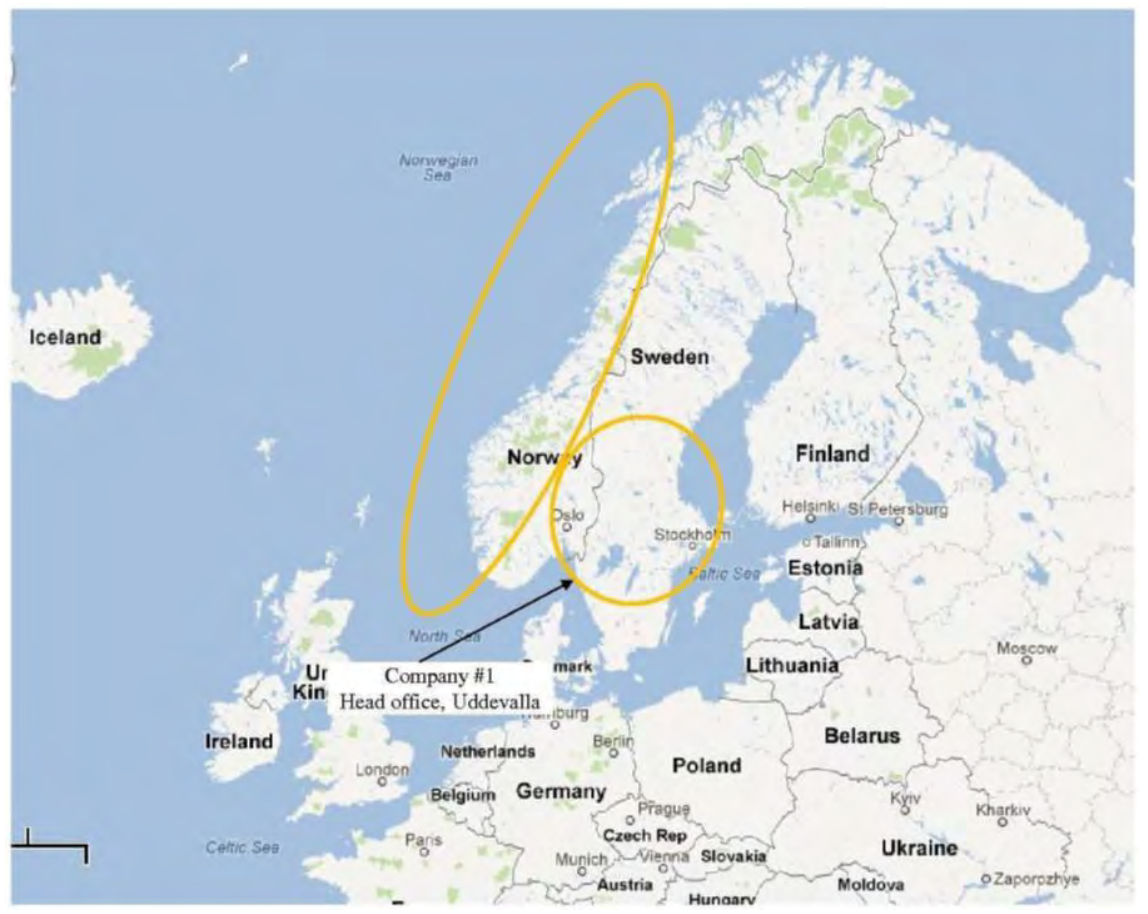




\section{Subcontractors}

Company \#1 has in total about 400 subcontractors of various importance. Traditional and historically important suppliers delivering countered plate are located in the local region (Uddevalla, Trollhät$\tan )$. One exception was when one of the purchasers was fond of speaking the German language and then some of the suppliers were actually located in Germany. However, no sub-components are standardized. Customized suppliers are also mainly in the local region however occasionally - and historically - some of these subcontractors are located abroad for instance in Finland (although with selling office on the Swedish west coast - Halmstad), Norway and Estonia. These subcontractors are also linked to pursuit of cost minimizing. Specialized goods and services are also available in the local region (occasionally in Germany). Company \#1 does not - in spite of previous activities - invest time in innovation and development. Still, the machinery is quite specialized and is imported from Taiwan - however provided by sales offices the in southern part of Sweden.

\section{Map 19.2. Company \#1. Distribution of subcontractors}

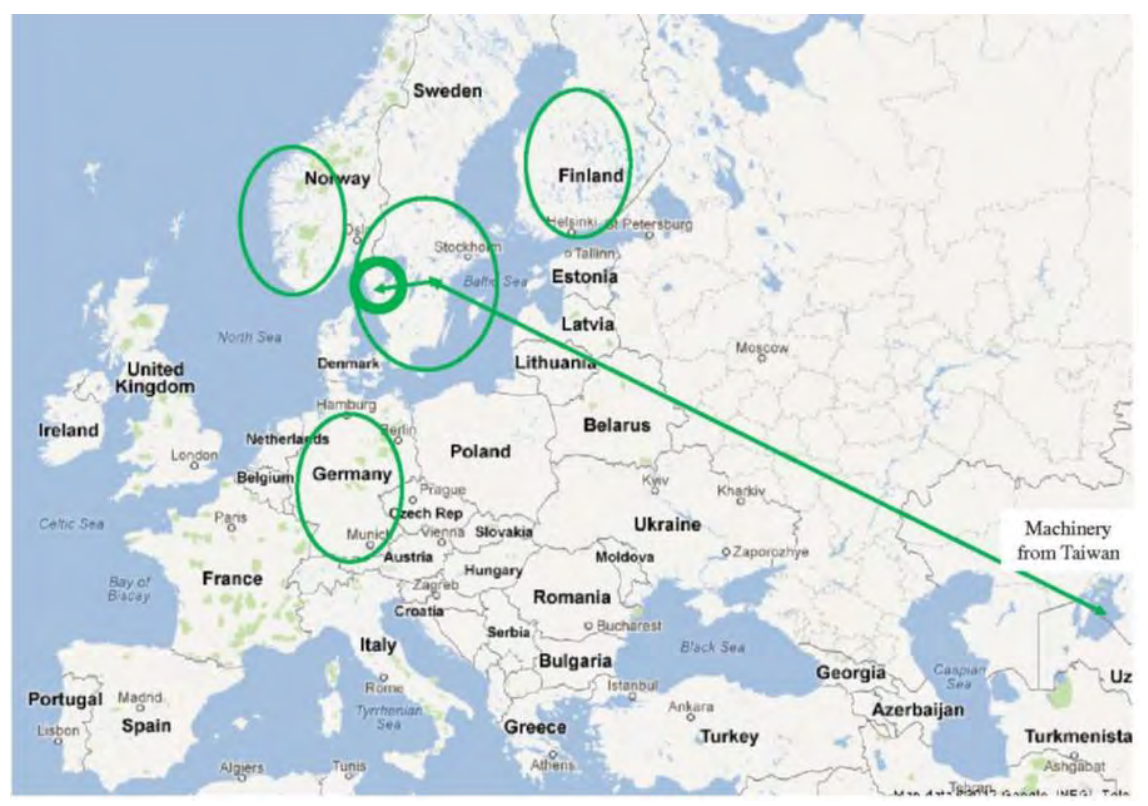




\section{Spatial effects}

Most employees live in the local region (Uddevalla, Göteborg, Trollhättan). Company \#1 is aware of the economic spin off effects in the local region. There is a spirit of regarding the industry as the fundament in the regional economy. Cooperation in education takes place with Siemens in the nearby Trollhättan and not in Uddevalla. Economies of localisation concerning the workforce are apparent. However, these effects are more regional comprising also Göteborg and parts of Norway. Also in the handling of large volume of material there is an awareness of common synergies between companies in the local region.

\section{Spatial prerequisites}

The location in a City region comprising Vänersborg and Trollhättan provides all skills in different business areas as advertising, business law, etc, needed. The highway system and the nearby harbour are considered to be of importance.

\section{Future plans}

The most important subcontractors are (always) under risk analysis and alternatives in the region are continuously considered. There are no plans for new markets. The potential of the Norwegian off shore market is regarded as immense.

\subsubsection{Company \#2}

46420 - Wholesale of clothing and footwear

Interview with Person \#2, Chief Financial Officer, 03.03.2012.

\section{Introduction and presentation of the company and the main product}

Company \#2 started 2001. It is a national company located in Göteborg, Sweden. The main product is fashion in jeans trousers and assessors. There are three owners where one of these worked initially in the Lee Company. The mother company is "Svenska Jeans AB." The mother company comprises Company \#2 Retail $\mathrm{AB}$ and Company \#2 Marketing AB. 50 people are employed. Company \#2 Marketing head office is located in Göteborg. The turnover 2000 was SEK 0 and in 2010 SEK 358 million. Company \#2's main business is the design and marketing of jeans. The production is maintained by subcontractors. One main pronounced competitive advantage is sustainable production and consumption, quality, control, agreements with, and revisions of subcontractors. This interest in sustainability is expressed as organically produced cotton, social sustainable production and engagement in Fair-trade foundation and Amnesty International. The trousers are also possible to repair and sell back to the company. Cost minimizing is not of great concern. 


\section{Innovation, design, research and development}

The design and development processes take place at the Company \#2 Marketing in Göteborg. Except for the experts employed at Company \#2 no specialists in specific design are temporarily contracted. Input for the design process is provided by subcontractors, sales offices, and distributors in the markets as well as visits at various exhibitions. Product development regarding material, etc is maintained in cooperation with a subcontractor in Italy. Apparently the washing procedure is an important sequence in the production procedure. No cooperation with universities or art schools is going on. No strategic partners are associated with Company \#2 Marketing AB. In summary design and development is an "in house" business.

\section{The markets}

Basically the market is global. The north part of Europe is managed by Company \#2 Marketing AB themselves. South part of Europe is managed by an associated company in Germany. Other markets are North America, South Korea and Japan, and Australia. 20\% of sales volume takes place in Sweden, rest of Europe 40\%, 10\% etc for North America, South Korea-Japan and Australia each.

\section{Map 19.3: Company \#2, organisation and markets}

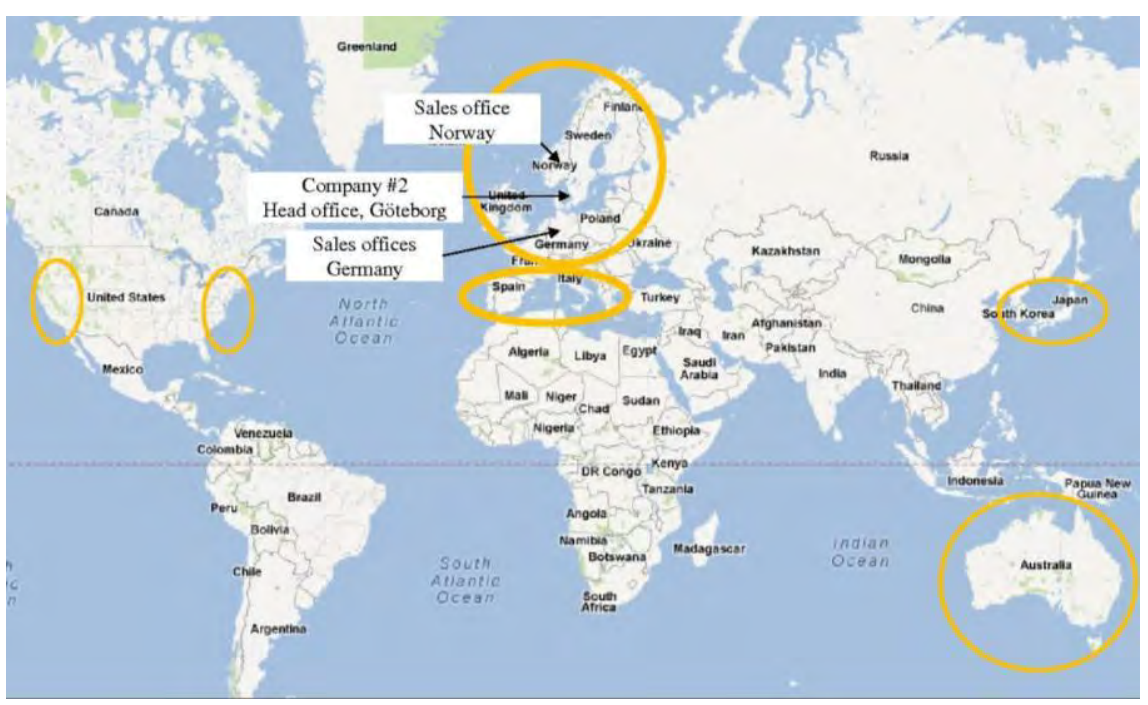




\section{Subcontractors}

Subcontractors of traditional supply for instance office material are purchased locally. Customised supply comprising IT support, software for economy and business managements, advice in law and business are provided in the local region. Software - and support of this kind of software - for the design process is provided in the region (Borås). The subcontractors in the material production - mainly in the Bologna-Perugia region in Italy - deliver the volume of complete products based on the design guidelines provided by Company \#2 Marketing AB. Thus, Company \#2 Marketing AB does not purchase any material for the production process. Most subcontractors are of historical importance (long term relations are one of the main ambitions in the company's ideology). Still important, these subcontractors are regarded as replaceable. No subcontractors are contracted because of cost minimization. Due to EU regulations the production for the Italian market is also transported from Italy and stored at the warehouse at Borås.

\section{Map 19.4: Company \#2. Spatial distribution of subcontractors}

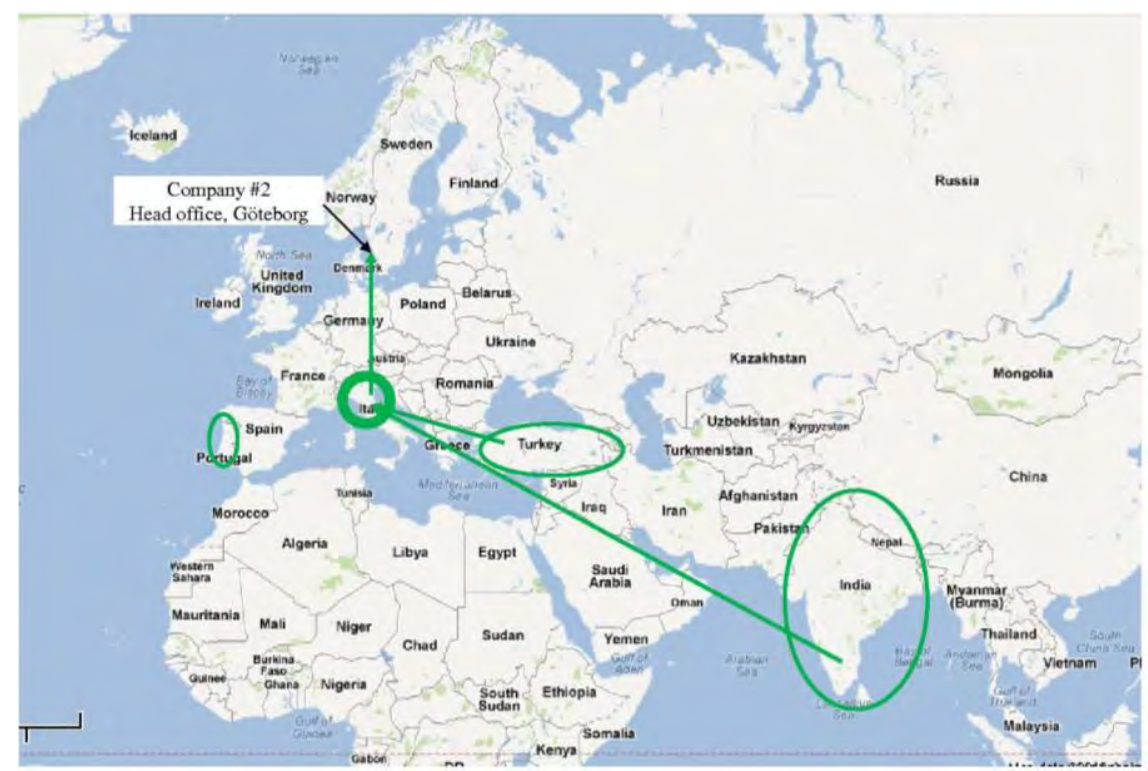




\section{Spatial spin-off effect}

Most employees at Company \#2 Marketing AB live in great Göteborg. The local economic effects of employment at Company \#2 are not an issue of concern. A localisation process related to economies of localisation - companies with similar activities are located in the neighbourhood - is not apparent. However, a company working with storage service has developed in Borås. This company has also contracts with other firms and synergies in transportation take place.

\section{Spatial prerequisites}

The urban environment is of great importance in order to attract skilled staff at the head office in Göteborg. Transport infrastructure is of intermediate importance.

\section{Future plans}

The ambition is to expand within existing market regions.

\subsection{Companies in the Stockholm region}

\subsubsection{Company \#3}

29200 - Manufacture of bodies for motor vehicles, manufacture of trailers and semi-trailers.

Interview with Person \#3, owner and CEO, 23.02.2012.

\section{Introduction and presentation of the company and the main product}

The head office of Company \#3 is located in Mariefred, in the periphery of the Stockholm Region. No subsidiary companies exist but "sister companies." Turnover the in year 2000 was SEK 240 millions and in 2010 SEK 53 millions (2009 SEK 181 millions). Company \#3 is a manufacturing company. The main products are building modules and containers. The simplest product is a steel construction and the most high tech product is a building module for backup power supply or modules for research in animal production comprising ventilation, heating system, regulation systems, waste management, etc. The Company \#3 manages the turn key contract and then coordinate a number of subcontractors. Usually the module is completed in the Company \#3 and then delivered in one piece.

Company \#3 produces containers/building modules for a number of different uses. Some not specialised, some specialised. For instance, their containers could comprise components for telecommunication, testing of engines for Scania trucks, animal production, TV production, laboratories for medicine testing and production, etc. Depending of the customer Company \#3 delivers a plain steel container or a completely equipped unit according to the specification of customer. The market is 
generally Nordic however occasionally worldwide. Although rather unspecialized production the subcontractors are evenly spread over Sweden - however biased towards the local-regional hinterland. Any difference between traditional, standardised and customized suppliers - according to their geographical distribution - cannot be interpreted.

\section{Map 19.5: Company \#3. Market areas}

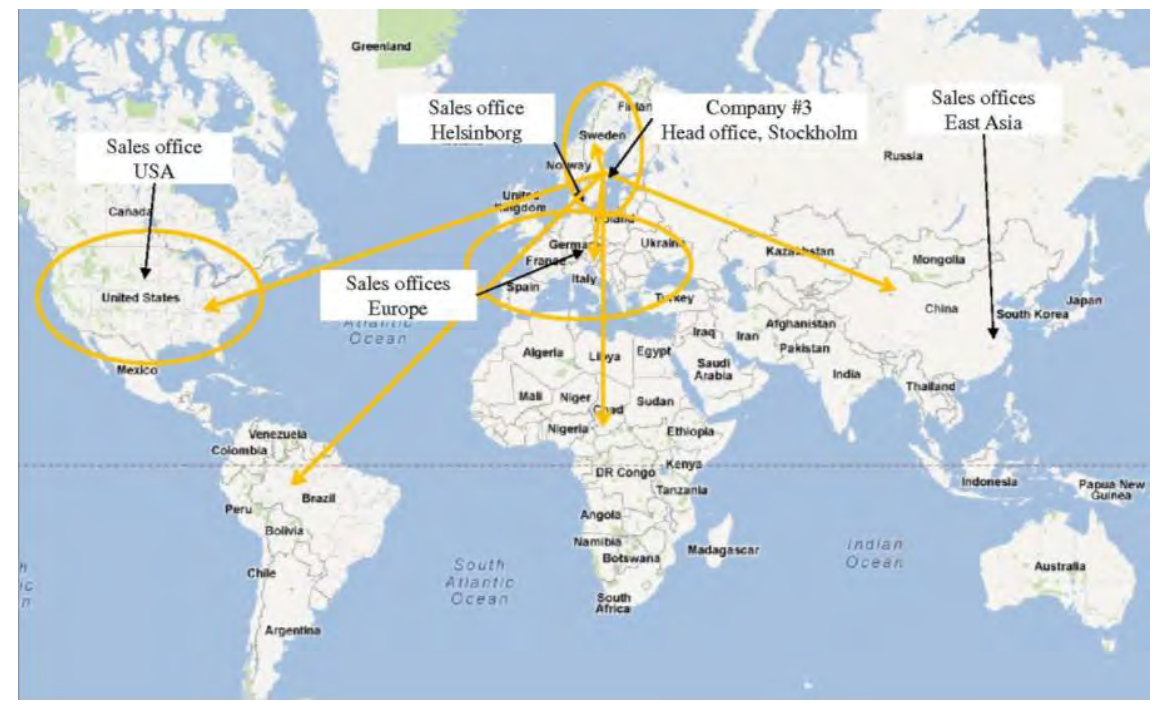

\section{Innovation, design, research and development}

Development and innovations are managed in cooperation with the customers.

\section{The markets}

The market is mainly national. Occasionally also in Norway, Denmark, (India and South America).

\section{Subcontractors}

Regional/national subcontractors deliver standard products as steel (Tibnor), plate (Gujab), isolation, electric components (Ahlsell, Sellberg) and paint (Hempel). And local subcontractors provide carpeting, etc. Customized supplies of paint and isolation material are provided by Nordfarbo in north of Sweden (Kramfors). Subcontractors are almost evenly distributed all over Sweden however with a concentration in the Mälardalen region. The total number of subcontractors is about $100.5 \%$ are local in the municipality. The rest $95 \%$ are evenly distributed all over Sweden. Power systems are provided by companies located in Eastern Europe although with sales companies located in Sweden. Subcontractors of strategic importance are supplier of paint and isolation. No subcontractors could be linked to great volume of material and cost minimizing pursue. 


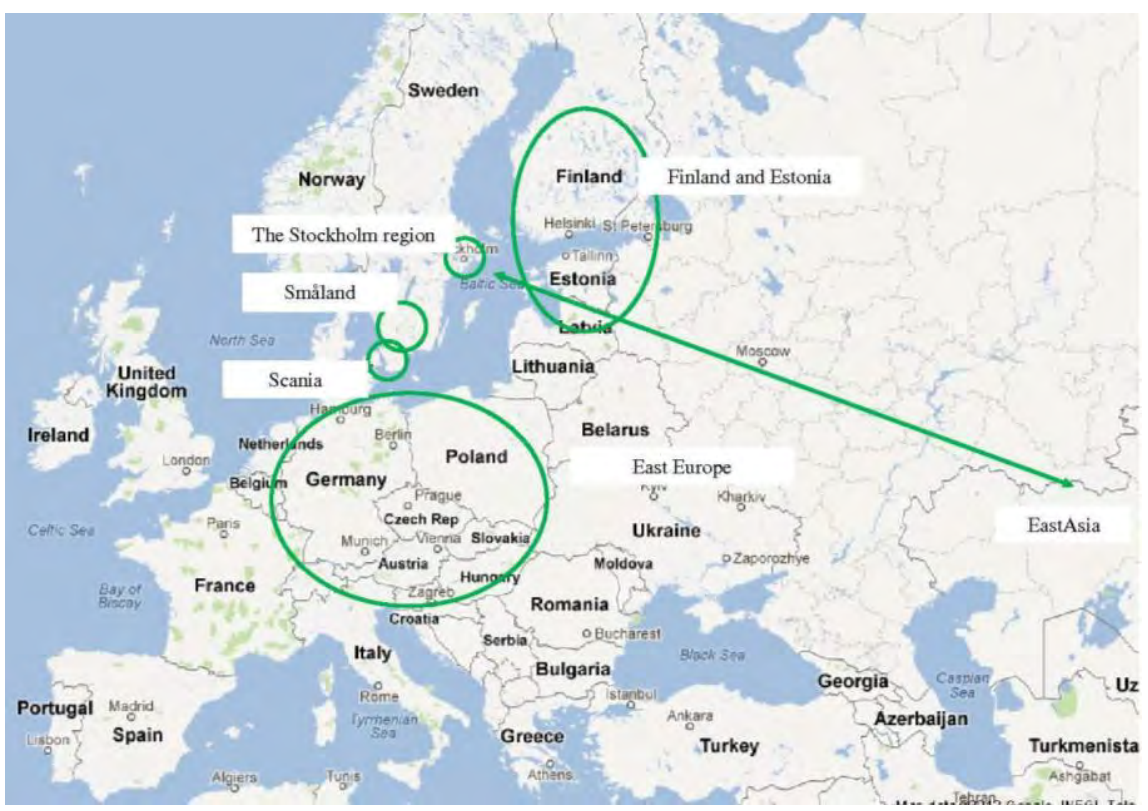

\section{Spatial spin-off effect}

Most employees at Company \#3 live in the local region and the extended local region covering Strängnäs, Eskilstuna and to some degree also at further distances in Sweden (weekly commuting). Some of the employees are also since the 1980s working at Company \#3 part time (Swedish wages) of the year and then return to Eastern Europe during vacations and other times. Company \#3 is well aware about local economic spinoff effects regarding effects of the employee's local consumption. Effects due to economies of localisation or urbanisation - flows of goods, employees, services, and localisation of subcontractors or services with other kinds of business as economy, law, etc - are not apparent.

\section{Spatial prerequisites}

The access to the Stockholm city region is of great importance with proximity to large companies as Scania and various construction companies. Access to business management, advertising connected to the Stockholm region is of no advantage. External environmental effects linked to the production process imply conflicts with the urban expansion of Mariefred. These kinds of consequences constrain future expansion of the industrial activity. Recent investments in transport infrastructure are regarded as mainly positive. Company \#3 is also one main local landowner.

\section{Future plans}

Expansion by the purchase of a workforce agency - already linked to Company \#3 - is planned. Any new network of subcontractors is not planned. 


\subsubsection{Company \#4}

- SNI code 26510 - Manufacture of instruments and appliances for measuring, testing and navigation.

- SNI code 62010 - Computer Programming.

- SNI code 71122 - Technical consulting in industrial engineering.

- Interview with Person \#4, CEO and co-owner, 28.03.2012.

Introduction and presentation of the company and the main product Company \#4 started 1985 by three friends with professional experiences in digital and analogue imaging. The aim was to create a flexible, efficient, small business managed by friends. The office is located in the industrial cluster in Kista, Stockholm. The ownership is national. Company \#4 is active within a range of services within the electronic and programming branch. The main product is consultancy and product development regarding software and electronics focused on imaging (other kinds of technique development also take place). Still, their core production is "cameras" and image management for testing production qualities within a range of industries such as truck production (SCANIA), air force (SAAB Gripen) but also tile production. Company \#4's field of specialization is the programming for image management, but also complete camera prototypes. All their business are characterised by innovation and development. When the prototype is developed in its final design the production is taken over by the customer. Business using Company \#4's products and services are for instance quality control for the car industry regarding active safety issues. Market areas are the car industry and the military industry. The prototype is delivered by Company \#4 and the production is then managed by the customer. Turn over the year 2000 was SEK 15 million and in 2010 SEK 18.6 million. Company \#4 are co-located (in the same section of an office building) with two other complementary companies (which are jointly owned).

\section{Innovation, design, research and development}

Innovations, design and development are Company \#4's main activities. Still specific development for instance design of optics and mechanics are subcontracted to local specialists in the northern part of Stockholm and Uppsala. Strategic partners do exist with companies that are active in complementary business. 


\section{The markets}

The market is regional and concentrated to Mälardalen region: Södertälje - Stockholm - Uppsala. A number of companies are present. These companies are however NTCs, for instance within the car and food industry. Even though Company \#4's market is national; they compete with other international companies. As the products basically are innovation and development of unique prototypes and not mass production the competition from low cost countries is not regarded as a main problem.

Map 19.7: Company \#4. Customers are located in the Mälardalen region but end users are globally distributed

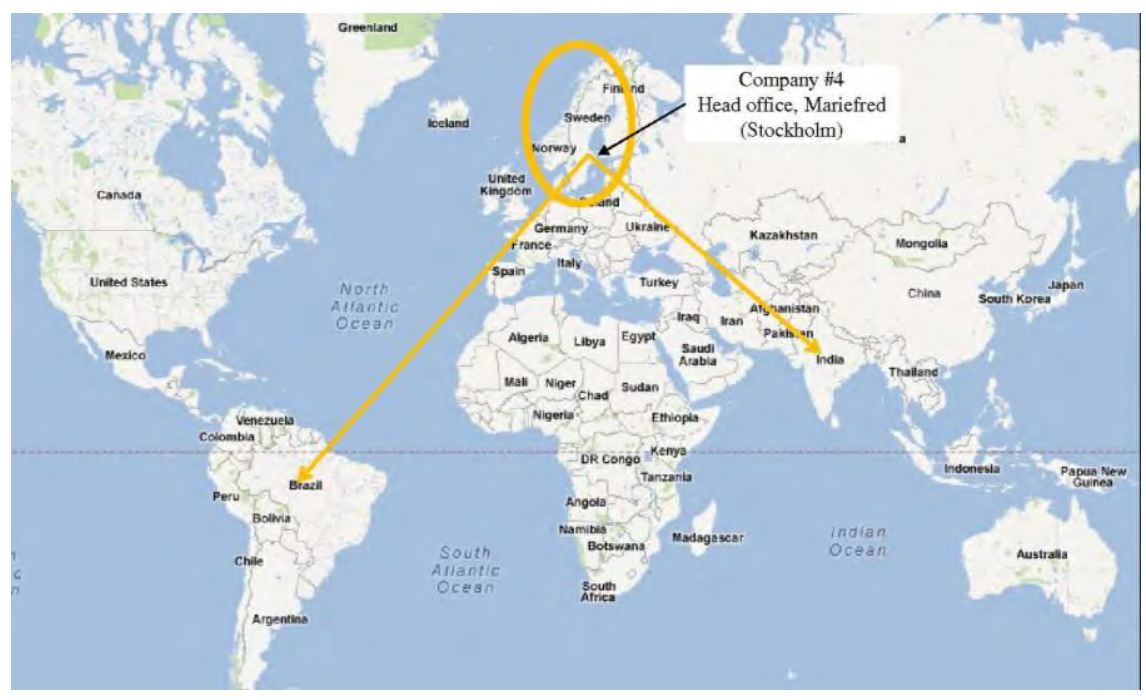

\section{Subcontractors}

The network of subcontractors is evenly spread over Sweden however strongly biased towards the Stockholm Region. In their production the partners, developing and customized suppliers are mainly located locally in the northwestern part of Stockholm. Once again innovation and development are their main services. One traditional/standardised although in some sense knowledge based and developing supplier - is however located in Mumbai, India.

Suppliers of standard products like economic revision, local cleaning, etc are purchased from the local market. Standardized circuit boards are also purchased mostly within the Stockholm region as well as from the global market: China, England, the Baltic countries. Suppliers of customized products like prototypes for circuit boards are mostly locally produced. Although it occurs that these kinds of services are located in China. Especially one historically important subcontractor delivering low cost customized products is located in India. Due to the need of communication proximity still is of great importance. Mechanical work is also subcontracted in the local region. One of the subcontractors in the local region has been linked to Company \#4 since 20 
years and is considered to be of historical importance. Others exist as well. Subcontractors of strategic importance - difficult to replace - do not exist. Subcontractors of economic importance - providing cheap components or service - do neither exist.

\section{Map 19.8: Company \#4. Spatial distribution of subcontractors}

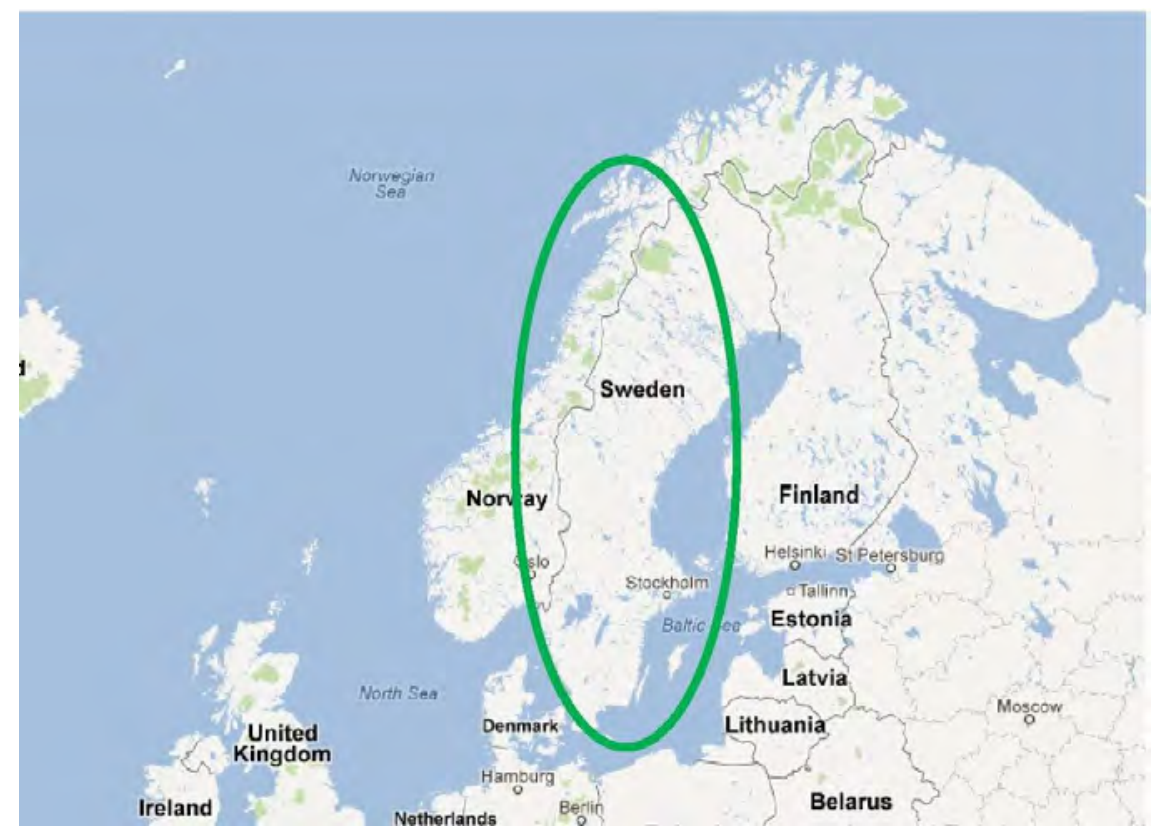

\section{Spatial effects}

The two co-located companies have an international orientation focused on the military industry. Basically Company \#4 supplies these two firms with knowledge, service and physical products. There is also a transfer of knowledge from this cooperation into Company \#4. The marketing aspect is also of importance in this network of companies. Thus economies of localisation are of great importance. Most employees live in great Stockholm. However, people living in radius of $150-200 \mathrm{~km}$ (Tierp, Rimbo, Kolmården) work at distance and have income from Company \#4. Company \#4 does not consider the economic effects on the regions. Economies of localisation concerning human resources exist both for input and output. However, these aspects are not apparent in the daily activities at Company \#4. However, the argument for the localisation of Company \#4 in Kista initially was due to proximity to one important customer - SAAB (that today is relocated). Economies of localisation concerning similar customers are not apparent. Basically, Company \#4 consider themselves as a quite small company that is located in proximity to other companies of similar or greater size. A sort of implicit network of companies is formed. This network in turn functions as a sort of market of subcontractors for greater companies. The location in the 
Kista and the Stockholm region is a conscious choice of Company \#4 in order to be part of this market of sub contractors. Economies of localisation are thus prevailing.

\section{Spatial prerequisites}

The location in an economically diverse city region where it is easy to access specialises in various businesses is of great importance. The proximity to a technically diverse city region is important. Proximity to similar companies and potential customers are also of importance. Transport infrastructure is important concerning accessibility for employees and customers.

\section{Future plans}

No specific expansion into new markets is planned. Company \#4 has a "flexible-low risk-high cost" ambition to increase turnover by contracting new subcontractors. Still, one ambition is to expand the business by also cover manufacturing, management, services and update of delivered products.

\subsubsection{Company \#5}

- SNI code 28250 - Manufacture of machinery and apparatus for cooling and ventilation equipment for household.

- SNI code 28990 - Manufacture of other special purpose machinery.

- Interview with Person \#5, Chief Financial Officer 08.05.2012.

\section{Introduction and presentation of the product}

Company \#5 started in the 1970s and has been located on the same location in Eriksbergs industrial cluster (Norsborg, Stockholm) since then. Company \#5 manufacture portable and stationary dust extractors. Turnover in the year 2000 was SEK 155 million, and in 2011 SEK 214 million. Company \#5 is specialized in point dust extraction for a variety of business as for pharmaceutical production, construction, food production, aerospace industry, combustion and printing, etc. The dust extractor's main parts are the motor, the separator, the filter and the chassis. In comparison with other firms the capacity of the filter and its technical integration in the extractor is Company \#5's competitive advantage. All parts of the extractors are designed (although not manufactured) and put together by Company \#5.

\section{Innovation, design, research and development}

Design and innovation are in-house processes achieved by a development group in the company. Also subcontractors at the European level participate in long term development. 
Map 19.9: Company \#5. Market areas

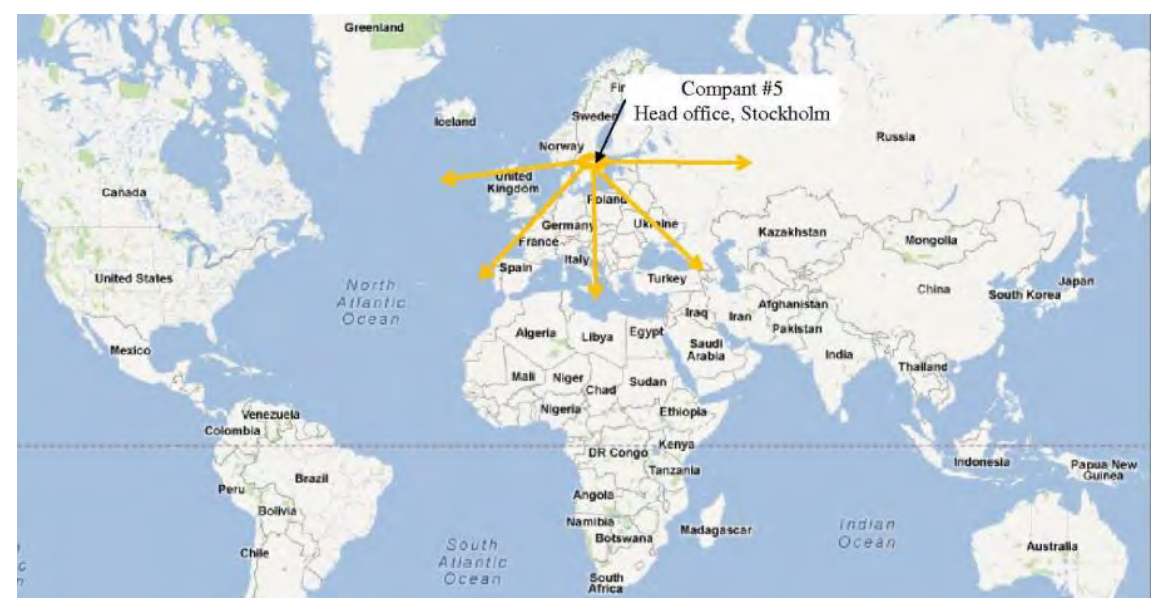

\section{The market}

The market is distributed on equal parts (25\%) on Sweden, Germany, United States and the rest of the world. In Sweden the construction business dominates and in Germany and USA pharmacy business dominates. On the national level in Sweden the Stockholm region dominates the market. Company \#5 has sales offices in all global regions as well as in Helsingborg and Stockholm.

The customers are more or less global and cover all continents except Africa. In all market regions Company \#5 has local offices that produce service, provision of installations, etc.

\section{Subcontractors}

Subcontractors of standardized product supply are mainly local within the Stockholm region (although some products are originally manufactured globally). Customized suppliers of services and products cover all of Sweden and are therefore mainly national - although Finland, Estonia and Asia are present as well. Long term relations are important and sometimes dominate the interest of minimizing transport costs. Suppliers connected to large volumes of supply are naturally sensitive to manufacturing and transport costs. Economically important subcontractors are located in east Europe, China and East Asia. Although due to the rather low production volume and grade of specialization this kind of subcontractors is not of great importance for Company \#5's economic performance.

A considerable degree of the subcontractors is of historical importance. This category is mainly located and evenly distributed between national regions: the Stockholm, the Småland regions, and one on the European level in Germany. One Subcontractor, located in Skåne, is noted as of strategic importance.

Subcontractors are mainly from the Stockholm and Småland regions. 


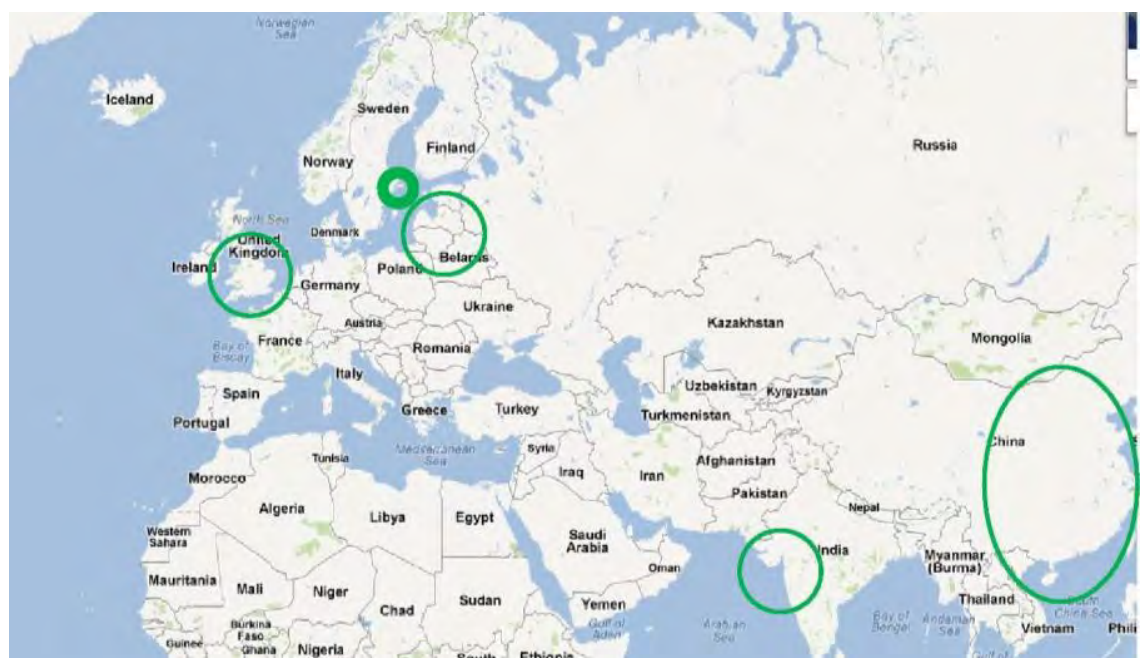

\section{Spatial effects}

Most employees live in the neighbouring suburbs as Botkyrka, Tumba, Södertälje and the Stockholm region in general. Thus the economic distribution effects due to wages and consumption are of local character. Company \#5 are also aware about these local economic effects. No specialists from other countries are employed.

Company \#5 has been located on the same location (Norsborg, Stockholm) since 1970s. Processes due to economies of localisations are not apparent except for transportation and cooperation regarding standard products for office activities. One subcontractor with close relation to the production process is located in the region (Södertälje) thus not in the industrial cluster of Eriksberg in Norsborg. Processes due to economies of urbanisation are not apparent.

\section{Spatial prerequisites}

Company \#5 does not regard the location in a metropolitan city region to be of importance. Local opportunities for expansion and restriction for production processes in Eriksberg are sufficient. No desires or plans for relocation exist. Most transports (daily) within Sweden and Europe take place by trucks. Proximity to the highway system (E4) is therefore important. Shipping services take place in Göteborg. The railway system is of no importance. Access to Arlanda airport is also of importance both for goods transport (subcontractors and customers) and for meetings abroad.

\section{Future plans}

The ambition is to grow organically by the sell offices in each global region. Except for investments in storage capacity in Germany no specific plans to expand in a new global region exists. 


\subsection{Companies in the industrial cluster of Timrå}

\subsubsection{Company \#6}

- SNI code 22210 Manufacture of semi-manufactured plastics.

- Interview with Person \#6, owner and CEO 22.03.2012.

Introduction and presentation of the company and the main product Company \#6 started in 1983. The main product at that time was a fibreglass sheet for isolation with possibilities for direct wallpapering. However, this product was not a success and the work was difficult to introduce in the construction firms as there was difficulties to decide what kind of profession that should do - according to the agreements with the unions - this job. The location in Timrå is due to favourable attitudes from Timrå municipality (about $50 \mathrm{~km}$ north of Sundsvall) reasons. The increase in employees from around 10 to 28 started in about 2003. The head office also comprising development and manufacturing is located in Timra and a second production unit is located in the nearby city of Sundsvall. The main products are used for interior constructions where the balance between strength, weight, fire risks is of main concern. The most important product is thus a light and fire- resistant moulded sheet of fibreglass composite. Standardised and traditional suppliers providing components for the manufacturing process are located nationally in Sweden and also in the continental northwest part of Europe. Company \#6's products are mainly used within the high speed trains for the Chinese and European market - as well as in the shipping industry. The turnover the year 2000 was SEK 6.5 millions. Turnover the year 2010 was SEK 35 millions. Ownerships are distributed between one Swedish private owner and three Nordic companies.

\section{Innovation, design, research and development}

Most innovation, research and development procedures take place at Company \#6. Loose plans for recruiting educated staff for research and development exist. Sufficient education exists in the local region. There is also cooperation with the University of Sundsvall. Development also takes place at the subcontractors. Strategic partners exist both among subcontractors and customers - however usually on informal basis.

\section{The market}

Customers are located in China and Europe. However, the end products are distributed all over the world. Thus, the market is global. 
Map 19.11: Company \#6. Spatial distribution of consumers

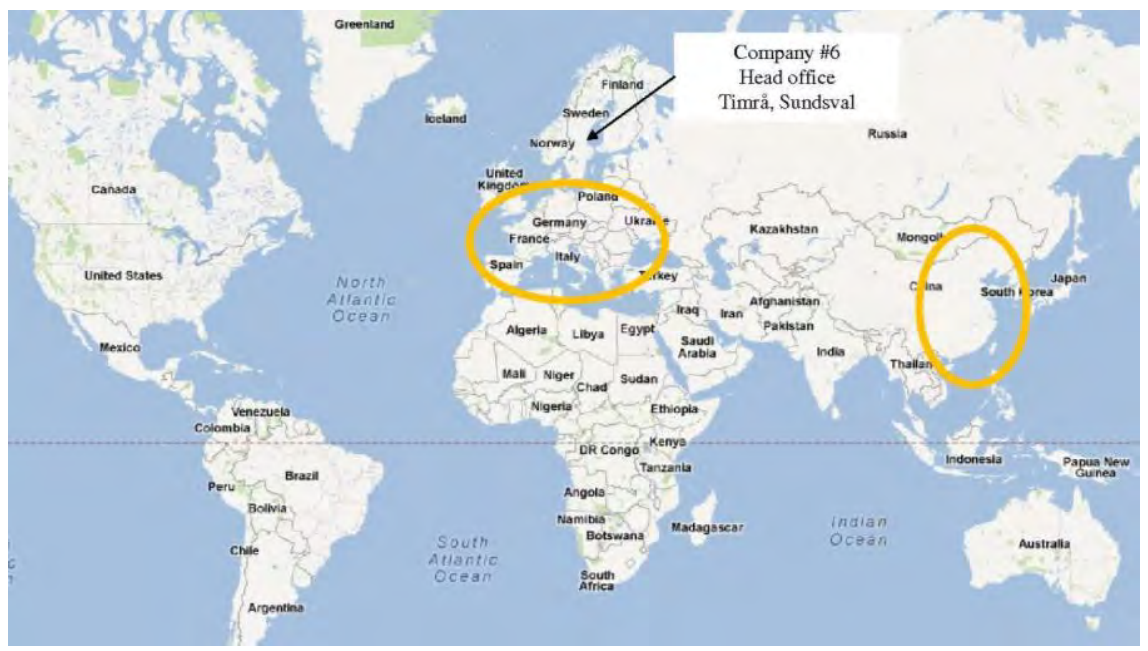

\section{Subcontractors}

Company \#6 works with three kinds of standard products: fibreglass, binding agent and another component for foaming. The foaming component is provided from subcontractors located in the local region. The binding component is delivered by subcontractors in south-west Sweden and Norway. Fibreglass is provided from subcontractors in France, Germany, UK and Finland and subcontractors of historical importance exist. Subcontractors of strategic, historic and economic importance exist both in the region and in Europe (1/3 the local region, 1/3 national and $1 / 3$ in the continental Europe).

\section{Map 19.12. Company \#6. Spatial distribution of subcontractors}

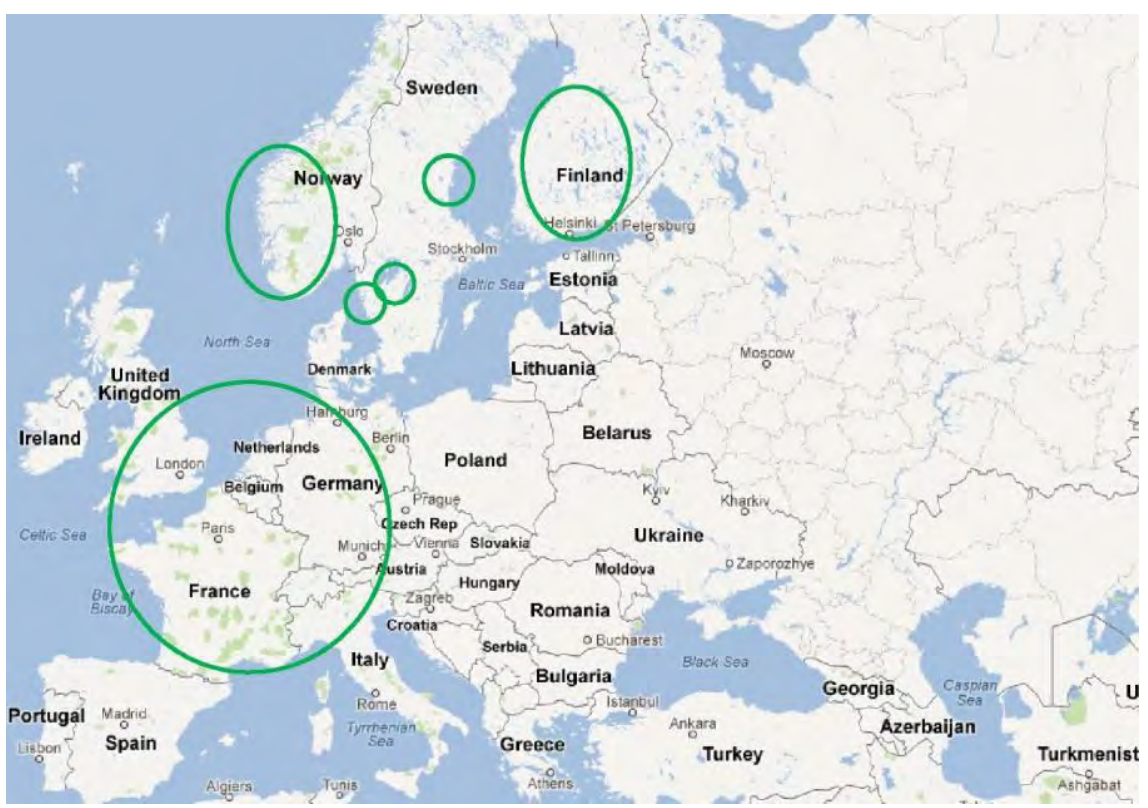




\section{Spatial effects}

Employees and therefore also wages are distributed in the local region: Härnösand, Timrå and Sundsvall. One full time employee is however located in China. Company \#6 is aware about economic spin off effects although this is not of main concern. The effect of these spin-offs is, however, expressed as a favourably disposed municipality in Timrå and local funders for local investments in production units. Other local subcontractors exist in the local region. However, no new localisations of these kinds of sub-tractors are apparent. There is always a trade-off between distance and quality. Specialised subcontractors that would be of great advantage to have in the neighbourhood - according to the high demand of communication in these relations - are - according to the high degree of specialisation - not available in the local region. Further on, Company \#6 is not aware of any spatial synergies linked to economies of localization.

\section{Spatial prerequisites}

Urban environment with access to mixed service linked to a city region is of importance. The local industrial environment not sensitive to local disturbance and with opportunities for physical expansion for new production capacity is also of importance. Access to transportation infrastructure as the high way (E4), railway and harbour in Sundsvall is of importance. Also the airport in Timrå is important. Transport costs are substantial.

\section{Future plans}

Possibly future international expansion. 


\section{Analysis}

The analysis provides evidence that the theory by Duranton and Puga (2000) have an explanatory value. Specialised companies working with innovation and testing need a diverse urban environment. When the production process then is further standardised the production take place in minor or medium sized towns, and/or in the periphery of the great cities.

\subsection{Differences in focus and degree of innovation}

When incorporating the degree of innovation, the spatial distribution of companies investigated and the spatial distribution of networks of subcontractors and customers follows Duranton and Pugas (2000) theories on the relation between degree of innovation in the production process and localisation in a diverse urban milieu, see Table 20.1. All companies investigated are innovative. They produce customized high qualitative products for a dynamic market. In four of the six companies investigated - Company \#1, Company \#3, Company \#5 and Company \#6 - the innovation process and the production process are integrated and co-located. In the remaining two companies - Company \#2 and Company \#4 - these functions are separated. The first companies are hereafter named: Production-Innovation Companies (PIC) and the second is here after named Innovation Companies (IC). ICs could in turn be divided into two kinds of companies: "order producing" (Company \#4) and "volume producing" (Company \#2). PICs are "business-to-business" types of companies. This means also that in the branches where ICs are active there is a need of this kind of specialisation in pure innovation in the production process. There is thus an increasing marginal productivity in these kinds of branches when the time spent on an innovation increases (Duranton and Puga, 2000). Company \#2 and Company \#4 however differ in between in the aspect of the role of customers and others, see below. Where Company \#4 has a well defined customer with whom they specify the product, this is not the case for Company \#2. 


\section{Production-Innovation Companies (PICs)}

The PICs are basically located in medium sized cities and/or in the periphery of great cities. They compose standardised components into new customized products. Their subcontractors providing these standardized (although of high quality) products (steel, paint, fibreglass, etc) are located in - and this an assumption - the urban periphery of small or medium sized cities. These cities might be national or international. If the components either have high complexity or are of high quality then control and communication and hence also proximity are of great importance. However, due to the degree of specialization (standardized products could naturally also be specialised) and thereby great market areas (due to the need of a critical mass of consumers) these products are not always possible to get in the local region. Thus, a tension between proximity and specialisation appear (see below under conclusion). Company \#3 slightly differs from this scheme. Possibly by cultivating long term relationship Company \#3 might achieve sufficient control and communication in spite of long distances. Transport costs seem to be of minor importance. Therefore in this example there is no need of contracting new subcontractors of similar standardized high qualitative products in the local region.

\section{Innovation Companies (ICs)}

The ICs are located in central urban positions. Company \#2's main product is design. However, if the end customized products is included it is composed of standardized components. Company \#4 and Company \#2 differ in this and other aspects. For instance, some of the subcomponents that are composed are for Company \#4 customized products and for Company \#2 standardized products. Therefore Company \#4's products are here regarded as not only customized complex - but also complicated (the sub-components are customized and imply innovative subcontractor) products. This high degree of complexity (and absence of production) implies for Company \#4 a need of communication with subcontractors and customers in the production process. This, need of communication is facilitated by their central urban position and proximity to subcontractors and customers. This is not really the case for Company \#2. According to the rather low degree of complexity and thereby also a rather low need of communication and control regarding the production process there is no need of co-locate the design process and the production process. Company \#2's central position might be explained by proximity to human resources and location preferences according to their lifestyles (Glaeser and Gottlieb 2006). The spatial distribution of market areas also differ. Company \#4's customers are located in the local region, end users are however globally located. Company \#2's customers are globally distributed. 
The common division between the production and the innovation process seems to be for different reasons. In the case of Company \#4 the high degree of complexity in the branch implies a situation where the division between innovation and production imply efficiency. The need of communication imply however a need of co-location. On the other hand in the case of Company \#2 the situation seems to be almost the opposite. The low degree of complexity implies no need of co-location. Still, the need of specialised human resources with specific lifestyles in the innovation process implies a need of a central inner city location. 
Table 20.1: Comparison of companies

\begin{tabular}{|c|c|c|c|c|c|c|}
\hline & Company \#4 & Company \#2 & Company \#1 & Company \#3 & Company \#5 & Company \#6 \\
\hline Type & IC & IC & PIC & PIC & PIC & PIC \\
\hline Location & City & Central City & $\begin{array}{l}\text { Periphery medi- } \\
\text { um/great City }\end{array}$ & Periphery medium City & Periphery great City & Periphery minor/medium City \\
\hline Product & $\begin{array}{l}\text { An idea } \\
\text { Complex, complicated } \\
\text { and complete products } \\
\text { for end users }\end{array}$ & $\begin{array}{l}\text { An idea } \\
\text { (Complex and com- } \\
\text { plete products for end } \\
\text { users) }\end{array}$ & $\begin{array}{l}\text { Steel constructions and } \\
\text { gas turbines Complex } \\
\text { and complete products } \\
\text { for end users }\end{array}$ & $\begin{array}{l}\text { Building modules Occasionally } \\
\text { complex and complete prod- } \\
\text { ucts for end users }\end{array}$ & $\begin{array}{l}\text { Dust extractors } \\
\text { Complex and complete products for } \\
\text { end users }\end{array}$ & $\begin{array}{l}\text { Fibreglass moulded sheets } \\
\text { Complete products for end users }\end{array}$ \\
\hline Components & $\begin{array}{l}\text { Non- standardized and } \\
\text { standardized }\end{array}$ & Standardized & Standardized & Standardized & Standardized & Standardized \\
\hline $\begin{array}{l}\text { Subcontractors' } \\
\text { location }\end{array}$ & $\begin{array}{l}\text { National } \\
\text { Central great City }\end{array}$ & International & $\begin{array}{l}\text { National } \\
\text { Periphery Medium City }\end{array}$ & $\begin{array}{l}\text { National/ } \\
\text { International } \\
\text { Periphery }\end{array}$ & $\begin{array}{l}\text { National/ } \\
\text { international }\end{array}$ & $\begin{array}{l}\text { National/ } \\
\text { International }\end{array}$ \\
\hline Customers & Local regional & International & Nordic & National & International & International \\
\hline Spin off & Local & International & Regional & National & National/International & Regional/National/International \\
\hline
\end{tabular}




\section{Discussion}

\subsection{Main message}

This investigation verifies the growth pole theory. There is a general spread of economic growth into the regions due to the growth of companies in the major city regions. Still, the distribution effects varies dependent of the degree of complexity in the production process. High complexity and complicity in the production process demands both testing opportunities of various methods and investments in communication between the subcontractors, the companies and the customers. These kinds of network develop within city regions. Therefore, growths of these kinds of companies are rather local. On the other hand, growths in medium complex companies who use standardised subcomponents usually buy these products regionally or nationally. Here a dichotomy between complexity and distance appear. When there is a complex/high qualitative product the great need of communication implies a favour for proximity between subcontractors, companies and consumer. On the other hand if the level of specialisation is high these products are usually not available in the region or perhaps not nationally either. In order to produce regional economic spread effects the sub-components should have a medium level of complexity and specialisation. If the components are to complex, the need of communication increases and a city position is to prefer. If the components are too special, the market areas of the sub-components increases and they might not be available on the national level.

\subsection{Critical assessment}

The size of the selected firms has implied, not only that the number of business relations has been manageable, but also that the complexity in products and in production procedures have been rather narrow. Thereby one of the focuses in the URAGO project concerning the distribution of "knowledge driven business" has been somewhat constrained. Even though all business is related to specialization and knowledge, the complexity in their products varies. The population is also quite small - only six companies have been analysed. Therefore the general conclusions presented here should be interpreted carefully. 


\subsection{Conclusion}

Even though there are some exceptions it seems as if distance matters. If possible, standardized products and services are purchased within the local area. However, large volumes of standardized products are bought from the cheapest provider even though these providers are globally located (see Company \#4). Long term relations might also give rise to a wider catchment area concerning standardized products (see Company \#3).

Any kind of network patterns possible to distinguish between different kinds of regions is not possible to extract from the empirical finding. The reason might be the limited number of - and different kinds of - companies in various kinds of geographical settings. For some of the companies local and regional networks are of high value (Company \#1), for other companies (Company \#3) these circumstances are of minor importance. However, one interesting outcome regarding the networks appears: On the one hand the value of proximity increases when the complexity of the products increases. The reason is the need of investment in communication in the production process. On the other hand, as the complexity in the products process increases the distance between contractors and sub-contractors also tend to increase. The reason is that specialised products and services need a vast market area in order to provide a critical mass of consumers. In other words, it is not easy to find a specialised producer in minor regions and towns. In order to overcome this difficulty complex production processes take place in large city regions where the critical mass of customers (business to business) is large enough (see Company \#4). This conclusion supports the Chistaller Central place theory and the findings presented by Duranton et al (2000). Thus, a further specialisation might imply a spatial extension of the networks - or a need of relocation.

There are regional effects due to economic growth in the major urban regions. If production process uses complex components the effects are local. If the production process uses specialised components and standard components there is a risk that these components are provided on the international market. Thus there is a trade off that comprise distance, complexity, specialisation and standardization.

\subsection{References}

Duranton, G. \& Puga, D. (2000). Diversity and Specialisation in cities: Why, Where and When does it matter? Urban studies (37) 3, 533-55.

Glaeser, E.L. \& Gottlieb, J. D. (2006). Urban resurgence and the consumer city. Urban Studies 43 (8), 1275-1299.

McCann, P. (2001). Urban and regional economics. Oxford: Oxford University Press. 


\section{Appendix 1 (in Swedish)}

\subsection{Introduktion}

Nedan följer ett antal frågor som vi vill ha belysta i projektet. Avsikten är inte att ni ska besvara frågorna nu - utan att ni under intervjun besvarar de frågor ni kan besvara och de frågor ni anser lämpliga att besvara. Exakt hur ert företag väljer att besvara dessa frågor under intervjun och hur ert företag vill att svaren slutgiltigt ska presenteras i forskningsprojektet avgör ni naturligtvis själva. Exempelvis så kanske ert företag inte vill ange namnet på alla underleverantörer - men kan tänka sig att ange bransch och lokalisering (stad/kommun). Dessa frågor ska ses som ett underlag för intervjun och inte som en exakt specifikation. Viss ändring av frågorna kan förekomma. Om Ni har några frågor eller synpunkter på formuleringarna nedan så är Ni mycket välkommen att höra av er via telefon eller e-post.

\subsection{Grundläggande frågor om företaget}

- Var ligger ert företags huvudkontor?

- Var finns ev. dotterbolag (tillverkning och FoU)?

- Vilken SNI kod har företaget?

- Är ägandet av företaget nationellt eller utländskt?

\subsection{Relationer}

Förbindelserna mellan bolaget - å ena sidan, och leverantörer och marknader - å andra sidan identifieras, lokaliseras och kvantifieras nedan. 


\subsection{Identifikation}

\subsubsection{Produkt relationer: Varifrån levereras följande produkter och tjänster?}

- Traditionella leveranser av tjänster och produkter relaterade till branschen, t.ex. "standard produkter och tjänster."

- Anpassade leveranser av tjänster och produkter, t ex utifrån tekniska specifikationer.

- Leverantörer av innovationer (produktinnovationer och/eller innovationer av tillverkningsprocesser).

- Kunskap, forskning och utveckling (FoU).

- Bedriver företaget egen forskning och utveckling?

- Samarbetar företaget med universitet eller andra forsknings/utvecklingsinstitutioner?

- Har företaget strategiska partners för sin forskning och utveckling?

- Hur ser marknaden ut?

- Den är lokal: Vilka kommuner?

- Den är regional: Vilka län?

- Den är nationell.

- Den är internationell: Vilka länder/regioner?

- Var bor företagets/arbetställets anställda?

- Lokalt i staden.

- Lokalt i kommunen.

- Regionalt i länet: Vilka kommuner?

- Nationellt.

- Internationellt: Vilka länder?

\subsection{Kvantifiering}

- Vilka underleverantörer är av "historisk betydelse" (pålitliga)?

- Vilka underleverantörer är av "strategisk betydelse" (t.ex. relaterade till kärnprodukt, FoU, långvarig)?

- Det vill säga: svåra att ersätta med en annan underleverantör, eller viktiga, men möjliga att ersätta.

- Vilka underleverantörer är "ekonomisk viktiga" (t.ex. billig arbetskraft eller leverantörer av stora marknadssegment)?

- Det vill säga: de har stor inverkan på priset (de leveranser som är kostsamma och påverka det slutliga priset på produkten). 


\subsection{Effekter}

Vilken typ av påverkan på stads- och regional utveckling är ert företag medvetet om? Se exempelvis alternativen nedan:

- "Spin off" från företaget: andra företag lokaliseras i staden regionen pga att:

- Era anställda tjänar pengar som genererar en efterfrågan på orten eller i regionen.

- Ert företag attraherar en viss typ av arbetskraft vars kvalifikationer andra företag är intresserad av.

- Ert företag attraherar en viss typ av kunder vars efterfrågan andra företag är intresserad av.

- Ert företag generar varuflöden eller behov av tjänster andra företag också är intresserad av.

- Underleverantörer som lokaliseras i närheten av ert företag.

\subsection{Strategier för framtiden}

Var (stad, kommun, region, land, annat land) planerar bolaget för eventuell expansion i framtiden? Med avseende på:

- Nya underleverantörer och marknader.

- Nya dotterbolag.

\subsection{Utvärdering av geografisk betydelse}

Hur vikig är nedanstående miljöer för ert företags lokalisering? Betygsätt 1-3!

- Urban miljö (storstadsmiljö) med stort utbud av varor, tjänster, olika typer av arbetskraft.

- Industriell miljö ej störningskänslig med expansionsmöjligheter och tillgång till andra liknande företag.

- Närhet till transportinfrastruktur med tillgängligheten till arbetsmarknader, produktmarknad, strategiska partners. 
Nordisk Ministerråd

Ved Stranden 18

DK-1061 København K

www.norden.org

\section{Urban Patterns of Growth}

Urban Patterns of Growth was carried out for the preparation of the Nordic regional policy co-operation programme 2013-2016 and national regional policies in the Nordic countries.

A key issue is the concentration of economic growth in the largest cities. This is favored by urbanization economies but also by the forming of specialized international networks of innovation and production established far beyond regional and national borders. Much research has focused upon these new global networks, leaving behind the question of the national spreading effects of the production that has not been outsourced.

The purpose of this study, therefore, is to elucidate, via case studies, the extent to which the purchases of supplies and services from knowledge firms are located in proximity of the company or whether these purchases have spread to the remaining part of the country. 